2. To: (Rocelving Organization)

Distribution

5. Proj./Prog./Dept./Div.:

73100

8. Originator Remarks:

For Approval/Release

11. Recelver Remarks:

11A. Design Baseline Document? $\bigcirc$ Yes

No
4. Related EDT No.:

$\mathrm{N} / \mathrm{A}$

7. Purchase Order No.:

$\mathrm{N} / \mathrm{A}$

9. Equip./Component No.:

$\mathrm{N} / \mathrm{A}$

10. System/Bidg./Facility:

200W/TY Tank Earm

12. Major Asqm. Dwg. No.:

$\mathrm{N} / \mathrm{A}$

13. Permit/Permit Application No.:

$\mathrm{N} / \mathrm{A}$

14. Required Response Date:

$\mathrm{N} / \mathrm{A}$

15.

DATA TRANSMITTED

\begin{tabular}{|l|r}
\hline $\begin{array}{c}\text { (A) } \\
\text { ltom } \\
\text { No. }\end{array}$ & (B) Document/Drawing No. \\
\hline 1 & HNE-3831 \\
\hline & \\
\hline & \\
\hline & \\
\hline & \\
\hline
\end{tabular}

16.

\begin{tabular}{|c|c|}
\hline Approval Designator (F) & \\
\hline $\begin{array}{c}\text { E, S, Q Q OR N/A } \\
\text { (See WiC.CM-3-5, } \\
\text { Sec. 12.7) }\end{array}$ & $\begin{array}{l}\text { 1. Approval } \\
\text { 2. Rolease } \\
\text { 3. Information }\end{array}$ \\
\hline
\end{tabular}

17.

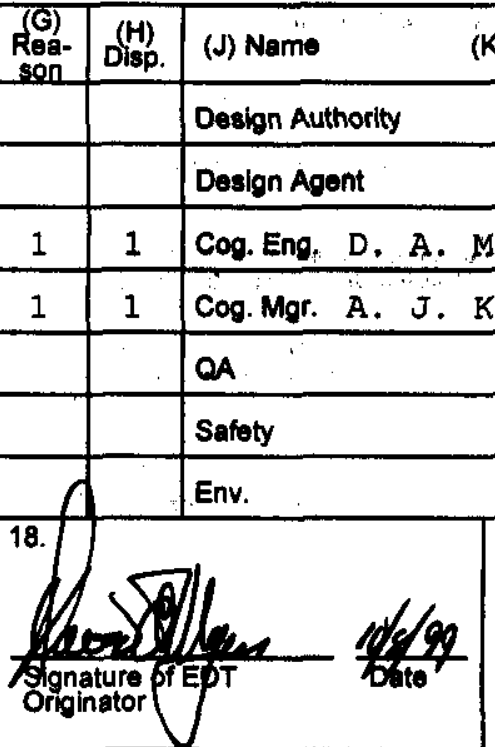

(K) Signature

(C) Sheet
No.

(E) Title or Description of Data Transmitted

All 0 Analysis of Historical

Gross Gamma Logging Data
(G)

\begin{tabular}{|c|c|c|c|}
\hline (F) & $(G)$ & $(H)$ & $(\mathbf{l})$ \\
\hline $\begin{array}{c}\text { Approval } \\
\text { Dasig- } \\
\text { nator }\end{array}$ & $\begin{array}{c}\text { Rogson Trans- } \\
\text { mittal }\end{array}$ & $\begin{array}{c}\text { Origi- } \\
\text { nator } \\
\text { Dispo- } \\
\text { stion }\end{array}$ & $\begin{array}{c}\text { Recaiv- } \\
\text { or } \\
\text { Dispo- } \\
\text { sition }\end{array}$ \\
\hline N & 2 & & \\
\hline
\end{tabular}

from TY Tank Farm

\begin{tabular}{l|l|l|} 
& & \\
& & \\
& & \\
\hline & & \\
\hline
\end{tabular}

Erom TY Tank Faxm

Reason for Transmittal (G)

4. Review

5. Post-Review

6. Dist. (Receipt Acknow. Required)
KEY SIGNATURE/DISTRIBUTION (See Approval Designator for required signatures)

\section{Approved \\ 2. Approved w/comment \\ 3. Disapproved w/comment \\ 4. Revlewed no/comment \\ 5. Reviewed w/comment \\ 6. Receipt acknowledged}

Disposition (H) \& (I)
(L) Date
(M) MSIN \begin{tabular}{l|l} 
Rea- & $(\mathrm{H})$ \\
Disp.
\end{tabular}
(J) Namo

(K) Signature

(L) Date (M) MSIN
21. DOE APPROVAL (if required) Ctri No.

Approved

OAproved w/comments

Disapproved w/comments
Authorized Representative for Recoiving Organization $\underset{\substack{\text { Deffign A } \\ \text { Cdgnizant Manager }}}{10-12-99} \frac{1}{\text { Date }}$
10-22

Date

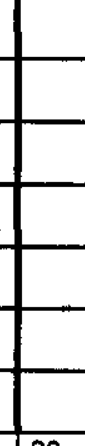

20. 


\title{
Analysis of Historical Gross Gamma Logging Data from TY Tank Farm
}

\author{
D. A. Myers \\ Waste Management Northwest/Three Rivers Scientific \\ Richland, WA 00352 \\ U.8. Department of Energy Contract DE-AC06-96RL13200
}

EDT/ECN: 627797

UC: 2010

Ong Code: 73100

Change Code: 106501/AJ60 fa HMLMO351

BAR Code:

EW3130010

Total Pages: 134

Key Words: Vadose Zone, TY Tank Farm, Dry Well Gross Gamma, Gross Gamma Logs

Abstract: Gross gamma ray logs, recorded from January 1975 through mid-year 1994 as part of the Single-Shell Tank Farm Dry Well Survelllance Program, have been reanalyzed for the TY tank farm to locate the presence of mobile radionuclides in the subsurface. This report presents the TY tank farm gross garma ray data in such a way as to assist others in their study of vadose zone mechanisms.

TRADEMARK DISCLAIMER. Roforence hereln to any spectife commerclal product, procese, or earvice by trade name, trademark, manufheturer, or otherwibe, does not necosearily constiute or imply lis endornement, necommendation, or fuvoring by the United Stites Government or any agency thereof or the contrectore or eubeontractors.

Printed in the United states of Americe. To obtain coples of this document, contuct: Document Control Servicas, P.O. Box 950, Malietop He-08, Richland WA 99352, Phone (509) 372-2420; Fax (500) 376-4989.

$\frac{\text { Bumen Approval }}{\text { Dato }}$

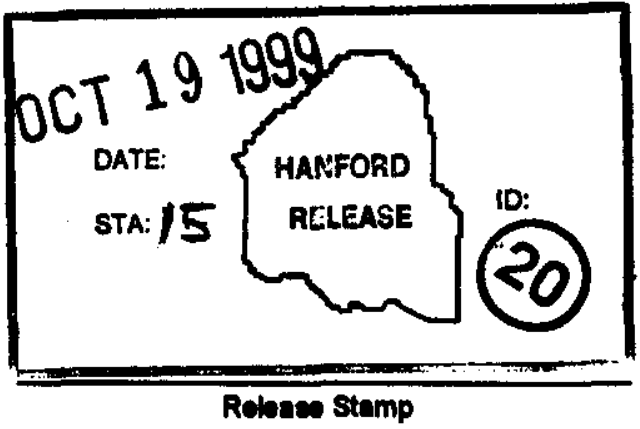

\section{Approved For Public Release}




\section{DISTRIBUTION SHEET}

To

Distribution

Project Title/Work Order

HNF-3831, Rev. O, Analysis of Historical Gross Gamma Logging Data from TY Tank Farm

Name

J. F. Bertsch

B. H. Ford

J. C. Henderson

A. J. Knepp

D. J. Moak

D. A. Myers

T. L. Steward

R. M. Yasek

Central files

DOE Reading Rm.
From

RPP Vadose zone Project

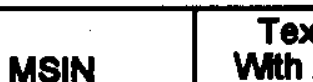

With Al Attach.

B1-42

H0-21

H0-22

HO-22

H1-11

H0-22

HO-21

H0-12

B] -07

$\mathrm{H} 2-53$
Page 1 of 1

Date $10 / 6 / 99$

EDT No. 627797

ECN No. N/A

Attach.J Text Only Appendix Only

EDT/ECN

Only 


\section{Summary of Data Analysis Results for the TY Single Shell Tank Farm Dry Well Gross Gamma Ray Surveillance Logs}

\subsection{Introduction}

The single shell tank farm dry well surveillance program was established 1947 as one of several methods used to identify leaking tanks and operated until 1994. Up until 1975, data were collected in a non-digital format and in 1975, the surveillance program was upgraded to a digital logging system. Under the new system, gross gamma ray logs were captured in digital form utilizing several logging detector types and reviewed in order to identify leaks of radioactive liquid from the underground tanks. The system was not implemented to identlfy the specific radionuclides contributing to the total gross gamma ray activity. However, gross gamma ray logs acquired from January 1975 through mid-year 1994 can and have been re-analyzed to identify radionuclides present in the subsurface within the period of data collection. Data acquired prior to 1975 require reformatting to be useful for this analysis. Details concerning how the analysis is accomplished are in "Analysis Techniques Applied to the Dry Well Surveillance Gross Gamma Ray Data at the SX Tank Farm," document number WMNW-TRS-ES-VZMA-001 (Randall and Price, 1998).

Integral to the analysis of the gross gamma ray data is the use of information provided from the spectral gamma logging analysis implemented from 1996 to 1997. The analysis was performed on TY Tank Farm wells by MACTEC-ERS of Grand Junction, Colorado for the U.S. Department of Energy (DOE) under contract \#DE-AC04-94AL96907 (MACTEC-ERS, 1997). The spectral gamma logging system (SGLS) employs a high-purity germanium (HPGe) detector to obtain data leading to the identification and depth of gamma ray emitting radioactive isotopes. Knowledge as to the isotopes that are present in the subsurface is required for interpretation of the tank farm dry well surveillance logs. By integrating SGLS data with historical dry well surveillance data, knowledge is gained concerning the behavior of radionuclides in the vadose zone over time.

This report provides a summary of the gross gamma ray data for the TY Tank Farm and is not intended to provide interpretation of the data relative to vadose zone mechanics. Overall trends in the data, as well as areas where additional information would be helpful in evaluating the unusual nature of some of the data, are discussed. It is anticipated that this presentation will support Tank Waste Remediation System (TWRS) activities for closure, characterization, remediation, and other vadose zone issues. In general, the data analysis resulted in the identification of five types of subsurface conditions that occur within discrete depth intervals called zones. They are defined as follows:

- CLEAN: no systematic trend above the detection threshold for the gross gamma ray logs is indicated by the data.

- STABLE: the decay rate of the isotope(s) identified in the zone matches the change in concentration of the isotope(s) as measured over time, and no noticeable deviation from the match is apparent within the timeframe that gross gamma ray data were collected.

- UNSTABLE: the decay rate of the isotope(s) identified in the zone does not match the change in concentration of the isotope(s) as measured during the timeframe that gross gamma ray data were collected. Those zones that exhibit an unstable condition early in this timeframe, but currently exhibit a stable condition, are called unstable early.

- TANK FARM ACTIVITY: the irregular change in the intensity of gross gamma rays between successive surveys at or near the surface suggests that contamination may be the result of tank farm activitles or logging procedure changes and not vadose zone mechanics. 
- UNASSIGNED DEVIATION: the decay rate of the isotope(s) identifled or hypothesized to have been present in the zone cannot be rigorously assigned as stable or unstable due to limits in the data avallable for analysis.

Stable vs. unstable is an apparent condition limited by the time interval over which data were collected; the sensitivity of the tools; and the level of contamination, and is not a statement concerning the fixed or mobile nature of a given isotope in the vadose zone. Currently, isotopes cannot be identified from gross gamma ray data alone. The presence of isotopes with a rapid rate of decay (i.e., Ru-106) may not be identifled if the level of radioactivity falls below detection limits prior to the collection of SGLS data. Their former presence can be speculated based on the fit of a decay curve to the gross gamma ray data and are labeled as hypothesized.

Note: The category names have changed since the Analysis Techniques report was prepared (Randall and Price, 1998), although the categories are basically the same (i.e., clean, stable, and changed vs. clean, stable, unstable early, and unstable). Additional categorles of instability were identifled in the TY Tank Farm data than in the SX Tank Farm data, which lead to a slight change in terminology.

It is beyond the scope of this project, to identify the source, rate of movement, or migration pathway of mobile radioactive contaminants and their ultimate impact to the environment. It is also pointed out that where boreholes do not exist, movement can occur without detection. This investigation is limited to the immediate area (approximately 20 inches) around each borehole from which gamma rays are readily detected, and is not rigorous enough to interpret the conditlon of the space between boreholes and outside of the Investigated area.

\subsection{Backomind}

A serles of six tanks were installed at the TY Tank Farm from 1946 to 1947 to recelve llquid waste resulting from activities at the Hanford site (Brevick, et. al.). These tanks are constructed on 100-foot centers and are 75 feet in diameter, leaving 25 feet between the sides of each tank. They are interconnected in a variety of ways, such as cascade and transfer lines, the details of which can be obtained from the engineering construction diagrams for this tank farm. A network of vadose monitoring wells (dry wells) was installed throughout the TY Tank Farm to monitor the subsurface condition (Figure 1). All of the 22 wells constructed have a single string of casing installed concurrent with the drilling activity to prevent collapse of the unconsolidated subsurface sediments (loose sand and gravel). The boreholes range in depth from 64 to 235 feet, with the majority being 100 feet deep. The gross gamma ray data that were acquired digitally from these wells between 1975 and 1994 were analyzed by Three Rivers Sclentific (under subcontract to Waste Management Federal Services, Inc., Northwest Operations, Richland, Washington). The analysis is presented in "Analysis of Historical Gross Gamma Logging Data from TY Tank Farm," (WMNW, 1998). 
HNF-3831 Rev 0

\section{TY Tank Farm}

Borehole Identification \&

Total Depth ( $t$ )
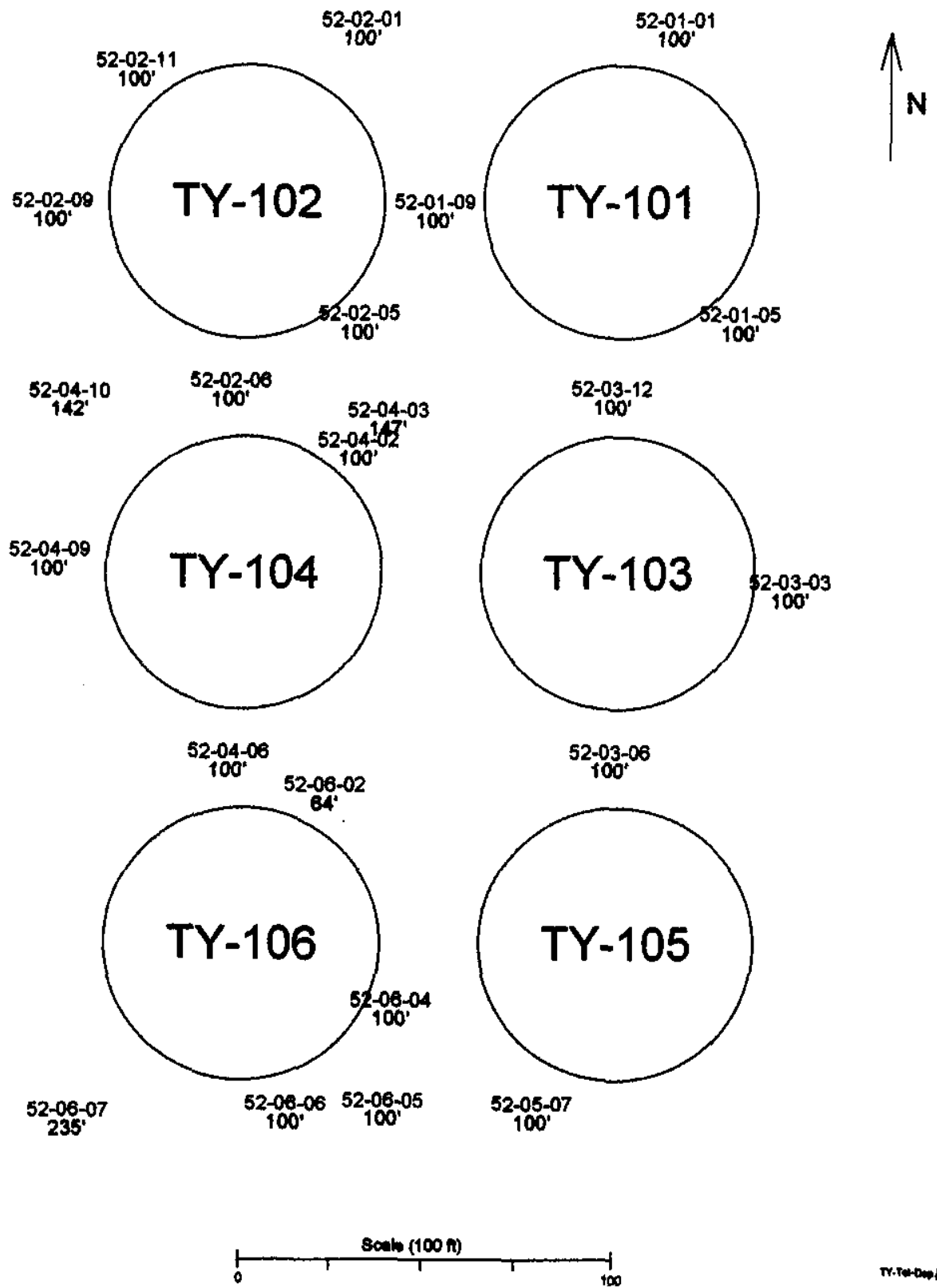

T.Tomistom

Figure 1. TY Tank Farm Borehole Locations and Total Depth

Page 3 


\subsection{Datmanalyin Dercriptlon:}

Data from the dry well logs are compiled through a number of iterations generating a data set that reveals any trend present. This process does not add or delete data, but merely compiles them into a useful, uncompromised data set. This data set is used to create a depth vs. time plot, or stack plot, to identify trends and zones of contamination. All historical log surveys for one dry well (borehole) are analyzed as a whole for each radioactive zone in a well, thus allowing statements to be made about the apparent condition or rate of change of any given radioactive interval. For clarity of presentation, logs are selected over a specific time interval (i.e., quarterly) to render the stack plot readable without affecting the integrity of the data.

Review of the historical gross gamma ray data revealed that limits in the system design for collecting data prior to 1983 created a situation where the zero point for the start of data collecting was inconsistent, as discussed in the Analysis Techniques report (Randall and Price, 1998). This difference in zero point makes evaluating trends in the data difficult. Several methods can be employed to overcome varying zero points and to essentially create a common starting point from which to view the data, making trend identification easier. One method applies a depth shift to the data, which is simply adjusting data up or down so that certain identifiable features in the data can be aligned and evaluated. Applying a depth shift to the data is avoided as much as possible since it can affect the ability to see downward movement of the isotopes. When a depth shift to the data was employed, it is noted in the TY Tank Farm data analysis (WMNW, 1998).

A second method utilizes a calculation called the grade thickness product (GTP) which can be applied over a depth interval wide enough to include all variances in depth so as not to require depth shifting. It is a summation of the values of logging instrument readings over the depth interval of interest minus background activity and times the distance between sample point depths, yielding a constant that is independent of the specific starting point. When the calculation is applied over the entire interval, the result is a more accurate representation of the condition of the zone over time.

Gross gamma ray log surveys were recorded over the length of the borehole at sampling intervals of approximately one foot. Differences in the zero-depth reference point cause variations in the maximum count rate for thin radloactive zones. The GTP calculation is used to eliminate this variable sampling effect upon the overall net change for a given zone. The average background activity of naturally occurring potassium, uranium, and thorium is obtained from review of the data for each survey and provides a level of confidence that the instrumentation worked consistently and that the gross gamma ray data are valid. The percentage of data values that are considered as representing a natural background formation response (frequency clean) is also calculated. The average background activity value is calculated for all survey depth samples between a lower and upper count rate limit. The lower count rate limit is generally set at zero $(0) \mathrm{c} / \mathrm{s}$; a value defined as indicating a data gap. The upper count rate limit is generally set at $50 \mathrm{c} / \mathrm{s}$ for probe type 04 ( NaI), a conservative value near what is considered background activity, yet one fourth of the count rate considered reportable by the leak detection program.

Note: Gross gamma ray data were collected using a variety of probe types. The values generated by these probe types do not directly correlate, as discussed in the Analysis Techniques report (Randall and Price, 1998). Caution must therefore be used when relating GTP values In zones recorded with different probe types (e.g., the Nal probe type 04 does not record values that relate to those recorded with the Green or Red GM probe types 01 and 02). Scaling factors between the different probe types are presented in "Dry Well Probe Calibrations" (Randall, 1999).

Zones where contamination is identified are examined using the GTP calculation. The average background actlvity is subtracted so that only the contaminated levels above background are included in the analysis. A graph is generated with GTP plotted against time for each depth interval analyzed. One or more decay lines are then overlaid on the graph based on isotopes identified by the SGLS data, knowledge of tank constituents, and the known presence of isotopes in other boreholes. Sometimes 
decay lines can be fit through the data a number of ways with none of them fitting perfectly. When two or more isotopes are identified, a least squares fit analysis for a multi-component decay is performed. A detailed discussion for how this is accomplished is in the Appendix to the Data Analysis Results for the BX Single Shell Tank Farm Dry Well Gross Gamma Ray Surveillance Log Surveys (WMNW, 1998). Isotopes that are known to exist in the inventory of the tank farm, or are identified in nearby wells, may not be identified by the SGLS due to being at or below detection levels. Such isotopes are hypothesized to have been present and are included in the least squares fit analysis. The decay rates for each of the components are held fixed in the fitting process and only the relative intensities of the components are calculated. The relative contribution of gross gamma rays from one component to another depends upon the nature of the isotopes and the detector design.

Note: Spurious data are generated during normal data collecting activities. Spurious zero values are called data gaps and are considered as unrealistically low natural background activity when recorded with the sodium-iodide probes. Between 1975 and 1982, the equipment would occasionally record a spurious data value of minus one (-1) or zero (0). A value of minus one represents an invalid count rate. Data gaps occur at various locations in the surveys, including in the background or in the middle of a high contamination zone within a borehole. Data gaps are not included in the calculation of average background, grade thickness product, or frequency clean values.

Comparing the GTP data and the decay line(s) reveals information about the rate of change of contamination within a zone over the timeframe that data were collected. When appropriate, multiple plots are generated to show the results for different zones within a borehole. The details for the use of GTP are covered in the Analysis Techniques report (Randall and Price, 1998).

The objective of the analysis is to assure that a consistent and thorough examination of dry well surveillance logs is performed, and that contamination did not abruptly enter the borehole survey region and quickly migrate out. All surveys are examined so that no unusual problems or conditions remain as undetected. Table 1 contains a list of the wells located in the TY Tank Farm as well as information concerning the identity, level, and depth of contamination. In order to demonstrate a spatial relationship to the subsurface contamination, a variety of maps depicting tank and data point locations are provided.

Certain limitations in the data available for analysis make evaluation less complete. Some of the limitations are as follows:

- Inability to Identify when down-hole contamination is a result of vadose zone mechanics or drag down during well installation

- Insufficient gross gamma ray data to establish a statistical trend or rigorous statistical analysis

- Incomplete timeframe over which data are available

- Lack of data below well bottom

- Inability to identify isotopes that have decayed to levels below the detection limits of the SGLS. 
Table 1. TY Tank Farm Zones

\begin{tabular}{|c|c|c|c|c|c|c|c|c|}
\hline $\begin{array}{l}\text { Borehole } \\
\text { Number }\end{array}$ & \begin{tabular}{l|} 
Total \\
Depth
\end{tabular} & $\begin{array}{l}\text { Number } \\
\text { of Surveys }\end{array}$ & \begin{tabular}{|l|} 
Probe \\
Type
\end{tabular} & Category & $\begin{array}{l}\text { Zone } \\
\text { Depth }\end{array}$ & $\begin{array}{l}\text { Max } \\
\text { GTP }\end{array}$ & $\begin{array}{c}\text { Year } \\
\text { Max GTP }\end{array}$ & $\begin{array}{l}\text { Isotopes } \\
\text { Present }\end{array}$ \\
\hline $52-01-01$ & 100 & 257 & 4 & ${ }^{\mathrm{b}} \mathrm{Clean}$ & & & & \\
\hline $52-01-05$ & 100 & 273 & 4 & 'Stable & $45-58$ & 500 & 1975 & $\mathrm{Ru}^{106}$ \\
\hline $52-01-09$ & 100 & 265 & 4 & Stable & $50-62$ & 450 & 1975 & $\mathrm{Ru}^{106}$ \\
\hline $52-02-01$ & 100 & 228 & 4 & Clean & - & - & & - \\
\hline $52-02-05$ & 100 & 242 & 4 & Clean & - & - & & - \\
\hline $52-02-06$ & 100 & 141 & 4 & Clean & - & - & & - \\
\hline $52-02-09$ & 100 & 220 & 4 & Clean & $\cdot$ & - & - & - \\
\hline $52-02-11$ & 100 & 153 & 4 & 'Unstable early & $36-50$ & 400 & 1980 & $\mathrm{Cs}^{137}$ \\
\hline \multirow[t]{2}{*}{ 52-03-03 } & 100 & 89 & 1 & $\begin{array}{r}\text { Stable } \\
\end{array}$ & $35-54$ & 2,700 & 1980 & $\mathrm{Cs}^{137}$ \\
\hline & & 92 & 2 & 'Unassigned Deviation & $\overline{54-62}$ & 150 & 1980 & $\mathrm{CS}^{137}$ \\
\hline $52-03-06$ & 100 & 309 & 4 & Unstable & $44-98$ & 65,000 & 1979 & $\mathrm{Co}^{60}$ \\
\hline \multirow[t]{2}{*}{$52-03-12$} & 100 & 276 & 4 & Unstable early & $48-60$ & 250 & 1977 & $\mathrm{CO}^{60}$ \\
\hline & & & & Unstable early & $60-75$ & 200 & 1984 & $\mathrm{CO}^{60}$ \\
\hline $52-04-02$ & 100 & 265 & 4 & Clean & $\cdot$ & & -1 & - \\
\hline $52-04-03$ & 147 & 279 & 4 & TFF Activity & $0-8$ & 50,000 & 1975 & $\mathrm{Cs}^{137}$ \\
\hline 52-04-06 & 100 & 251 & 4 & Clean & - & - & 7 & - \\
\hline $52-04-09$ & 100 & 253 & 4 & Stable & $85-100$ & 100 & 1975 & $\mathrm{Cs}^{137}$ \\
\hline $52-04-10$ & 142 & 246 & 4 & Clean & - & & -1 & $\cdot$ \\
\hline \multirow[t]{4}{*}{$52-05-07$} & 100 & 265 & 4 & Unstable early & $51-57$ & 3,000 & 1975 & $\mathrm{Cs}^{137} ; \mathrm{CO}^{60} ; \mathrm{Sb}^{125}$ \\
\hline & & & & Unstable early & $57-66$ & 10,000 & 1975 & $\mathrm{Co}^{60} ; \mathrm{Sb}^{125}$ \\
\hline & & & & Unstable early & $66-82$ & 10,000 & 1975 & $\mathrm{CO}^{60} ; \mathrm{Sb}^{125}$ \\
\hline & & & & Unstable early & $82-100$ & 4,000 & 1975 & $\mathrm{Co}^{60}$ \\
\hline $52-06-02$ & 64 & 37 & 4 & TF Activity & $0-10$ & 150 & 1975 & $\mathrm{Cs}^{137}$ \\
\hline 52-06-04 & 100 & 234 & 4 & Stable & $47-56$ & 200 & 1975 & $\mathrm{CS}^{137} ; \mathrm{Sb}^{125}$ \\
\hline $52-06-05$ & 100 & 176 & 4 & Unstable early & $50-90$ & 3,800 & 1975 & $\mathrm{Cs}^{137} ; \mathrm{CO}^{60}$ \\
\hline \multirow[t]{2}{*}{ 52-06-06 } & 100 & 179 & 4 & Stable & $5-25$ & 200 & 1975 & $\mathrm{Cs}^{137}$ \\
\hline & & & & Stable & $72-82$ & 350 & 1975 & $\mathrm{Sb}^{125}$ \\
\hline $52-06-07$ & 235 & 172 & 4 & Stable & $86-100$ & 200 & 1975 & $\mathrm{CO}^{60}$ \\
\hline
\end{tabular}

Mpobe type: 1 = Green GM, moderately sensitive; reads moderate levels of gamma ray activity.

2 = Red GM, least sensitive; reads highest level of gamma ray activity.

$4=\mathrm{NaI}$, most sensitive, reads lowest level of gamma ray activity.

Caution must be used when relating GTP values in zones recorded with different probe types.

bNo systematic trend above the detection threshold for the gross gamma ray logs is indicated by the data.

The decay rate of the isotope(s) Identified in the zone matches the change in concentration of the isotope(s) as measured over time, and no noticeable deviation from the match is apparent within the timeframe that gross gamma ray data were collected.

The decay rate of the isotope(s) identified in the zone does not match the change in concentration of the isotope(s) as measured during the timeframe that gross gamma ray data were collected. Those zones that exhlbit an unstable condition early in this timeframe, but currently exhibit a stable condition, are called unstable early.

The decay rate of the isotope(s) identified or hypothesized to have been present in the zone cannot be rigorously assigned as stable or unstable due to limits in the data available for analysis.

'An irregular change in the intensity of gross gamma rays between successive surveys at or near the surface suggests that contamination may be the result of tank farm activities or logging procedure changes and not vadose zone mechanics.

"Currently, isotopes cannot be identffed from gross gamma ray data alone; therefore, if the period of instabillty is prior to the collection of SGLS data, isotopes with a rapid rate of decay (l.e., Ru-106), or at levels that decay below detection limits, may not be identified.

Stable vs. unstable is an apparent condition limited by the time interval over which data were collected and the level of contamination, and is not a statement concerning the fixed or mobile nature of a given isotope. 


\subsection{Subsurface Condition Categories}

\subsection{Clean:}

A clean well is one that exhibits no observable change in the character of the activity over the logging history of the well, and does not have any isotopes identified by the SGLS greater than the average background levels of naturally occurring gamma ray emitting isotopes. Although spurious surveys (those readings that do not repeat over time) may exist in the frequency clean and the average background plots, the trend of the data is clear. Eight out of 22 wells in the TY Tank Farm are considered clean (Figure 2) and are listed in Table 2. The remaining 14 wells are considered contaminated and are further categorized and discussed in the following sections.

Table 2. TY Tank Farm Clean Wells

\begin{tabular}{|r|r|r|}
\hline $\begin{array}{r}\text { Borehole } \\
\text { Number }\end{array}$ & $\begin{array}{r}\text { Total } \\
\text { Depth }\end{array}$ & Category \\
\hline $52-01-01$ & 100 & Clean \\
\hline $52-02-01$ & 100 & Clean \\
\hline $52-02-05$ & 100 & Clean \\
\hline $52-02-06$ & 100 & Clean \\
\hline $52-02-09$ & 100 & Clean \\
\hline $52-04-02$ & 100 & Clean \\
\hline $52-04-06$ & 100 & Clean \\
\hline $52-04-10$ & 142 & Clean \\
\hline
\end{tabular}

\subsection{Contaminated:}

Identification of specific gamma emitting isotopes that are in the subsurface is attainable from data acquired by the SGLS. Integration of the decay rate of the radionuclide species with the gross gamma ray data collected during the dry well surveillance program provides insight as to the rate of change, if any, of radionuclides in the subsurface. During the analysis of TY Tank Farm data, four isotopes were identifled or hypothesized to have occurred in radioactive zones. They are cesium-137 (Cs-137), cobalt60 (Co-60), antimony-125 (Sb-125), and ruthenium-106 (Ru-106). Cesium-137 and Co-60 are the most commonly identified isotopes and are often not associated with other isotopes, although they are found with one or more of the other isotopes in some wells.

Ruthenlum-106 is not currently present above the detection threshold in any of the wells examined by the SGLS. This is due to the very rapid exponential decline over a short half-life of 1.02 years. Ruthenium-106 is hypothesized to have been present in two wells in 1975 on the basis of the gross gamma ray data and the resulting GTP calculations that mimic the decay rate of Ru-106, coupled with the inventory list of known radionuclides for that time period. However, the method of fitting a decay curve to the observed GTP trend identifies only those contaminants that are not changing. Ruthenium-106 is assumed to be present if the decay curve for Ru-106 matches the GTP plot. If any decay curve does not match, then the contaminants cannot be identified with this method without additional information. The isotopes identified with the SGLS are primarily found to be present under four subsurface conditions: stable, unstable, tank farm activity, and unassigned deviation. The location of wells labeled with the conditions of subsurface zones is shown in Figure 2. A different condition can be indicated for each zone within a well with multiple zones. 
HNF-3831 Rev 0
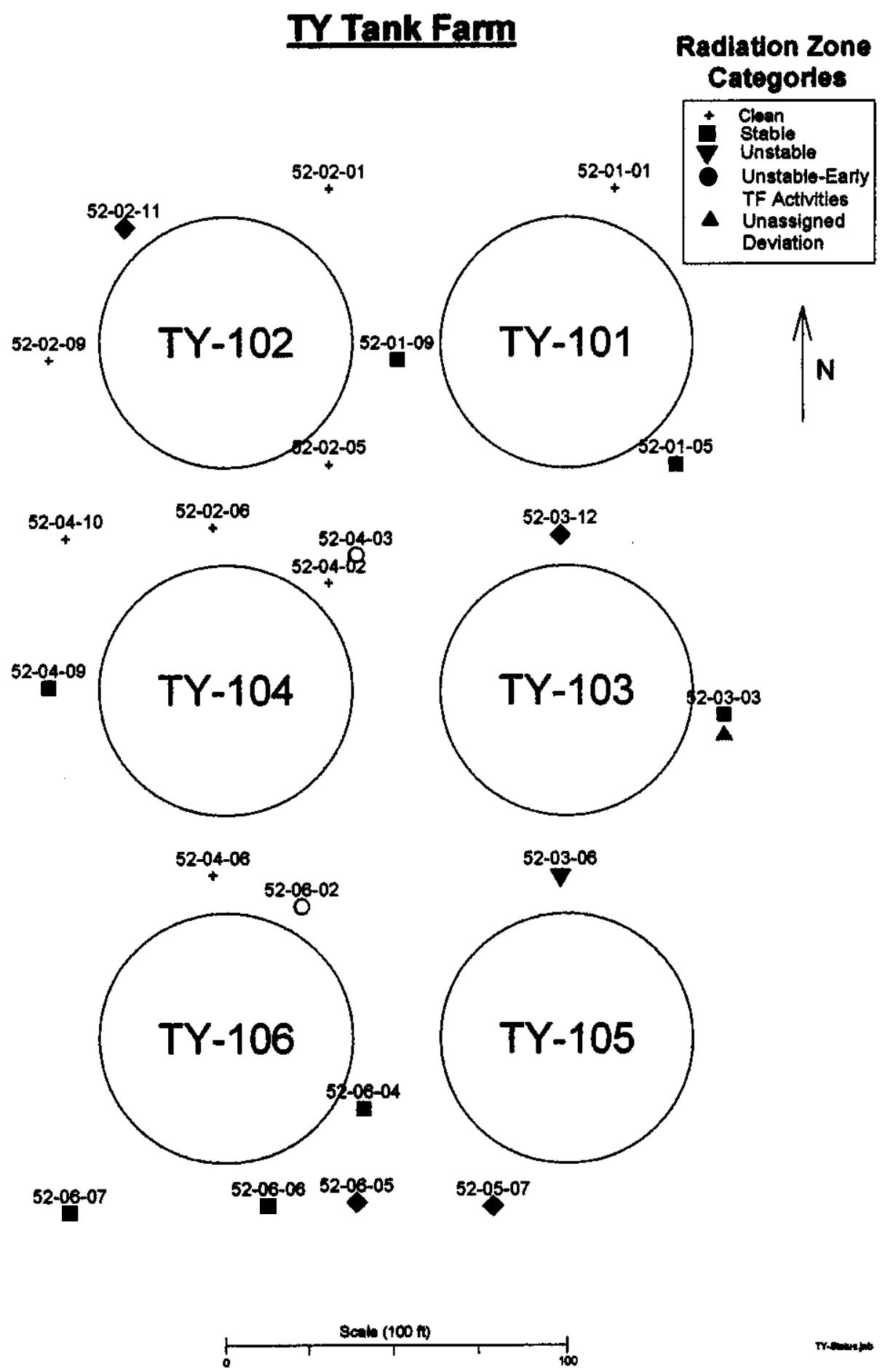

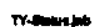

Figure 2. TY Tank Farm Radiation Zone Categories 


\subsubsection{Tank Farm Attributed:}

An irregular change in the intensity of gross gamma rays between successive surveys at or near the surface suggest that contamination may be the result of tank farm activities or logging procedure changes and not vadose zone mechanics. Radioactive contamination is near the surface in two wells, apparently as the result of tank farm activities (i.e., logging procedure changes, transfer line operations, valve box and conduit leaks, surface spills, etc.), and are listed in Table 3.

Table 3. TY Tank Farm Activity Zones

\begin{tabular}{|r|r|r|c|c|c|c|}
\hline $\begin{array}{c}\text { Borehole } \\
\text { Number }\end{array}$ & $\begin{array}{c}\text { Total } \\
\text { Depth }\end{array}$ & Category & $\begin{array}{c}\text { Zone } \\
\text { Depth }\end{array}$ & $\begin{array}{c}\text { Max } \\
\text { GTP }\end{array}$ & $\begin{array}{c}\text { Year } \\
\text { Max GTP }\end{array}$ & $\begin{array}{c}\text { Isotopes } \\
\text { Present }\end{array}$ \\
\hline $52-04-03$ & 147 & TF Activity & $0-8$ & 50,000 & 1975 & $\mathrm{Cs}^{137}$ \\
\hline $52-06-02$ & 64 & TF Activity & $0-10$ & 150 & 1975 & $\mathrm{Cs}^{137}$ \\
\hline
\end{tabular}

\subsubsection{Unassianed Deviation:}

Infrequently, the decay rate of the isotope(s) identified or hypothesized to have been present in the zone cannot be rigorously assigned as stable or unstable due to limits in the data available for analysis. One zone out of 28 zones in the 22 wells examined has an unassigned deviation (Table 4).

Table 4. TY Tank Farm Unasslgned Deviation Zones

\begin{tabular}{|c|c|c|c|c|c|c|c|}
\hline $\begin{array}{c}\text { Borehole } \\
\text { Number }\end{array}$ & $\begin{array}{c}\text { Total } \\
\text { Depth }\end{array}$ & Category & $\begin{array}{c}\text { Zone } \\
\text { Depth }\end{array}$ & $\begin{array}{c}\text { Max } \\
\text { GTP }\end{array}$ & $\begin{array}{c}\text { Year } \\
\text { Max GTP }\end{array}$ & $\begin{array}{c}\text { Isotopes } \\
\text { Present }\end{array}$ & Comments \\
\hline $52-03-03$ & 100 & Unassigned Deviation & $54-62$ & 150 & 1980 & Cs $^{137}$ & Green GM \\
\hline
\end{tabular}

\subsubsection{Stoble:}

The subsurface condition of a zone with radioactive contamination is considered stable when:

- The decay rate of the isotope(s) identified with SGLS matches the trend observed in the GTP of the gross gamma ray data

- Contaminants continue to decrease at a rate consistent with the hypothesized isotope(s) half-life

- No noticeable change in concentration is apparent over the short timeframe that data were collected.

Seven zones are considered stable and are listed in Table 5. 
Table 5. TY Tank Farm Stable Zones

\begin{tabular}{|r|r|r|r|r|r|r|l|}
\hline $\begin{array}{l}\text { Borehole } \\
\text { Number }\end{array}$ & $\begin{array}{r}\text { Total } \\
\text { Depth }\end{array}$ & Category & $\begin{array}{c}\text { Zone } \\
\text { Depth }\end{array}$ & $\begin{array}{c}\text { Max } \\
\text { GTP }\end{array}$ & $\begin{array}{c}\text { Year } \\
\text { Max GTP }\end{array}$ & $\begin{array}{c}\text { Isotopes } \\
\text { Present }\end{array}$ & Comments \\
\hline $52-01-05$ & 100 & Stable & $45-58$ & 500 & 1975 & $\mathrm{Ru}^{106}$ & \\
\hline $52-01-09$ & 100 & Stable & $50-62$ & 450 & 1975 & $\mathrm{Ru}^{106}$ & \\
\hline $52-03-03$ & 100 & Stable & $35-54$ & 2,700 & 1980 & $\mathrm{Cs}^{137}$ & Red GM \\
\hline $52-06-04$ & 100 & Stable & $47-56$ & 200 & 1975 & $\mathrm{Cs}^{137} ;{ }^{*} \mathrm{Sb}^{125}$ & \\
\hline $52-06-06$ & 100 & Stable & $5-25$ & 200 & 1975 & $\mathrm{Cs}^{137}$ & \\
\hline & & Stable & $72-82$ & 350 & 1975 & ${ }^{*} \mathrm{Sb}^{125}$ & \\
\hline $52-06-07$ & 235 & Stable & $86-100$ & 200 & 1975 & $\mathrm{Co}^{60}$ & \\
\hline
\end{tabular}

Currently, isotopes cannot be identified from gross gamma ray data alone; therefore, If the period of instability is prior to the coliection of SGLS data, isotopes with a rapid rate of decay (i.e., Ru-106), or at levels that decay below detection limits, may not be identified.

Currently, the radioactlve condition of the subsurface prior to or after the gross gamma ray and SGLS data collection period is undetermined. If a new driver were introduced, such as the influx of a large volume of liquid, contamination could be remobilized. Given the current data, it cannot be determined if remobilization will or will not occur.

\subsubsection{Unstabler}

The subsurface condition of a zone with radioactive contamination is considered unstable when, at some point within the timeframe of data collection, contamination was not decreasing at the decay rate of the isotope(s) identifled with SGLS. In this case, the decay curve does not match the trend observed in the GTP of the identifled or hypothesized isotope considered. In the TY Tank Farm, zones were identified which exhibited periods of instability early in the timeframe that gross gamma ray data were collected. These zones have since developed a consistent rate of decrease through when the last data were collected and are called unstable early. Four data sets (containing 8 zones) out of the 22 examined captured unstable periods early in the well (Table 6). One additional data set indicates unstable conditions throughout the data collection period.

Table 6. TY Tank Farm Unstable Zones

\begin{tabular}{|r|r|r|c|r|r|c|}
\hline $\begin{array}{r}\text { Borehole } \\
\text { Number }\end{array}$ & $\begin{array}{r}\text { Total } \\
\text { Depth }\end{array}$ & Category & $\begin{array}{c}\text { Zone } \\
\text { Depth }\end{array}$ & $\begin{array}{c}\text { Max } \\
\text { GTP }\end{array}$ & $\begin{array}{c}\text { Year } \\
\text { Max GTP }\end{array}$ & $\begin{array}{c}\text { Isotopes } \\
\text { Present }\end{array}$ \\
\hline $52-02-11$ & 100 & Unstable early & $36-50$ & 400 & 1980 & $\mathrm{Cs}^{137}$ \\
\hline $52-03-06$ & 100 & Unstable & $44-98$ & 65,000 & 1979 & $\mathrm{Co}^{60}$ \\
\hline $52-03-12$ & 100 & Unstable early & $48-60$ & 250 & 1977 & $\mathrm{Co}^{60}$ \\
\hline & & Unstable early & $60-75$ & 200 & 1984 & $\mathrm{Co}^{60}$ \\
\hline $52-05-07$ & 100 & Unstable early & $51-57$ & 3,000 & 1975 & $\mathrm{Cs}^{137} ; \mathrm{Co}^{60} ;{ }^{*} \mathrm{Sb}^{125}$ \\
\hline & & Unstable early & $57-66$ & 10,000 & 1975 & $\mathrm{Co}^{60} ;{ }^{*} \mathrm{Sb}^{125}$ \\
\hline & & Unstable early & $66-82$ & 10,000 & 1975 & $\mathrm{Co}^{60} ;{ }^{*} \mathrm{Sb}^{125}$ \\
\hline & & Unstable early & $82-100$ & 4,000 & 1975 & $\mathrm{Co}^{60}$ \\
\hline $52-06-05$ & 100 & Unstable early & $50-90$ & 3,800 & 1975 & $\mathrm{Cs}^{137} ; \mathrm{Co}^{60}$ \\
\hline
\end{tabular}

"Currently, isotopes cannot be Identfled from gross gamma ray data alone; therefore, If the period of instability is prior to the collection of SGLS data, isotopes with a rapid rate of decay (i.e., Ru-106), or at levels that decay below detection limits, may not be identified. 


\subsection{Detalls of Contaminated Conditions}

\subsection{Stable Zenesi}

Several zones within a number of wells exhiblt gross gamma ray activity above natural background. Many of these radioactive intervals are observed to be stable as verified by the change in GTP over time coinciding with the decay rate of the isotope(s) identified as, or hypothesized to have been, present in the well within the timeframe data were collected. The isotopes present in these stable zones vary and are presented in Table 5. In general, they occur as follows:

- Cs-137 is present in over half of the zones, occasionally with other isotopes.

- $\quad \operatorname{co-60}$ is present in nearly half of the zones, often with other isotopes.

- Sb-125 is usually present with other isotopes, rarely without other isotopes.

- Ru-106 is hypothesized to have existed early in the history of two wells without other isotopes.

The fixed decay rate of the isotope(s) present is used to calculate the decay line (Flgure 3). Europium154 and U-235/238 are included in the figure although they are not encountered in the TY Tank Farm. Table 7 lists the half-life of the isotopes encountered in TY Tank Farm.

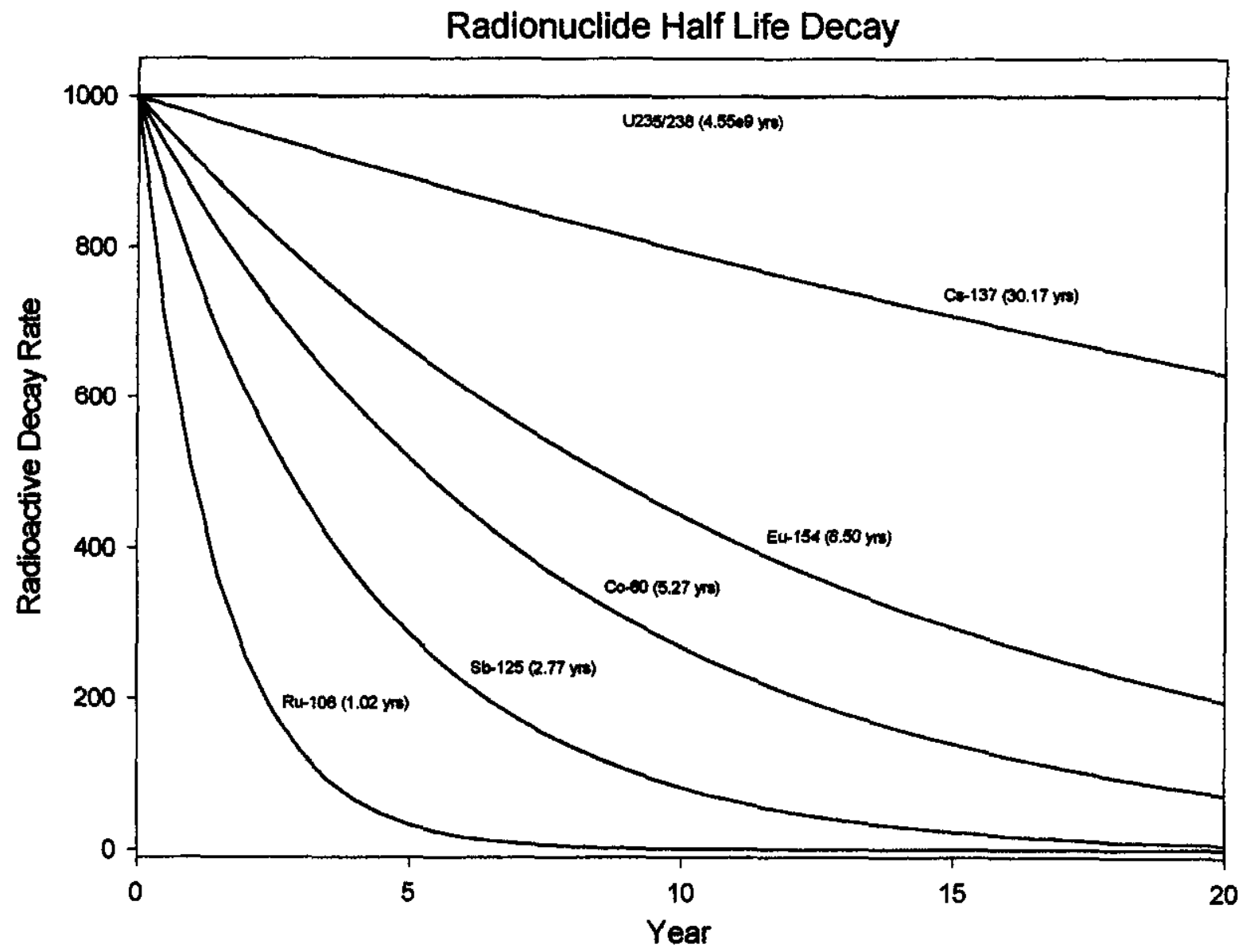

Flgure 3. Radionuclide Half-life Decay Rates 
HNF-3831 Rev 0

Table 7. Half-life of Isotopes Identified in the TY Tank Farm

\begin{tabular}{|l|c|}
\hline \multicolumn{1}{|c|}{ Isotope } & $\begin{array}{c}\text { Half-life } \\
\text { Years }\end{array}$ \\
\hline $\mathrm{Cs}^{137}$ & 30.17 \\
\hline $\mathrm{Co}^{60}$ & 5.27 \\
\hline $\mathrm{Sb}^{125}$ & 2.77 \\
\hline $\mathrm{Ru}^{106}$ & 1.02 \\
\hline
\end{tabular}

When a contaminated interval contains multiple isotopes, the intensity of each isotope is included in the calculation for the decay curve that is then overlain on the GTP plot. When the decay curve does not fit the trend of the GTP values over the entire timeframe, then it is fit to the later years in order to align the data so trends can be observed. When the decay curve fits the GTP plot, a stable condition is said to exist. When the decay curve does not fit any portion of the GTP plot, stability cannot be established.

\subsection{Depth of Contamination:}

The range in depth of contamination is variable throughout the TY Tank Farm. In general, the contaminated interval is less than 20 feet thick throughout the tank farm, except from the south of the 101 tank to the southwest of the 105 tank where the interval ranges from 27 to 54 feet. The depth to the top of contamination is primarily 35 to 51 feet throughout the tank farm, except where it is at the surface due to tank farm activities, and where it is at 85 to 86 feet west of the 104 and 106 tanks (Figure 4). Well 52-06-06 has two zones of contamination, one from 5 to 25 feet and one from 72 to 82 feet. The northwest portion of the tank farm is mostly clean.

The observable depth of contamination (Figure 5) is dependent upon the depth to which instrumentation can penetrate the subsurface. However, data analysis can identify movement of contamination by the changes in the gross gamma ray activity occurring at a rate that is faster than the decay rate of the isotope(s) present in the zone. If contamination continues to move out of the well, whether downward or laterally, it is reasonable to assume that movement would continue in the same manner beyond the confines of the well or the timeframe over which data has been collected, provided subsurface conditions have not changed.

Although the contamination in well 52-04-09 is continuous from 85 feet to the bottom of the well, the level of Cs-137 is very low and the condition is stable, and there is not enough evidence to indicate if contamination went deeper than the bottom of the well. Analysis indicates that the downward trend of the contamination in well 52-03-06 continues past the bottom of the well at 100 feet. Contamination is continuous from 51 to 100 feet in well 52-05-07. However, there is insufflcient data to determine whether the downward trend of contamination movement continues below the bottom of the well. Although the depth of well 52-06-07 was completed at 235 feet, gross gamma logs were only obtained to 150 feet. An SGLS survey was run in 1996 or 1997, which identified Cs-137 and Co-60 at 200 to 214 feet.

Wells that have high contaminant levels below the surface may indicate proximity to infiltration events. Figure 6 depicts zones where the GTP is greater than $1,000 \mathrm{ft}{ }^{*} \mathrm{c} / \mathrm{s}$. These zones occur primarily in the southeast portion of the tank farm, with the highest level of contamination east of the 103 tank. Caution must be used when relating GTP values in zones recorded with different probe types since they were designed to read different intensities of contamination. In addition, the GTP values for intervals of different thickness are not directly comparable. Since GTP incorporates both the depth interval and the intensity of gross gamma ray activity, possible differences in interval thickness must be accounted for before comparing the GTP values between intervals. The distribution of GTP values with depth range (in order of depth range) and contributing isotope(s) is shown in Table 8. 

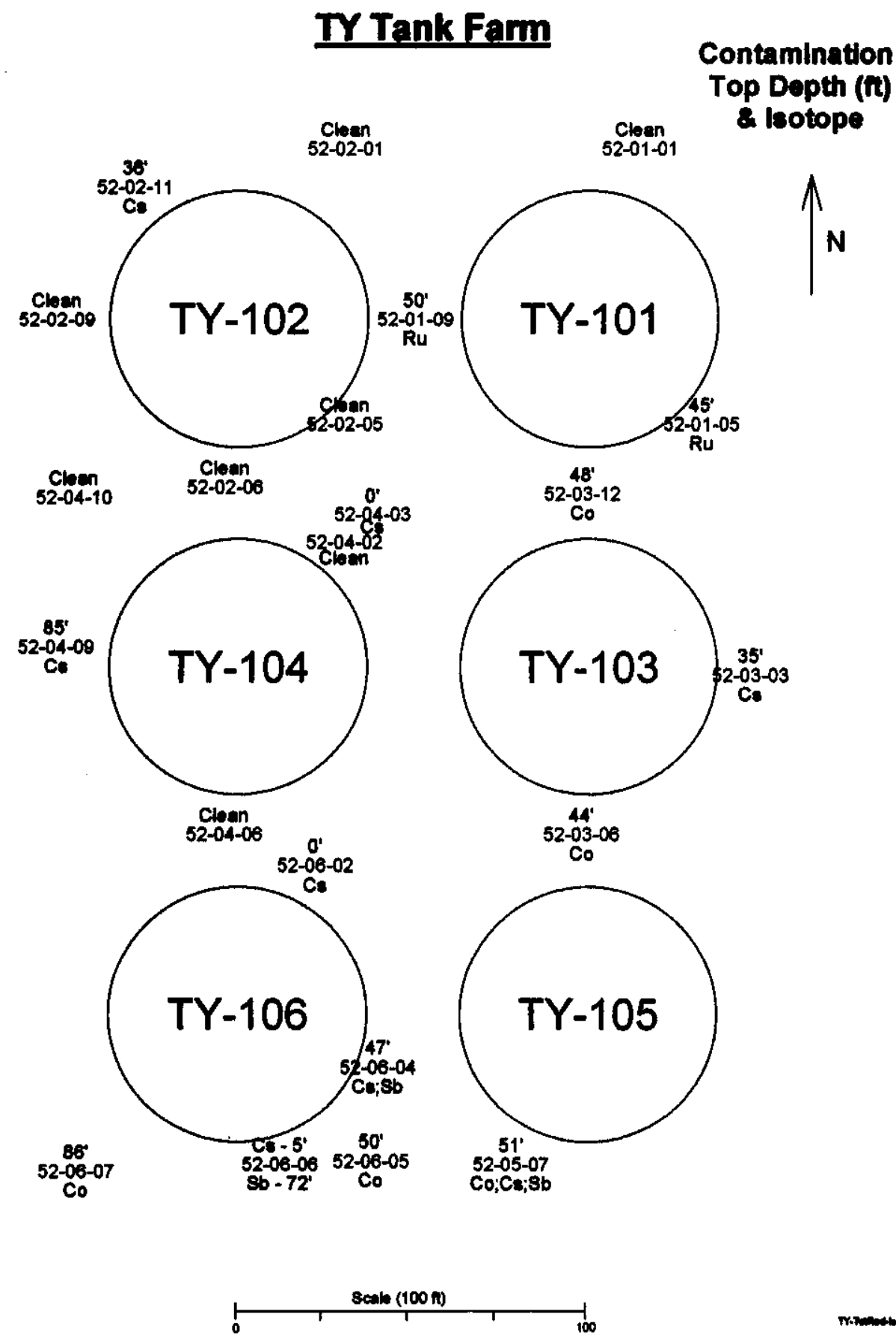

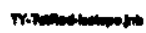

Flgure 4. TY Tank Farm Top of Contamination 
HNF-3831 Rev 0

\section{TY Tank Farm}

Contamination

Bottom Depth (tt)
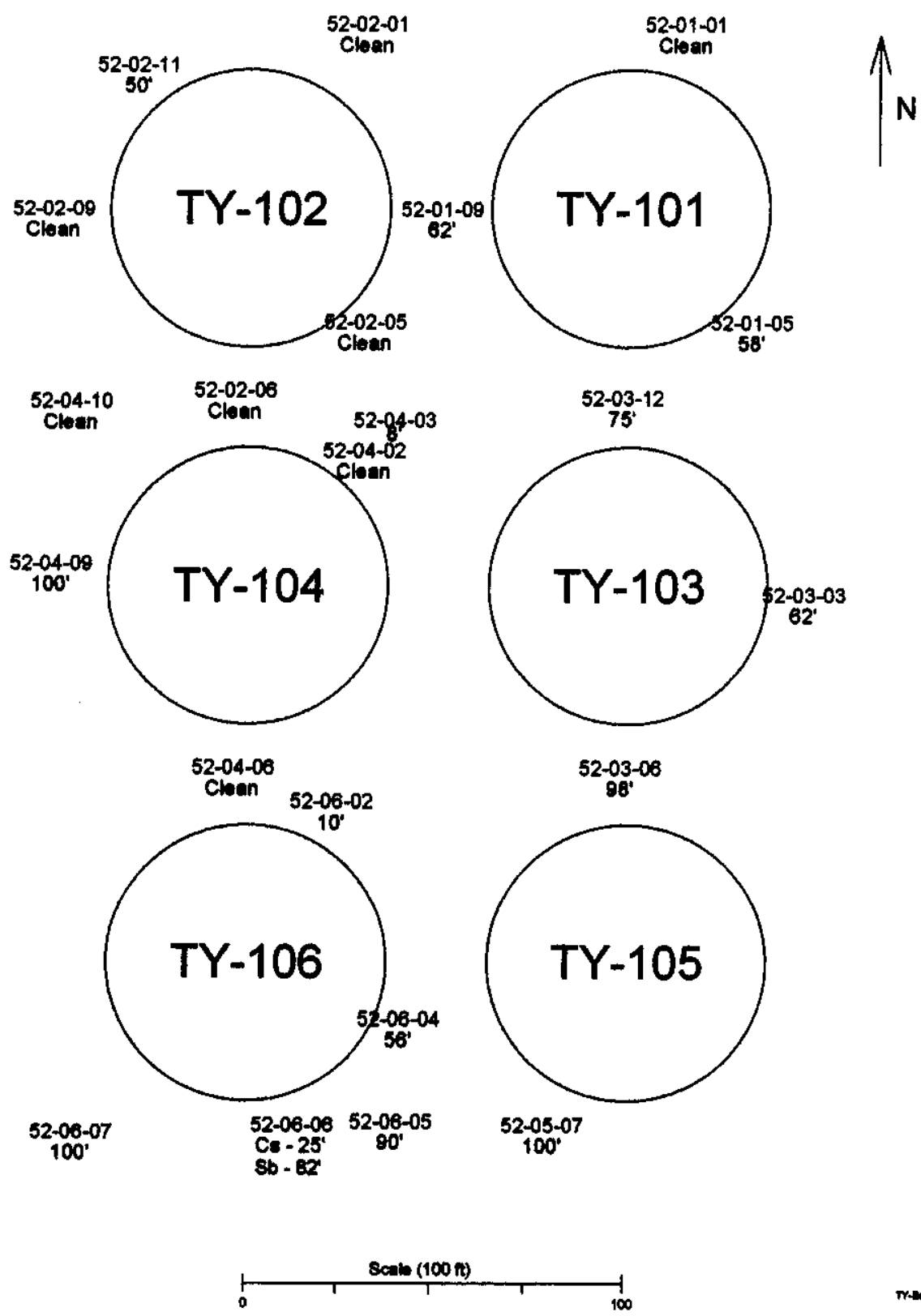

Figure 5. TY Tank Farm Observable Bottom of Contamination 
HNF-3831 Rev 0

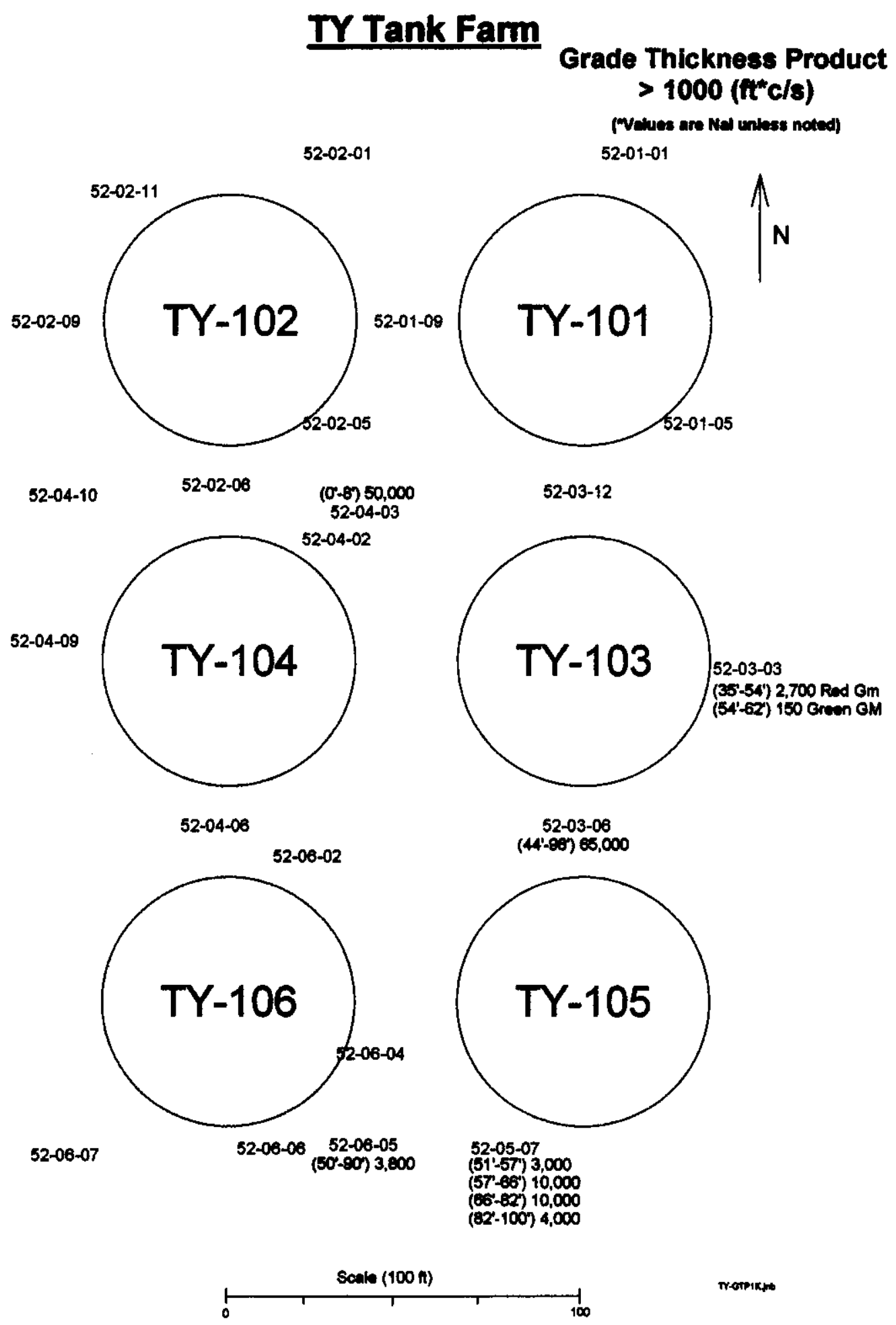

Figure 6. TY Tank Farm Grade Thickness Product Greater Than 1,000 ft*c/s 
Table 8. TY Tank Farm Depth Range

\begin{tabular}{|c|c|c|c|c|c|c|c|c|}
\hline Borehole & & Year & $\operatorname{Max}$ & Zone & \multicolumn{4}{|c|}{ Isotopes Present } \\
\hline $52-04-03$ & 4 & 1975 & 50,000 & $0-8$ & $\mathrm{Cs}^{135}$ & & & \\
\hline $52-06-02$ & $\overline{4}$ & 1975 & 150 & $0-10$ & $\mathrm{Cs}^{135}$ & & & \\
\hline 52-06-06 & 4 & 1975 & 200 & $5-25$ & $\mathrm{Cs}^{135}$ & & & \\
\hline $52-03-03$ & 1 & 1980 & 2,700 & $35-54$ & $\mathrm{Cs}^{135}$ & & & \\
\hline $52-02-11$ & 4 & 1980 & 400 & $36-50$ & $\mathrm{Cs}^{135}$ & & & \\
\hline 52-03-06 & 4 & 1979 & 65,000 & $44-98$ & & $\mathrm{CO}^{60}$ & & \\
\hline $52-01-05$ & 4 & 1975 & 500 & $45-58$ & & & ${ }^{7} \mathrm{Ru}^{106}$ & \\
\hline $52-06-04$ & 4 & 1975 & 200 & 47.56 & $\mathrm{Cs}^{135}$ & & & ${ }^{*} \mathrm{Sb}^{125}$ \\
\hline $52-03-12$ & 4 & 1977 & 250 & $48-60$ & & $\mathrm{CO}^{60}$ & & \\
\hline $52-01-09$ & 4 & 1975 & 450 & $50-62$ & & & ${ }^{*} \mathrm{Ru}^{106}$ & \\
\hline $52-06-05$ & 4 & 1975 & 3,800 & $50-90$ & $\mathrm{Cs}^{135}$ & $\mathrm{CO}^{60}$ & & \\
\hline 52-05-07 & 4 & 1975 & 3,000 & $51-57$ & $\mathrm{Cs}^{135}$ & $\mathrm{Co}^{60}$ & & $\mathrm{Sb}^{125}$ \\
\hline $52-03-03$ & 2 & 1980 & 150 & $54-62$ & $\mathrm{Cs}^{135}$ & & & \\
\hline $52-05-07$ & 4 & 1975 & 10,000 & $57-66$ & & $\mathrm{Co}^{60}$ & & $\mathrm{Sb}^{125}$ \\
\hline $52-03-12$ & 4 & 1984 & 200 & $60-75$ & & $\mathrm{Co}^{60}$ & & \\
\hline 52-05-07 & 4 & 1975 & 10,000 & $66-82$ & & $\mathrm{Co}^{60}$ & & ${ }^{7} \mathrm{Sb}^{125}$ \\
\hline 52-06-06 & 4 & 1975 & 350 & $72-82$ & & & & ${ }^{*} \mathrm{Sb}^{125}$ \\
\hline 52-05-07 & 4 & 1975 & 4,000 & $82-100$ & & $\mathrm{CO}^{60}$ & & \\
\hline 52-04-09 & 4 & 1975 & 100 & $85-100$ & $\mathrm{Cs}^{135}$ & & & \\
\hline $52-06-07$ & 4 & 1975 & 200 & $86-100$ & & $\mathrm{CO}^{60}$ & & \\
\hline
\end{tabular}

"Probe type: 1 = Green GM, moderately sensitive; reads moderate levels of gamma ray activity. 2 = Red GM, least sensitive; reads highest level of gamma ray activity.

$4=\mathrm{Nal}$, most sensitive, reads lowest level of gamma ray activity.

Caution must be used when relating GTP values in zones recorded with different probe types.

"Currently, isotopes cannot be identified from gross gamma ray data alone; therefore, if the period of instability is prior to the collection of SGLS data, isotopes with a rapid rate of decay (i.e., Ru-106), or at levels that decay below detection limits, may not be Identified.

\subsection{Isotopes Identifled:}

Four man-made isotopes are known to be, or hypothesized to have been present, in the TY Tank Farm at or above the detection limit for the gross gamma ray logging equipment. They are listed in Table 7 along with their half-life. Cesium-137 and Co-60 are the most common isotopes found in the TY Tank Farm and occur throughout the farm at varying depths and intensities. They occur alone, with each other, and with other isotopes. Antimony-125 occurs in three wells at the south end of the tank farm. Ruthenium106 is hypothesized to have been present in two wells located in the northeast portion of the farm. The half-life of Ru-106 is short (1.02 years) and Ru-106 is no longer detectable in the wells by the HPGe detector. However, it was an inventoried isotope and the decay line calculated for Ru-106 matches well with the GTP calculations in two wells. The distribution and depth to top of the isotopes that occur in the TY Tank Farm are shown in Figure 4. 


\subsection{Ilmeframe:}

Data evaluation is limited to when digital data were first captured in 1975 to the last digital datacollecting event in 1994. Three general conditions are observed concerning the life cycle of contamination events with respect to the timeframe in which digital data are available for analysis. Within this timeframe, the data appear to represent:

- The middle or end of a period (initiated prior to inception of digital data collection) where subsurface conditions were unstable and the beginning of apparent stability

- Stable subsurface conditions at the beginning of data collection, whereby an unstable condition develops (indicated by a rate of change that is inconsistent with the decay rate of known isotopes in the well), followed by apparent stability

- Stable subsurface conditions at the beginning of data collection, whereby an unstable condition develops (indicated by a rate of change that is inconsistent with the decay rate of known isotopes in the well) that does not become stable within the timeframe of data collection.

There is insufficient information available to determine if contamination at depth may be the result of well installation activities.

Usually, the maximum GTP calculated for the gross gamma ray data seems to coincide with the start of digital data collection. There are three exceptions:

- Well 52-02-11 had a maximum GTP calculated for Cs-137 from 36 to 50 feet in 1980 that may be related to well deepening activities in 1977.

- Well 52-03-06 had a maximum GTP calculated for Co-60 from 44 to 98 feet in 1979.

- Well 52-03-12 had a maximum GTP calculated for Co-60 in the zone from 48 to 60 in 1977 and in the zone from 60 to 75 in 1980.

\subsection{Unstable Zonesi}

For the unstable zones (Table 6), data collection started while conditions in the zone were still unstable. Periods of instability were usually short and occurred very early in the timeframe over which digital data were collected.

\subsection{Summary}

A summary of the radionuclides present in the vadose zone of TY Tank Farm has been presented in this report. By integrating SGLS data with historical dry well surveillance data, knowledge is gained concerning the behavior of radionuclides in the vadose zone over time. The SGLS data allow a rigorous conclusion about the identity, character, and decay trends of isotopes present in a contaminated zone identified within the twenty-year period that the dry well data were collected.

Five subsurface conditions were discerned during the analysis of the historical dry well data: clean, stable, unstable, tank farm activity, and unassigned deviation. This classification reflects the conditions in which contamination is present (or not present) within the timeframe gross gamma ray data were collected electronically, but does not represent the conditions within the subsurface today. However, an assumption that the trend of the data might continue unaltered seems reasonable, barring any event that 
changes the hydrogeologic or geochemical conditions in the subsurface. On the basis of the data available at the time and within the scope of this report, a statement cannot be made as to whether any of the isotopes present in the subsurface of the TY Tank Farm can be remobilized.

Most of the clean wells occur in the northern half of the tank farm. Nearly half of the contaminated zones appear to exist under a stable condition. Within the timeframe that digital data are available, most of the zones that exhibit an unstable condition early on are currently stable. One zone located east of tank 103 from 54 to 64 feet has an unassigned deviation and one zone south of the 103 tank from 44 to 98 feet is unstable at the end of data collection. Two wells have indications of tank farm activity at the surface and are located northeast of tanks 104 and 106.

The most common isotopes present throughout the subsurface of the TY Tank Farm are Cs-137 and Co60 , which occur in all but two of the contaminated wells. The depth range of Cs-137 is 0 to 100 feet. The depth range of Co-60 is 44 to 100 feet. Anitmony-125 occurs in three wells from 47 to 82 feet. In the northeast portion of the tank farm, Ru-106 is hypothesized to have existed in the subsurface from 45 to 62 feet in two wells, although it is no longer at detectable levels.

There are four wells with contamination at greater than $1,000 \mathrm{ft}^{*} \mathrm{c} / \mathrm{s}$ GTP that is not due to tank farm activities. They occur in the southeast portion of the tank farm. The wells showing high levels of contamination are surrounded by wells with significantly lower levels of contamination, or no contamination at all, and may indicate proximity to point sources. It is not known if contamination exists beneath the bottom of any given well.

An anomaly In the data analysis is noteworthy. According to the current understanding of chemistry, Ru106 is very mobile. It is unlikely to be identified using the analysis methods employed for this project since it should be unstable (i.e., moving). However, Ru-106 sometimes exists under stable conditions, as apparent by it's identification in two wells. Given the mobile nature of Ru-106, it is also expected to be deeper and more laterally extensive than is indicated in the TY Tank Farm. Lack of data over the timeframe that Ru-106 was likely to have been present at detectable levels, as well as limits to the depth and lateral extent of data available, makes evaluation incomplete and as such the apparent anomaly is unable to be explained.

Information as to how or whether geology and/or geochemistry effect the direction and extent of isotope migration in the subsurface is not considered in this report.

\section{References}

Brevick, C. H., R. L. Newell, J. W. Funk, May 1996, "Supporting Document for the Historical Tank Content Estimate for BX Tank Farm," WHC-SD-WM-ER-311, Rev. 1, Westinghouse Hanford Company, Richland, Washington.

MACTEC-ERS, 1997, Work performed under contract \#DE-AC04-94AL96907, U.S. Department of Energy, 1996 to 1997, by MACTEC-ERS, Grand Junction, CO.

Randall, R. R., R. K. Price, 1998, "Analysis Techniques Applied to the Dry Well Surveillance Gross Gamma Ray Data at the SX Tank Farm," WMNW/TRS-ES-VZMA-001, Waste Management Federal Services, Inc., Northwest Operations, Richland, Washington.

Randall, R. R., R. K. Price, 1998, "Monitoring Results for the SX Single Shell Tank Farm Dry Well Gamma Ray Surveillance Log Surveys," WMNW/TRS-ES-VZMA-002, Waste Management Federal Services, Inc., Northwest Operations, Richland, Washington. 


\section{HNF-3831 Rev 0}

Randall, R. R., 1999, "Dry Well Probe Calibrations," HNF-3861, In Situ Technologies, Inc., West Richland, Washington.

WMNW, 1998, "Analysis of Historical Gross Gamma Logging Data from BX Tank Farm," Project 772028, Task 23020001, Three Rivers Scientific, West Richland, Washington. 
HNF $=3831-$ REV 0

\section{TY Tank Farm Dry Well Surveillance Analysis Summary}

\begin{tabular}{|c|c|c|c|c|c|c|c|c|c|}
\hline DW-No. & Borehole & Tot_Dep & \#Logs & Type Categ & Z_Top & Base MxG & & YMxGTP & Isotope \\
\hline $52-01-01$ & 0299-W10-088 & $100^{\circ}$ & 257 & 4 Clean & & & & & \\
\hline $52-01-05$ & 0299-W10-089 & $100^{\prime}$ & 273 & 4 Stable & 45 & 58 & 500 & 1975 & $\mathrm{Ru}$ \\
\hline $52-01-09$ & 0299-W10-090 & $100^{\prime}$ & 265 & 4 Stable & 50 & 62 & 450 & 1975 & $\mathrm{Ru}$ \\
\hline $52-02-01$ & 0299-W10-091 & $100^{\prime}$ & 228 & 4 Clean & & & & & - \\
\hline $52-02-05$ & 0299-W10-092 & $100^{\prime}$ & 242 & 4 Clean & & & & & - \\
\hline $52-02-06$ & 0299-W10-171 & $100^{\prime}$ & 141 & 4 Clean & & & & & - \\
\hline $52-02-09$ & 0299-W10-093 & $100^{\prime}$ & 220 & 4 Clean & & & & & - \\
\hline $52-02-11$ & 0299-W10-161 & $100^{\prime}$ & 153 & 4 Unstable early & 36 & 50 & 400 & 1980 & Cs \\
\hline $52-03-03$ & 0299-W10-095 & $100^{\prime}$ & $\begin{array}{l}89 \\
92\end{array}$ & $\begin{array}{l}1 \text { Stable } \\
2 \text { Unassigned Deviation }\end{array}$ & $\begin{array}{l}35 \\
54\end{array}$ & $\begin{array}{l}542.7 \mathrm{~K} \\
62\end{array}$ & 150 & $\begin{array}{l}1980 \\
1980\end{array}$ & $\begin{array}{l}\text { Cs } \\
\text { Cs }\end{array}$ \\
\hline $52-03-06$ & 0299-W10-096 & $100^{\prime}$ & 309 & 4 Unstable & 44 & $9865 \mathrm{~K}$ & & 1979 & $\mathrm{Co}$ \\
\hline $52-03-12$ & 0299-W10-094 & $100^{\prime}$ & 276 & $\begin{array}{l}4 \text { Unstable early } \\
\text { Unstable early }\end{array}$ & $\begin{array}{l}48 \\
60\end{array}$ & $\begin{array}{l}60 \\
75\end{array}$ & $\begin{array}{l}250 \\
200\end{array}$ & $\begin{array}{l}1977 \\
1984\end{array}$ & $\begin{array}{l}\text { Co } \\
\text { Co }\end{array}$ \\
\hline $52-04-02$ & 0299-W10-097 & $100^{\prime}$ & 265 & 4 Clean & & & & & - \\
\hline $52-04-03$ & 0299-W10-083 & $147^{\prime}$ & 279 & 4 TF Activity & 0 & $850 \mathrm{~K}$ & & 1975 & $\mathrm{Cs}$ \\
\hline 52-04-06 & 0299-W10-098 & $100^{\prime}$ & 251 & 4 Clean & & & & & - \\
\hline 52-04-09 & 0299-W10-099 & $100^{\prime}$ & 253 & 4 Stable & 85 & 100 & 100 & 1975 & $\mathrm{Cs}$ \\
\hline 52-04-10 & 0299-W10-082 & $142 '$ & 246 & 4 Clean & & & & & - \\
\hline $52-05-07$ & 0299-W15-186 & $100^{\prime}$ & 265 & $\begin{array}{c}4 \text { Unstable early } \\
\text { Unstable early } \\
\text { Unstable early } \\
\text { Unstable early }\end{array}$ & $\begin{array}{l}51 \\
57 \\
66 \\
82\end{array}$ & $\begin{array}{rl}57 & 3 \mathrm{~K} \\
66 & 10 \mathrm{~K} \\
82 & 10 \mathrm{~K} \\
100 & 4 \mathrm{~K}\end{array}$ & & $\begin{array}{l}1975 \\
1975 \\
1975 \\
1975\end{array}$ & $\begin{array}{l}5 \mathrm{Cs} ; \mathrm{Co} ; \mathrm{Sb} \\
5 \mathrm{Co} ; \mathrm{Sb} \\
5 \mathrm{Co} ; \mathrm{Sb} \\
5 \mathrm{Co}\end{array}$ \\
\hline 52-06-02 & 0299-W10-100 & $\begin{array}{l}64^{\prime} \\
100^{\prime}\end{array}$ & $\begin{array}{r}37 \\
234\end{array}$ & 4 TF Activity & 0 & $\begin{array}{l}10 \\
56\end{array}$ & 150 & $\begin{array}{l}1975 \\
1075\end{array}$ & $5 \mathrm{Cs}$ \\
\hline $\begin{array}{l}52-06-04 \\
52-06-05\end{array}$ & 0299-W15-185 & $\begin{array}{l}100^{\prime} \\
100^{\prime}\end{array}$ & $\begin{array}{l}234 \\
176\end{array}$ & 4 Stable & $\begin{array}{l}47 \\
50\end{array}$ & $\begin{array}{l}56 \\
903.8 \mathrm{~K}\end{array}$ & 200 & $\begin{array}{l}1975 \\
1975\end{array}$ & $\begin{array}{l}5 \mathrm{Cs} ; \mathrm{Sb} \\
\mathrm{Cs} \cdot \mathrm{Co}\end{array}$ \\
\hline $52-06-06$ & 0299-W15-184 & $100^{\prime}$ & 179 & 4 Stable & 5 & 25 & 200 & 1975 & Cs \\
\hline & & & & Stable & 72 & 82 & 350 & 1975 & $5 \mathrm{Sb}$ \\
\hline 52-06-07 & 0299-W15-003 & 210'SGLS & 172 & 4 Stable & 86 & 100 & 200 & 1975 & $5 \mathrm{Co}$ \\
\hline
\end{tabular}


HNF-3831-REVO

\section{TY Tank Farm}

Radiation Zone Categories

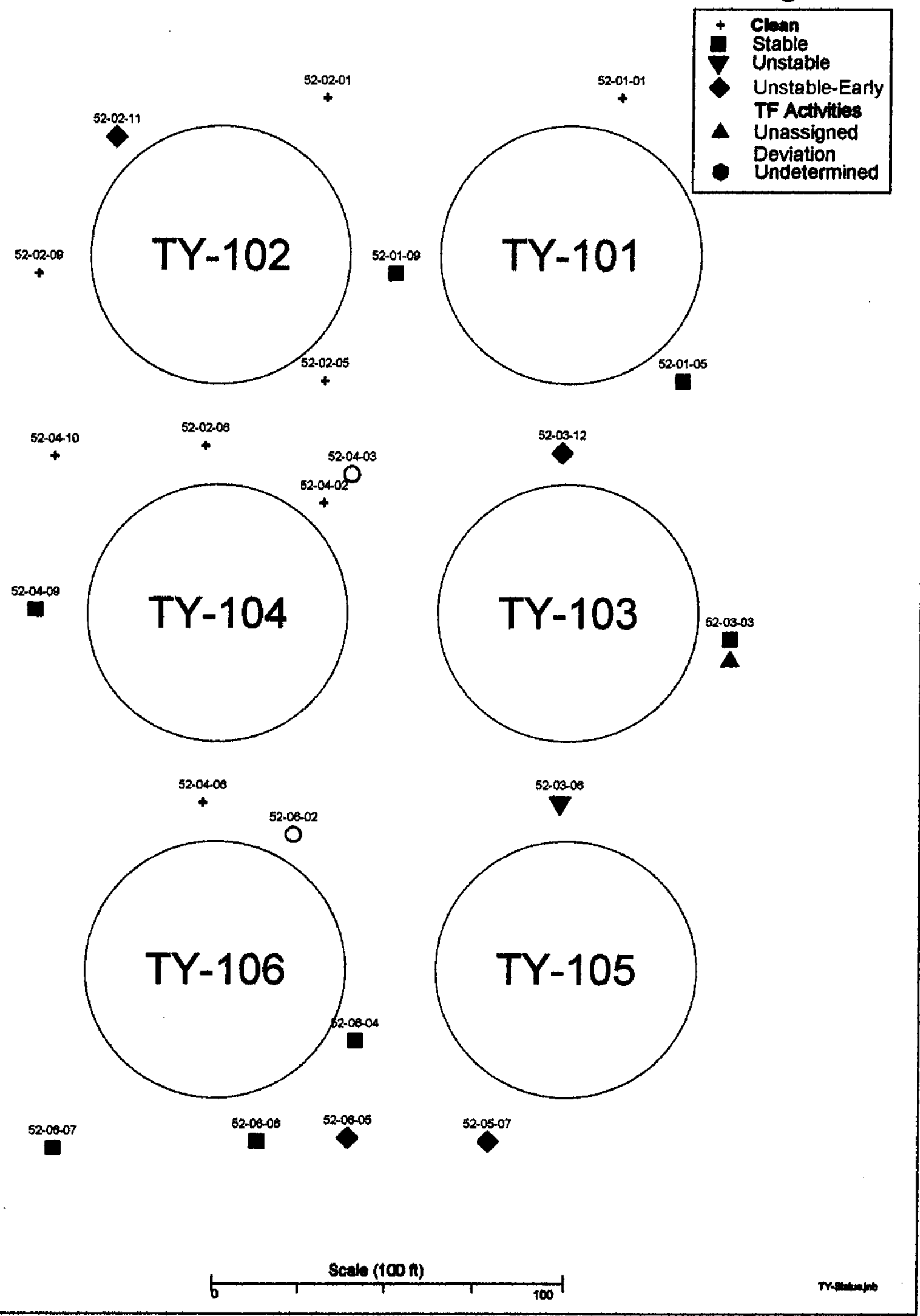




\section{$H N F-3831-R E V 0$}

\section{Borehole 52-01-01}

\section{No Gamma Ray Emitting Contamination was identified.}

No significant levels of gamma ray contamination are present, based upon gross gamma data, above the survey probe detection threshold between 1975 and 1994 in the vadose zone from 2 to 98 feet. The HPGe logging system did not detect any man-made radionuclides

Gross Gamma Survey Information

\begin{tabular}{|r|l|}
\hline Probe Type : & $04: \mathrm{NaI}$ \\
\hline Other Probe Types : & $03:$ Neutron \\
\hline Borehole Depth : & $100 \mathrm{ft}$ \\
\hline Survey Depth : & $100 \mathrm{ft}$ \\
\hline First Survey Date : & $1 / 9 / 1975$ \\
\hline Last Survey Date : & $5 / 25 / 1994$ \\
\hline Number Surveys : & 257 \\
\hline
\end{tabular}

Analysis Notes

\begin{tabular}{|r|l|l|}
\hline Number Surveys Rejected : & 0 & \\
\hline Lower Threshold for Bad Survey Values : & $<=0$ \\
\hline Method Used to Compute Background : & Threshold $0<$ val $<50$ \\
\hline & \\
\hline $\begin{array}{r}\text { Depth(s) where Contamination Identified } \\
\text { in Gross Gamma Surveys : }\end{array}$ & NONE \\
\hline & \\
\hline Analyst Name : & R.R. Randall \\
\hline Company Name : & Three Rivers Scientific \\
\hline
\end{tabular}


HNF -3831 - REVO

\section{Borehole 52-01-01}

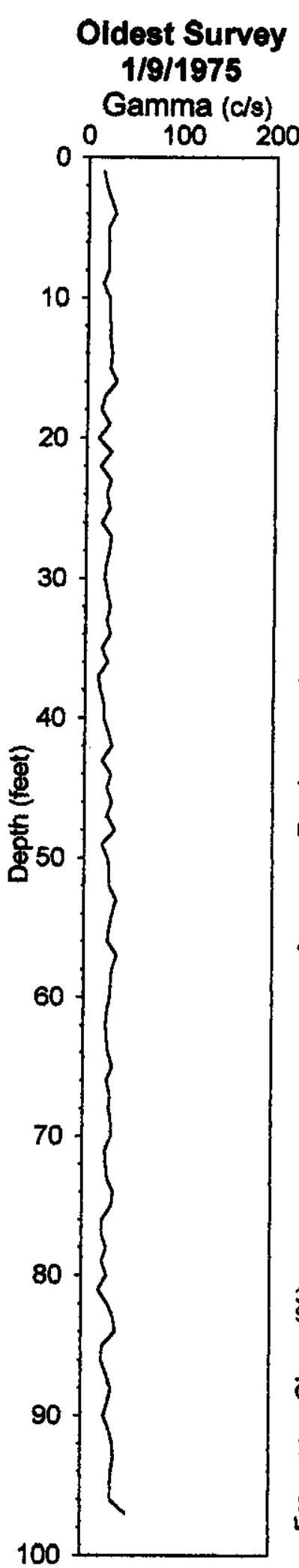

\section{No Gamma-Ray Emitting Contamination Above Survey Detection Threshold}
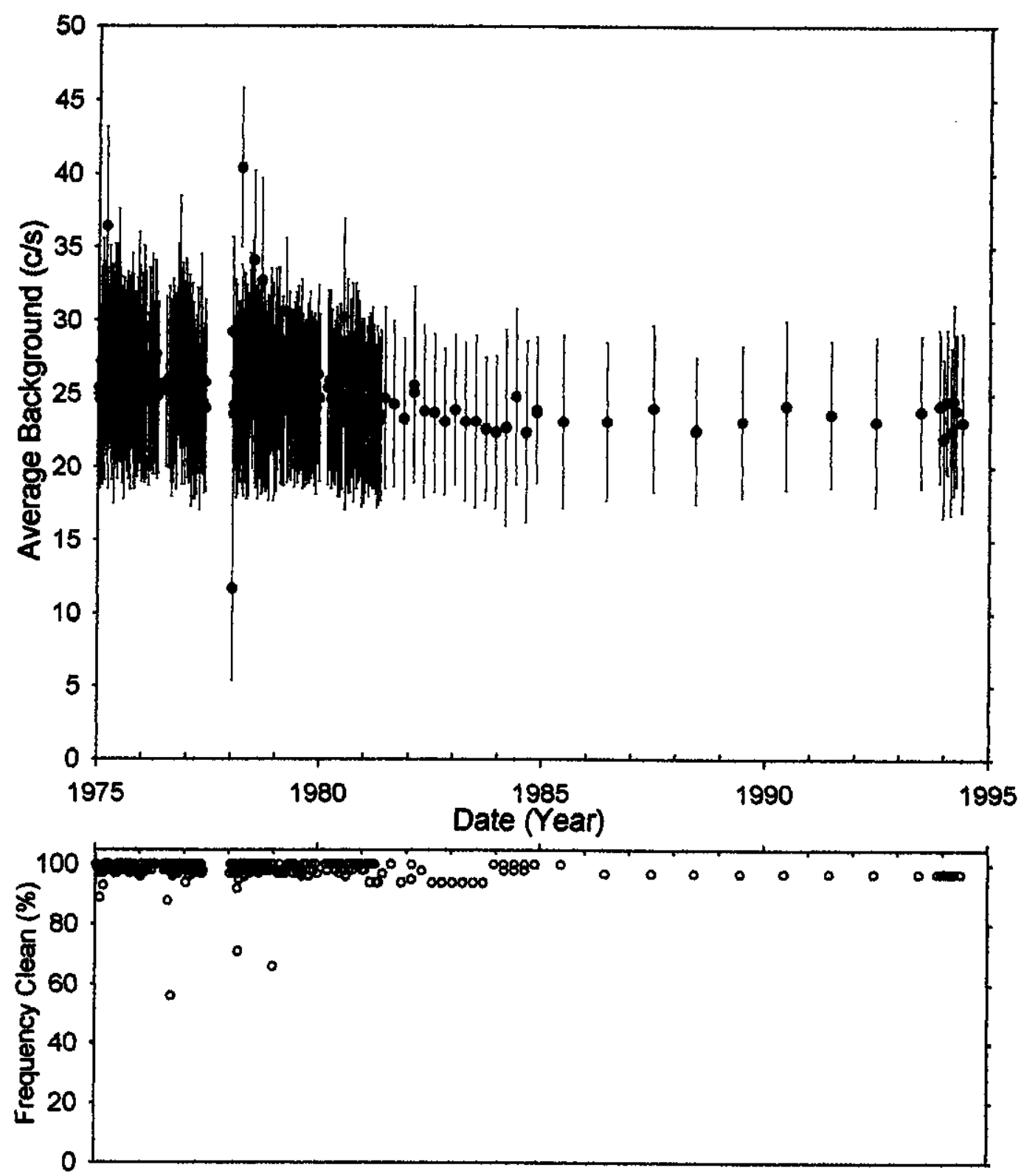

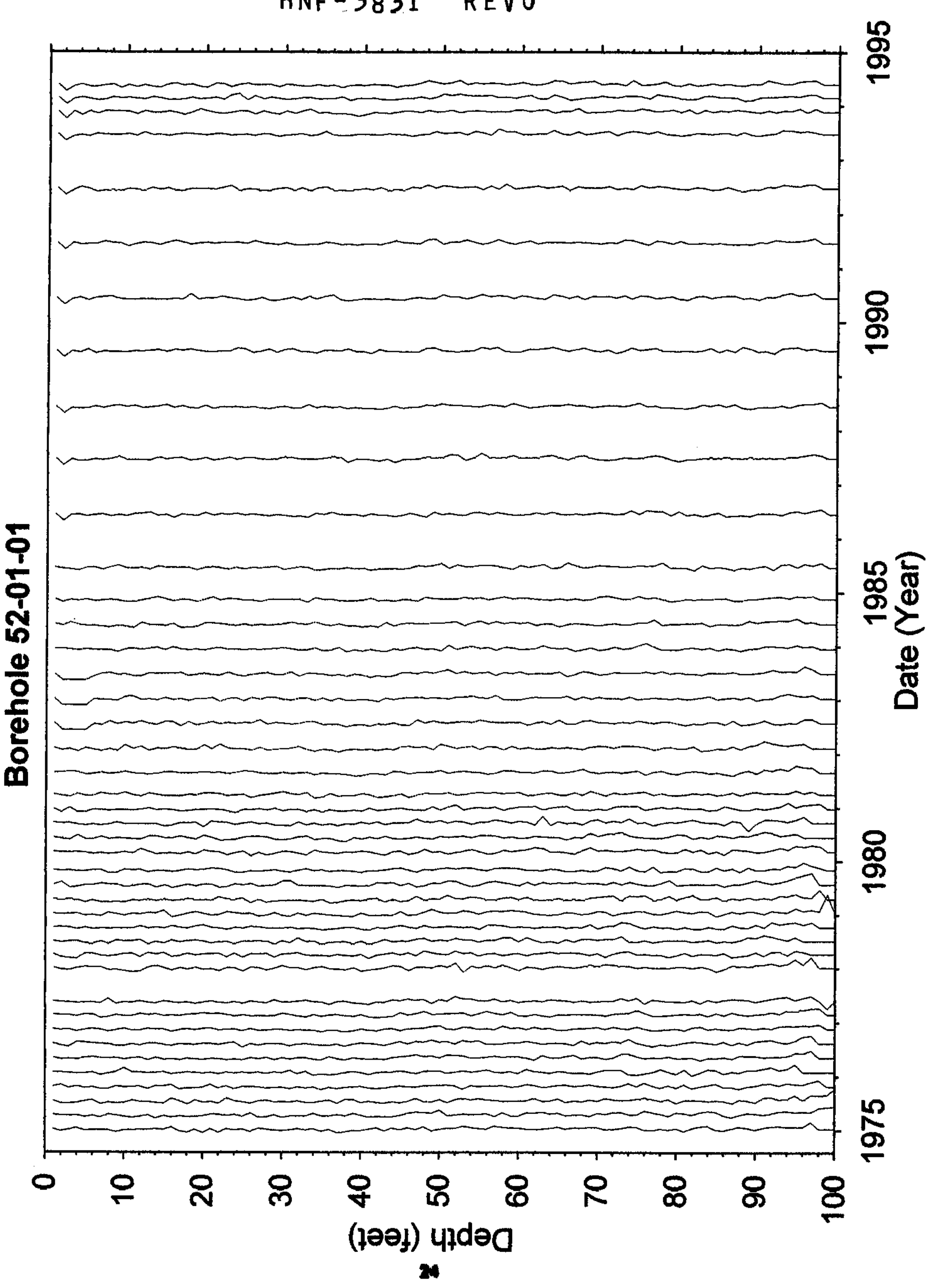


\section{$H N F-3831-R E V 0$}

\section{Borehole 52-01-05}

\section{Contamination (Ru-106) from 45-58 feet is Stable}

Grade thickness product from $\mathbf{4 5}$ to 58 feet is decreasing consistent with $\mathrm{Ru}-106$ (hypothesis) from 1975 to 1994 . The HPGe data did indicate low levels of Cs-137 at 40 feet, but is below detection with the gross gamma logs.

Gross Gamma Survey Information

\begin{tabular}{|r|l|}
\hline Probe Type : & $04:$ Nal \\
\hline Other Probe Types : & $03:$ Neutron \\
\hline Borehole Depth: & $100 \mathrm{ft}$ \\
\hline Survey Depth : & $100 \mathrm{ft}$ \\
\hline First Survey Date : & $1 / 9 / 1975$ \\
\hline Last Survey Date : & $5 / 25 / 1994$ \\
\hline Number Surveys : & 273 \\
\hline
\end{tabular}

Analysis Notes

\begin{tabular}{|r|l|l|}
\hline Number Surveys Rejected : & 0 & \\
\hline Lower Threshold for Bad Survey Values : & $<=0$ \\
\hline Method Used to Compute Background : & $60-90$ feet \\
\hline & \\
\hline $\begin{array}{r}\text { Depth(s) where Contamination Identified } \\
\text { in Gross Gamma Surveys : }\end{array}$ & $45-58$ Stable \\
\hline & \\
\hline Analyst Name : & R.R. Randall \\
\hline Company Name : & Three Rivers Scientific \\
\hline
\end{tabular}


HNF-3831-REVO

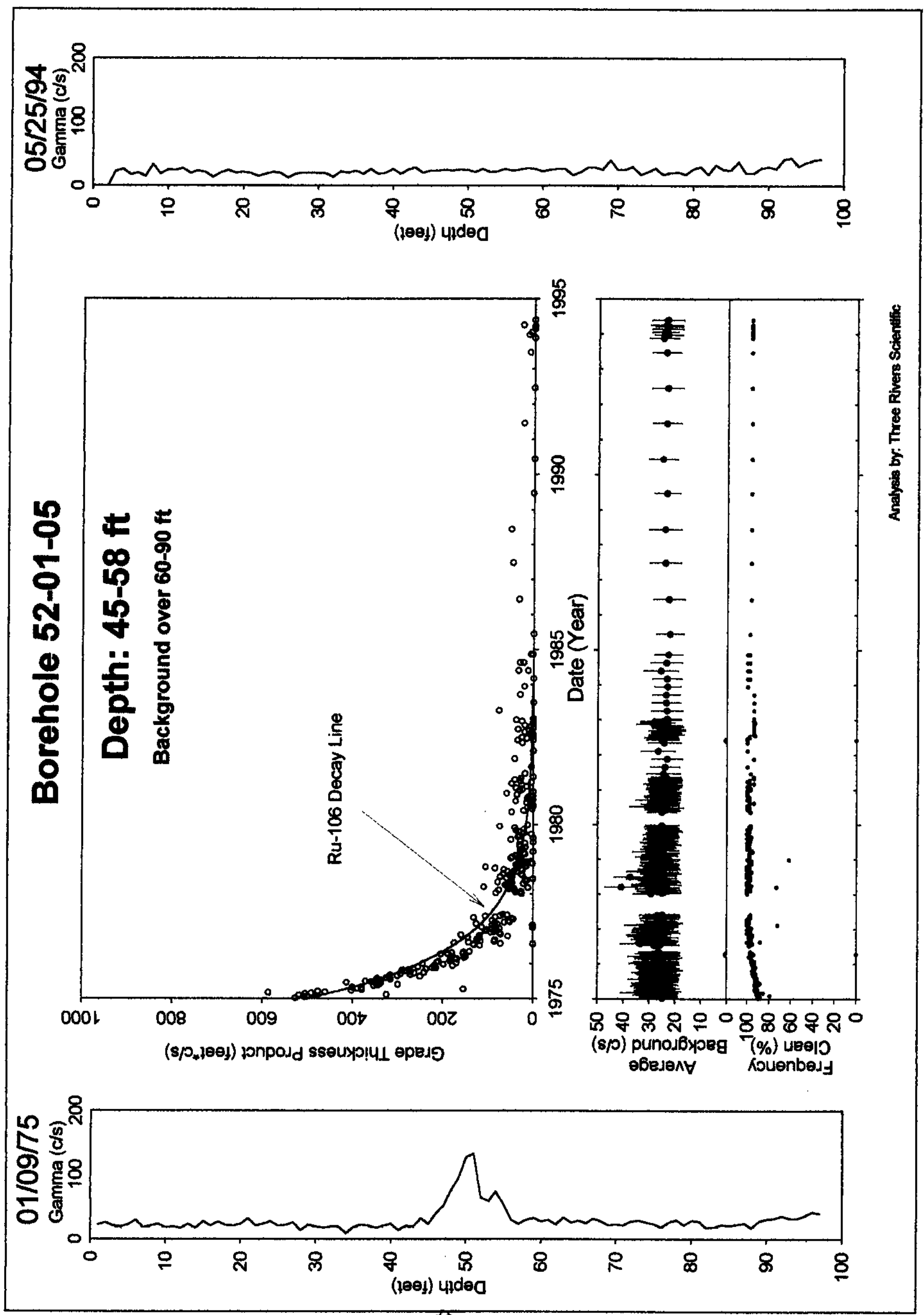




\section{HNF-3831-REVO}






\section{HNF-3831-REVO}

\section{Borehole 52-01-09}

\section{Contamination (Ru-106) from 50-62 feet is Stable}

Grade thickness product from 50 to 62 feet is decreasing consistent with Ru-106 (hypothesis) from 1975 to 1994 . The HPGe data did indicate low levels of Cs-137 from 95 to 100 feet, but is below detection with the gross gamma logs.

Gross Gamma Survey Information

\begin{tabular}{|r|l|}
\hline Probe Type : & $04:$ NaI \\
\hline Other Probe Types : & $03:$ Neutron \\
\hline Borehole Depth : & $100 \mathrm{ft}$ \\
\hline Survey Depth : & $100 \mathrm{ft}$ \\
\hline First Survey Date : & $1 / 23 / 1975$ \\
\hline Last Survey Date : & $5 / 25 / 1994$ \\
\hline Number Surveys : & 265 \\
\hline
\end{tabular}

Analysis Notes

\begin{tabular}{|r|l|l|}
\hline Number Surveys Rejected : & 0 & \\
\hline Lower Threshold for Bad Survey Values : & $<=0$ \\
\hline Method Used to Compute Background : & $65-92$ feet \\
\hline & \\
\hline $\begin{array}{r}\text { Depth(s) where Contamination Identified } \\
\text { in Gross Gamma Surveys : }\end{array}$ & $50-62$ Stable \\
\hline & \\
\hline Analyst Name : & R.R. Randall \\
\hline Company Name : & Three Rivers Scientific \\
\hline
\end{tabular}

Company Name : Three Rivers Scientific 
HNF-3831-REVO

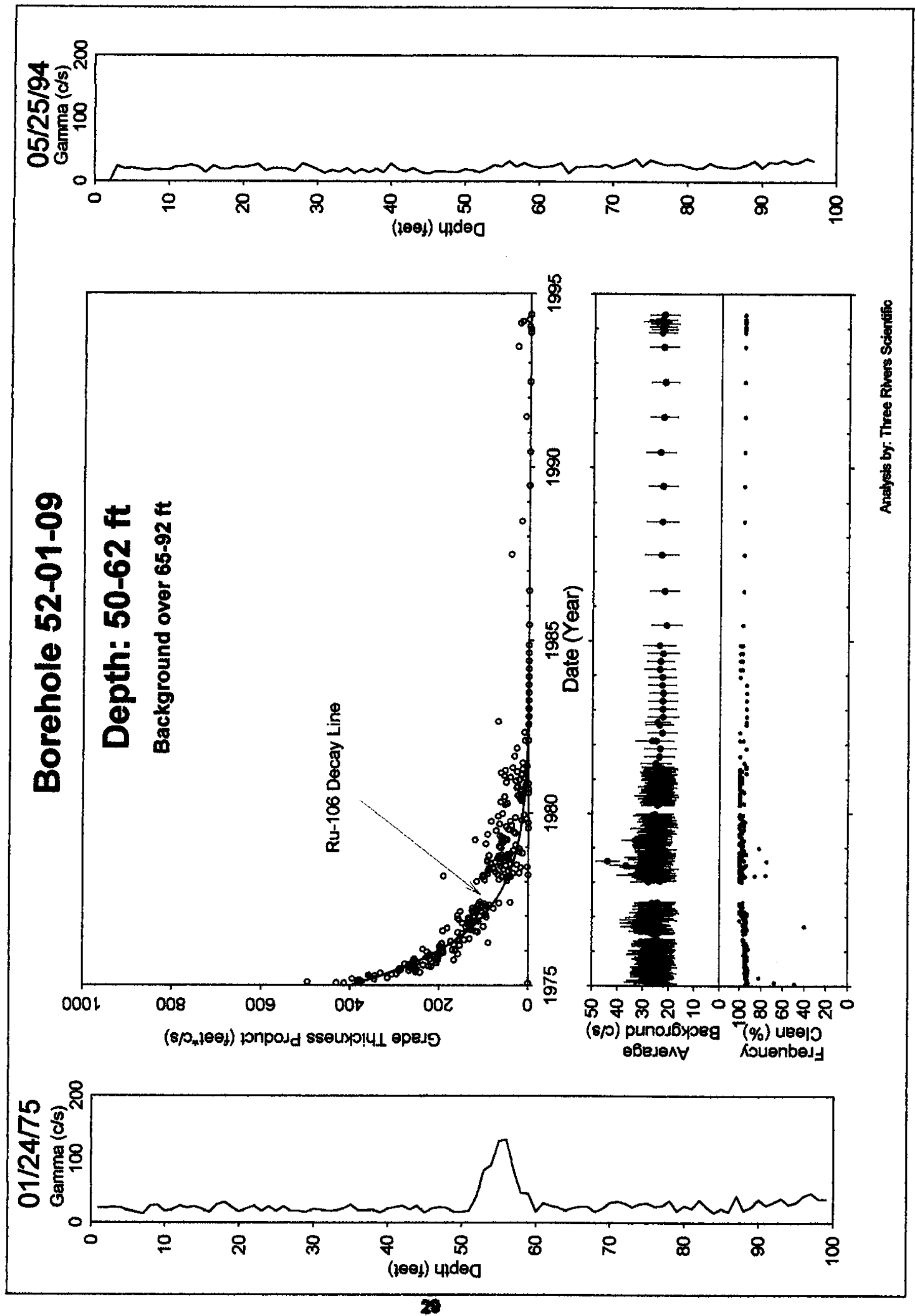


HNF-3831-REVO

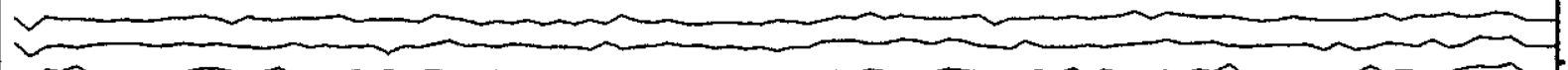

$\sim$

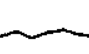

$$
\checkmark
$$

$\checkmark$

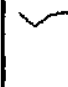

$\sim$

$\sim$

$\sim$

$\checkmark$

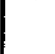

1

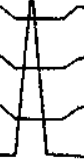

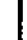

m

r

(2)

N

${ }_{2}$

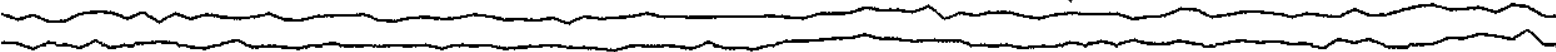

(2)

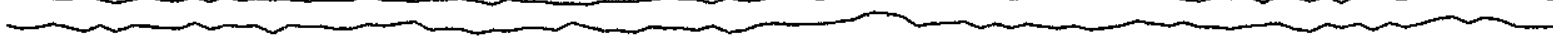

C C

C

(2)

(2)

$2+2$

ron

(2)

(2)

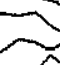

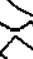

(1) C (2)

$\mathrm{N}_{2}$

- $ᄋ$ 위 


\section{HNF-3831-REVO}

\section{TY Dry Well Survey Analysis - Notes}

$\begin{array}{lll}\text { Borehole } 52-01-01 & \begin{array}{l}\text { Total \# Surveys } 258 \\ \text { \# neutron surveys } 1 \\ 5-25-94 \text { Last }\end{array} & \begin{array}{l}\text { Probe Type } 04 \\ \text { \# GR Surveys } 257\end{array} \\ \text { Presentation Plot Dates }\end{array}$

Contamination Zone Depth(s): L nowe

Isotope from Spectral Survey: (MMML \&maloce

GAPS.Txt

\begin{tabular}{|l|l|l|l|}
\hline Survey Date & num. Gaps & num. Samples & Comment \\
\hline & & & \\
\hline & & & \\
\hline & & & \\
\hline & & & \\
\hline
\end{tabular}

HI-ZONES.TXt

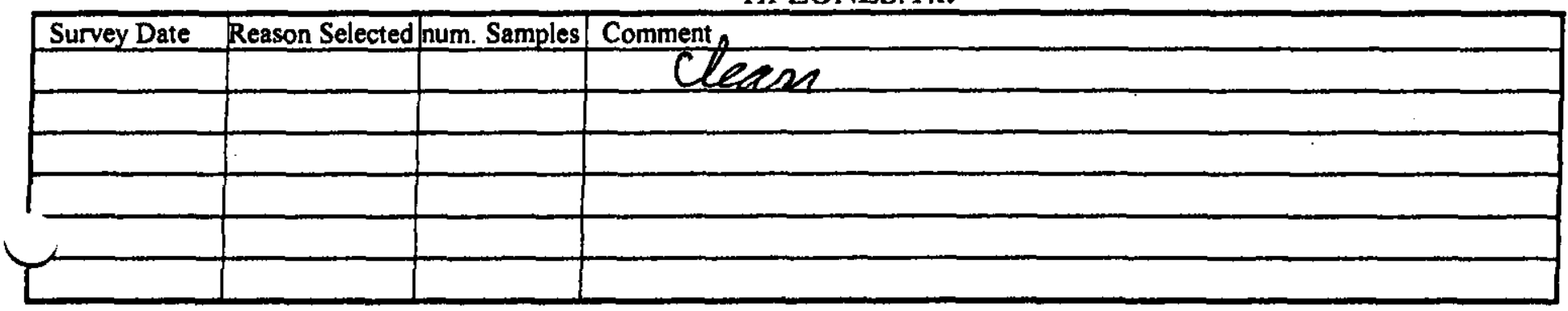

BackGnd.Txt

\begin{tabular}{|l|l|l|l|l|l|}
\hline Survey Date & Reason Selected & num. Samples & Feq.Clean & Avg. Bkg & Comment \\
\hline & & & & & \\
\hline & & & & & \\
\hline & & & & & \\
\hline & & & & & \\
\hline & & & & & \\
\hline & & & & & \\
\hline & & & & & \\
\hline
\end{tabular}

Analysis Notes

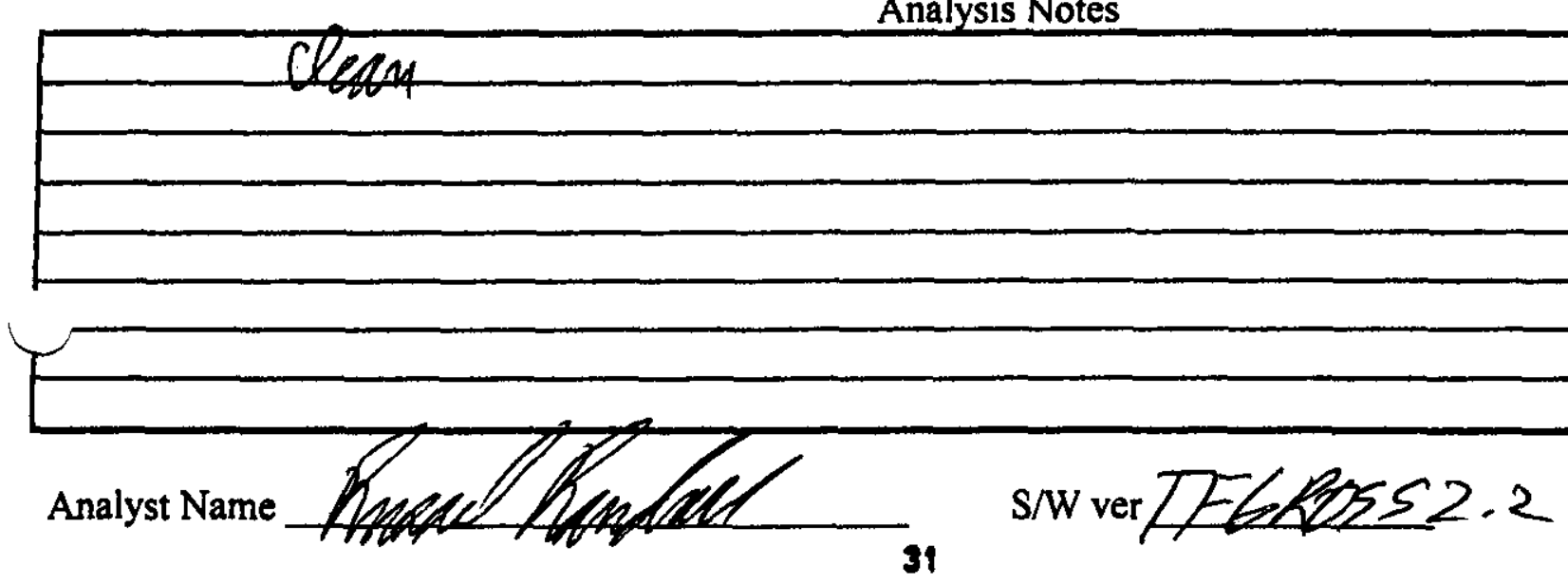




\section{TY Dry Well Survey Analysis - Notes}
Borehole $52-01-05 \quad$ Total \# Surveys 280
Log Date: $1-9-7 \% 1^{\text {st }}$
\# neutron surveys 7
$5-25-94$ Last

Contamination Zone Depth(s):

Isotope from Spectral Survey:
Probe Type 04

\# GR Surveys 273

Presentation Plot Dates

If difterent from $1^{\prime \prime}$ \&ast)

\section{GAPS.Txt}

\begin{tabular}{|l|l|l|l|}
\hline Survey Date & num. Gaps & num. Samples & Comment \\
\hline & & & \\
\hline & & & \\
\hline & & & \\
\hline & & & \\
\hline
\end{tabular}

HI-ZONES.TXt

\begin{tabular}{|l|l|l|l|}
\hline Survey Date & Reason Selected num. Samples & Comment \\
\hline & & & Penk bo supid deacy \\
\hline & & & \\
\hline & & & \\
\hline & & & \\
\hline & & & \\
\hline
\end{tabular}

BackGnd.Txt

\begin{tabular}{|l|l|l|l|l|l|}
\hline Survey Date & Reason Selected & num. Samples & Feq.Clean & Avg. Bkg & Comment \\
\hline & & & & & \\
\hline & & & & & \\
\hline & & & & & \\
\hline & & & & & \\
\hline & & & & & \\
\hline & & & & & \\
\hline & & & & & \\
\hline
\end{tabular}

Analysis Notes

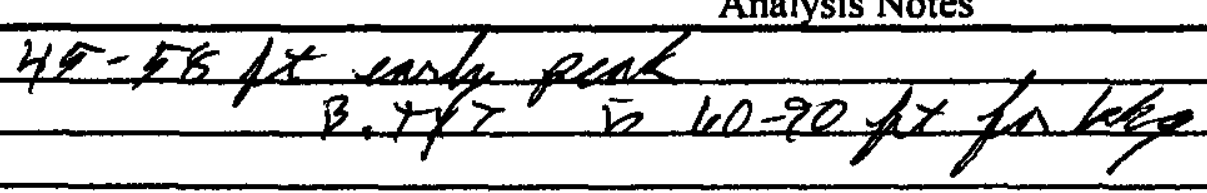

Analyst Name

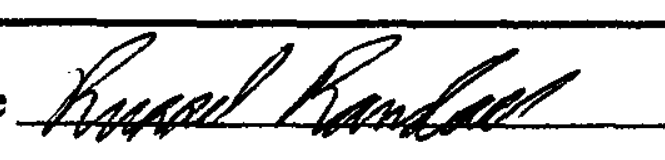

S/W ver TFGROSS2-2 


\section{TY Dry Well Survey Analysis - Notes}

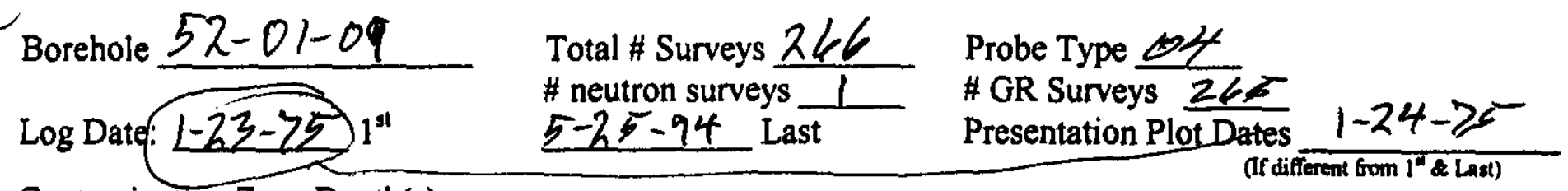

Contamination Zone Depth(s):

Isotope from Spectral Survey: $\mathrm{Ce} 95-100 \mathrm{ft}$ liw $\quad$ Max Survey Depth 100

GAPS.Txt

\begin{tabular}{|l|l|l|l|}
\hline Survey Date & num. Gaps & num. Samples & Comment \\
\hline & & & \\
\hline & & & \\
\hline & & & \\
\hline & & & \\
\hline
\end{tabular}

HI-ZONES.TXt

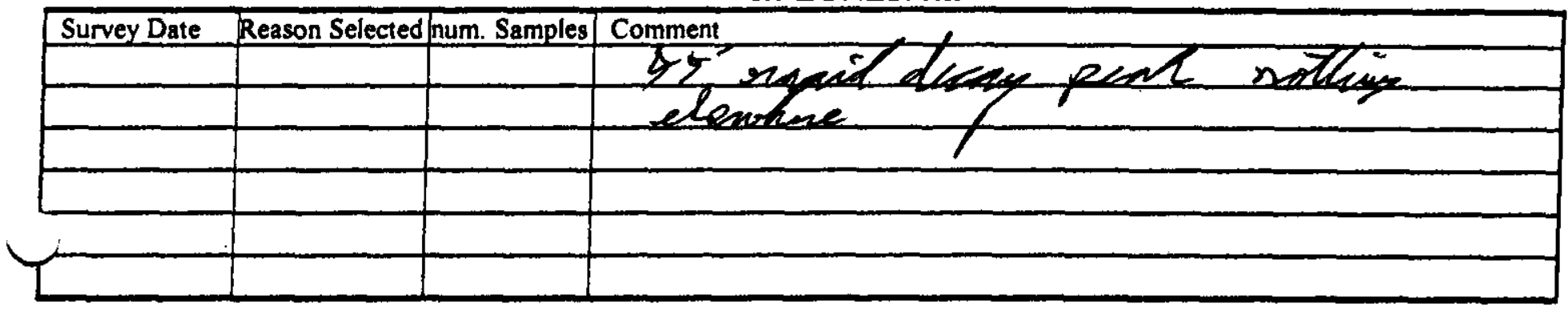

BackGnd.Txt

\begin{tabular}{|l|l|l|l|l|l|}
\hline Survey Date & Reason Selected & num. Samples & Feq.Clean & Avg.Bkg & Comment \\
\hline & & & & & \\
\hline & & & & & \\
\hline & & & & & \\
\hline & & & & & \\
\hline & & & & & \\
\hline & & & & & \\
\hline & & & & & \\
\hline
\end{tabular}

Analysis Notes

Enom Glak we 50-62 GtP \& Fly 


\section{HNF-3831-REVO}

\section{Borehole 52-02-01}

\section{No Gamma Ray Emitting Contamination was identified.}

No significant levels of gamma ray contamination, based upon gross gamma data, are present above the survey probe detection threshold between 1975 and 1993 in the vadose zone from 2 to 98 feet. The HPGe logging system did not detect any man-made radionuclides.

Gross Gamma Survey Information

\begin{tabular}{|r|l|}
\hline Probe Type : & $04:$ NaI \\
\hline Other Probe Types : & $03:$ Neutron \\
\hline Borehole Depth : & $100 \mathrm{ft}$ \\
\hline Survey Depth : & $100 \mathrm{ft}$ \\
\hline First Survey Date : & $1 / 9 / 1975$ \\
\hline Last Survey Date : & $6 / 22 / 1993$ \\
\hline Number Surveys : & 228 \\
\hline
\end{tabular}

Analysis Notes

\begin{tabular}{|r|l|l|}
\hline Number Surveys Rejected : & 0 & \\
\hline Lower Threshold for Bad Survey Values : & $<=0$ \\
\hline Method Used to Compute Background : & Threshold 0<val<50 \\
\hline & \\
\hline $\begin{array}{r}\text { Depth(s) where Contamination Identified } \\
\text { in Gross Gamma Surveys : }\end{array}$ & NONE \\
\hline Analyst Name : & R.R. Randall \\
\hline Company Name : & Three Rivers Scientific \\
\hline
\end{tabular}


HNF-3831-REVO

\section{Borehole 52-02-01}

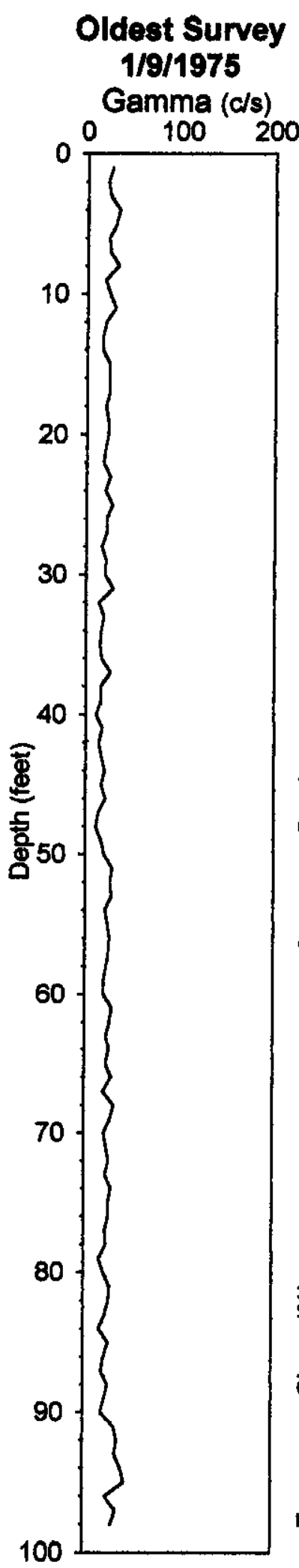

No Gamma-Ray Emitting Contamination
Above Survey Detection Threshold
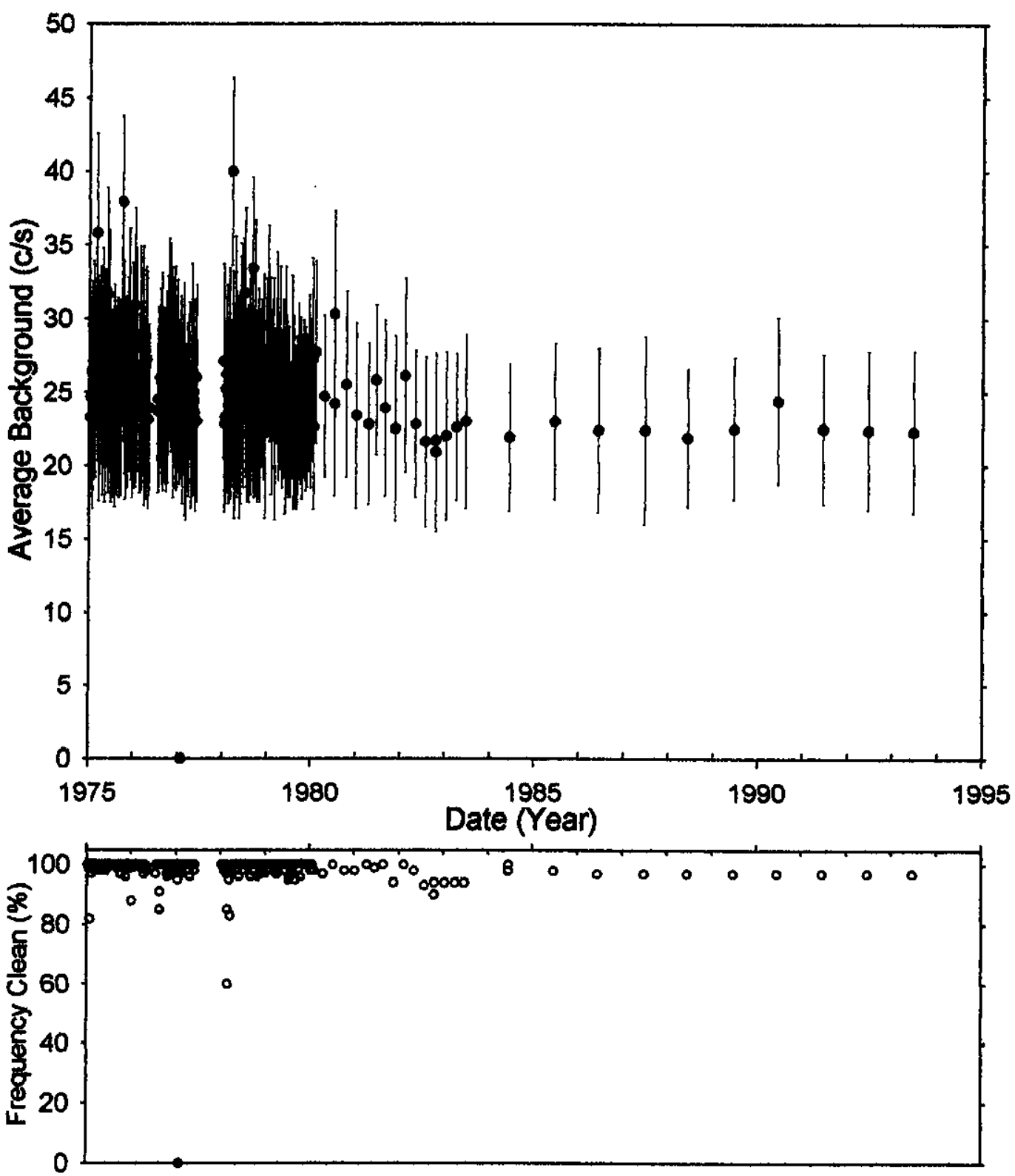


\section{HNF-3831-REVO}
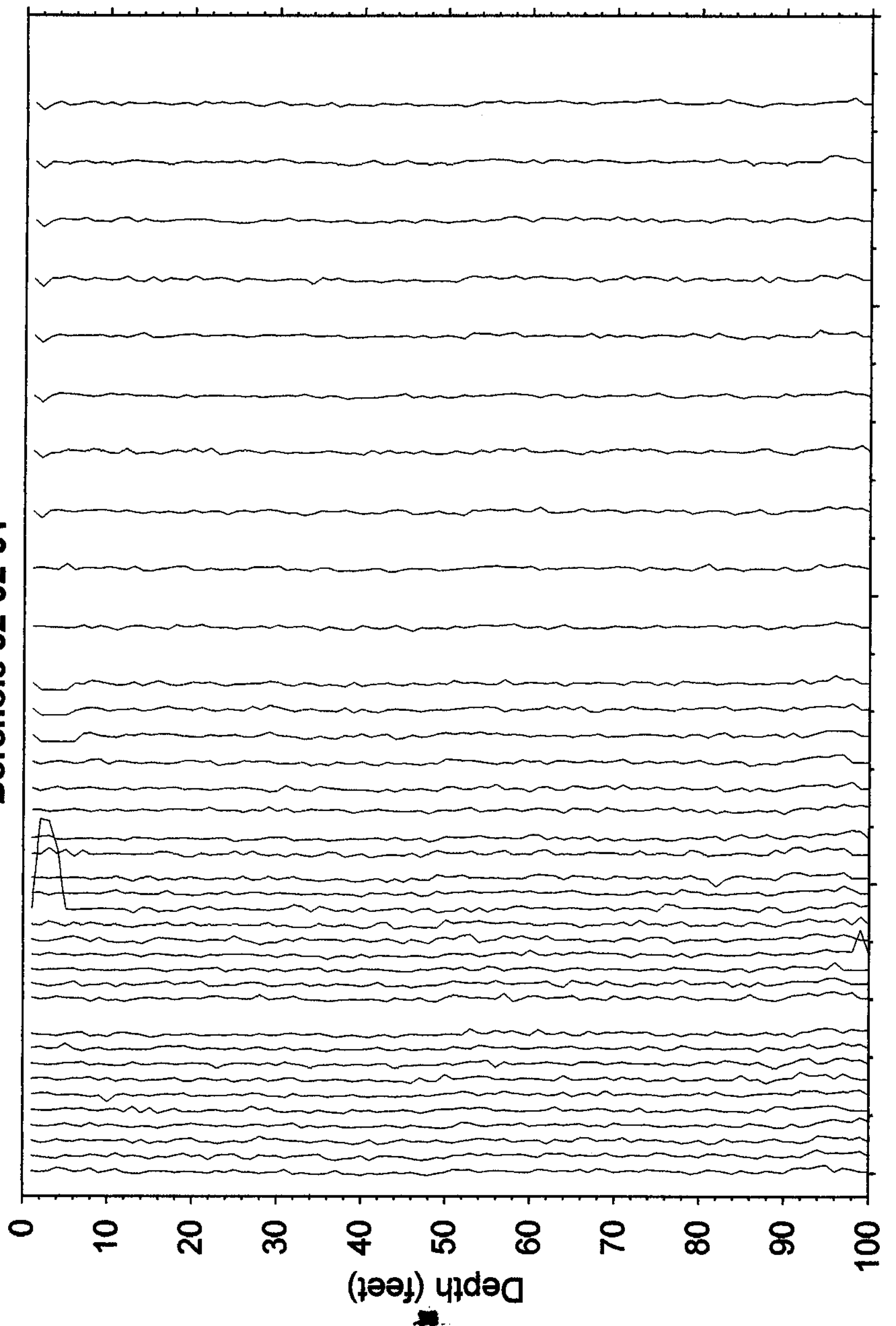


\section{HNF-3831-REVO}

\section{Borehole 52-02-05}

\section{No Gamma Ray Emitting Contamination was identified.}

No significant levels of gamma ray contamination, based upon the gross gamma data, are present above the survey probe detection threshold between 1975 and 1993 in the vadose zone from 2 to 98 feet. The HPGe logging system registered Cs-137 near threshold for the logging program.

Gross Gamma Survey Information

\begin{tabular}{|r|l|}
\hline Probe Type : & $04:$ Nal \\
\hline Other Probe Types : & $03:$ Neutron \\
\hline Borehole Depth: & $100 \mathrm{ft}$ \\
\hline Survey Depth : & $100 \mathrm{ft}$ \\
\hline First Survey Date : & $1 / 9 / 1975$ \\
\hline Last Survey Date : & $6 / 22 / 1993$ \\
\hline Number Surveys : & 242 \\
\hline
\end{tabular}

Analysis Notes

\begin{tabular}{|r|l|l|}
\hline Number Surveys Rejected : & 0 & \\
\hline & & \\
\hline Lower Threshold for Bad Survey Values : & $<=0$ \\
\hline Method Used to Compute Background : & Threshold $0<$ val $<50$ \\
\hline $\begin{array}{r}\text { Depth(s) where Contamination Identified } \\
\text { in Gross Gamma Surveys : }\end{array}$ & NONE \\
\hline Analyst Name : & R.R. Randall \\
\hline Company Name : & Three Rivers Scientific \\
\hline
\end{tabular}




\title{
Borehole 52-02-05
}

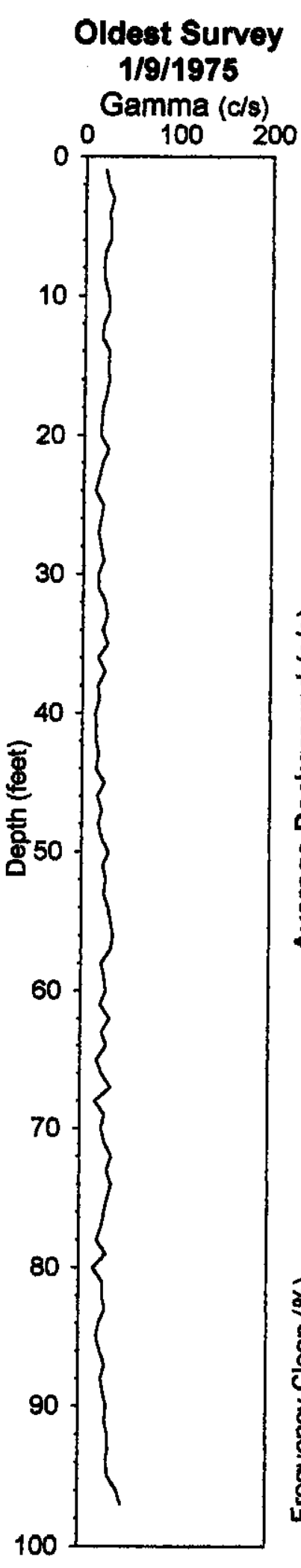

\author{
No Gamma-Ray Emitting Contamination \\ Above Survey Detection Threshold
}
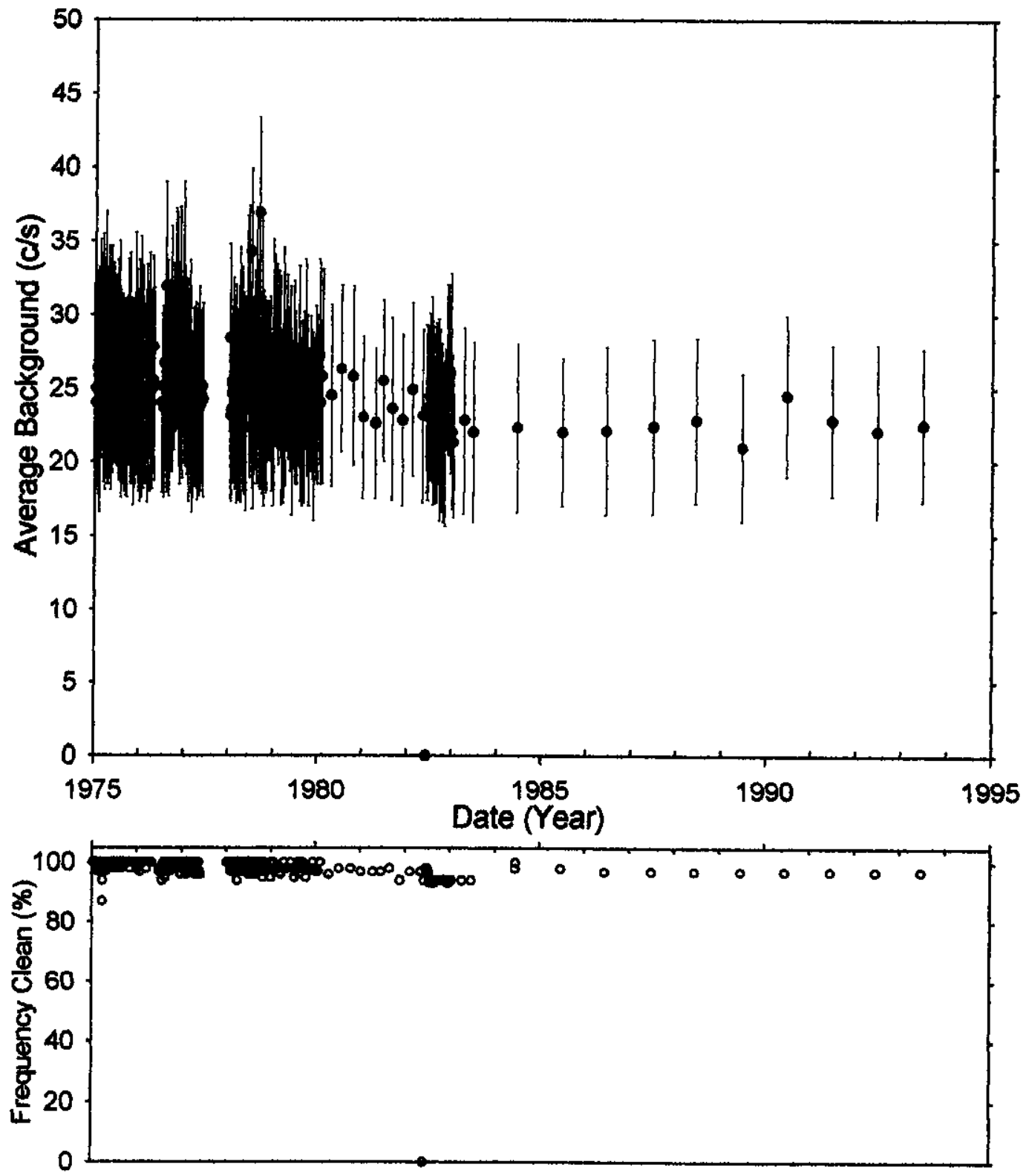
HNF-3831-REVO

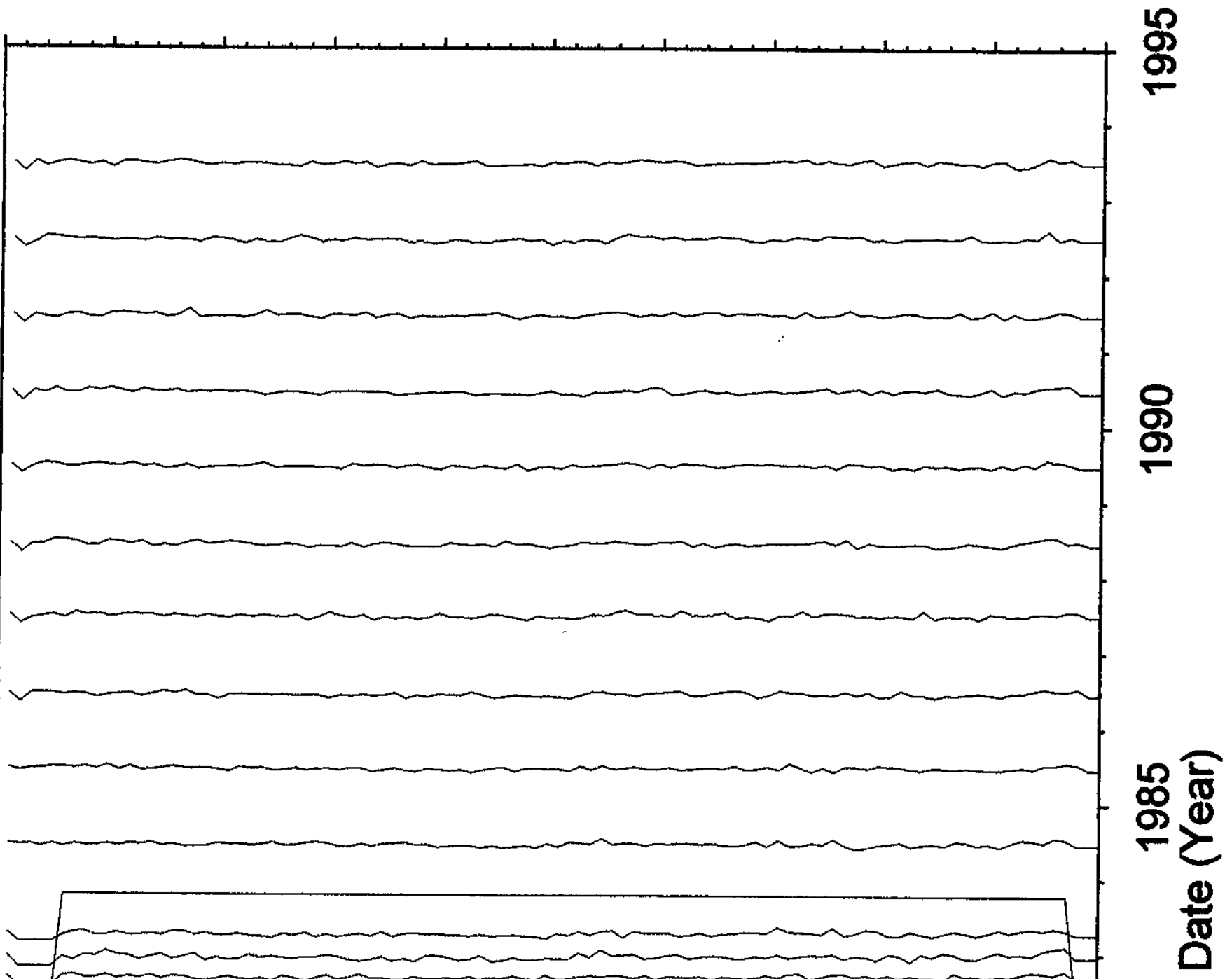

品

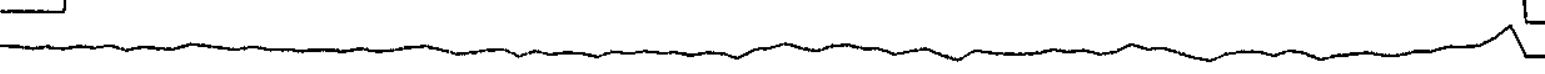

(

(2)

(1)

(2) C

8

$\infty$

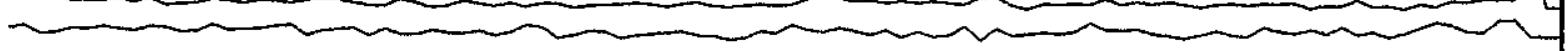

(2)

N

(n)

(1)

$\stackrel{1}{\underline{O}}$

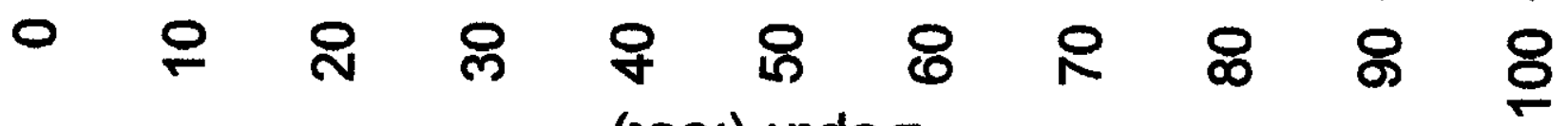

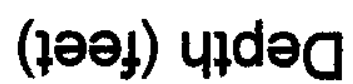




\section{HNF-3831-REVO}

\section{Borehole 52-02-06}

\section{No Gamma Ray Emitting Contamination was identified.}

No significant levels of gamma ray contamination, based upon gross gamma data, are present above the survey probe detection threshold between 1978 and 1993 in the vadose zone from 2 to 100 feet. The HPGe logging system observed low levels of Cs-137 near the surface and Cs-137 near threshold for most of the well depth.

Gross Gamma Survey Information

\begin{tabular}{|r|l|}
\hline Probe Type : & $04: \mathrm{NaI}$ \\
\hline Other Probe Types : & $03:$ Neutron \\
\hline Borehole Depth : & $100 \mathrm{ft}$ \\
\hline Survey Depth : & $100 \mathrm{ft}$ \\
\hline First Survey Date : & $1 / 5 / 1978$ \\
\hline Last Survey Date : & $6 / 22 / 1993$ \\
\hline Number Surveys : & 141 \\
\hline
\end{tabular}

Analysis Notes

\begin{tabular}{|r|l|l|}
\hline Number Surveys Rejected : & 0 & \\
\hline Lower Threshold for Bad Survey Values : & $<=0$ \\
\hline Method Used to Compute Background : & Threshold 0<val<50 \\
\hline & \\
\hline $\begin{array}{r}\text { Depth(s) where Contamination Identified } \\
\text { in Gross Gamma Surveys : }\end{array}$ & NONE \\
\hline Analyst Name : & R.R. Randall \\
\hline Company Name : & Three Rivers Scientific \\
\hline
\end{tabular}




\section{Borehole 52-02-06}

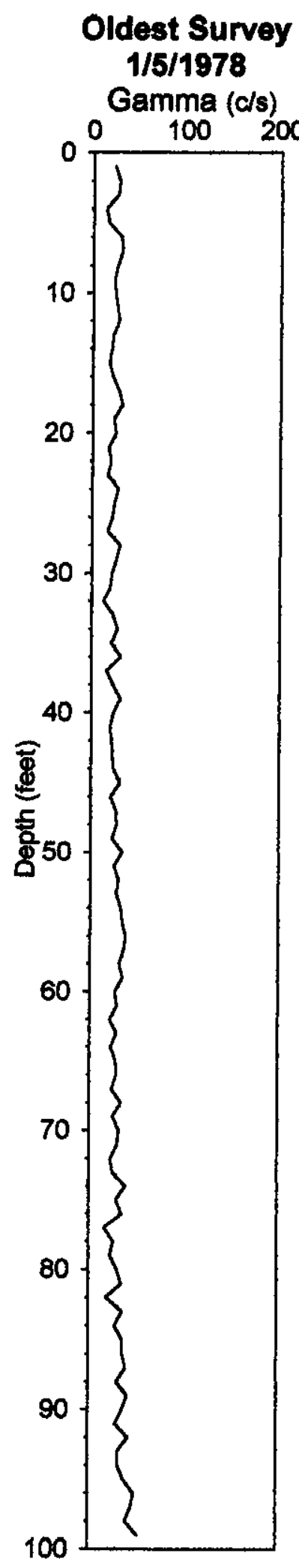

\section{No Gamma-Ray Emitting Contamination Above Survey Detection Threshold}

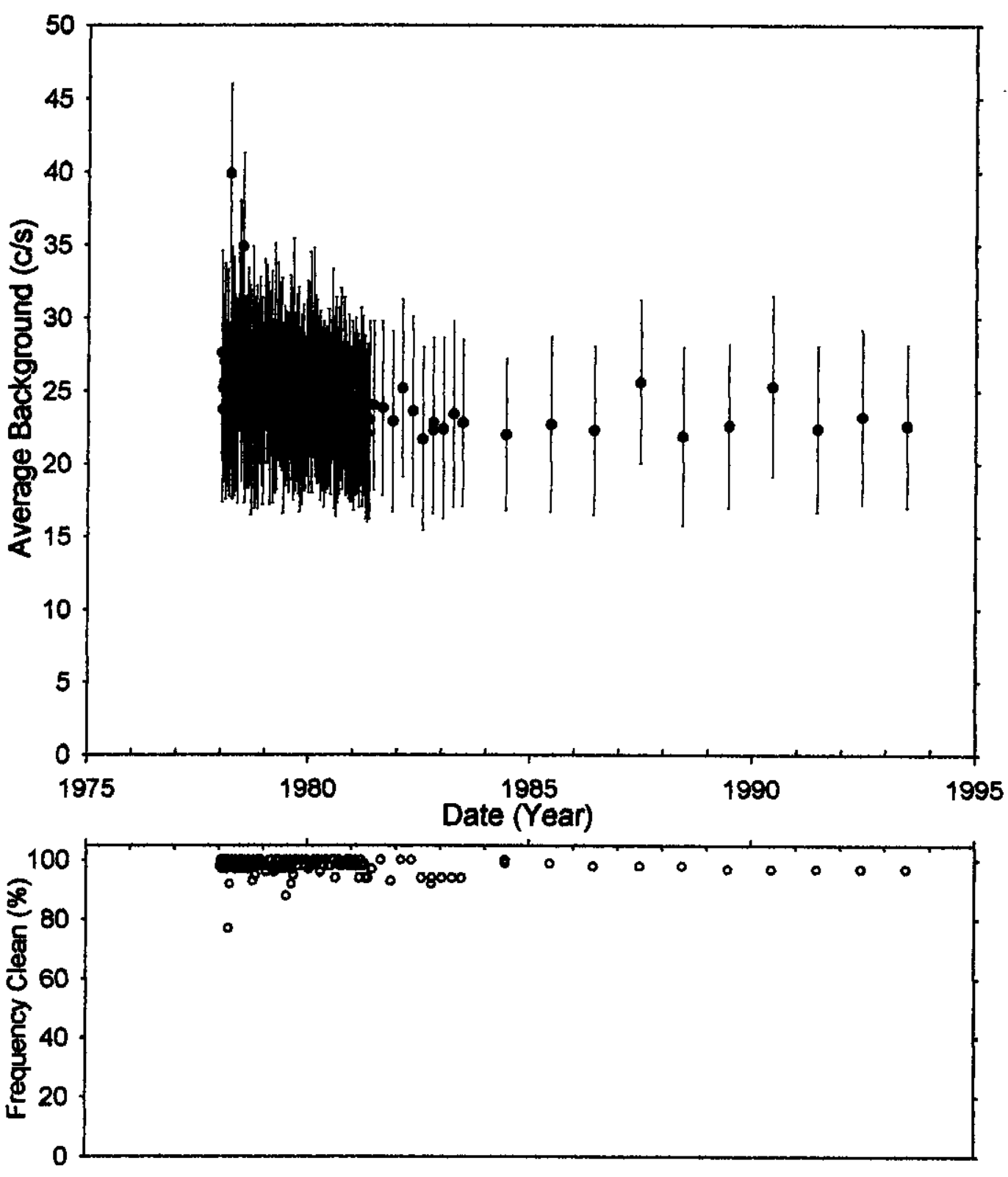

Analysis by: Three Rivers Scientiflc 


\section{HNF-3831-REVO}

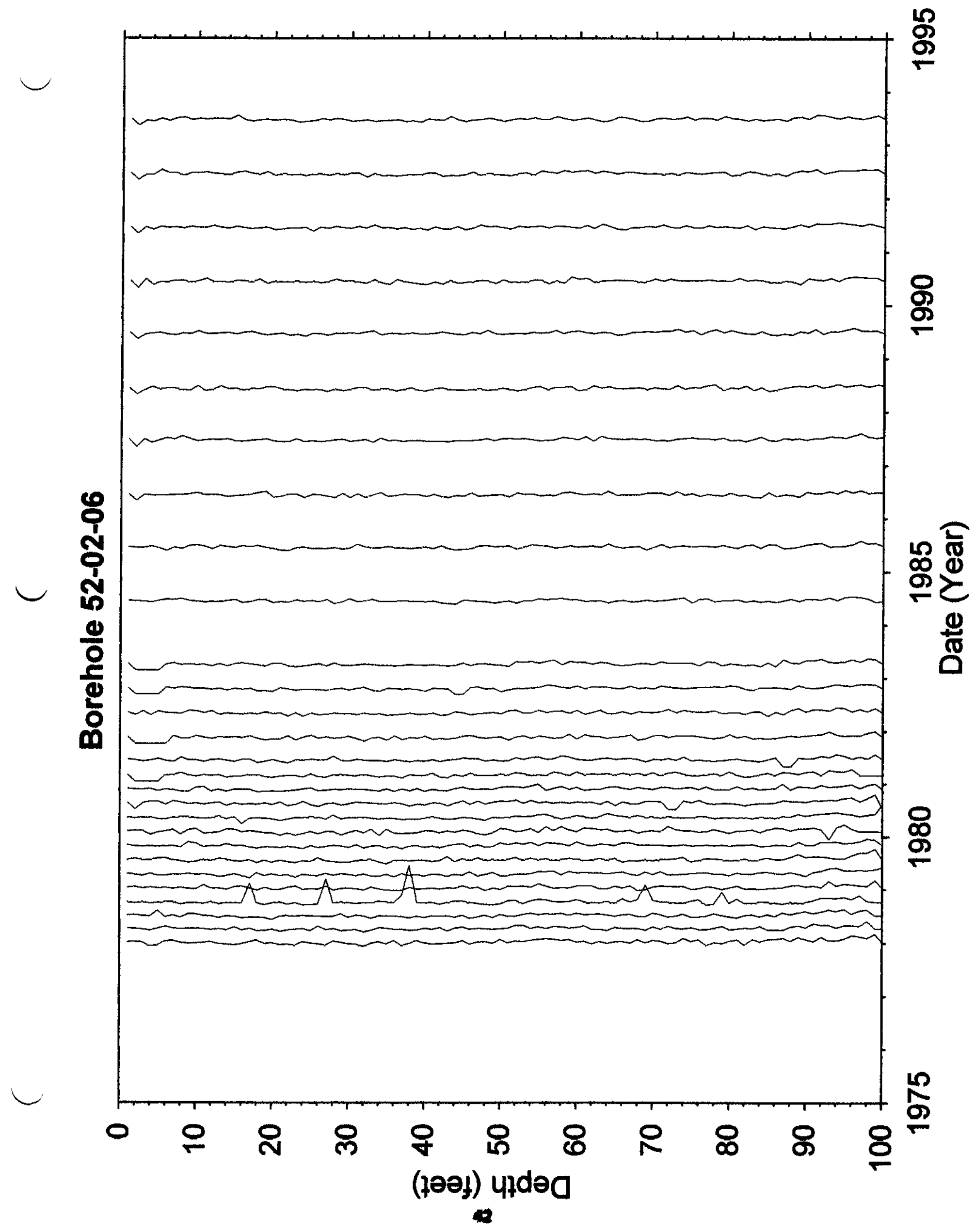




\section{HNF- $3831-$ REVO}

\section{Borehole 52-02-09}

\section{No Gamma Ray Emitting Contamination was identified.}

No significant levels of gamma ray contamination, based upon gross gamma data, are present above the survey probe detection threshold between 1975 and 1993 in the vadose zone from 2 to 98 feet. The HPGe logging system registered Cs-137 at or near threshold at selected depth intervals.

Gross Gamma Survey Information

Probe Type : $04: \mathrm{NaI}$

Other Probe Types: $03:$ Neutron

Borehole Depth : $100 \mathrm{ft}$

Survey Depth : $100 \mathrm{ft}$

First Survey Date : $1 / 9 / 1975$

Last Survey Date : $6 / 22 / 1993$

Number Surveys : 220

Analysis Notes

\begin{tabular}{|r|l|l|}
\hline Number Surveys Rejected : & 0 & \\
\hline Lower Threshold for Bad Survey Values : & $<=0$ \\
\hline Method Used to Compute Background : & Threshold $0<$ val $<50$ \\
\hline & \\
\hline Depth(s) where Contamination Identified & NONE \\
in Gross Gamma Surveys : & \\
\hline & \\
\hline Analyst Name : & R.R. Randall \\
\hline Company Name : & Three Rivers Scientific \\
\hline
\end{tabular}


Borehole 52-02-09

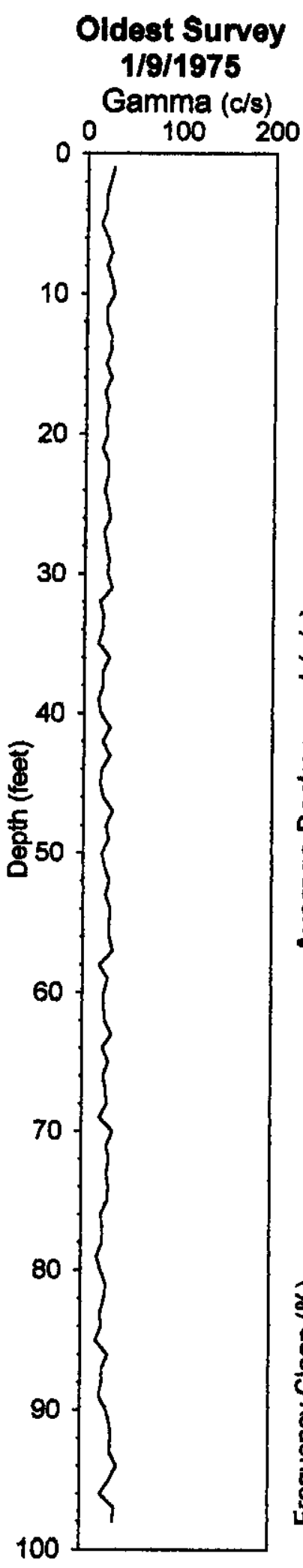

\section{No Gamma-Ray Emitting Contamination Above Survey Detection Threshold}

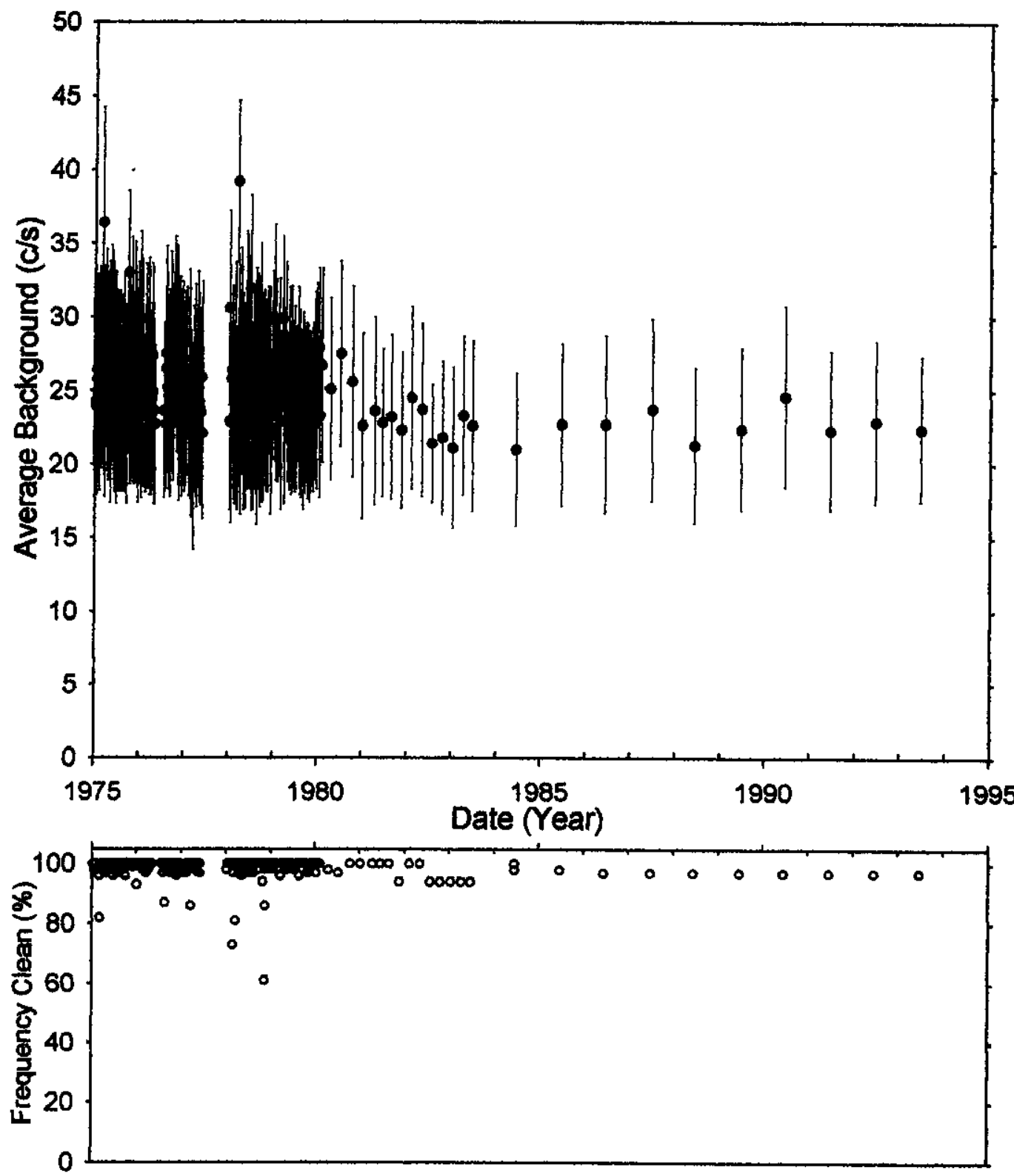




\section{$H N F-3831-R E V 0$}
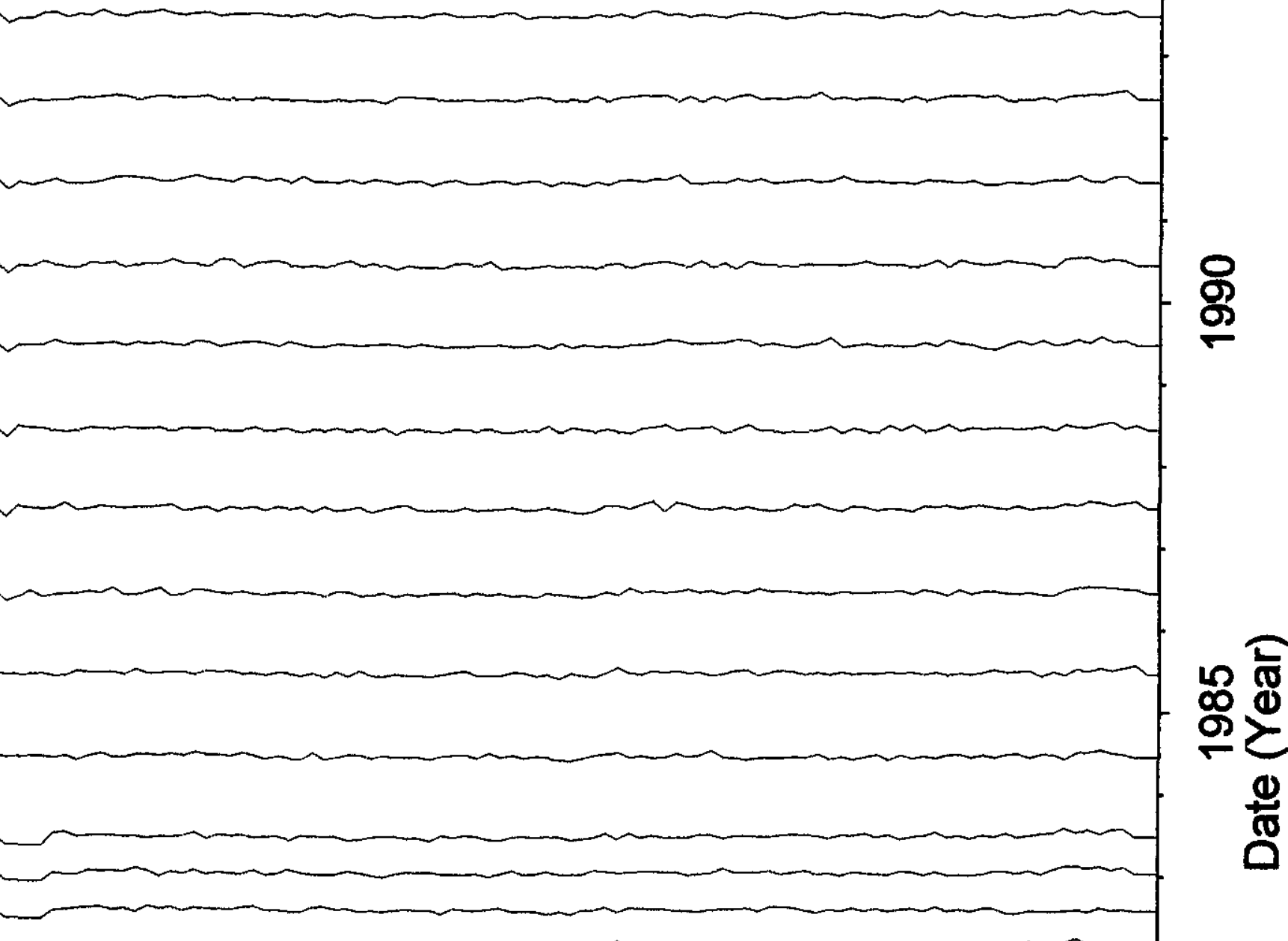

-

(2) (n) (2)

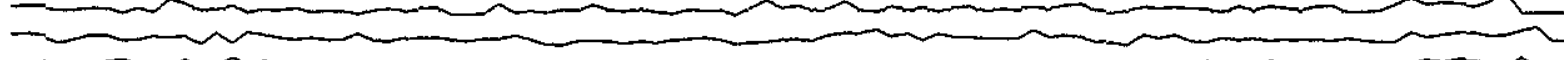
(2) (2) $\mathrm{C}_{2}$ (1) N C N C

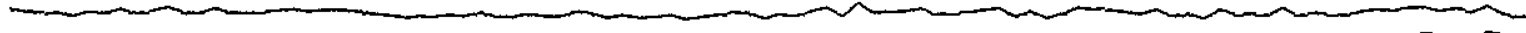

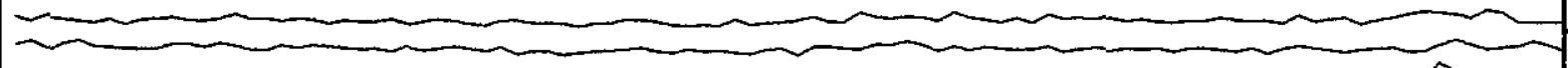
(n)

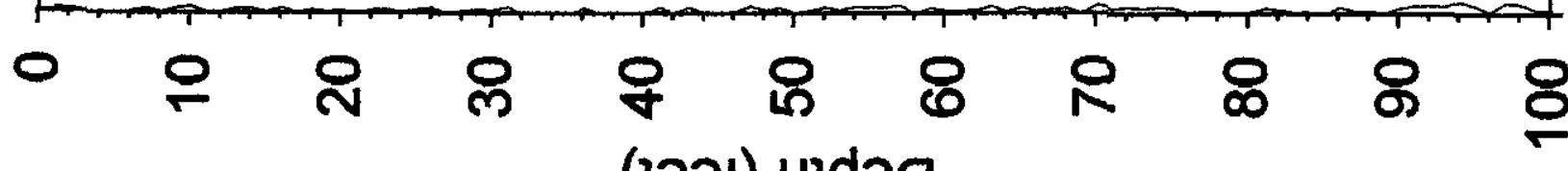




\section{HNF-3831-REVO}

\section{Borehole 52-02-11}

\section{Contamination (Cs-137) from 36-50 feet is Unstable Early}

Grade thickness product from 36 to 50 feet is changing erratically from 1977 to 1985 . Also, the logged interval appears to have deepened after 5/26/77. After the apparent deepening, the peak is not visible until early 1979. After 1979 a small increase occurs, after 1980 a large increase occurs, and after 1985 a small increase occurs. From 1985 to 1993 the grade thickness product appear consistent with Cs-137 (HPGe identified) decay.

Gross Gamma Survey Information

\begin{tabular}{|r|l|}
\hline Probe Type : & $04:$ NaI \\
\hline Other Probe Types : & $03:$ Neutron \\
\hline Borehole Depth: & $100 \mathrm{ft}$ \\
\hline Survey Depth : & $100 \mathrm{ft}$ \\
\hline First Survey Date : & $1 / 20 / 1977$ \\
\hline Last Survey Date : & $6 / 22 / 1993$ \\
\hline Number Surveys: & 153 \\
\hline
\end{tabular}

Analysis Notes

\begin{tabular}{|r|l|l|}
\hline Number Surveys Rejected : & 0 & \\
\hline Lower Threshold for Bad Survey Values : & $<=0$ \\
\hline Method Used to Compute Background : & $60-90$ feet \\
\hline & \\
\hline $\begin{array}{r}\text { Depth(s) where Contamination Identified } \\
\text { in Gross Gamma Surveys : }\end{array}$ & $36-50$ Unstable early \\
\hline & \\
\hline Analyst Name : & R.R. Randall \\
\hline Company Name : & Three Rivers Scientific \\
\hline
\end{tabular}


HNF-3831-REVO

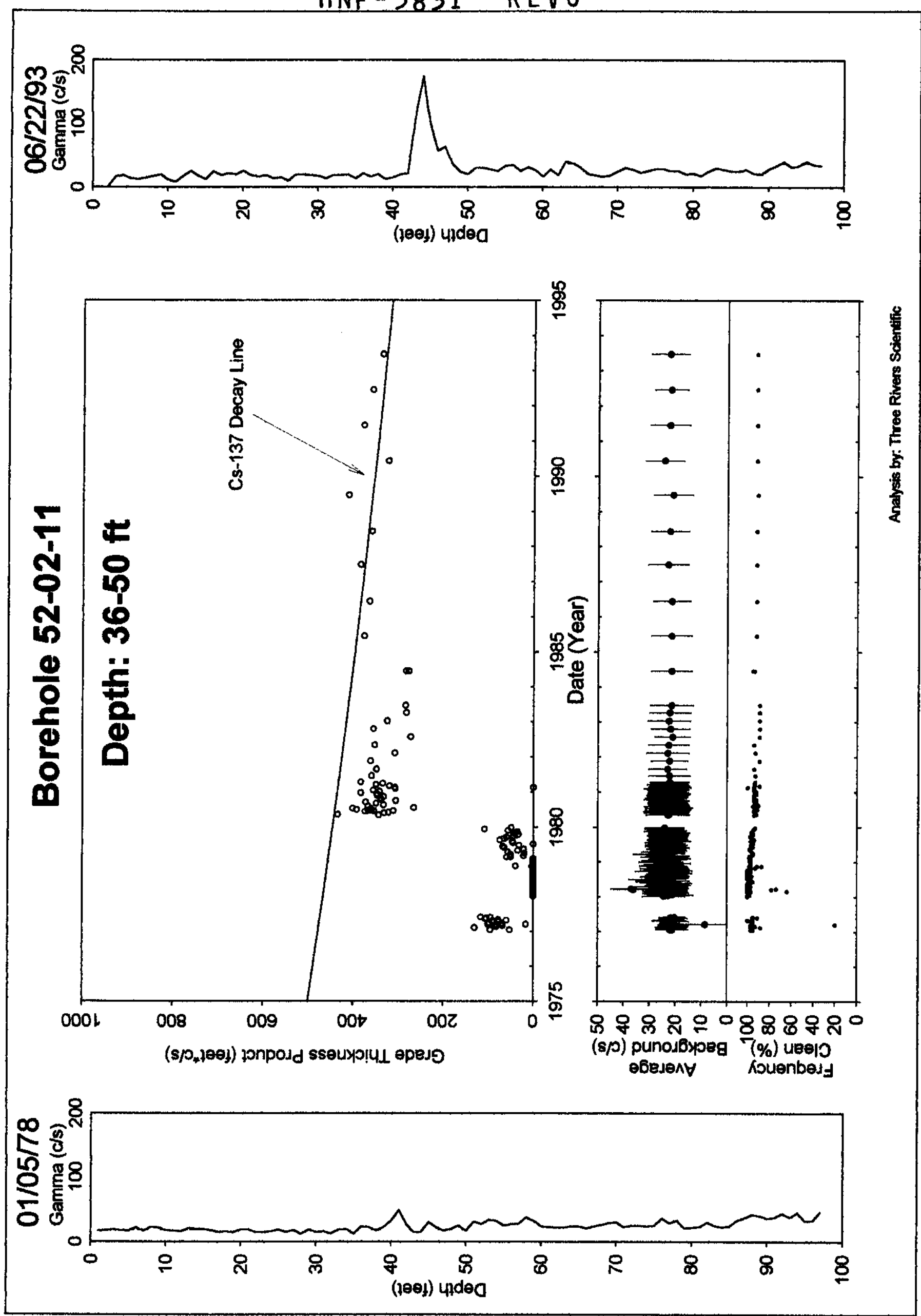


HNF-3831-REVO

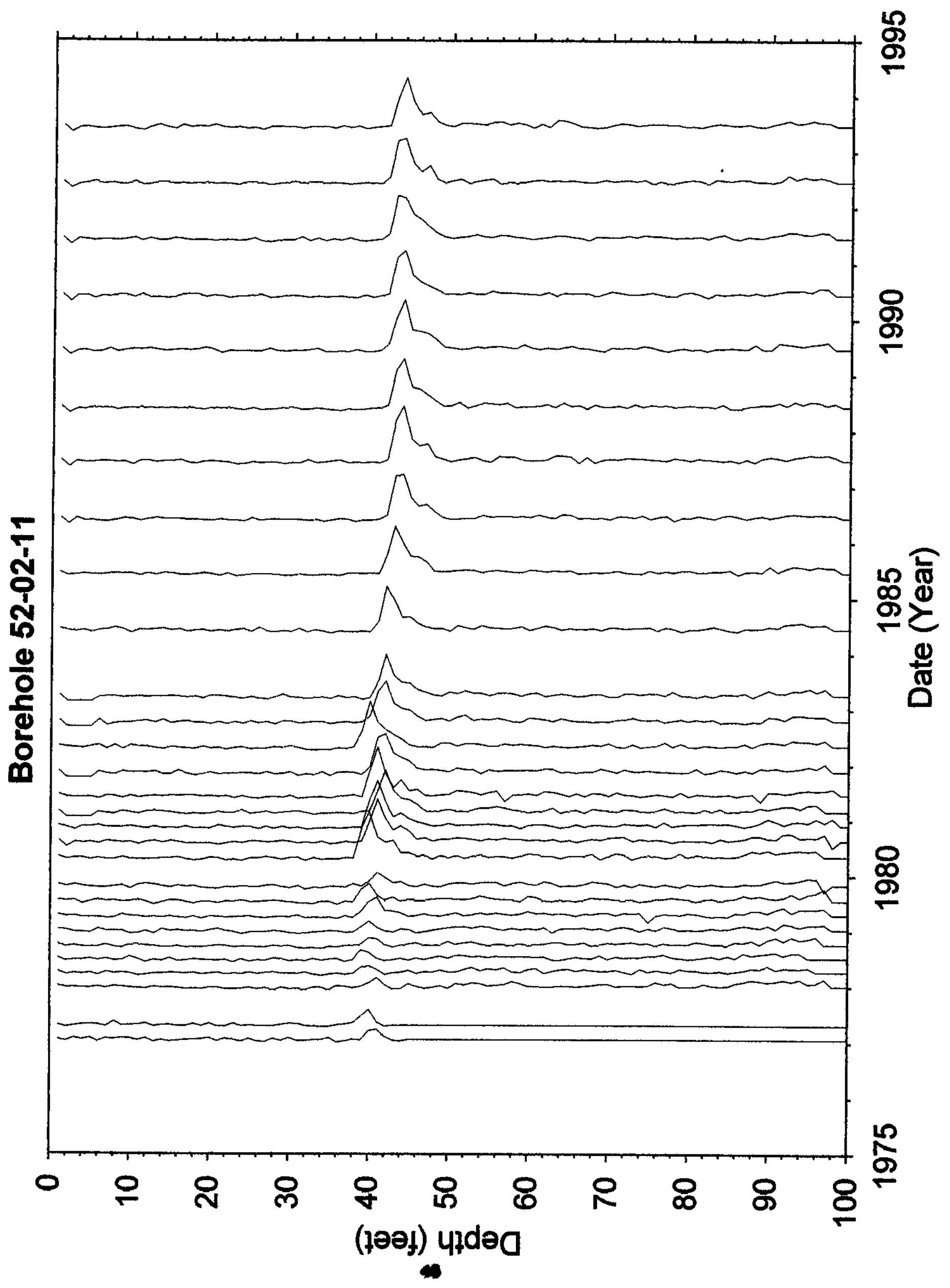




\section{HNF-3831-REVO}

\section{TY Dry Well Survey Analysis - Notes}
Borehole 52-02-01
Total \# Surveys 229
Probe Type 04
Log Date: $1-9-751^{\text {st }}$
\# neutron surveys 1 \# GR Surveys 228
le-22-93 Last
Presentation Plot Dates

(If difierent from $1^{\text {th }}$ Last)

Contamination Zone Depth(s): none

Isotope from Spectral Survey: nome (mupLDRm/I

GAPS.Txt
Max Survey Depth 100

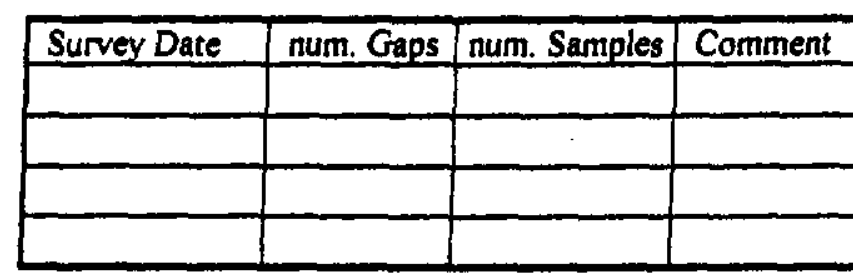

HI-ZONES.TXt

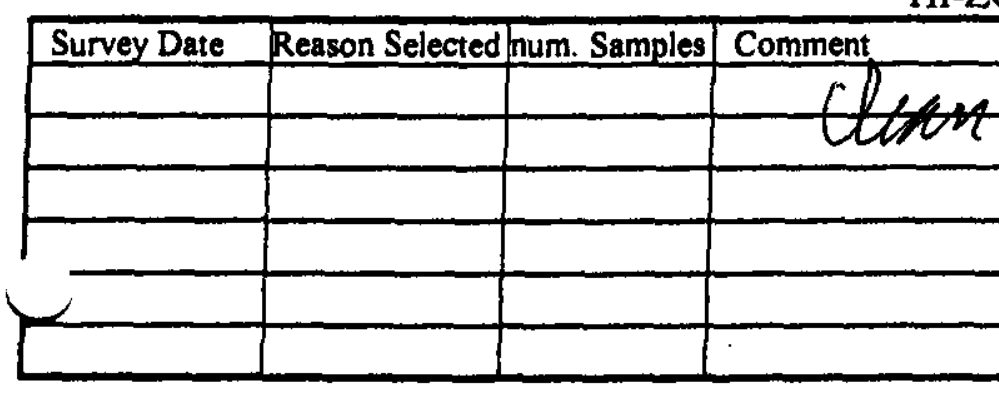

BackGnd.Txt

\begin{tabular}{|l|l|l|l|l|l|}
\hline Survey Date & Reason Selected & num. Samples & Feg. Clean & Avg. Bkg & Comment \\
\hline & & & & & \\
\hline & & & & & \\
\hline & & & & & \\
\hline & & & & & \\
\hline & & & & & \\
\hline & & & & & \\
\hline & & & & & \\
\hline
\end{tabular}

Analysis Notes

Analyst Name

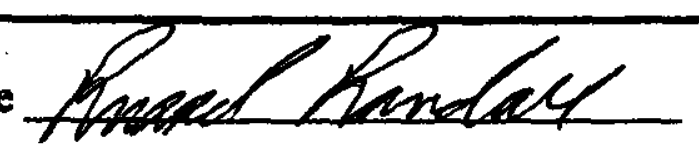

S/W ver TFEROSE Z- 2 


\section{TY Dry Well Survey Analysis - Notes}

Borehole 52-02-05 Total \# Surveys 248 Probe Type 04

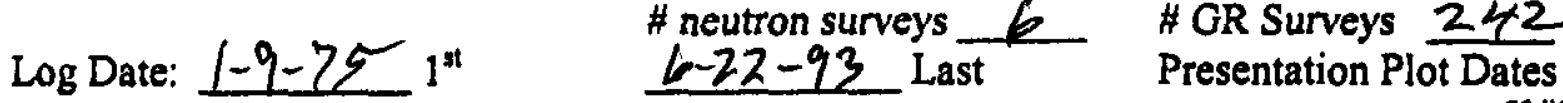

Contamination Zone Depth(s):

Isotope from Spectral Survey: $C_{\&} \sim M R L$

(If different from It Last)

Max Survey Depth 100

GAPS.Txt

\begin{tabular}{|l|l|l|l|}
\hline Survey Date & num. Gaps & num. Samples & Comment \\
\hline & & & \\
\hline & & & \\
\hline & & & \\
\hline & & & \\
\hline
\end{tabular}

HI-ZONES.TXt

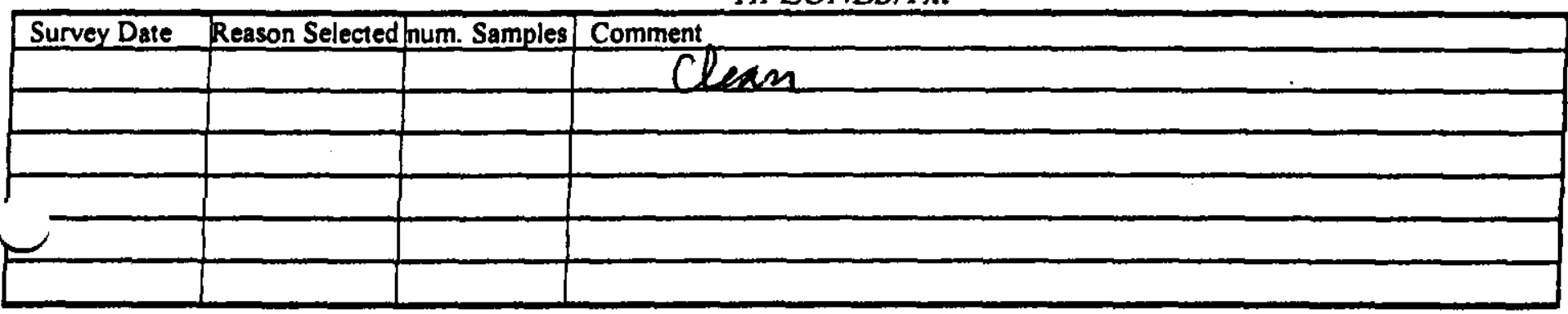

BackGnd.Txt

\begin{tabular}{|l|l|l|l|l|l|}
\hline Survey Date & Reason Selected & num. Samples & Feq.Clean & Avg. Bkg & Comment \\
\hline & & & & & \\
\hline & & & & & \\
\hline & & & & & \\
\hline & & & & & \\
\hline & & & & & \\
\hline & & & & & \\
\hline & & & & & \\
\hline
\end{tabular}

Analysis Notes

Analyst Name 


\section{Dry Well Survey Analysis - Notes}

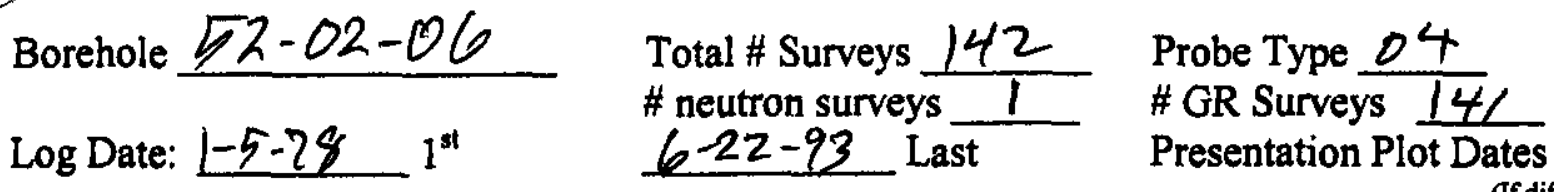

Contamination Zone Depth(s):

Isotope from Spectral Survey: Is neanem reat $\sim$ MOL_ Max Survey Depth 100

GAPS.TXt

\begin{tabular}{|l|l|l|l|}
\hline Survey Date & num. Gaps & num. Samples & Comment \\
\hline & & & \\
\hline & & & \\
\hline & & & \\
\hline & & & \\
\hline
\end{tabular}

HI-ZONES.TXt

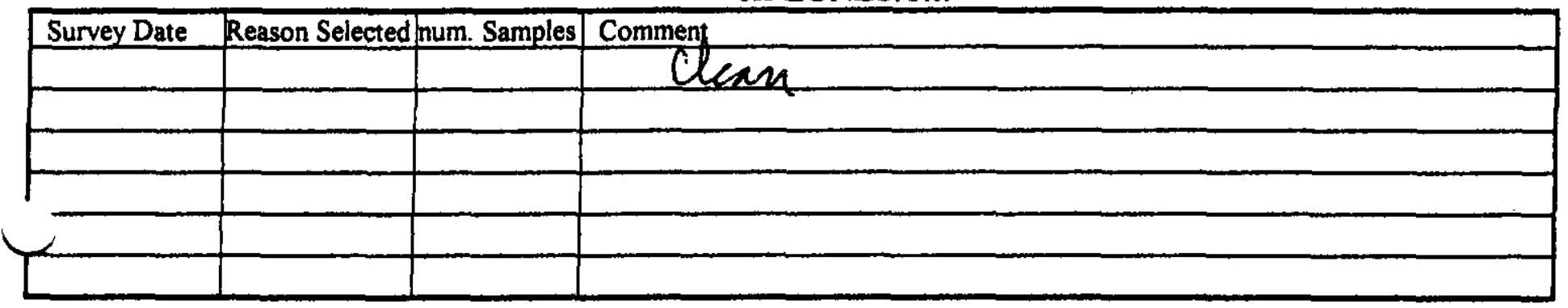

BackGnd.Txt

\begin{tabular}{|l|l|l|l|l|l|}
\hline Survey Date & Reason Selected & num. Samples & Feq.Clean & Avg.Bkg & Comment \\
\hline & & & & & \\
\hline & & & & & \\
\hline & & & & & \\
\hline & & & & & \\
\hline & & & & & \\
\hline & & & & & \\
\hline & & & & & \\
\hline
\end{tabular}

Stanh $\rightarrow$ cleanater (an espected fem HChe) 


\section{Ty Dry Well Survey Analysis - Notes}

$\begin{array}{lll}\text { Borehole } 52-02-69 & \begin{array}{l}\text { Total \# Surveys } 221 \\ \text { Log Date: } 1-9-75 \\ 6-22-93\end{array} 1^{\text {st }} & \begin{array}{l}\text { Probe Type } \frac{04}{\text { \# GR Surveys } 220} \\ \text { Presentation Plot Dates }\end{array}\end{array}$

Contamination Zone Depth(s): hone

Isotope from Spectral Survey: MPL on $C_{S} \quad$ Max Survey Depth 100

(If different from I" Last)

GAPS.Txt

\begin{tabular}{|l|l|l|l|}
\hline Survey Date & num. Gaps & num. Samples & Comment \\
\hline & & & \\
\hline & & & \\
\hline & & & \\
\hline & & & \\
\hline
\end{tabular}

HI-ZONES.Txt

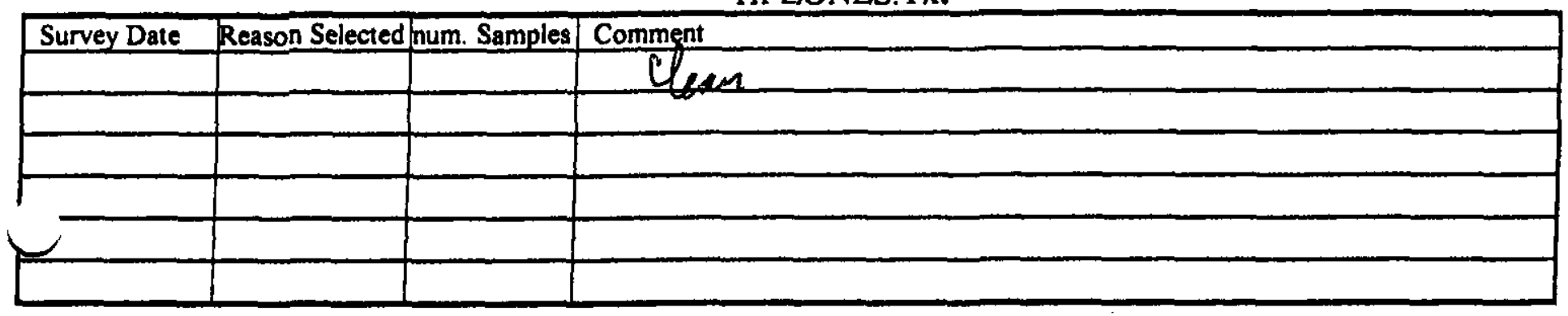

BackGnd.Txt

\begin{tabular}{|l|l|l|l|l|l|}
\hline Survey Date & Reason Selected & num. Samples & Feq.Clean & Avg.Bkg & Comment \\
\hline & & & & & \\
\hline & & & & & \\
\hline & & & & & \\
\hline & & & & & \\
\hline & & & & & \\
\hline & & & & & \\
\hline & & & & & \\
\hline
\end{tabular}

Analysis Notes

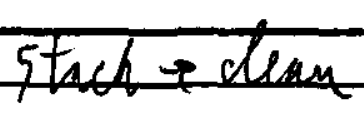




\section{TY Dry Well Survey Analysis - Notes}

Borehole $52-02-11 \quad$ Total \# Surveys 154

Log Date: $(-20-7) 1^{\text {st }} \quad \begin{aligned} & \text { \# neutron surveys } \\ & 6-22-93 \text { Last }\end{aligned}$

Contamination Zone Depth(s): $40^{*}$ ft

Isotope from Spectral Survey: $\frac{C 40-51}{4}$ low anf $\quad$ Max Survey Depth 100

GAPS.Txt

HI-ZONES. TXt

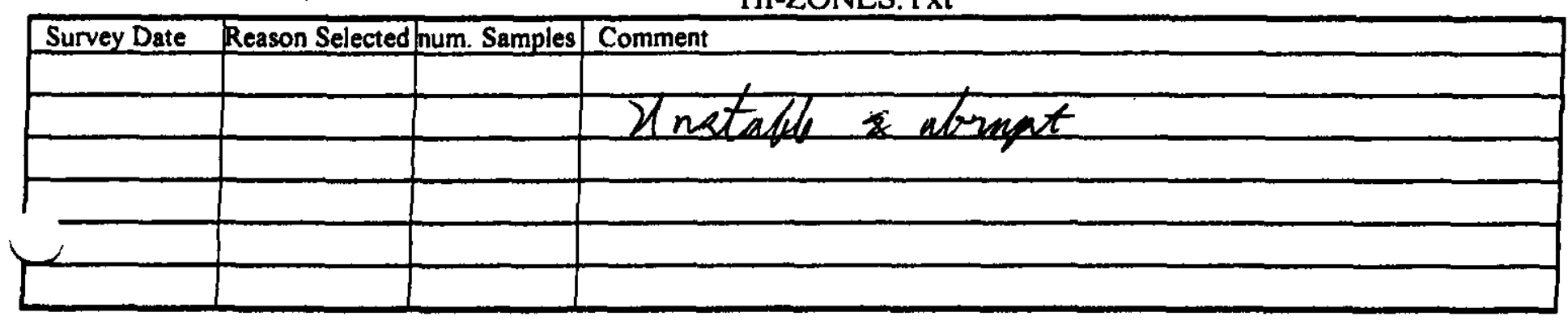

BackGnd.Txt

\begin{tabular}{|l|l|l|l|l|l|}
\hline Survey Date & Reason Selected & num. Samples & Feq.Clean & Avg.Bkg & Comment \\
\hline & & & & & \\
\hline & & & & & \\
\hline & & & & & \\
\hline & & & & & \\
\hline & & & & & \\
\hline & & & & & \\
\hline & & & & & \\
\hline
\end{tabular}

$$
\text { Stuk } \rightarrow \text { matale } c \text { Analysis Notes }
$$

Finet tan and on

bute tike Toate Enm action (?) 


\section{Borehole 52-03-03}

\section{Contamination (Cs-137) from 35-54 feet is Stable Contamination (Cs-137) from 54-62 feet is Unassigned Deviation}

Grade thickness product from 35 to 54 feet is decreasing consistent with the Cs- 137 (HPGe saturated, but identified above and below) decay. This zone also exceeds the limits for the green GM, thus the Red GM is used for the grade thickness plot.

Grade thickness product from 54 to 62 feet is not decreasing consistent with the Cs-137 (HPGe identified) decay. However, the early rapid change could be either a fast decay radionuclide such as Ru-106 or contaminant movement, but the time span of the data is not long enough to make such a determination. Thus the classification of Unassigned deviation. Note that Co-60 is also HPGe identified in this interval, but at levels too low to register on the gross gamma instrumentation. The green $\mathrm{GM}$ data are used for the grade thickness plot since it is more sensitive than the red GM response, and for this interval does not exceed count rate limitations.

Gross Gamma Survey Information

Probe Type: $01:$ Green GM \& 02: Red GM

Other Probe Types: $04: \mathrm{NaI}, 14:$ Shielded NaI, \& 03: Neutron

Borehole Depth : $100 \mathrm{ft}$

Survey Depth : $100 \mathrm{ft}$

First Survey Date : 7/25/1980 Green GM 7/7/1980 Red GM

Last Survey Date : $6 / 30 / 1989$ Green GM 6/30/1989 Red GM

Number Surveys : 89 Green GM \& 92 Red GM

Analysis Notes

\begin{tabular}{|r|l|l|}
\hline Number Surveys Rejected : & 0 & \\
\hline Lower Threshold for Bad Survey Values : & $<=0$ \\
\hline Method Used to Compute Background : & $\begin{array}{l}\text { Threshold } 0<\text { val }<10 \text { Green GM } \\
\text { Threshold } 0<\text { val }<2 \text { Red GM }\end{array}$ \\
\hline & \\
\hline Depth(s) where Contamination Identified \\
in Gross Gamma Surveys : & $\begin{array}{l}35-54 \text { Stable } \\
54-62 \text { Unassigned Deviation }\end{array}$ \\
\hline & \\
\hline Analyst Name : & R.R. Randall \\
\hline Company Name : & Three Rivers Scientific \\
\hline
\end{tabular}




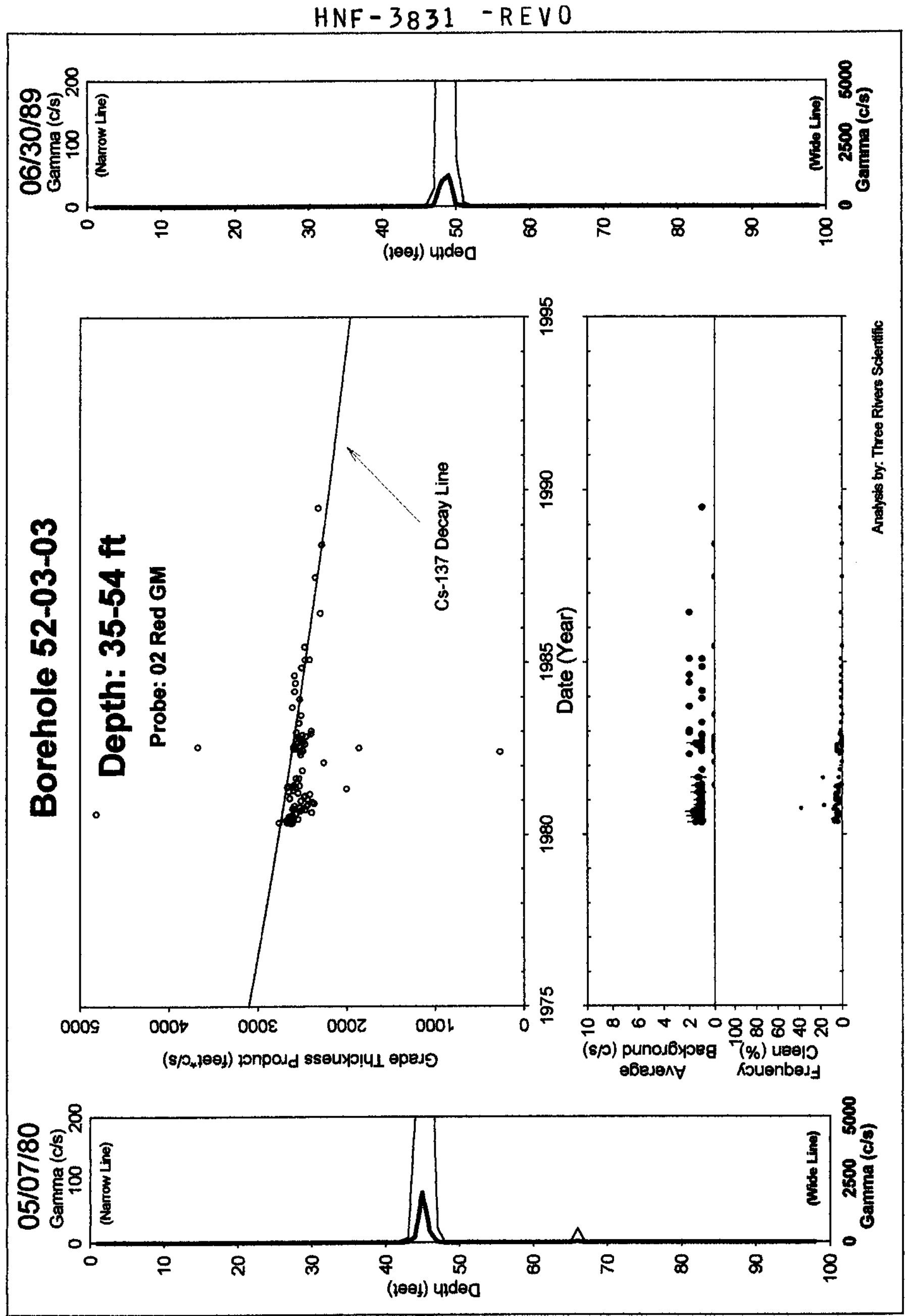


HNF-3831-REVO
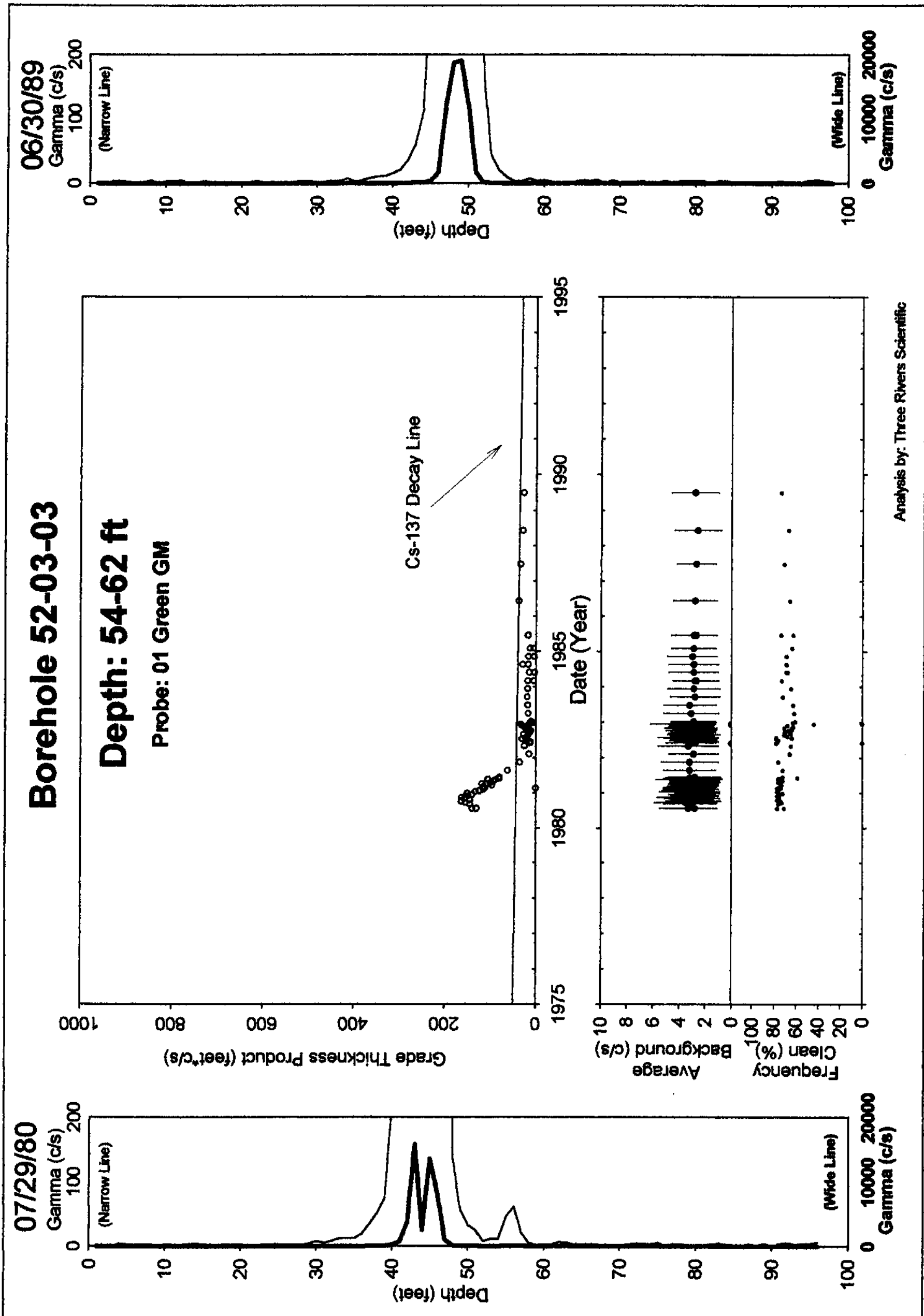
HNF-3831-REVO

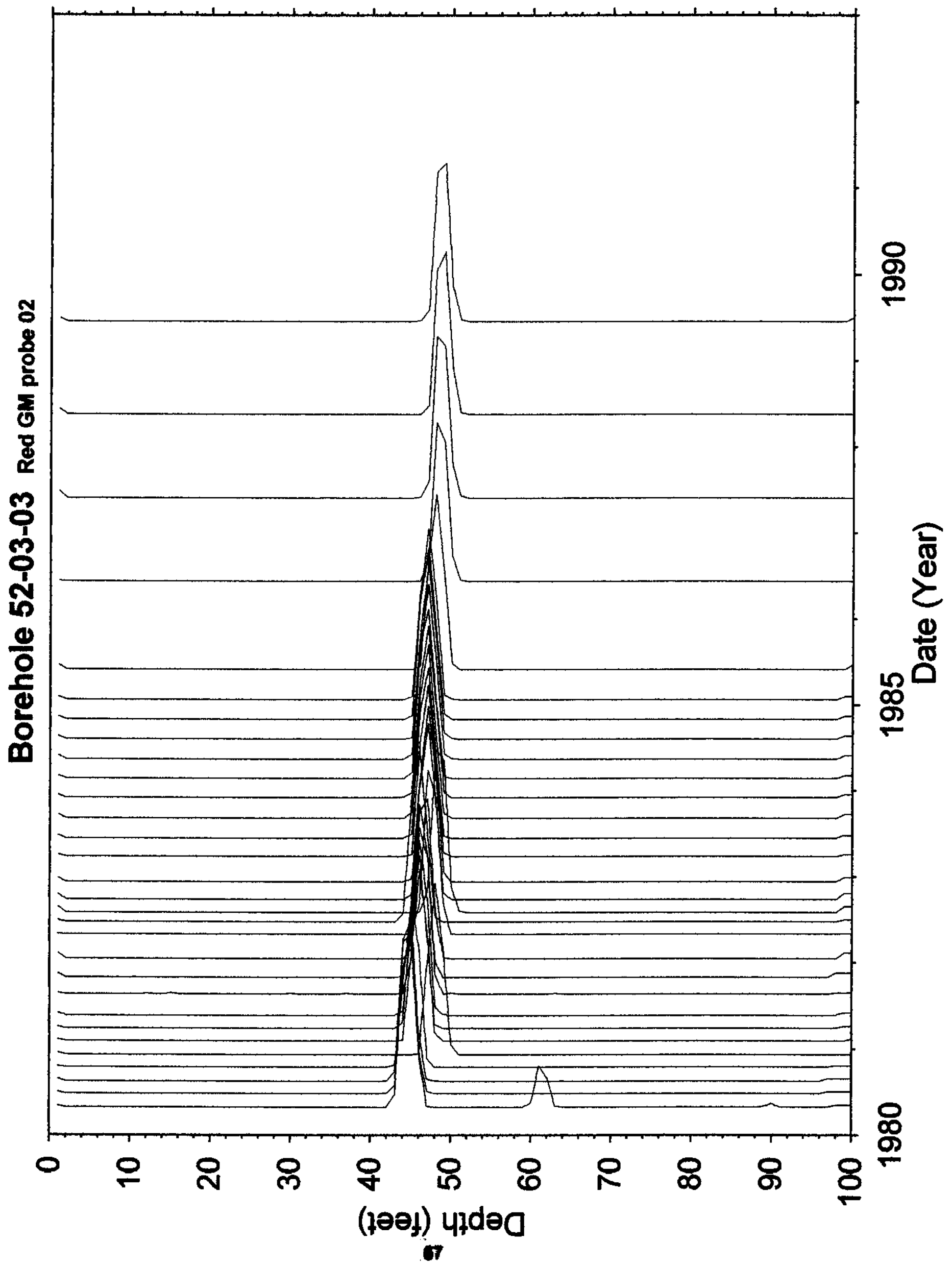


HNF-3831-REVO

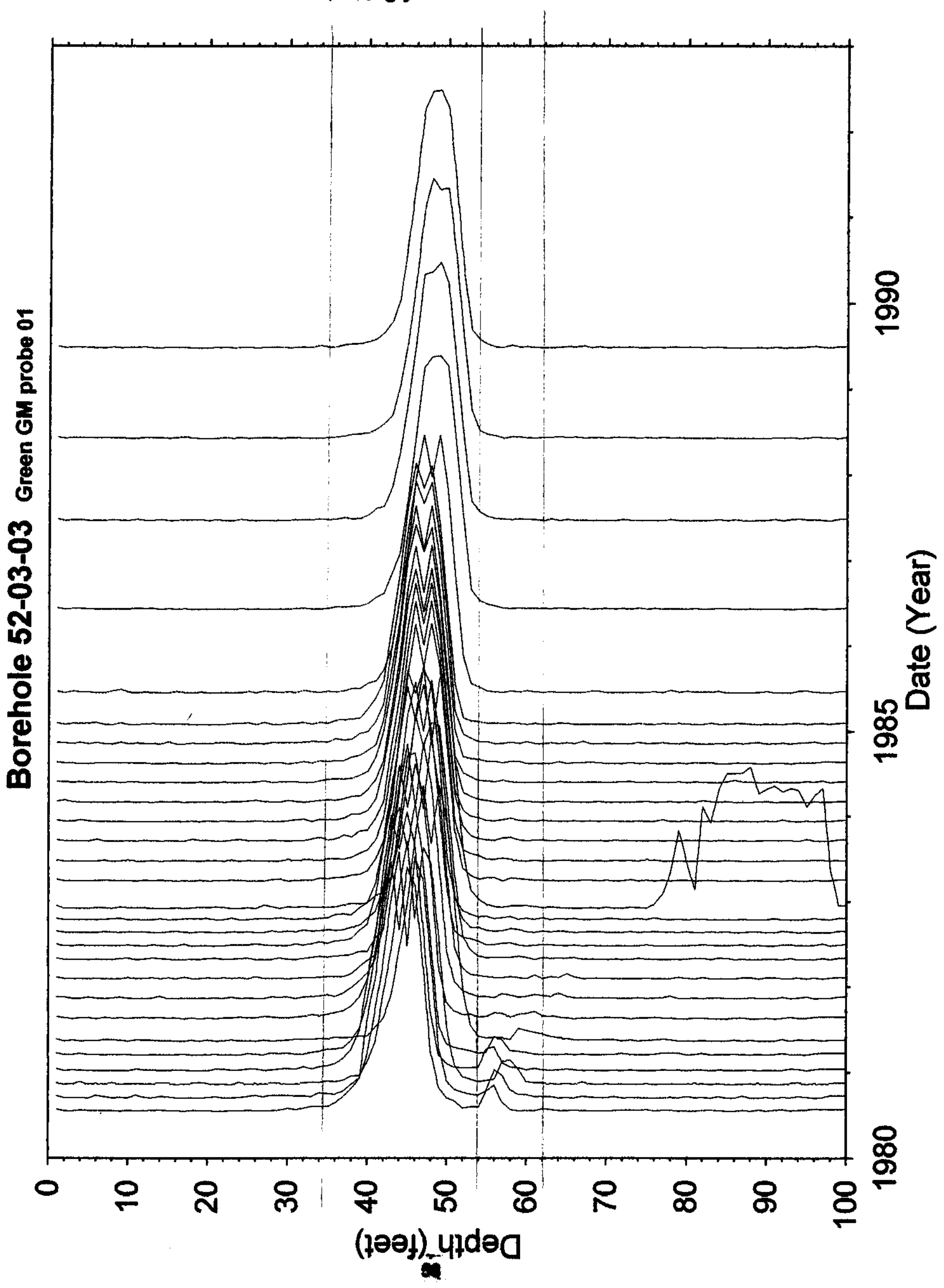




\section{HNF-3831-REVO}

\section{Borehole 52-03-06 \\ Contamination (Co-60) from 44-98 feet is Unstable}

Grade thickness product is computed over 44 to 98 feet in order to assess the conservation of Co60 (HPGe identified) movement downward, refer to stack plot. The grade thickness product for this interval shows a slow continued increase from 1975 to 1978 . From 1978 to 1985 there is a slower change, and from 1985 to end of data collection 1994, there is a decrease faster than the decay of Co-60.

The grade thickness product for 54 to 70 feet is computed and plotted in order to address only the latter time, at least 1990 and later, for the possibility of residual Co-60 left behind after the downward movement has passed. No clear match to the decay rate of Co-60 is present for the later times.

Additionally, the grade thickness product over 88 to 98 feet is computed to examine the onset of possible downward movement into this interval. The grade thickness product shows a continual increase from 1975 to 1985, and a decrease faster than Co-60 decay from 1985 to 1994 . The increase could be due to either lateral influx and/or downward influx into this interval. Since the decrease from 1985 to 1994 is faster than Co-60 decay, the implication is continued downward movement past the bottom of the borehole.

Gross Gamma Survey Information

\begin{tabular}{|r|l|}
\hline Probe Type : & $04: \mathrm{NaI}$ \\
\hline Other Probe Types : & $03:$ Neutron \\
\hline Borehole Depth: & $100 \mathrm{ft}$ \\
\hline Survey Depth : & $100 \mathrm{ft}$ \\
\hline First Survey Date : & $1 / 9 / 1975$ \\
\hline Last Survey Date : & $2 / 28 / 1994$ \\
\hline Number Surveys : & 309 \\
\hline
\end{tabular}

Analysis Notes

\begin{tabular}{|r|l|}
\hline Number Surveys Rejected : & 0 \\
\hline Lower Threshold for Bad Survey Values : & $<=0$ \\
\hline Method Used to Compute Background : & Threshold 0<val<50 \\
\hline & \\
\hline $\begin{array}{r}\text { Depth(s) where Contamination Identified } \\
\text { in Gross Gamma Surveys : }\end{array}$ & $44-98$ Unstable \\
\hline & \\
\hline Analyst Name : & R.R. Randall \\
\hline Company Name: & Three Rivers Scientific \\
\hline
\end{tabular}


HNF-3831-REVO
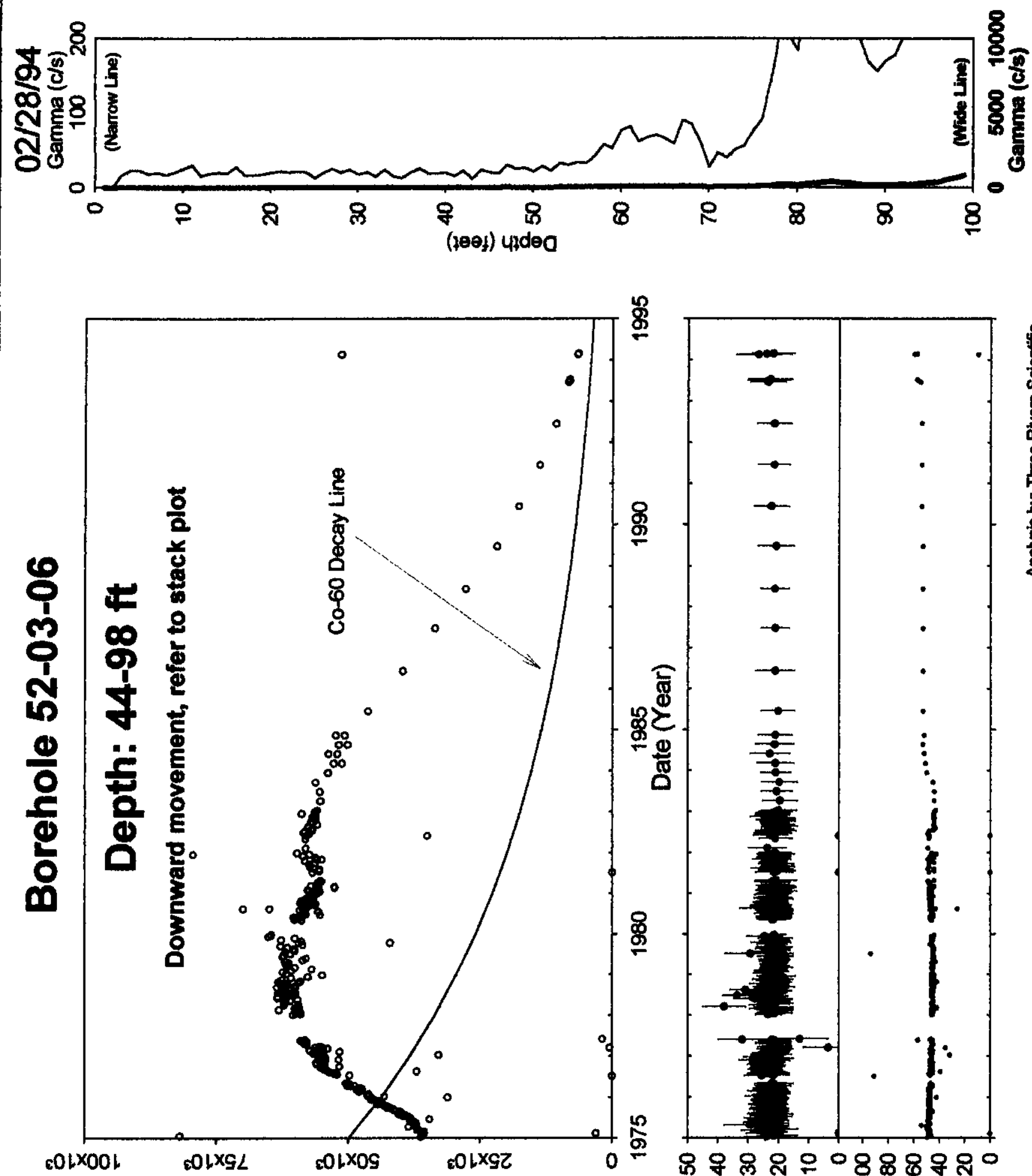

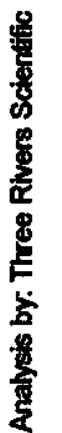

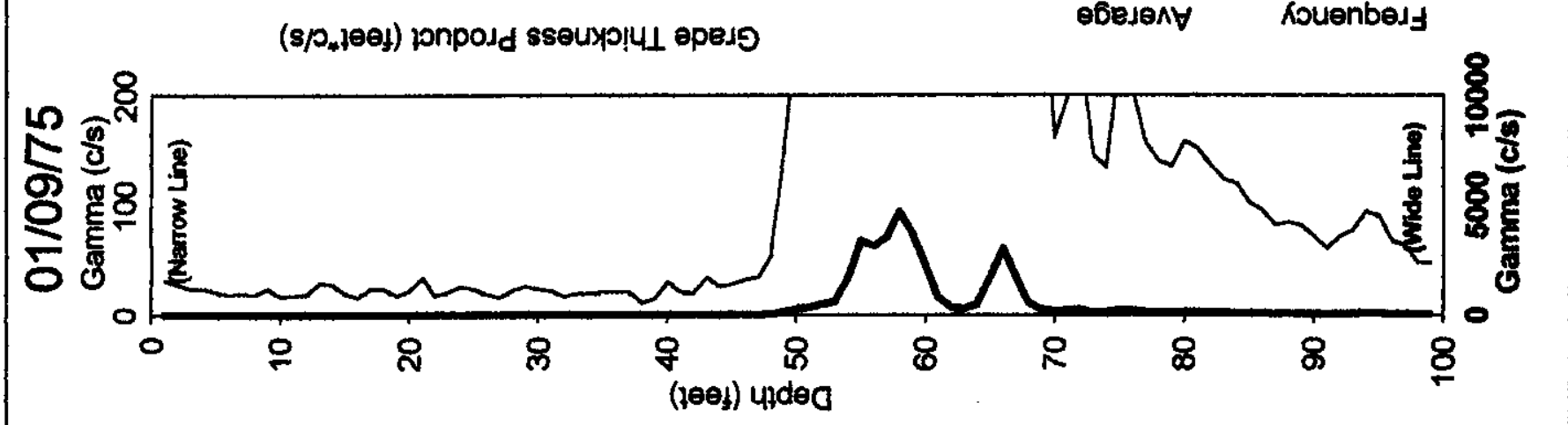




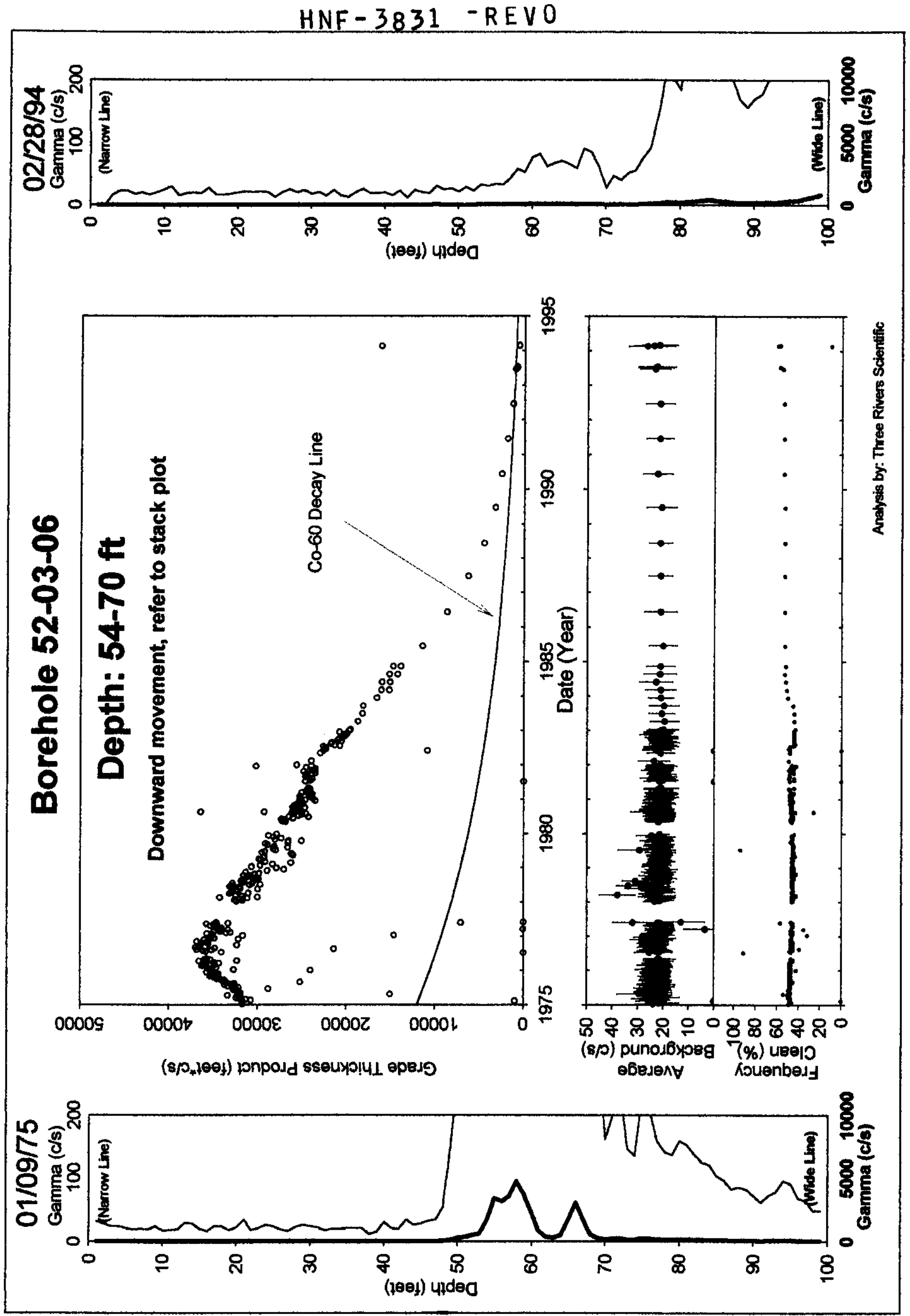


HNF-3831-REVO
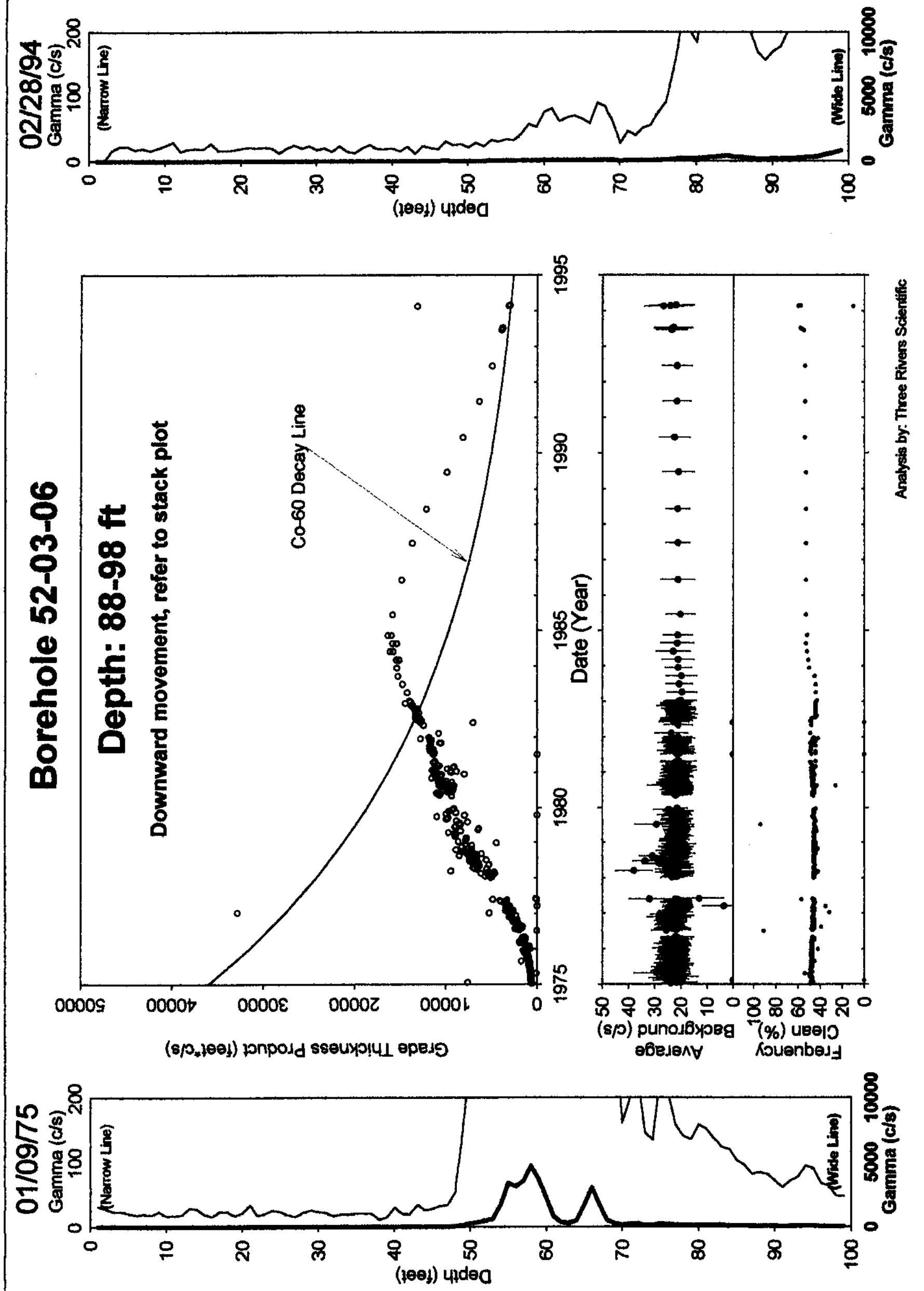
HNF-3831-REVO

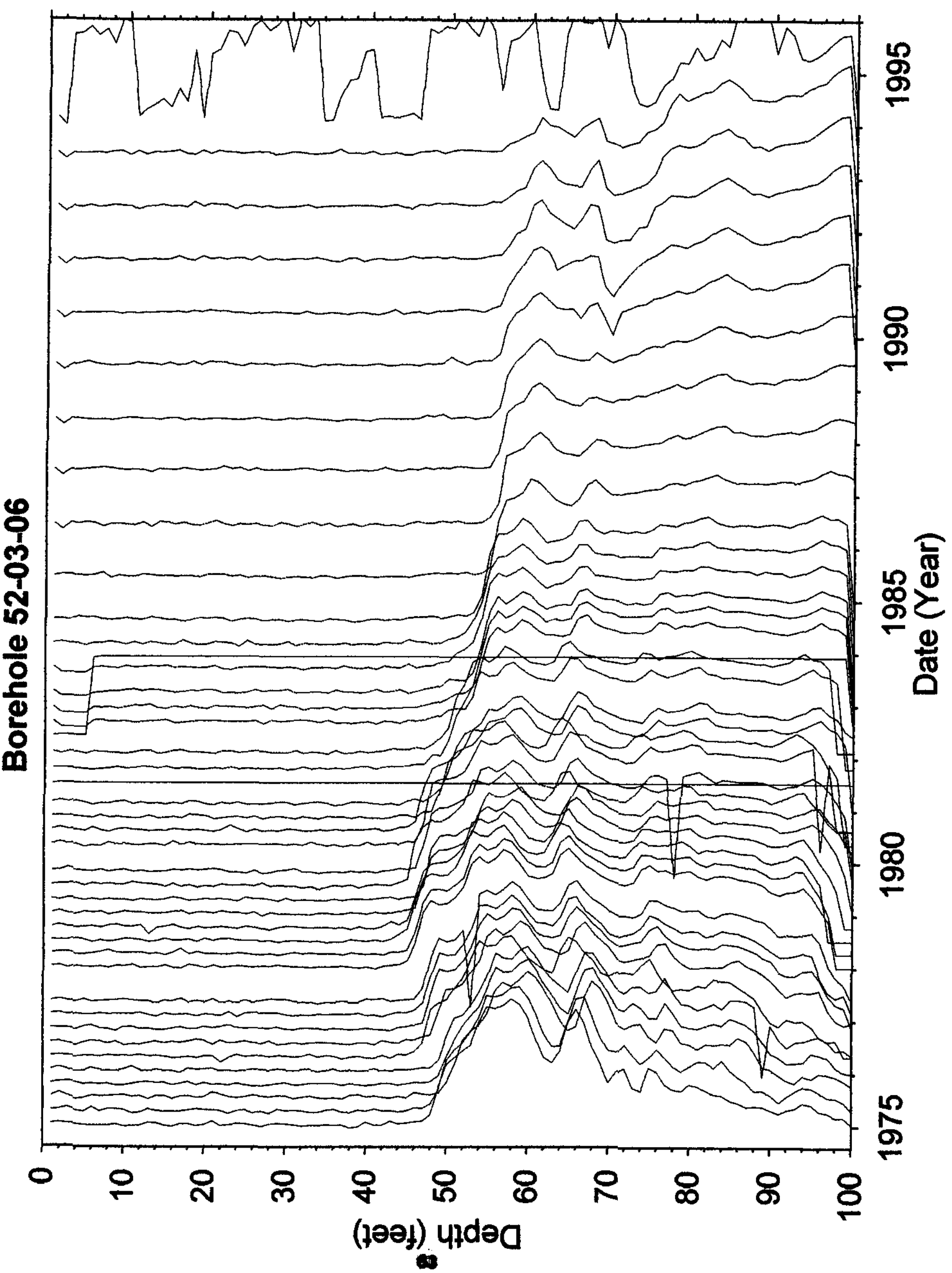




\section{Borehole 52-03-12}

\section{Contamination (Co-60) from 48-60 feet is Unstable Early Contamination (Co-60) from 60-75 feet is Unstable Early}

Grade thickness product over 48 to 60 feet is increasing starting 1975 until mid 1976. After mid 1976, the grade thickness product for this interval is not exactly matching the decay for Co-60 (hypothesis). The levels are too low to make a rigorous determination of Co-60 on the basis of these data only; however, Co-60 is HPGe identified deeper in this borehole. Given the initial rise, the zone is unstable early regardless of the isotope.

Grade thickness product over 60 to 75 feet is slowly increasing until 1985, but after this time decreases consistent with Co-60 (HPGe identified) until 1994. Since the upper zone shows lower levels in 1994 than this depth interval, and was marginally decreasing faster than $\mathrm{Co}-60$, it is possible that some downward movement occurred from the upper interval to this lower interval. A clear classification for downward movement cannot be made on the basis of only these data.

Gross Gamma Survey Information

\begin{tabular}{|r|l|}
\hline Probe Type : & $04: \mathrm{NaI}$ \\
\hline Other Probe Types : & $03:$ Neutron \\
\hline Borehole Depth : & $100 \mathrm{ft}$ \\
\hline Survey Depth : & $100 \mathrm{ft}$ \\
\hline First Survey Date : & $1 / 9 / 1975$ \\
\hline Last Survey Date : & $2 / 23 / 1994$ \\
\hline Number Surveys : & 276 \\
\hline
\end{tabular}

Analysis Notes

\begin{tabular}{|r|l|}
\hline Number Surveys Rejected : & 0 \\
\hline Lower Threshold for Bad Survey Values : & $<=0$ \\
\hline Method Used to Compute Background : & Threshold 0<val<50 \\
\hline & \\
\hline $\begin{array}{r}\text { Depth(s) where Contamination Identified } \\
\text { in Gross Gamma Surveys : }\end{array}$ & $48-60 \& 60-75$ Unstable Early \\
\hline & \\
\hline Analyst Name : & R.R. Randall \\
\hline Company Name : & Three Rivers Scientific \\
\hline
\end{tabular}


HNF-3831-REVO

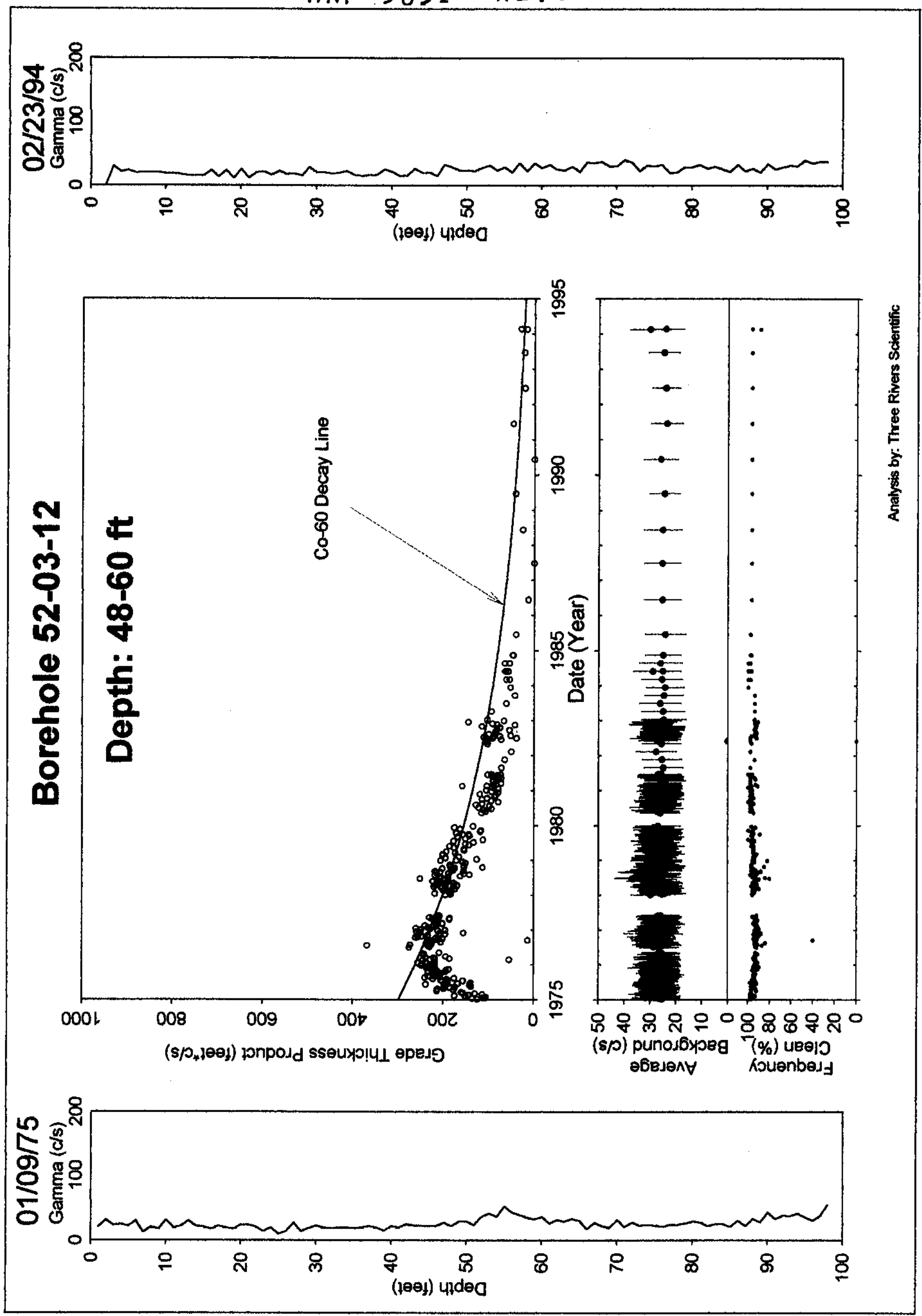


HNF-3831-REVO
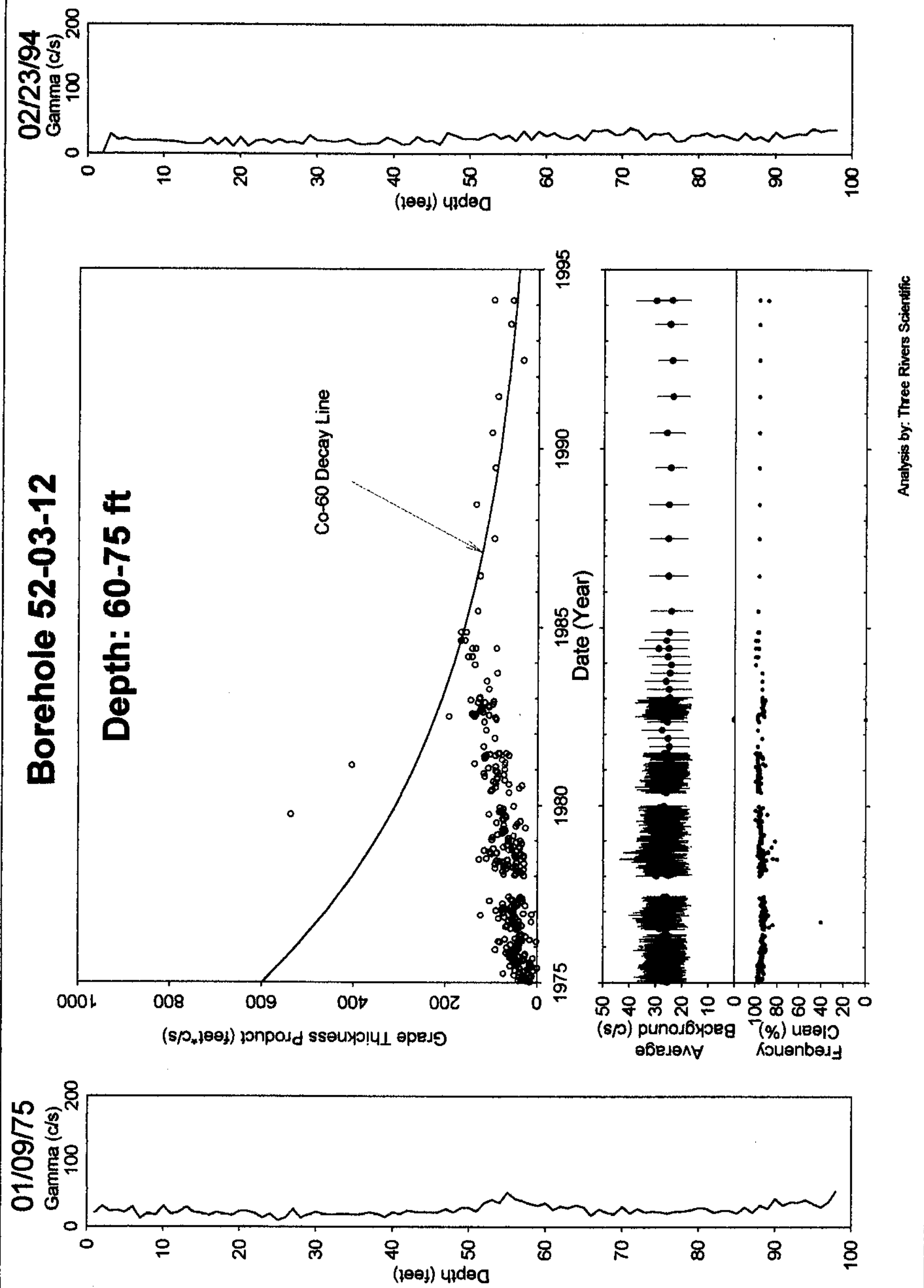


\section{HNF-3831-REVO}

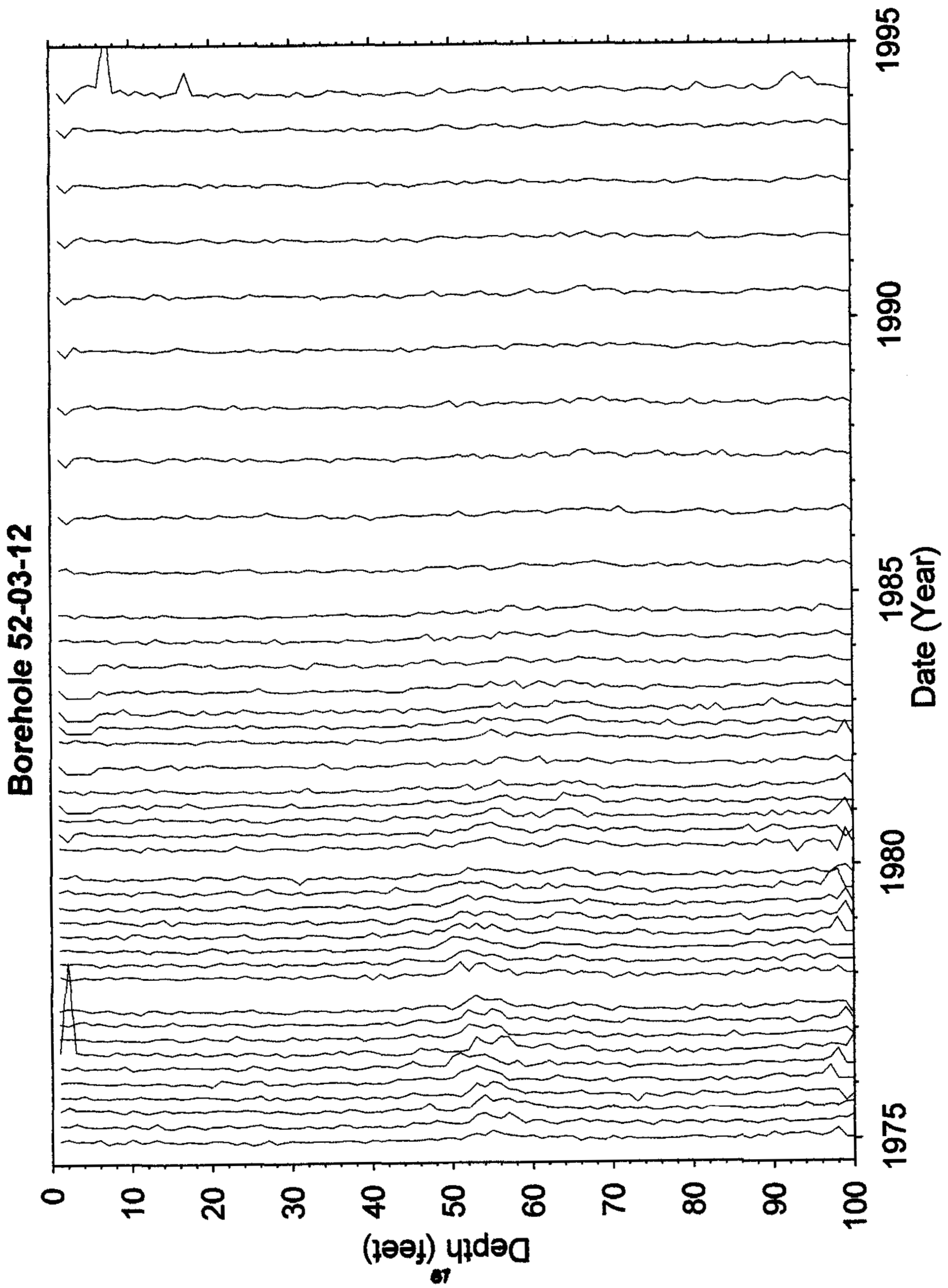




\section{Ty Dry Well Survey Analysis - Notes}

¿ Ty

Borehole 52-03-03

Total \# Surveys 192 \# neutron surveys 84

Log Date: zu kelour $1^{\text {st }}$

suekelone Last

Contamination Zone Depth(s): an kelow

Isotope from Spectral Survey: $C_{S} \& C_{0}$ \& Saturation

Probe Type $01 \quad 1404 \quad 02$

\# GR Surveys

Presentation Plot Dates

af difierent form la (LAB)

Max Survey Depth 100

GAPS.Txt

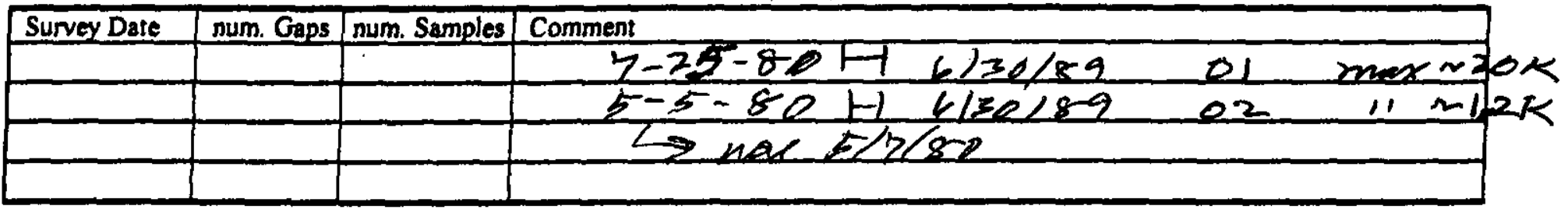

HI-ZONES.TXt

\begin{tabular}{|c|c|c|c|c|}
\hline Survey Date & Reason Selected hum. Samples & Comment & & \\
\hline & & 02: palh & one alow & 2425 \\
\hline & & $01=\quad 117$ & 11,1 & 11 \\
\hline & & & & \\
\hline & & & & \\
\hline & & & & \\
\hline & & 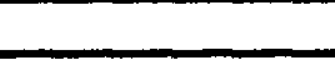 & 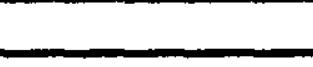 & 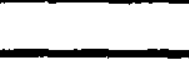 \\
\hline
\end{tabular}

BackGnd.Txt

\begin{tabular}{|l|l|l|l|l|l|}
\hline Survey Date & Reason Selected & num. Samples & Feq.Clean & Avg. Bkg & Comment \\
\hline & & & & & \\
\hline & & & & & \\
\hline & & & & & \\
\hline & & & & & \\
\hline & & & & & \\
\hline & & & & & \\
\hline & & & & & \\
\hline
\end{tabular}

Analysis Notes
02
$0<b \ln <2$
$40-54$
Q 1
$0<11<10$
$35-54 \quad 54-63$ 
HNF-3831-REVO

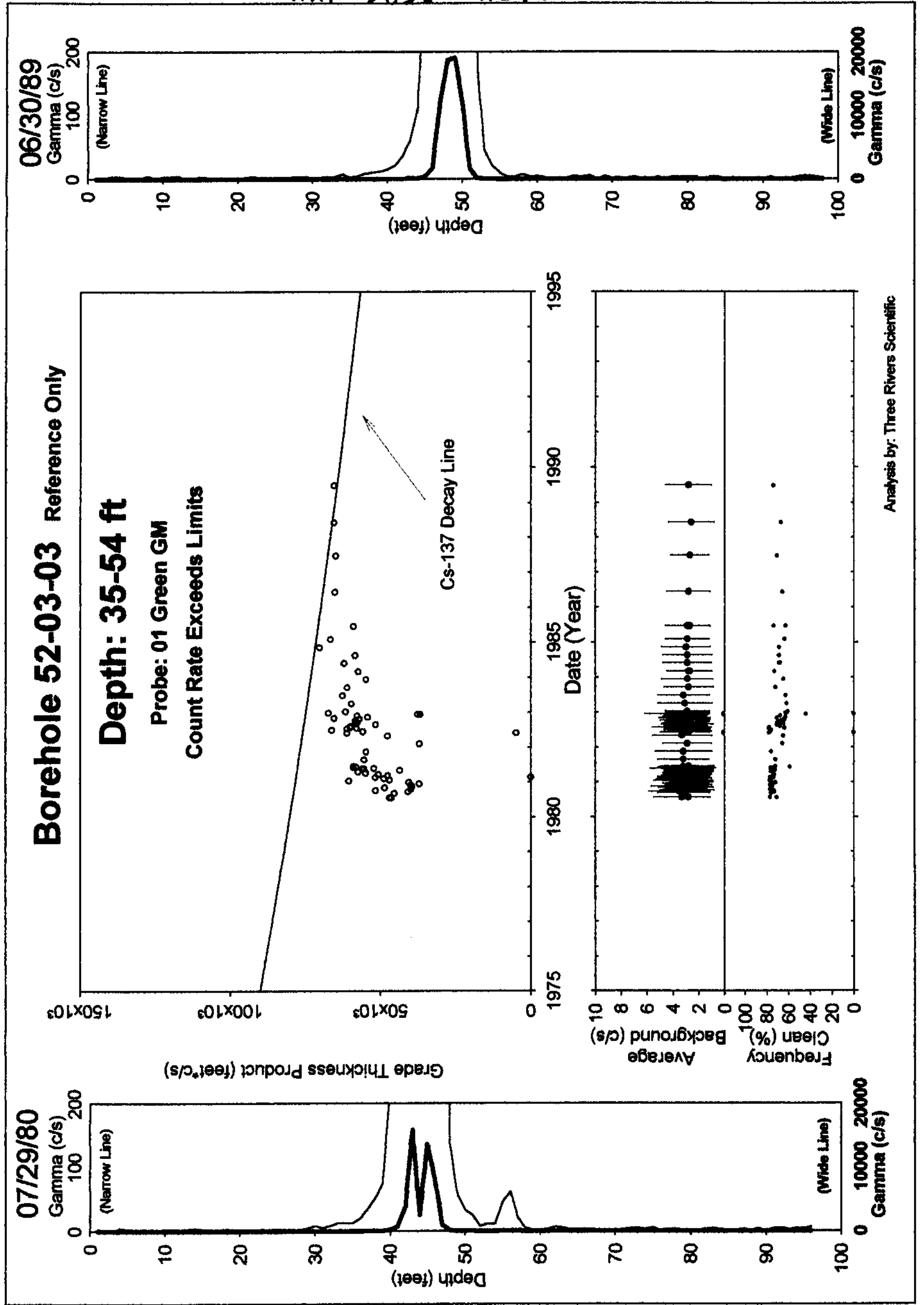




\section{$T Y$ \\ Dry Well Survey Analysis - Notes}

Borehole $52-03-06 \quad$ Total \# Surveys 317 Probe Type 04

Log Date: $1-9-251^{\text {st }} \quad$ \# neutron surveys

Contamination Zone Depth(s):

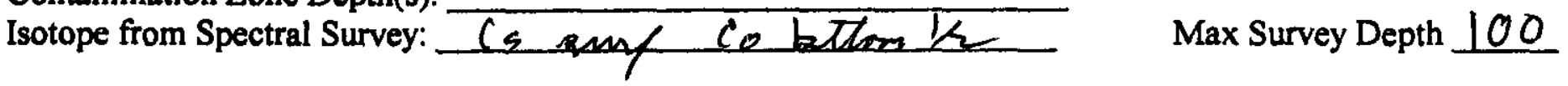
ates

GAPS.Txt

\begin{tabular}{|l|l|l|l|}
\hline Survey Date & num. Gaps & num. Samples & Comment \\
\hline & & & \\
\hline & & & \\
\hline & & & \\
\hline & & & \\
\hline
\end{tabular}

HI-ZONES.Txt

\begin{tabular}{|c|c|c|}
\hline Survey Date & Reason Selected num. Samples & Comment \\
\hline & & no pm $40-$ battom nol stack \\
\hline & & \\
\hline & & \\
\hline & & \\
\hline 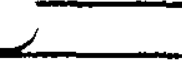 & & \\
\hline & & \\
\hline
\end{tabular}

BackGnd.Txt

\begin{tabular}{|c|c|c|c|c|c|}
\hline Survey Date & Reason Selected & num. Samples & Feq.Clean & Ayg.Bkg & Comment \\
\hline & & & & & \\
\hline & & & & & \\
\hline & & & & & \\
\hline & & & & & \\
\hline & & & & & \\
\hline & & & & & \\
\hline & & & & & \\
\hline & & & & & \\
\hline
\end{tabular}

Analysis Notes

downwand noment

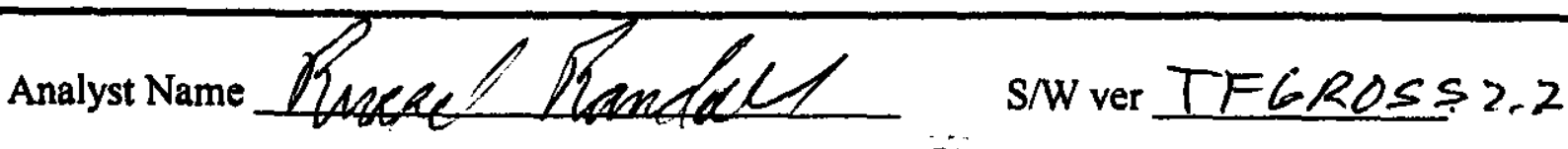


HNF-3831-REVO

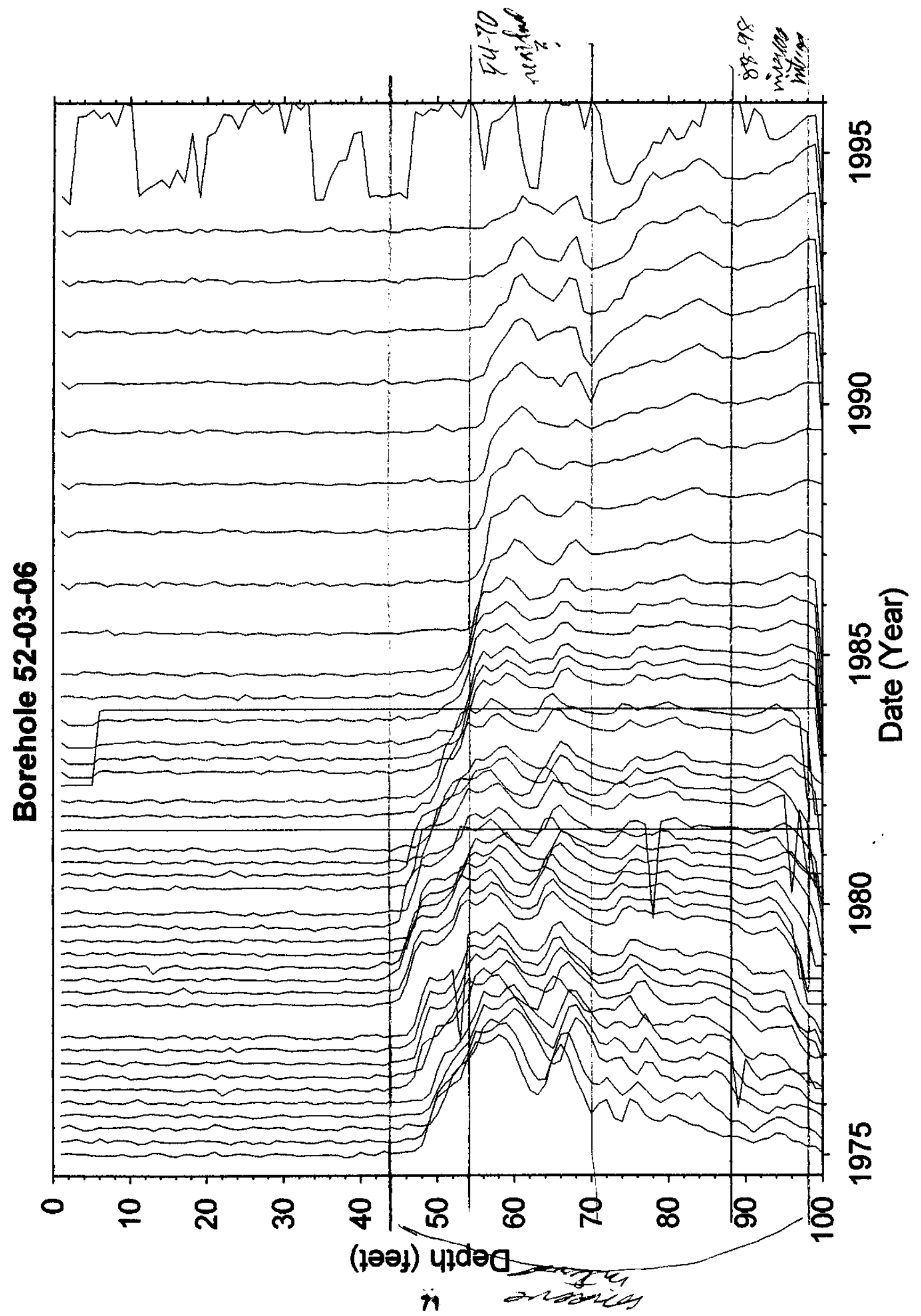




\section{TY}

Borehole 52-03-12

Log Date: $1-9-751^{\text {st }}$

Contamination Zone Depth(s)

Isotope from Spectral Survey:

Depth shift yes no

Lower threshold

\section{Dry Well Survey Analysis - Notes}

Total \# Surveys 283 Probe Type 04

\# neutron surveys 7 \# GR Surveys 276

$2-23-94$ Last
Presentation Plot Dates

(If different from !" \& Last)

\begin{tabular}{|l|l|l|}
\hline Survey Date & Reason Selected & Comment GAPS.Txt \\
\hline & & \\
\hline & & \\
\hline & & \\
\hline & & \\
\hline & & \\
\hline & & \\
\hline & & \\
\hline
\end{tabular}

HI-ZONES.TXt

\begin{tabular}{|l|l|l|}
\hline Survey Date & Reason Selected & Comment \\
\hline & & hN Ray Rene \\
\hline & & \\
\hline & & \\
\hline & & \\
\hline & & \\
\hline & & \\
\hline & & \\
\hline & & \\
\hline
\end{tabular}

Analysis Notes

Analyst Name 
HNF-3831-REV 0

\section{Borehole 52-04-02}

\section{No Gamma-Ray Emitting Contamination was identified}

No significant levels of gamma ray contamination are present above the survey probe detection threshold between 1975 and 1994 in the vadose zone from 2 to 98 feet. The HPGe survey identified Cs-137 at intermittent intervals throughout the borehole at concentrations less than $0.4 \mathrm{pCi} / \mathrm{g}$.

Gross Gamma Survey Information

\begin{tabular}{|r|l|}
\hline Probe Type: & 04: Nal \\
\hline Other Probe Types: & 03: Neutron (6 surveys) \\
\hline Borehole Depth: & $100 \mathrm{ft}$ \\
\hline Survey Depth: & $100 \mathrm{ft}$ \\
\hline First Survey Date: & $1 / 09 / 1975$ \\
\hline Last Survey Date: & $2 / 23 / 1994$ \\
\hline Number Surveys: & 265 \\
\hline
\end{tabular}

Analysis Notes

\begin{tabular}{|r|l|}
\hline Number Surveys Rejected : & 0 \\
\hline Lower Threshold for Bad Survey Values : & $<=0$ \\
\hline Method Used to Compute Background : & Threshold $(0<$ val $<50)$ \\
\hline & \\
\hline Depth(s) where Contamination Identified in & NONE \\
Gross Gamma Surveys : & \\
\hline & \\
\hline Analyst Name: & R.K. Price \\
\hline Company Name: & Three Rivers Scientific \\
\hline
\end{tabular}




\section{Borehole 52-04-02}

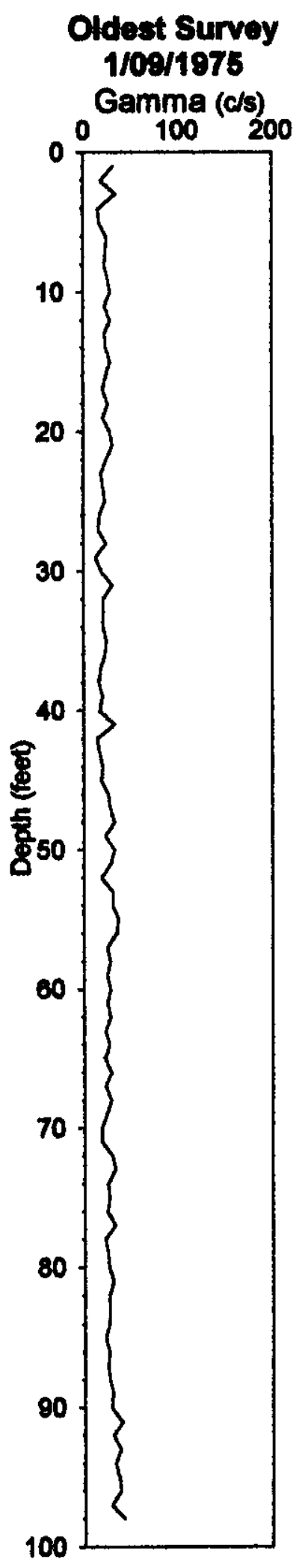

\section{No Gamma-Ray Emitting Contamination Above Survey Detection Threshold}
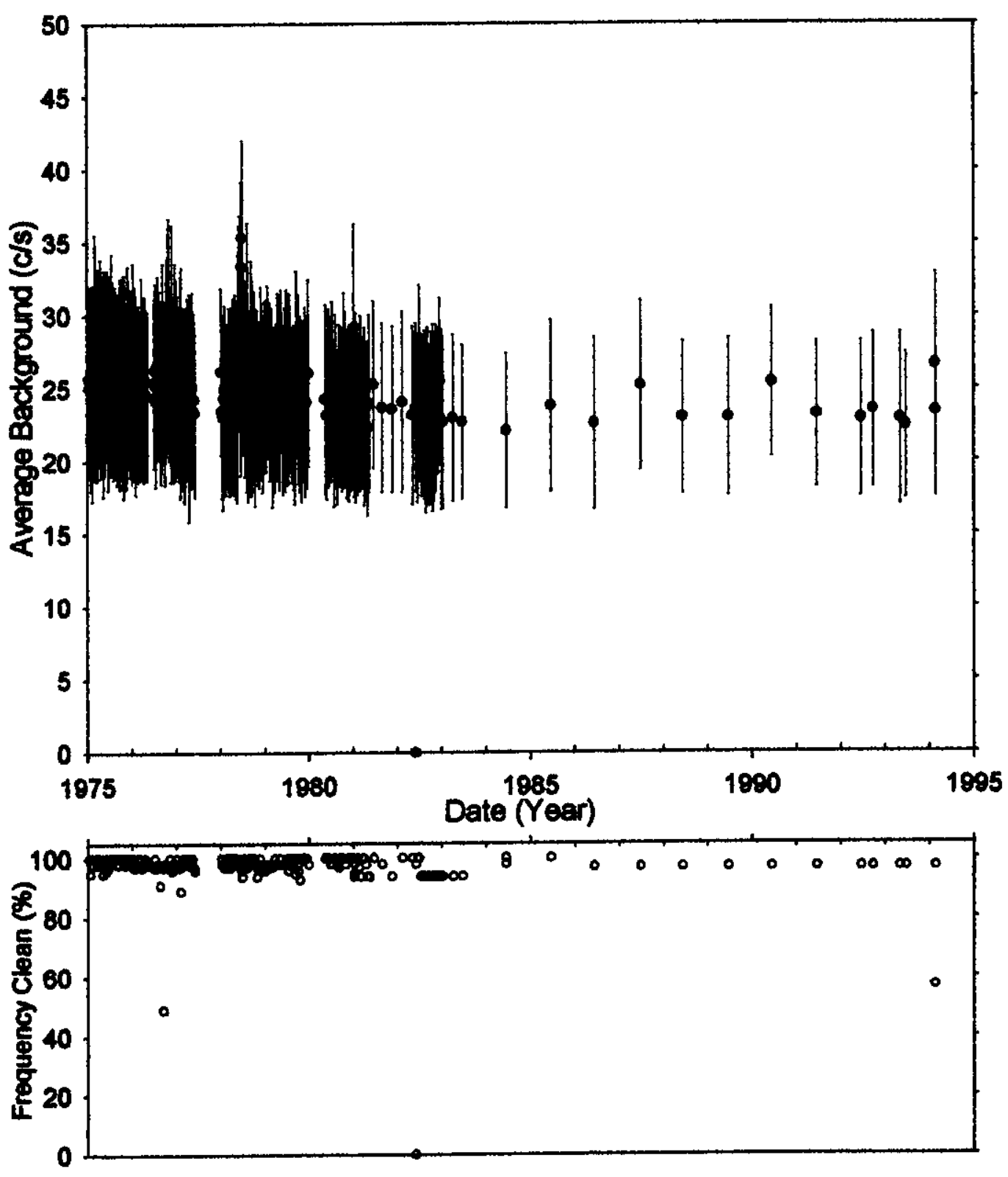
HNF-3831-REVO

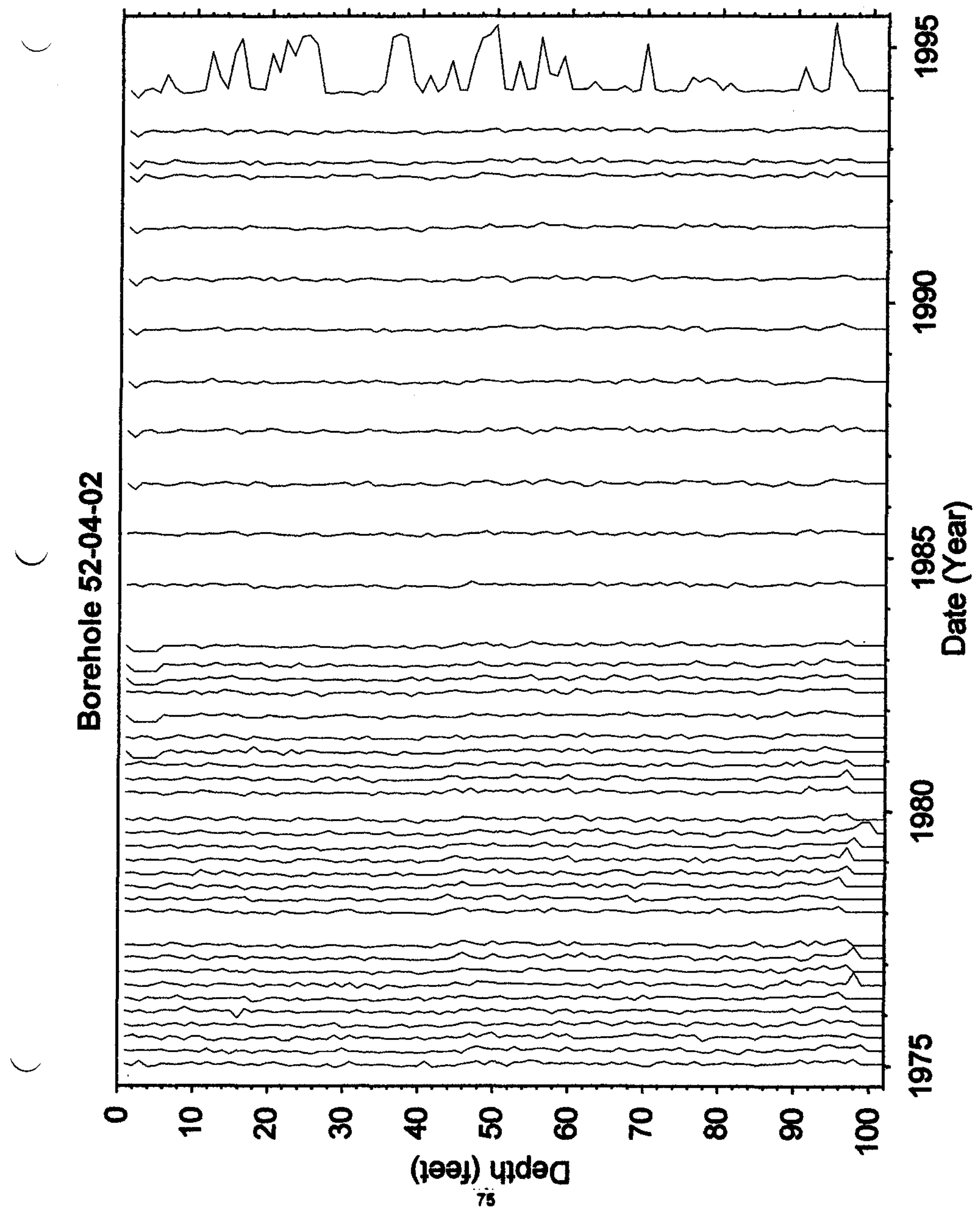




\section{Borehole 52-04-03}

\section{Contamination (Cs-137) from 0-8 feet is Tank Farm Activity}

Grade thickness product from 0 to 8 feet is erratic from 1975 through 1994, and is categorized as Tank Farm activity. The gross gamma activity exceeds 20,000 counts per second, which is beyond the linear region of the counting system. A Cs-137 (HPGe identified) decay line is plotted to demonstrate the erratic character of the grade thickness product that was computed from the monitoring surveys.

The stack plot shows a depth interval (90-105 ft) of slightly elevated gross gamma activity that is confirmed by the HPGe baseline survey and is identified to contain only natural radionuclides with slightly elevated natural uranium and thorium.

Gross Gamma Survey Information

\begin{tabular}{|r|l|}
\hline Probe Type : & 04: Sodium Iodide Scintillator \\
\hline Other Probe Types : & $03:$ Neutron (6 surveys) \\
\hline Borehole Depth: & $147 \mathrm{ft}$ \\
\hline Survey Depth: & $147 \mathrm{ft}$ \\
\hline First Survey Date : & $1 / 09 / 1975$ \\
\hline Last Survey Date : & $2 / 23 / 1994$ \\
\hline Number Surveys : & 279 \\
\hline
\end{tabular}

Analysis Notes

\begin{tabular}{|r|l|}
\hline Number Surveys Rejected : & 0 \\
\hline Lower Threshold for Bad Survey Values : & $<=0$ \\
\hline Method Used to Compute Background : & $10-30 \mathrm{ft}$ \\
\hline & \\
\hline Depth(s) where Contamination Identified in \\
Gross Gamma Surveys : & $0-8$ feet is TF Activity \\
\hline Analyst Name : & R.K. Price \\
\hline Company Name : & Three Rivers Scientific \\
\hline
\end{tabular}




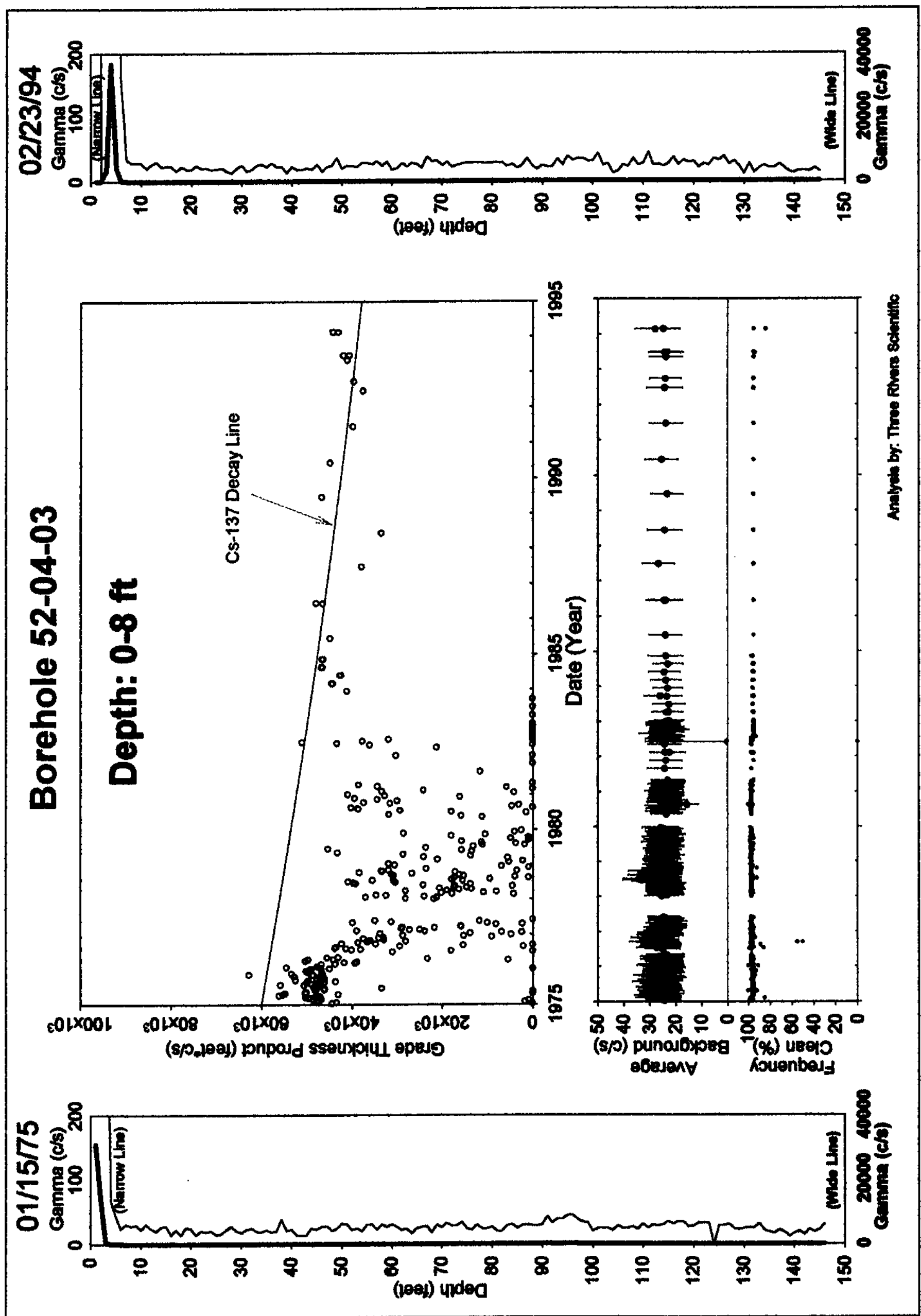




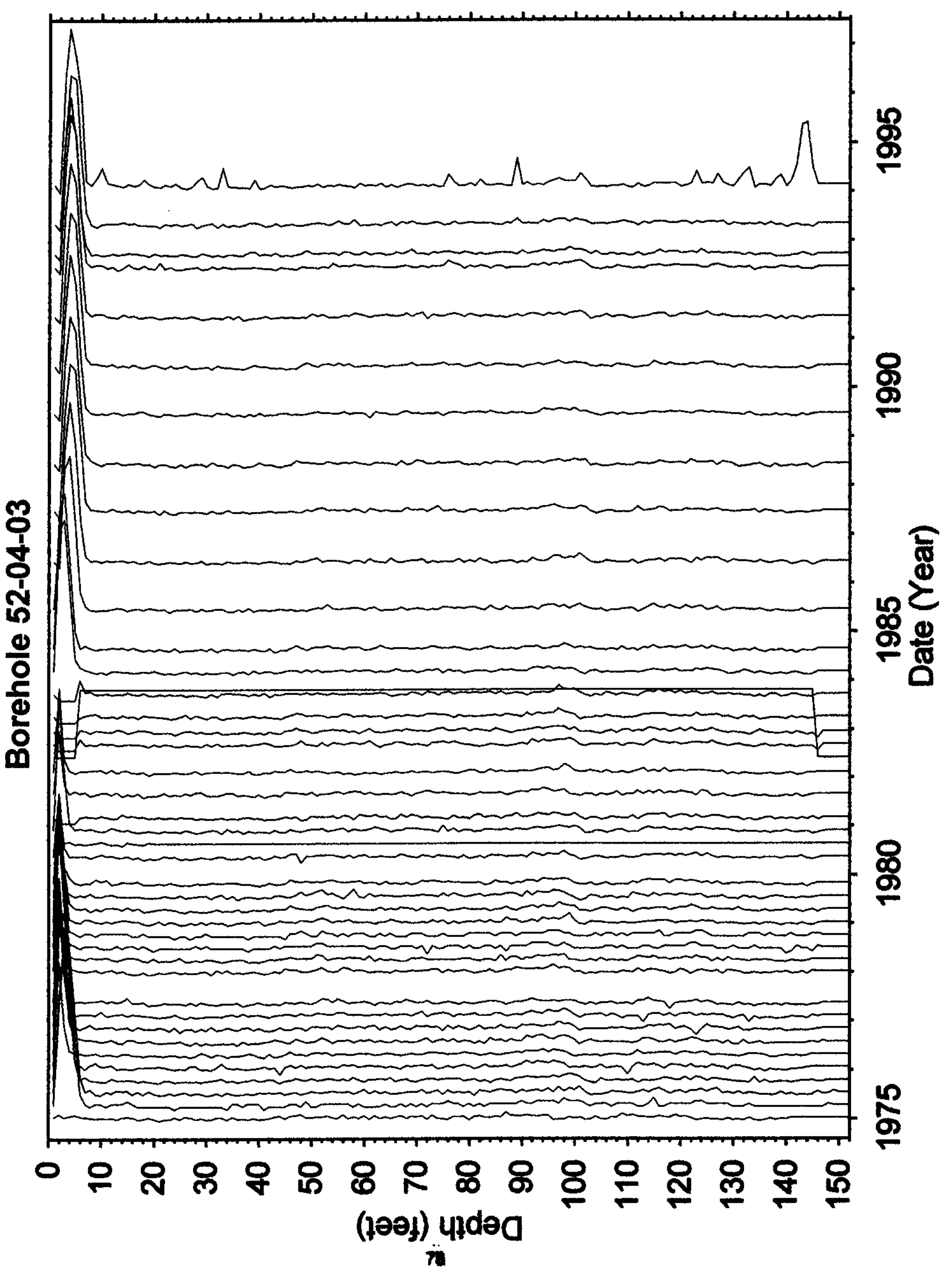




$$
\text { HNF-3831-REVO }
$$

\section{Borehole 52-04-06}

\section{No Gamma-Ray Emitting Contamination was identified}

No significant levels of gamma ray contamination are present above the survey probe detection threshold between 1975 and 1994 in the vadose zone from 2 to 98 feet. The HPGe survey identified Cs-137 from 0-12 ft at concentrations less than $1 \mathrm{pCi} / \mathrm{g}$.

Gross Gamma Survey Information

\begin{tabular}{|r|l|}
\hline Probe Type : & 04: NaI \\
\hline Other Probe Types: & $03:$ Neutron (1 surveys) \\
\hline Borehole Depth: & $100 \mathrm{ft}$ \\
\hline Survey Depth: & $100 \mathrm{ft}$ \\
\hline First Survey Date : & $1 / 09 / 1975$ \\
\hline Last Survey Date : & $2 / 23 / 1994$ \\
\hline Number Surveys : & 251 \\
\hline
\end{tabular}

\section{Analysis Notes}

\begin{tabular}{|r|l|}
\hline Number Surveys Rejected : & 0 \\
\hline Lower Threshold for Bad Survey Values : & $<=0$ \\
\hline Method Used to Compute Background: & Threshold ( $0<$ val < 50) \\
\hline & \\
\hline $\begin{array}{r}\text { Depth(s) where Contamination Identified in } \\
\text { Gross Gamma Surveys : }\end{array}$ & NONE \\
\hline Analyst Name: & R.K. Price \\
\hline Company Name: & Three Rivers Scientific \\
\hline
\end{tabular}




\section{Borehole 52-04-06}

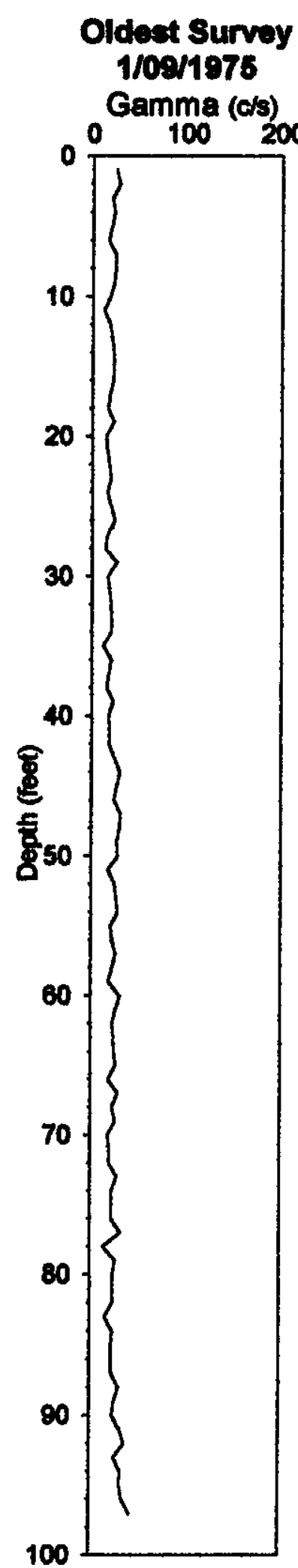

No Gamma-Ray Emitting Contamination
Above Survey Detection Threshold
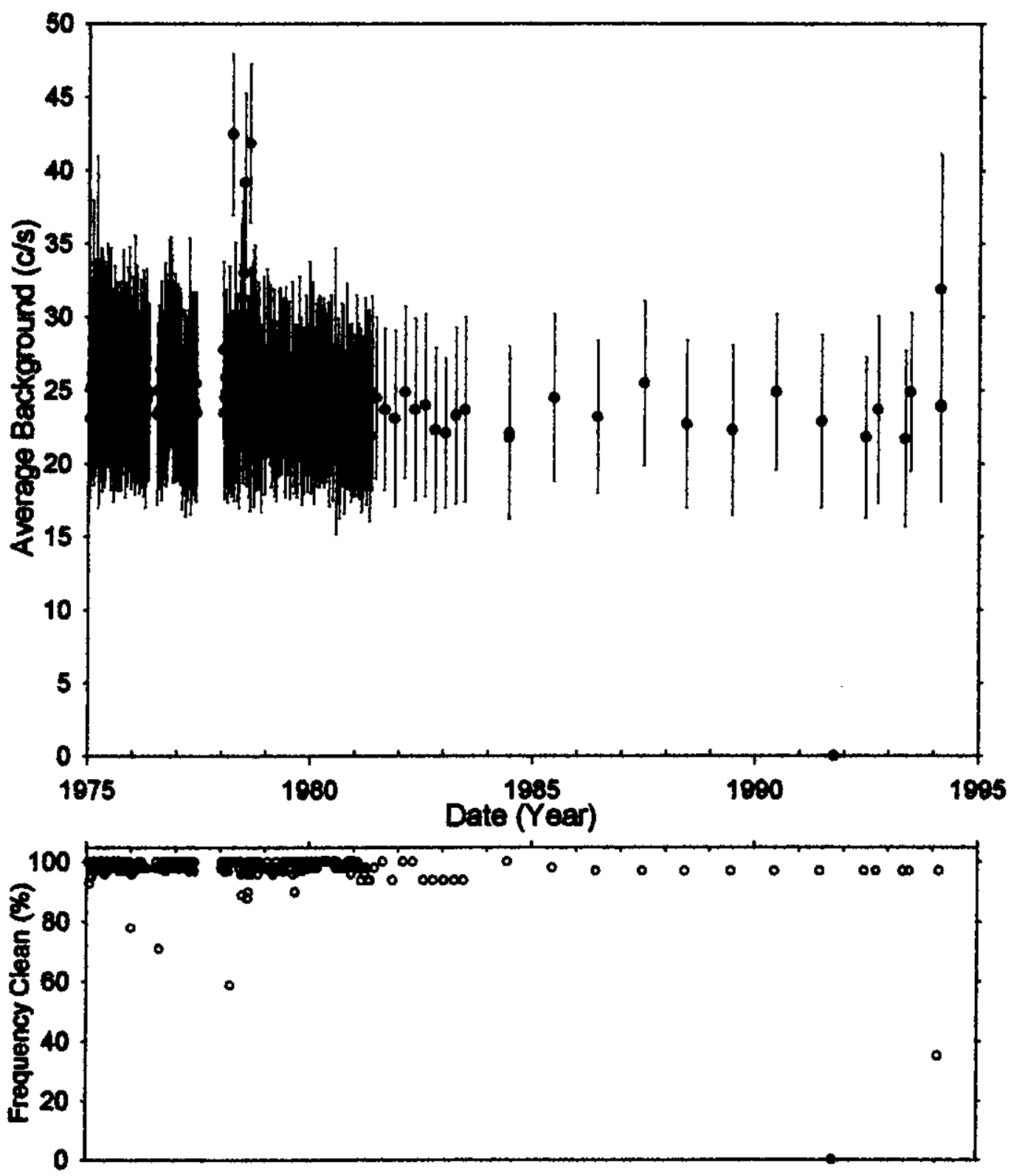
HNF-3831-REVO

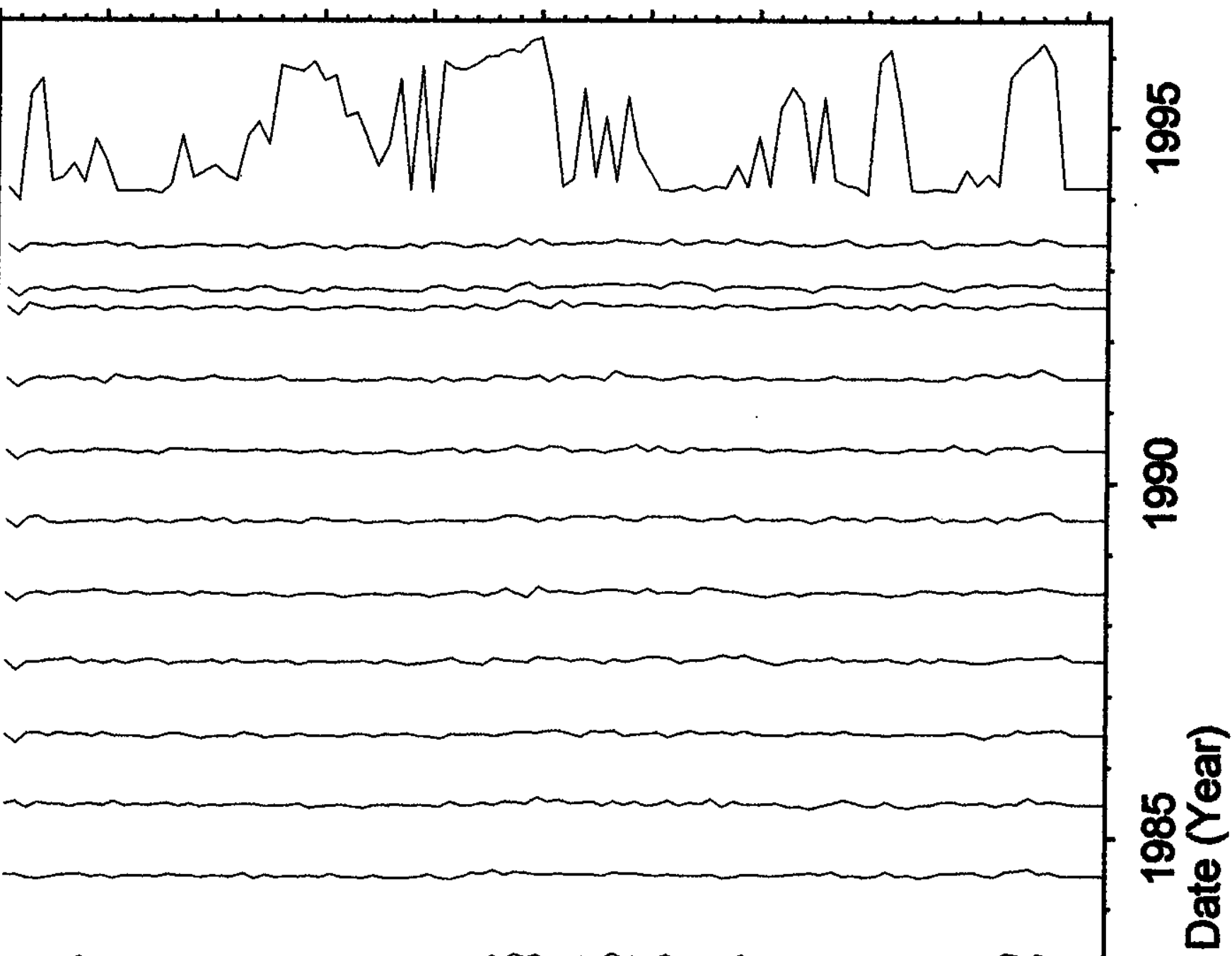

6

ح- (2)

(

(2)

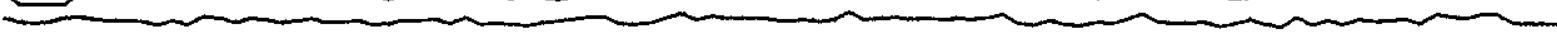

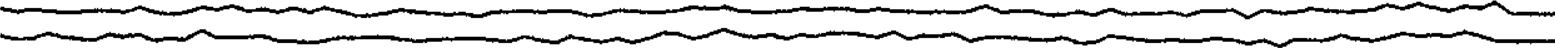

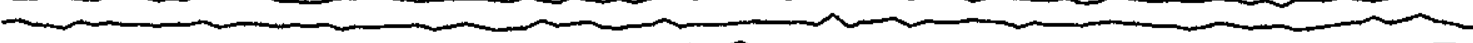

2

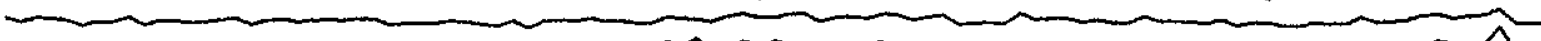

(1)

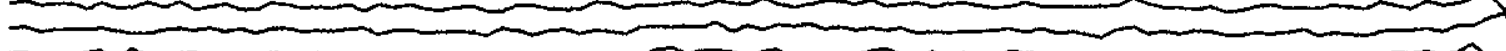

(1)

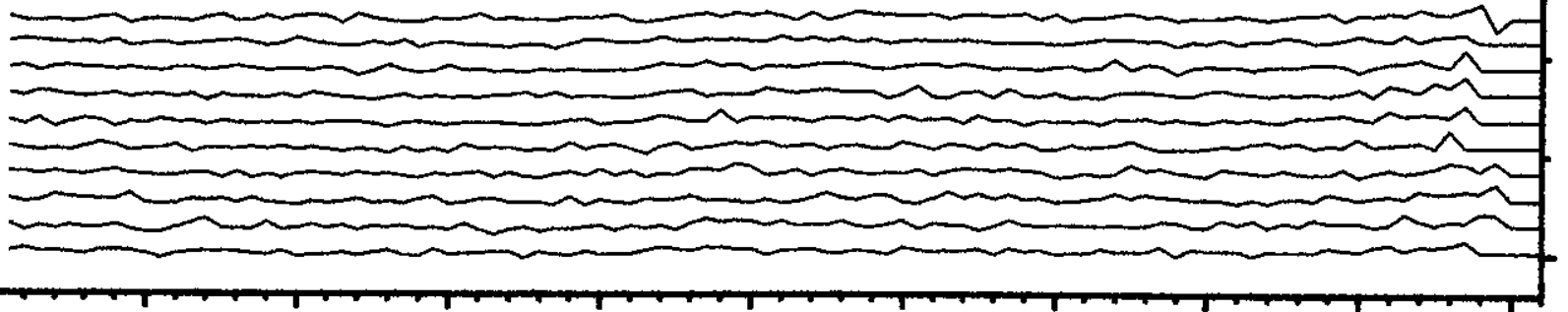




\section{Borehole 52-04-09}

\section{Contamination (Cs-137) from $85-100$ feet is Stable}

Grade Thickness Product for the low level radioactive zone (85-100 feet) of Cs-137 (HPGe identified) is stable within observed systematic limitations. The Cs-137 concentration measured by the HPGe in this depth interval was generally less than $1 \mathrm{pCi} / \mathrm{g}$.

Gross Gamma Survey Information

Probe Type: 04 : Sodium Iodide Scintillator

Other Probe Types : $03:$ Neutron (1 surveys)

Borehole Depth : $100 \mathrm{ft}$

Survey Depth : $100 \mathrm{ft}$

First Survey Date : $1 / 09 / 1975$

\begin{tabular}{l|l} 
Last Survey Date : & 2/23/1994 \\
\hline
\end{tabular}

Number Surveys: 253

Analysis Notes

\begin{tabular}{|r|l|}
\hline Number Surveys Rejected : & 0 \\
\hline Lower Threshold for Bad Survey Values : & $<=0$ \\
\hline Method Used to Compute Background : & $50-80 \mathrm{ft}$ \\
\hline & \\
\hline $\begin{array}{r}\text { Depth(s) where Contamination Identified in } \\
\text { Gross Gamma Surveys : }\end{array}$ & $85-100 \mathrm{ft}$ is Stable \\
\hline Analyst Name : & R.K. Price \\
\hline Company Name : & Three Rivers Scientific \\
\hline
\end{tabular}


HNF-3831-REVO

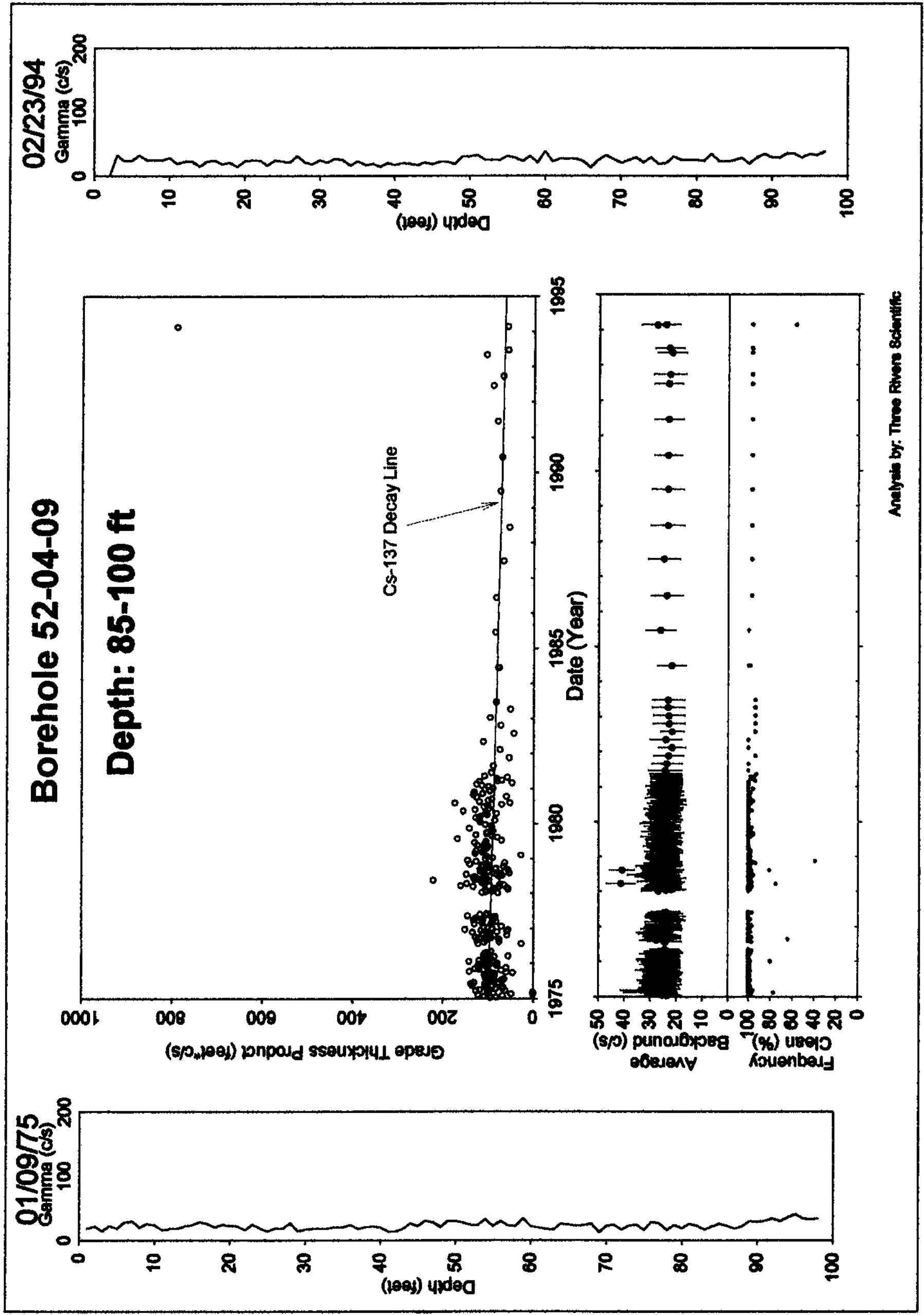


HNF-3831-REVO

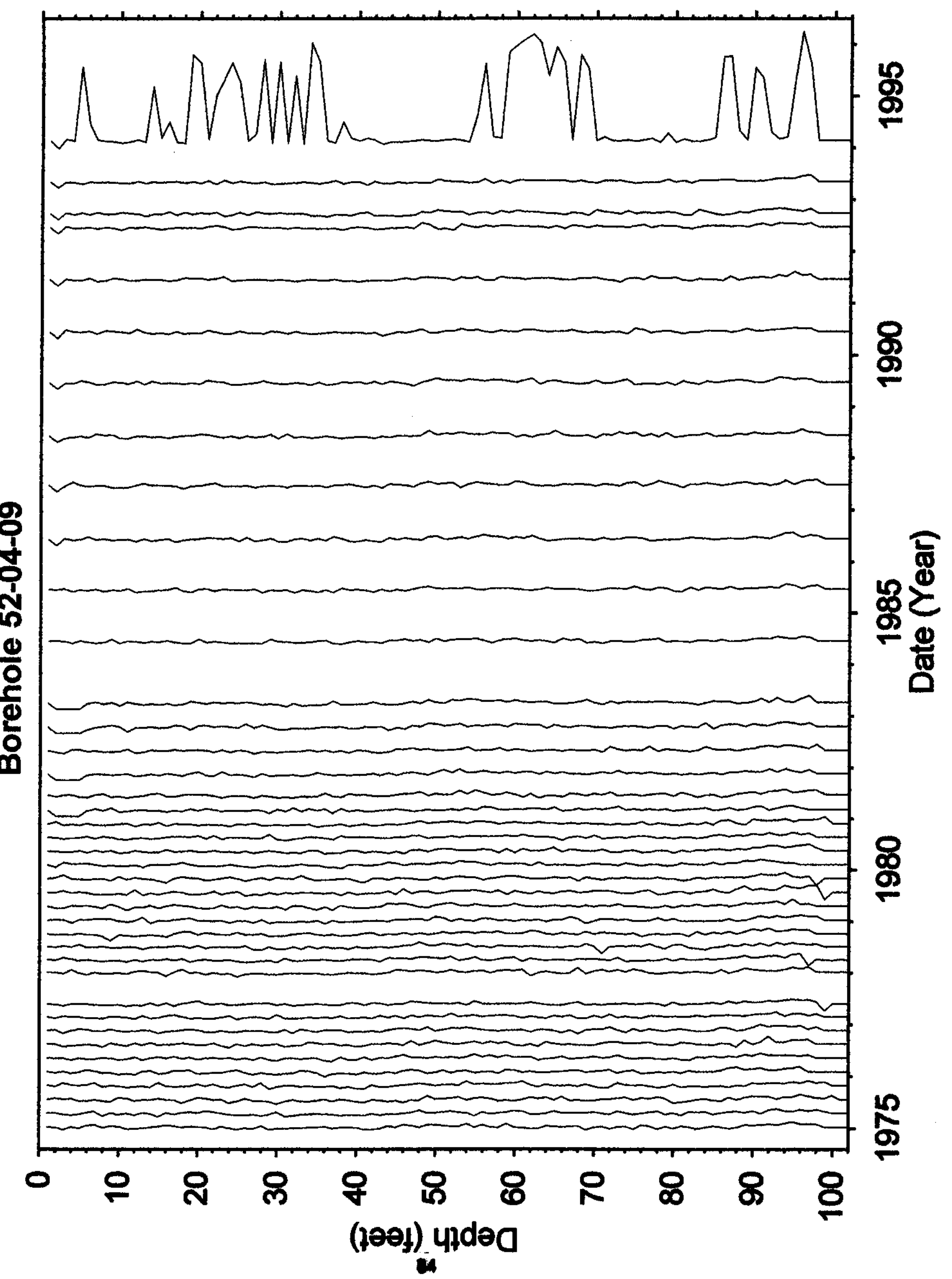




$$
\text { HNF-3831-REVO }
$$

\section{Borehole 52-04-10}

\section{No Gamma-Ray Emitting Contamination was identified}

No significant levels of gamma ray contamination are present above the survey probe detection threshold between 1975 and 1994 in the vadose zone from 2 to 142 feet. The HPGe survey identified Cs-137 at the surface (0-1 ft) and at intermittent intervals throughout the borehole at concentrations less than $1 \mathrm{pCi} / \mathrm{g}$.

The stack plot shows a depth interval (90-105 ft) of slightly elevated gross gamma activity that is confirmed by the HPGe baseline survey and is identified to contain only natural radionuclides with slightly elevated natural uranium and thorium.

Gross Gamma Survey Information

\begin{tabular}{|r|l|}
\hline Probe Type : & 04: NaI \\
\hline Other Probe Types: & $03:$ Neutron (3 surveys) \\
\hline Borehole Depth: & $142 \mathrm{f}$ \\
\hline Survey Depth: & $142 \mathrm{ft}$ \\
\hline First Survey Date: & $1 / 09 / 1975$ \\
\hline Last Survey Date : & $2 / 23 / 1994$ \\
\hline Number Surveys : & 246 \\
\hline
\end{tabular}

Analysis Notes

\begin{tabular}{|r|l|}
\hline Number Surveys Rejected : & 0 \\
\hline Lower Threshold for Bad Survey Values : & $<=0$ \\
\hline Method Used to Compute Background : & Threshold $(0<\mathrm{val}<50)$ \\
\hline & \\
\hline Depth(s) where Contamination Identified in & NONE \\
Gross Gamma Surveys : & \\
\hline Analyst Name: & R.K. Price \\
\hline Company Name: & Three Rivers Scientific \\
\hline
\end{tabular}


HNF-3831-REVO

\section{Borehole 52-04-10}

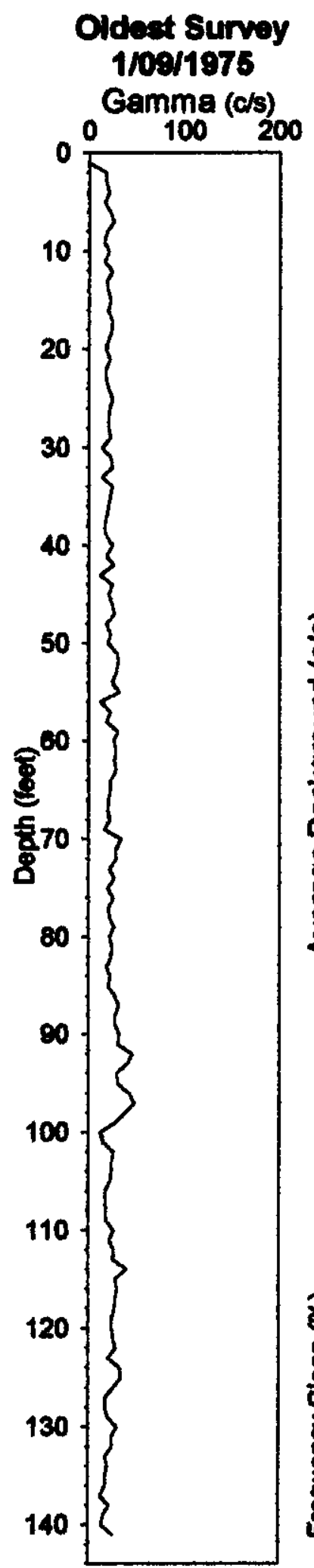

No Gamma-Ray Emitting Contamination Above Survey Detection Threshold
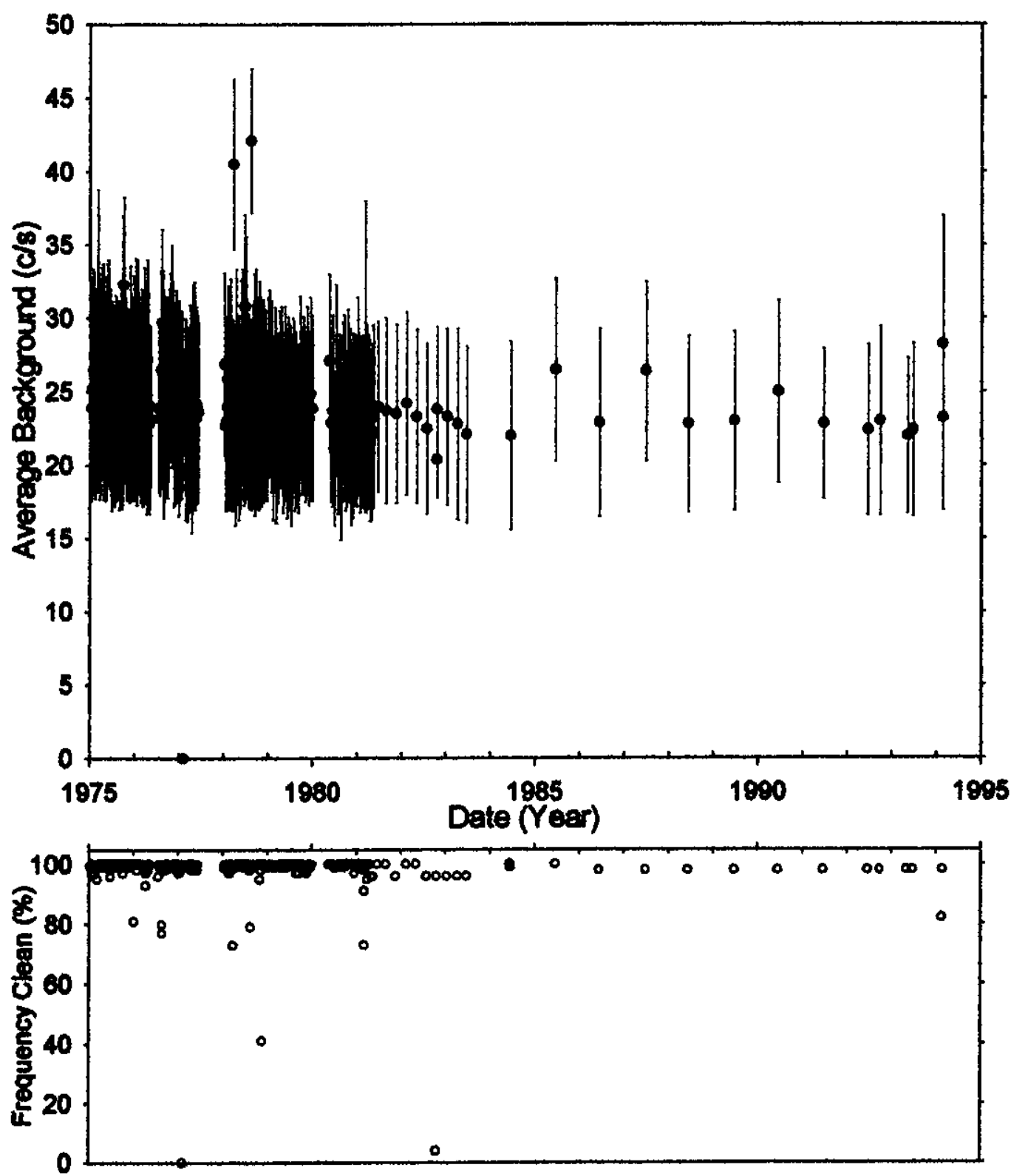


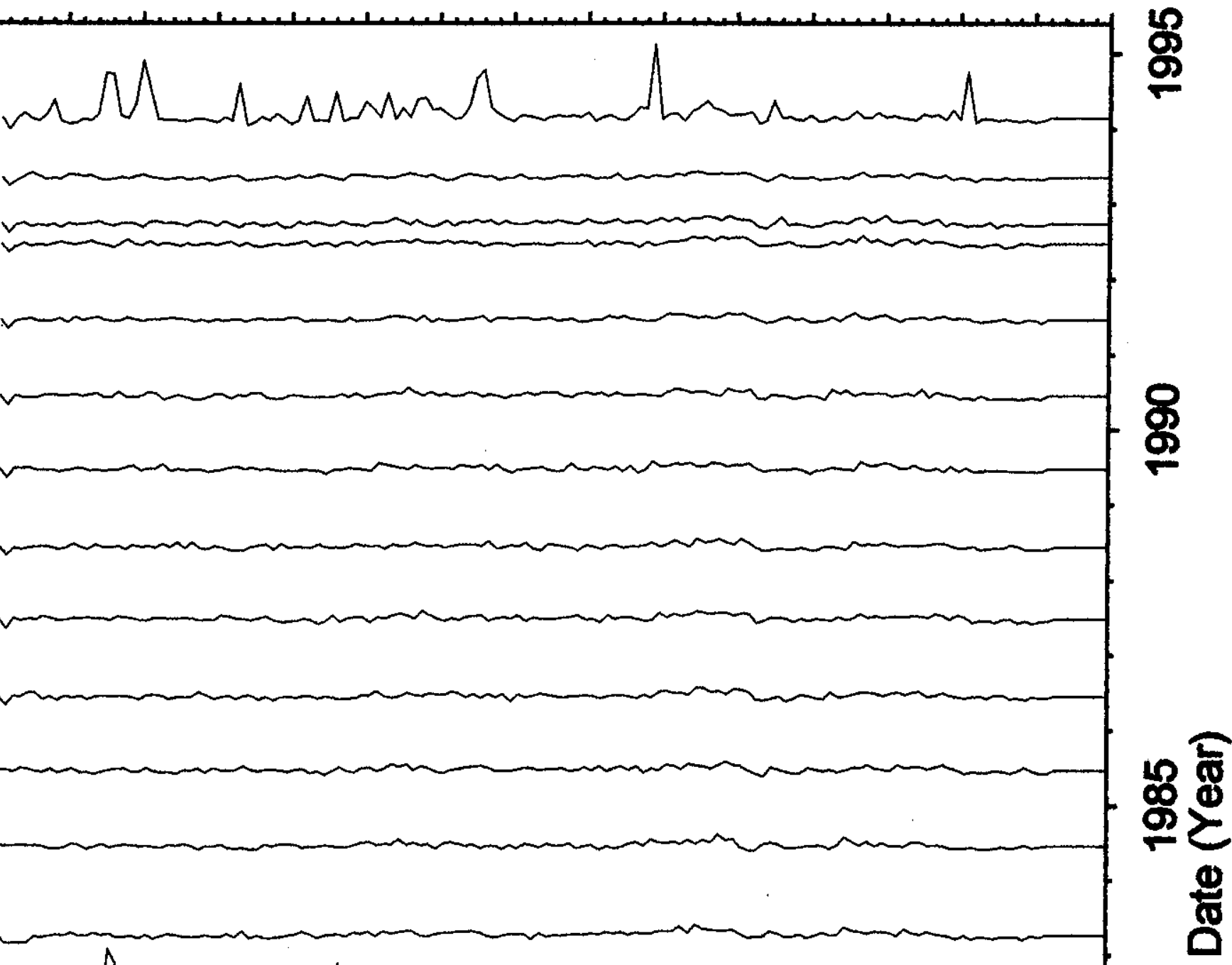




$$
\text { HNF-3831-REVO }
$$

Dry Well Survey Analysis - Notes

Borehole TY (52-04-02)

Log Date: $75-01-091^{\text {st }}$

Isotope from Spectral Survey: Contamination Zone Depths):
Total \# Surveys 271 \# neutron surveys 6 94-a2-23 Last
Probe Type 04
\# GR Surveys 265
Presentation Plot Dates

(If different from $1^{2} \&$ Lest)

Max Survey Depth 100

GAPS.Txt

\begin{tabular}{|l|l|l|l|}
\hline Survey Date & nut. Gaps & approx \#Sampl's & Comment \\
\hline $76-09-16$ & 27 & 55 & \\
\hline & & & \\
\hline & & & \\
\hline & & & \\
\hline
\end{tabular}

HI-ZONES.TXt

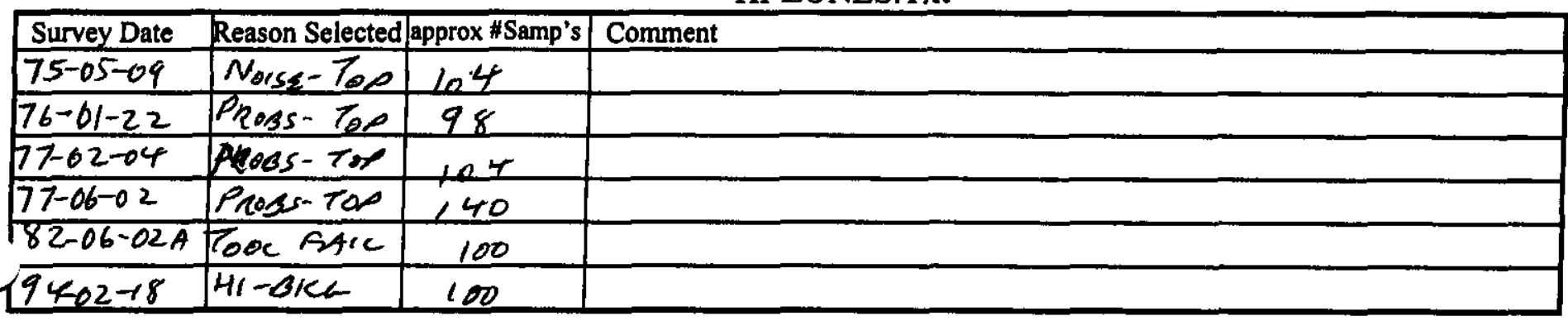

BackGnd.Txt

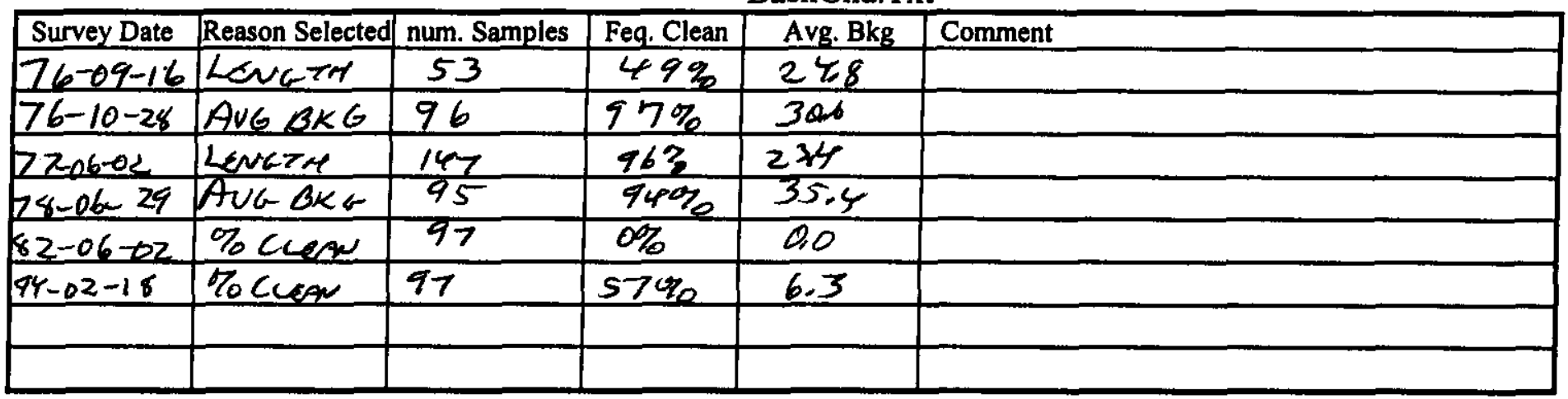

Analysis Notes

mum surveys rejected: $(0) \quad$ M $\sqrt{3} \quad$ Background $=(0<\mathrm{val}<50)$

No RA ZONRS

Category: (Stable, TF Activity, Undetermined, CHANGED CLEM

Analyst Name Randall Puss S/W ver(TFGROSS) V2. 20. 
HNF-3831-REVO

\section{Dry Well Survey Analysis - Notes}
Borehole TY $(52-04-03)$
Total \# Surveys 285
Probe Type 04
\# neutron surveys 6
Log Date: 7Iol-of $1^{\text {st }}$
$94-02-23$ Last
\# GR Surveys 279
Presentation Plot Dates 75-01-15 (If different from $1^{\text {* \& Last) }}$

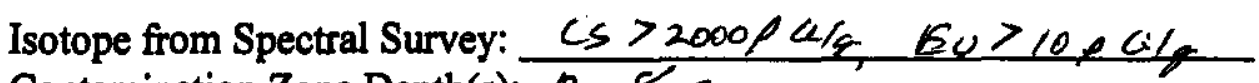
Max Survey Depth 147
Contamination Zone Depth(s): $0-8 \kappa 7$

GAPS.Txt

\begin{tabular}{|l|l|l|l|}
\hline Survey Date & num. Gaps & approx \#Sampl's Comment \\
\hline $76-07-5$ & 25 & 170 & \\
\hline $76-08-19$ & 12 & 150 & \\
\hline $76-09-16$ & 21 & 40 & \\
\hline & & & \\
\hline
\end{tabular}

HI-ZONES.Txt

\begin{tabular}{|l|l|l|l|}
\hline Survey Date & Reason Selected & approx \#Samp's & Comment \\
\hline $75-02-08$ & &
\end{tabular}

\begin{tabular}{|l|l|l|}
\hline $75-02-08$ & $H_{1}-B K G$ & 150 \\
\hline
\end{tabular}

\begin{tabular}{l|l|l|}
\hline $75-04-24 B$ & SHORT LaW & 80
\end{tabular}

\begin{tabular}{l|l|l|l}
\hline $75-05-15$ & BNo LOC & 158 \\
\hline
\end{tabular}

Z6-01-08 no RAOZOne 90

78-07-14 BAD SURUEY 160

\begin{tabular}{l|l|l|l|}
\hline $82-06-02$ & ToOC FAIC & 150
\end{tabular}

BackGnd.Txt

\begin{tabular}{|c|c|c|c|c|c|}
\hline Survey Date & Reason Selected & num. Samples & Feq. Clean & Avg. Bkg & Comment \\
\hline $75-04 \cdot 24$ & LENCYM & 68 & $92 \%$ & 25,6 & \\
\hline $76-07-15$ & LENG 7 HA $^{\prime}$ & 300 & $86 \%$ & 27,2 & \\
\hline $78-06-29$ & AUK BKC & 145 & 96\% & 34,0 & \\
\hline $80-08-19$ & $\angle E N G T H$ & 19 & $100 \%$ & 15.5 & \\
\hline $82-06-02$ & Oo Llean & 146 & $0 \%$ & 0.0 & \\
\hline & & & & & \\
\hline & & & & & \\
\hline
\end{tabular}

Analysis Notes

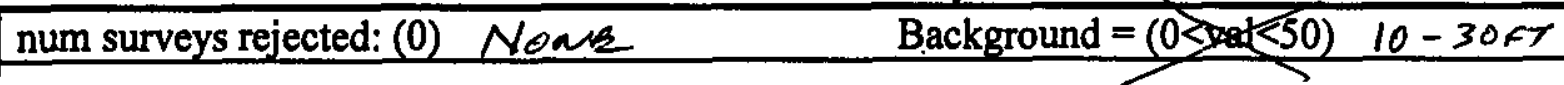

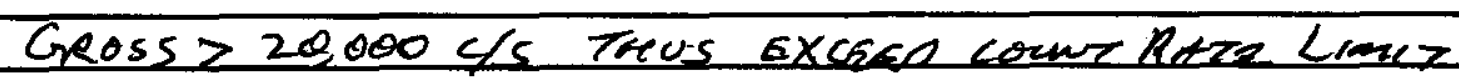

Category: (Stable TF Activity, Undetermined, CHANGED

Analyst Name Randall Pues

$\mathrm{S} / \mathrm{W}$ ver (TFGROSS) $\mathrm{V} 2.20$ 
HNF-3831-REVO

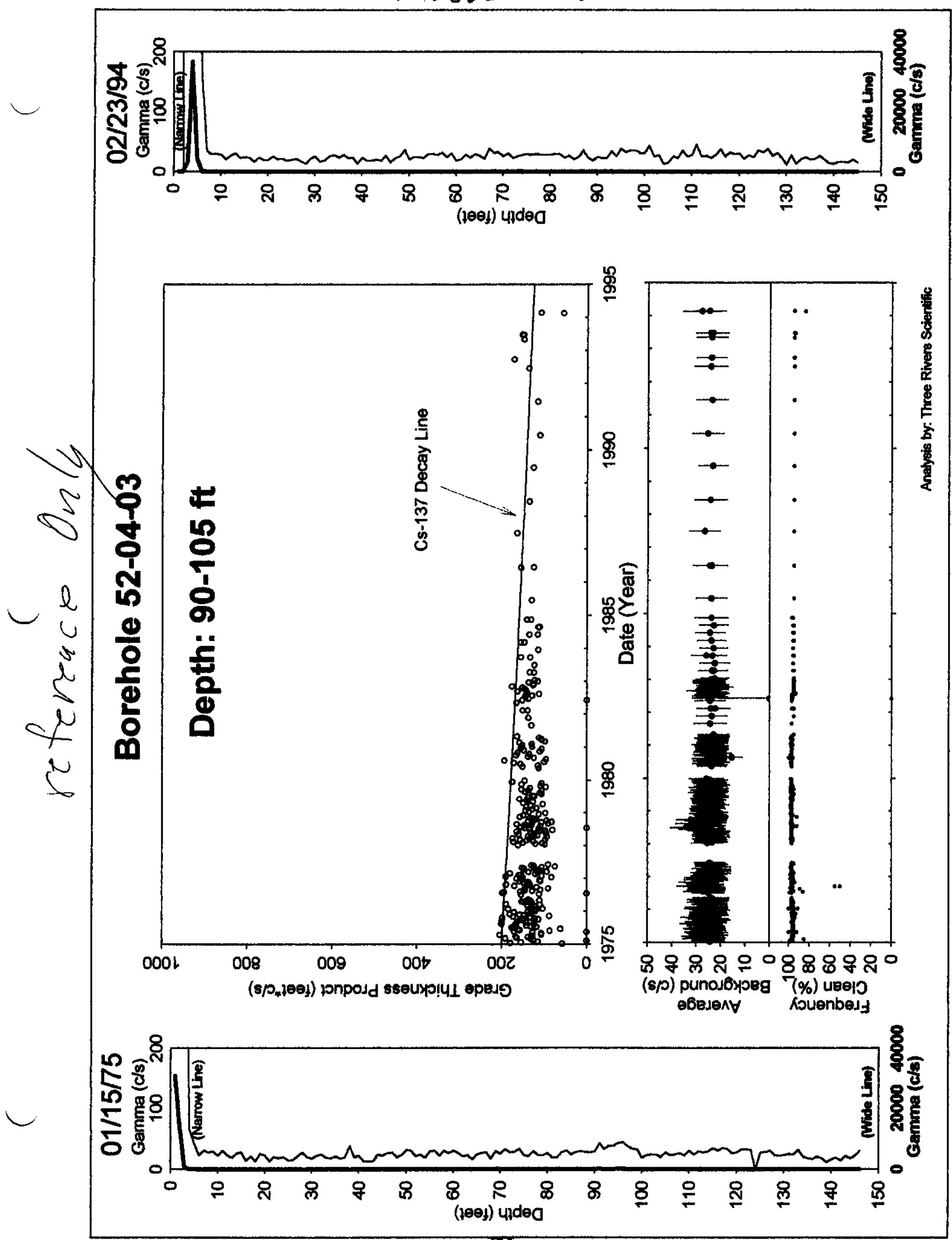




\section{HNF-3831-REVO}

\section{Dry Well Survey Analysis - Notes}
Borehole TY (52-04-06)
Total \# Surveys 252
Probe Type OY
Log Date: 75-01-09 $1^{\text {st }}$
\# neutron surveys
\# GR Surveys 251
$94-02-23$ Last
Presentation Plot Dates

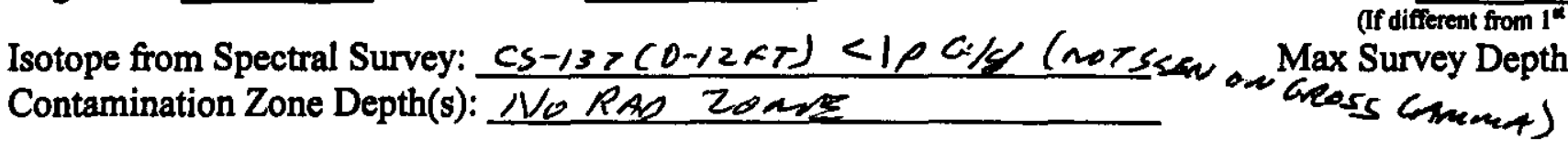

GAPS.Txt

\begin{tabular}{|l|c|c|l|}
\hline Survey Date & num. Gaps & approx \#Sampl's & Comment \\
\hline $75-12-31$ & 15 & 70 & \\
\hline $76-08-19$ & 23 & 80 & \\
\hline $79-09-05$ & 9 & 100 & \\
\hline & & & \\
\hline
\end{tabular}

HI-ZONES.Txt

\begin{tabular}{|l|l|l|l|}
\hline Survey Date & Reason Selected & approx \#Samp's & Comment \\
\hline $75-01-23$ & BAD SURy & 100 & \\
\hline $78-03-23$ & 11 BKG & 100 & \\
\hline $78-06-25$ & He BKC & 100 & \\
\hline $94-02-18$ & Teoc FAc & 100 & \\
\hline & & & \\
\hline & & & \\
\hline
\end{tabular}

BackGnd.Txt

\begin{tabular}{|l|c|c|c|c|l|}
\hline Survey Date & Reason Selected & num. Samples & Feq. Clean & Avg. Bkg & Comment \\
\hline $75-03-06$ & $A \cup G$ BKa & 99 & $98 \%$ & 33.6 & \\
\hline $78-03-23$ & $A \cup G$ BKC & 97 & $59 \%$ & 425 & \\
\hline $78-08-11$ & $A \vee G B K G$ & 96 & $88 \%$ & 41.9 & \\
\hline $94-02-18$ & $70 C C 2 A v$ & 97 & $35 \%$ & 31.9 & \\
\hline & & & & & \\
\hline & & & & & \\
\hline & & & & & \\
\hline & & & & & \\
\hline
\end{tabular}

Analysis Notes

num surveys rejected: $(0)$ No $\sim 2 \quad$ Background $=(0<v a l<50)$

Category: (Stabte, IF Activity, Undetermined, CHANGED

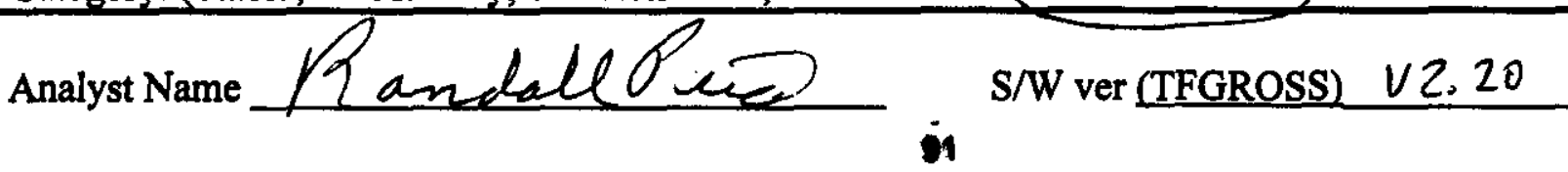




\section{Dry Well Survey Analysis - Notes}

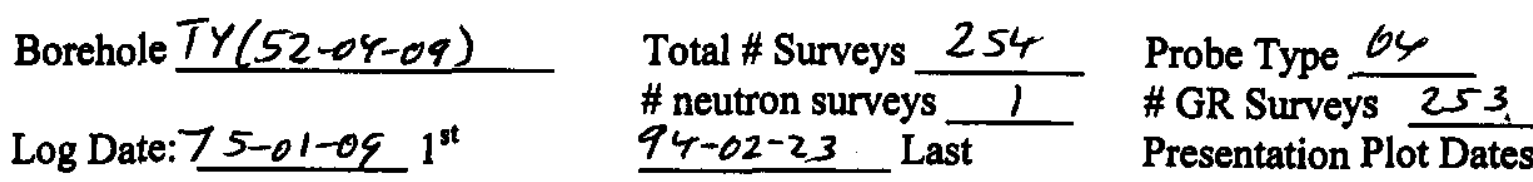

(ff different from Ix \& Lest)

Isotope from Spectral Survey: $\mathrm{CS}-137(85-100 \mathrm{AT})<1 \mathrm{e}$ (ifg $\quad$ Max Survey Depth 100

Contamination Zone Depth(s): No Rad Zones

GAPS.Txt

\begin{tabular}{|l|l|l|l|}
\hline Survey Date & num. Gaps & approx \#Sampl's & Comment \\
\hline $75-12-31$ & 19 & 100 & \\
\hline $76-08-19$ & 11 & 30 & \\
\hline $78-11-15$ & 39 & 65 & \\
\hline & & & \\
\hline
\end{tabular}

HI-ZONES.TXt

\begin{tabular}{|l|l|l|l|}
\hline Survey Date & Reason Selected & approx \#Samp's & Comment \\
\hline $75-62-12$ & $H 1-B K G$ & 160 & \\
\hline $78-03-23$ & $H 1-B K G$ & 100 & \\
\hline $78-08-11$ & $H 1-B K G$ & 98 & \\
\hline $80-08-05$ & NOSS -70 & 104 & \\
\hline $94-02-18$ & ToO FA, & 100 & \\
\hline & & & \\
\hline
\end{tabular}

BackGnd.Txt

\begin{tabular}{|l|l|l|l|l|l|}
\hline Survey Date & Reason Selected & num. Samples & Feq. Clean & Avg. Bkg & Comment \\
\hline $75-03-06$ & AVG BKG & 94 & $96 \%$ & 33.2 & \\
\hline $76-08-19$ & LENG TA & 31 & $64 \%$ & 25.8 & \\
\hline $78-03-23$ & $A \cup 6$ BKG & 97 & $75 \%$ & 41.3 & \\
\hline $78-08-11$ & AVG BKG & 97 & $81 \%$ & 40.8 & \\
\hline $94-02-18$ & $\%$ CLSAN & 97 & $57 \%$ & 27.6 & \\
\hline & & & & & \\
\hline & & & & & \\
\hline & & & & & \\
\hline
\end{tabular}

Analysis Notes

num surveys rejected: $(0) \quad X$ lon 2 Background $=(0<\mathrm{val} 550) \quad 50-80<7$

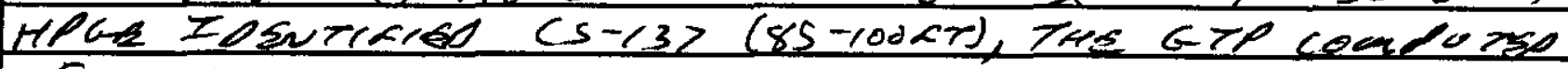
FOR THES INTERVAL

Category: (Stablo, IFActity, Undetmined, CHANEED CLEAN

Analyst Name Randall Pue $=$ s/W ver(TFGROSS) V2. 20. 


\section{HNF-3831-REVO \\ Dry Well Survey Analysis - Notes}

\begin{tabular}{|c|c|c|}
\hline Borehole $T Y(52-04-10)$ & $\begin{array}{l}\text { Total \# Surveys } \frac{249}{3} \\
\text { \# neutron surveys } 3\end{array}$ & $\begin{array}{l}\text { Probe Type } \frac{\Delta 4}{} \\
\text { \# GR Surveys } 246\end{array}$ \\
\hline Log Date: $\frac{75-01-09}{13 t}$ & $94-02-23$ Last & $\begin{array}{l}\text { Presentation Plot Dates } \\
\text { (If different from 1" \& Lest) } \\
\text { Max Survey Depth } / 42\end{array}$ \\
\hline
\end{tabular}

GAPS.Txt

\begin{tabular}{|l|c|c|c|}
\hline Survey Date & num. Gaps & approx \#Sampl's & Comment \\
\hline $75-12-31$ & 26 & 145 & \\
\hline $76-68-19$ & 15 & 75 & \\
\hline $76-67-15$ & 10 & 200 & \\
\hline $78-11-15$ & 54 & 100 & \\
\hline $82-10-19$ & 134 & 150 &
\end{tabular}

\section{HI-ZONES.Txt}

\begin{tabular}{|c|c|c|c|}
\hline Survey Date & Reason Selected & approx \#Samp's & Comment \\
\hline $77-62-04$ & Teel FAlC & $1 \infty$ & \\
\hline $78-63-23$ & $H A B G$ & 150 & \\
\hline $78-08-11$ & $H-B K G$ & 150 & \\
\hline $78-11-15$ & Tooc Norse & 100 & \\
\hline $81-03-06$ & Tooc AArC & 150 & \\
\hline $94-02-18$ & $H A-B K a$ & 150 & \\
\hline
\end{tabular}

BackGnd.Txt

\begin{tabular}{|l|l|l|l|l|l|}
\hline Survey Date & Reason Selected & num. Samples & Feg. Clean & Avg. Bkg & Comment \\
\hline $75-03-06$ & $A \cup G-B K C$ & 143 & $95 \%$ & 31.7 & \\
\hline $75-10-02$ & $A \cup C B K C$ & 143 & $97 \%$ & 32.3 & \\
\hline $76-67-15$ & CENGTK & 250 & $46 \%$ & 23.9 & \\
\hline $77-02-04$ & $\%$ CCEA & 98 & $0 \%$ & 0.0 & \\
\hline $78-03-23$ & $A \cup G B K G$ & 142 & $73 \%$ & 40.5 & \\
\hline $78-08-11$ & $A \cup G$ BKG & 96 & $41 \%$ & 25.8 & \\
\hline $82-10-19$ & $\%$ CLEN & 14 & $4 \%$ & 26.4 & \\
\hline & & & & & \\
\hline
\end{tabular}

\section{Analysis Notes}

\begin{tabular}{|lll}
\hline num surveys rejected: $(0)$ & Non & Background $=(0<\mathrm{val}<50)$
\end{tabular}

Category: (Stable, IE Activity, Undetermined, CHANGED $C C \& A$

Analyst Name frandall Pure is is ver(TFGROSS) V 2.20. 


\section{HNF $-3831-$ REVO}

Borehole 52-05-07

page 1 of 2

\section{Contamination (Cs-137\&Co-60\&Sb-125) from $51-57$ feet is Unstable Early}

Contamination (Co-60\&Sb-125) from 55-66 feet is Unstable Early Contamination (Co-60\&Sb-125) from 66-82 feet is Unstable Early Contamination (Co-60) from 82-100 feet is Unstable Early

The radioactive contamination zone was analyzed as four sub zones (i.e. 51-57, 57-66, 6682, and 82-100 ft.) The HPGe survey identified Co-60 and Cs-137 in each interval but did not identify Sb-125 (hypothesis). The highest ratio of Cs-137 to Co-60 occurred in the shallowest zone as is normally observed. The level of Sb-125 in this borehole is believed to be below the minimum detectable threshold at the time of the HPGe baseline survey. Since 1985 the radioactive contaminants in each zones are categorized as stable. A grade thickness product plot for the combined zone (51-100 ft) is included as a reference.

The shallowest sub zone ( $51-57 \mathrm{ft}$ ) identified two time intervals of unstable contaminants (i.e. early in 1975 and from 1980 to 1982 .) The grade thickness product plot shows a rapid decrease in radiation levels during in the early part of 1975 and an increase in radiation levels during 1980 . Deviations in the grade thickness product plot are noted during the same two time intervals for the remaining three sub zones.

The deviation during early 1975 in grade thickness product from the least squares fit decay line is much less noticeable in the 57-66 ft depth zone, is definitely noticeable in the 66-82 $\mathrm{ft}$ interval, and is clearly noticeable with a slight influx of radioactive materials in the 82$100 \mathrm{ft}$ depth interval. A possible interpretation of the unstable condition in 1975 is that the monitoring surveys recorded the final redistribution phase of the contaminants from an earlier release.

The deviation during 1980 in grade thickness product is less noticeable in the 57-66 $\mathrm{ft}$ depth zone, is not clear in the 66-82 $\mathrm{ft}$ interval, and is not present in the 82-100 $\mathrm{ft}$ depth interval. Since the shallowest interval $(51-57 \mathrm{ft}$ ) had a noticeable increase in radiation levels a possible interpretation is that the unstable condition in 1980 may have been from a minimal influx of contaminants that was restricted to the upper contamination intervals and did not impact the complete radiation interval.

The least squares fit of multiple radio-isotopes results in a gross gamma contribution ratio for each depth zone as follows.

Depth zone: $51-100 \mathrm{ft}$, Cs-137 : Co-60 : Sb-125 of $122: 24,000: 2220$ on January 1975

Depth zone: $51-57 \mathrm{ft}$, Cs-137 : Co-60 : Sb-125 of $667: 653: 727$ on January 1975

Depth zone: $57-66 \mathrm{ft}, \mathrm{Co}-60: \mathrm{Sb}-125$ of $6530: 4660$ on January 1975

Depth zone: $66-82 \mathrm{ft}$, Co-60 : Sb-125 of $8620: 3180$ on January 1975 
HNF-3831 -REVO

\section{Borehole 52-05-07}

page 2 of 2

Gross Gamma Survey Information

\begin{tabular}{|r|l|}
\hline Probe Type: & 04: Sodium Iodide Scintillator \\
\hline Other Probe Types: & $03:$ Neutron (3 surveys) \\
\hline Borehole Depth: & $100 \mathrm{ft}$ \\
\hline Survey Depth: & $100 \mathrm{ft}$ \\
\hline First Survey Date : & $1 / 09 / 1975$ \\
\hline Last Survey Date: & $5 / 25 / 1994$ \\
\hline Number Surveys : & 265 \\
\hline
\end{tabular}

\section{Analysis Notes}

\begin{tabular}{|r|l|}
\hline Number Surveys Rejected : & 0 \\
\hline Lower Threshold for Bad Survey Values : & $<=0$ \\
\hline Method Used to Compute Background : & $25-45 \mathrm{ft}$ \\
\hline & \\
\hline Depth(s) where Contamination Identified in & $51-57 \mathrm{ft}$ is Unstable Early \\
Gross Gamma Surveys : & $57-66 \mathrm{ft}$ is Unstable Early \\
& $66-82 \mathrm{ft}$ is Unstable Early \\
& $82-100 \mathrm{ft}$ is Unstable Early \\
\hline & \\
\hline Analyst Name : & R.K. Price \\
\hline Company Name: & Three Rivers Scientific \\
\hline
\end{tabular}


HNF- $3831-R E V O$

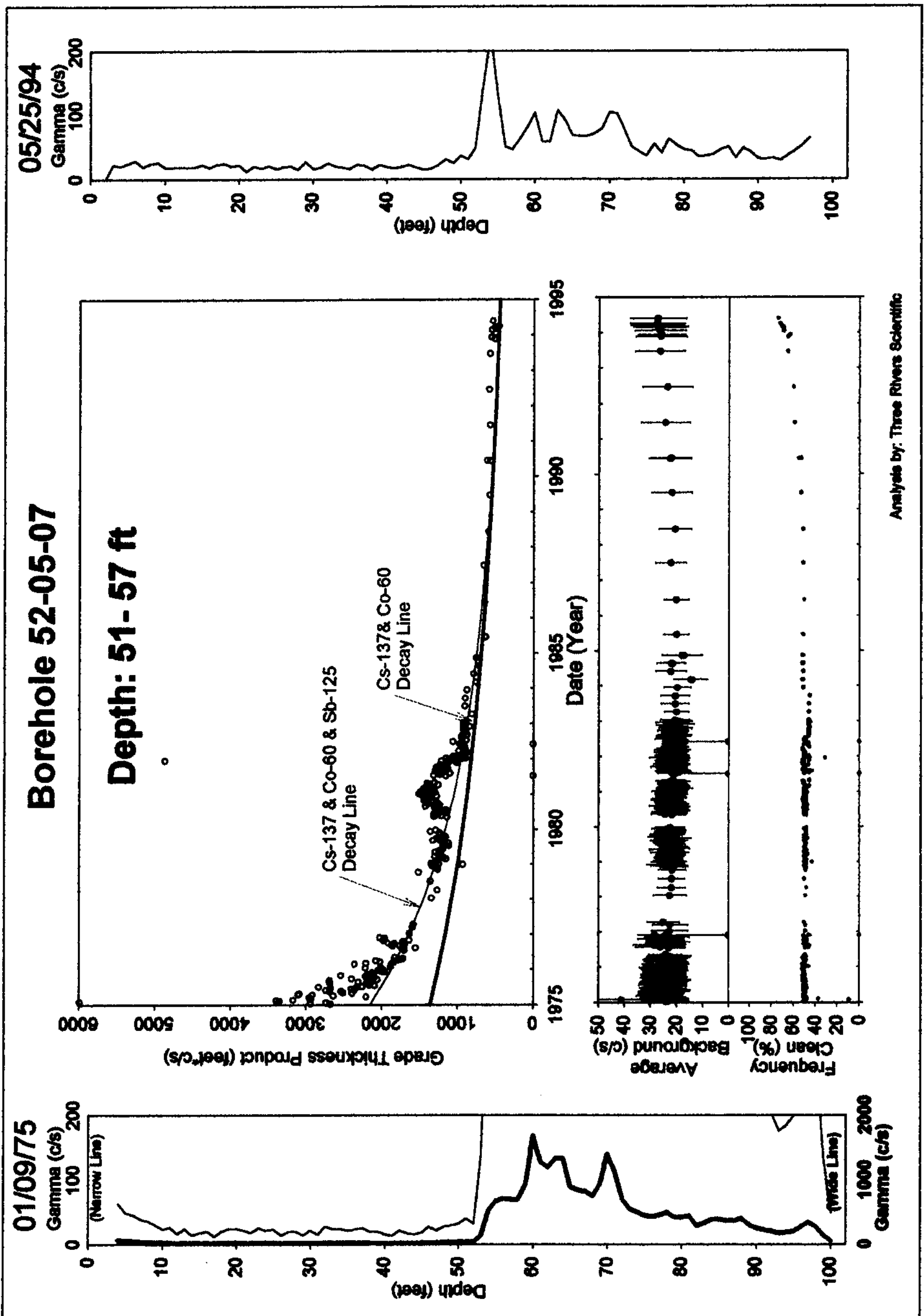


HNF- 3831 -REVO

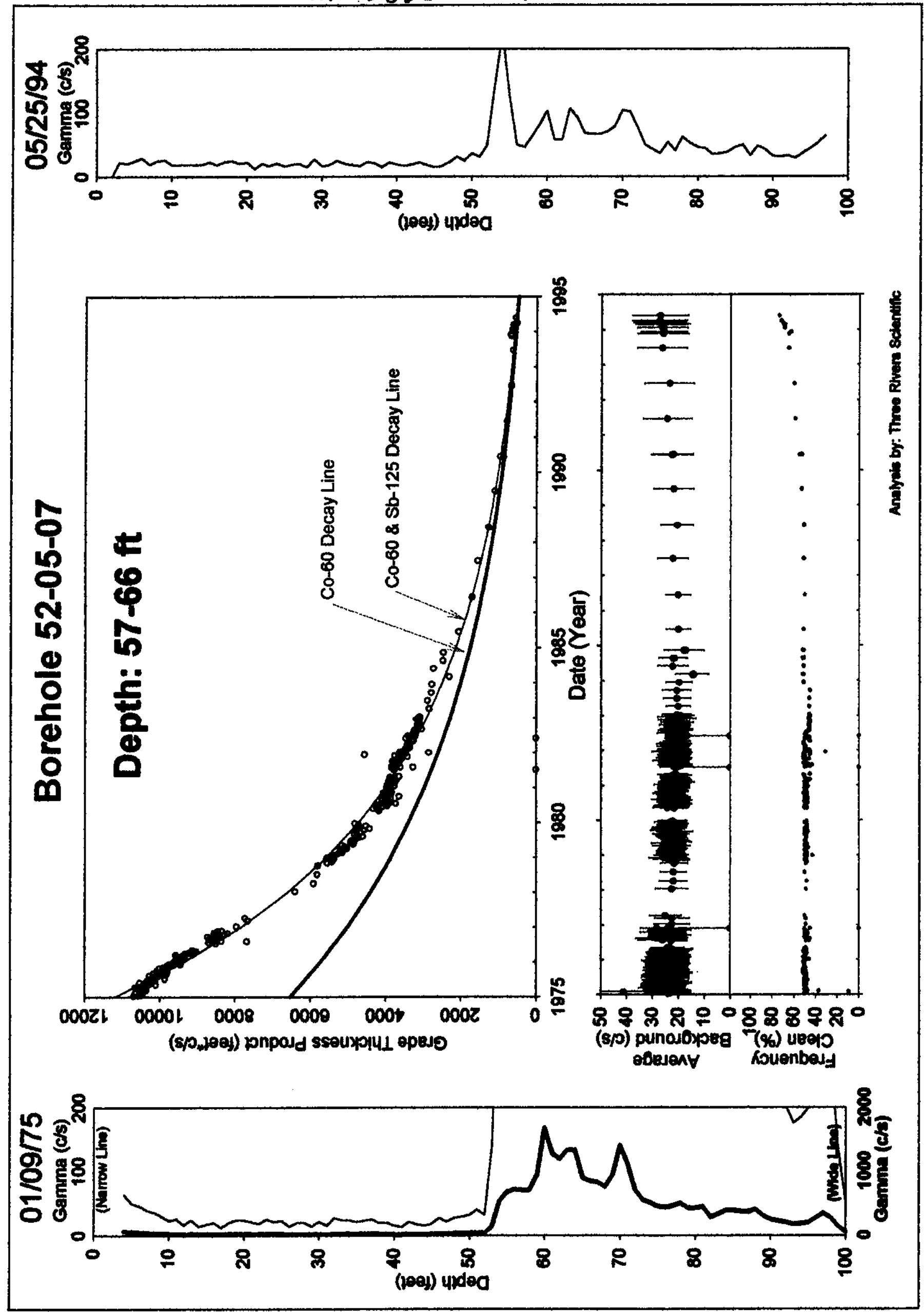


HNF-3831-REVO
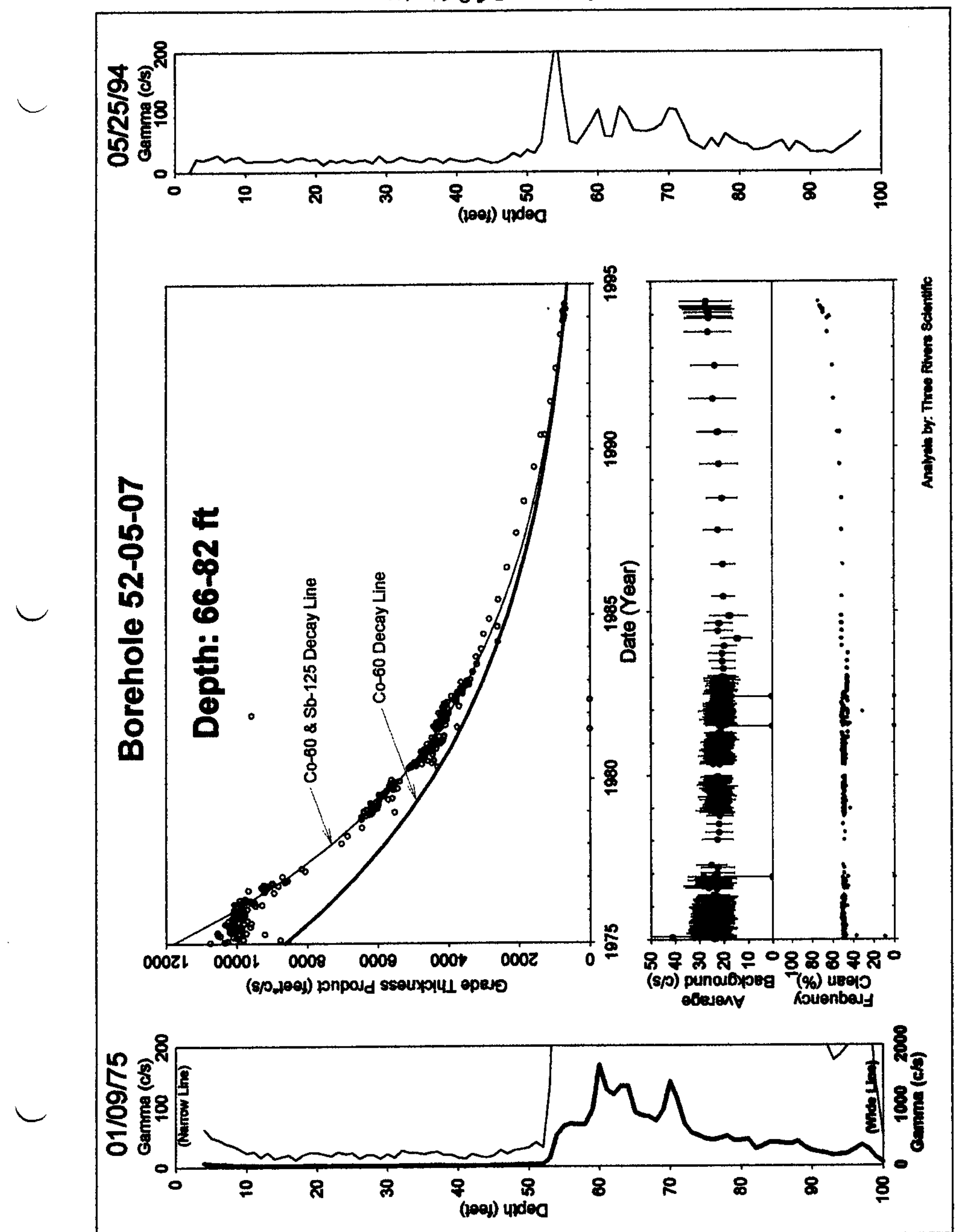
HNF-3831-REVO

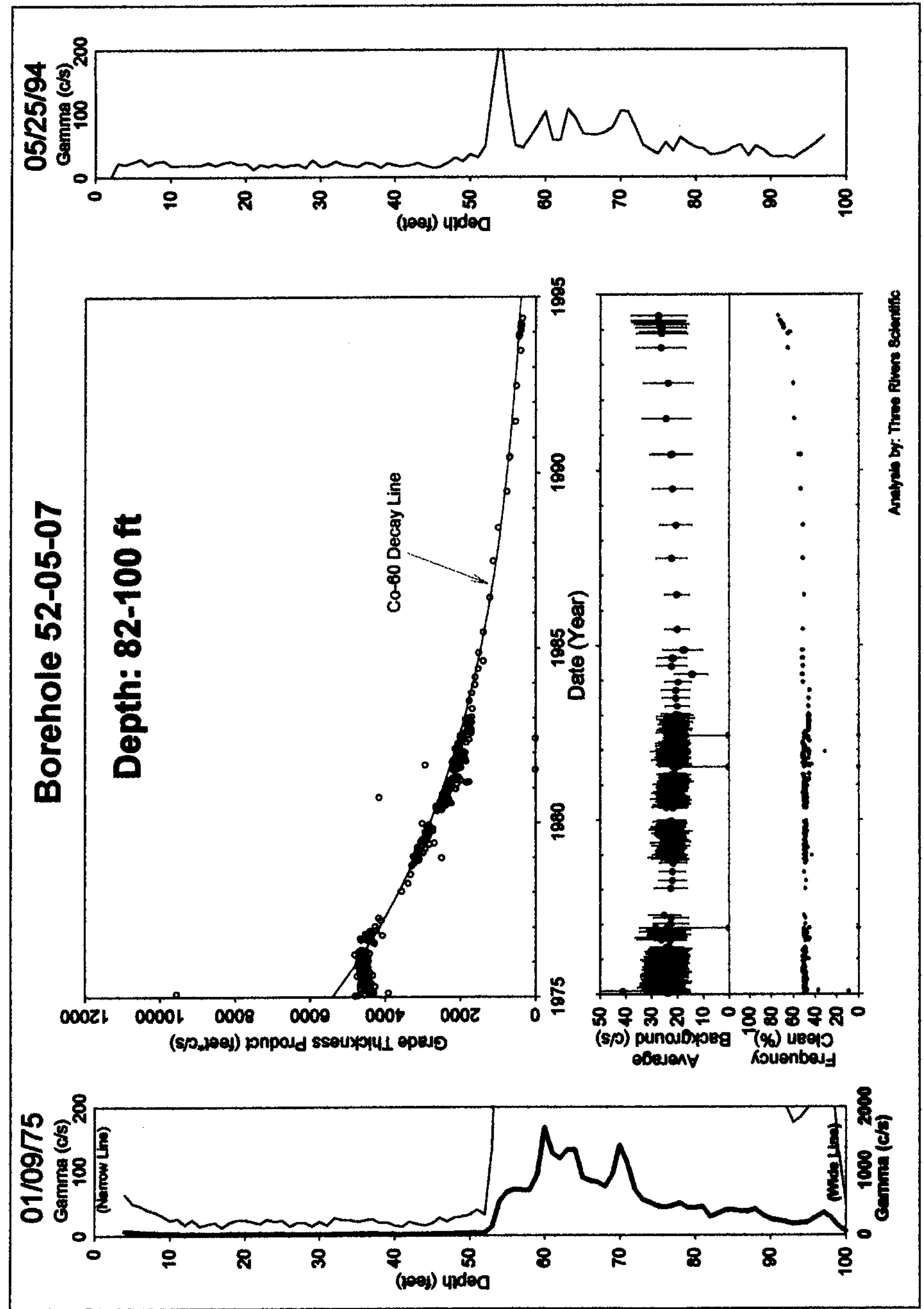


HNF -3831 - REVO
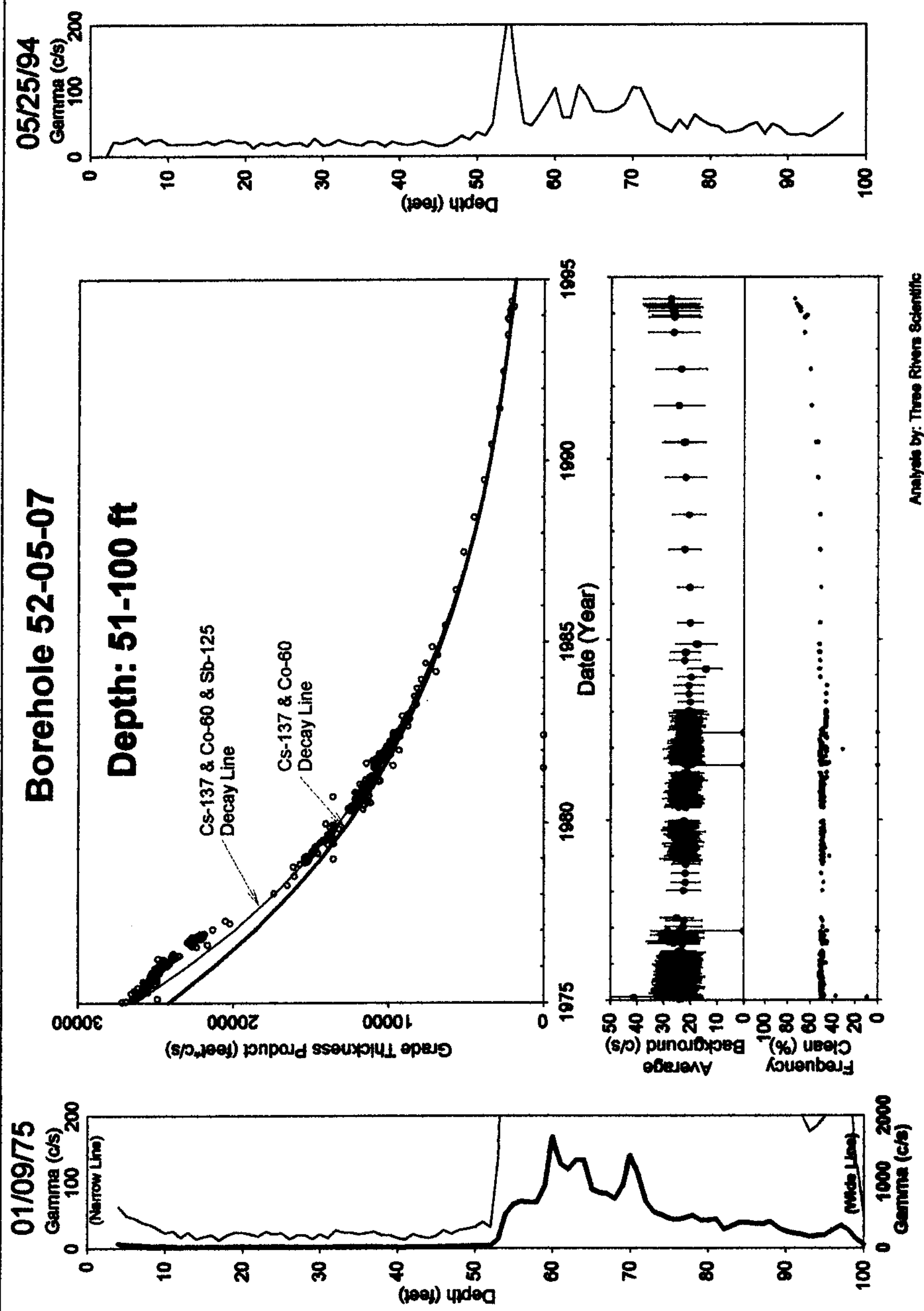


\section{HNF-3831-REVO}

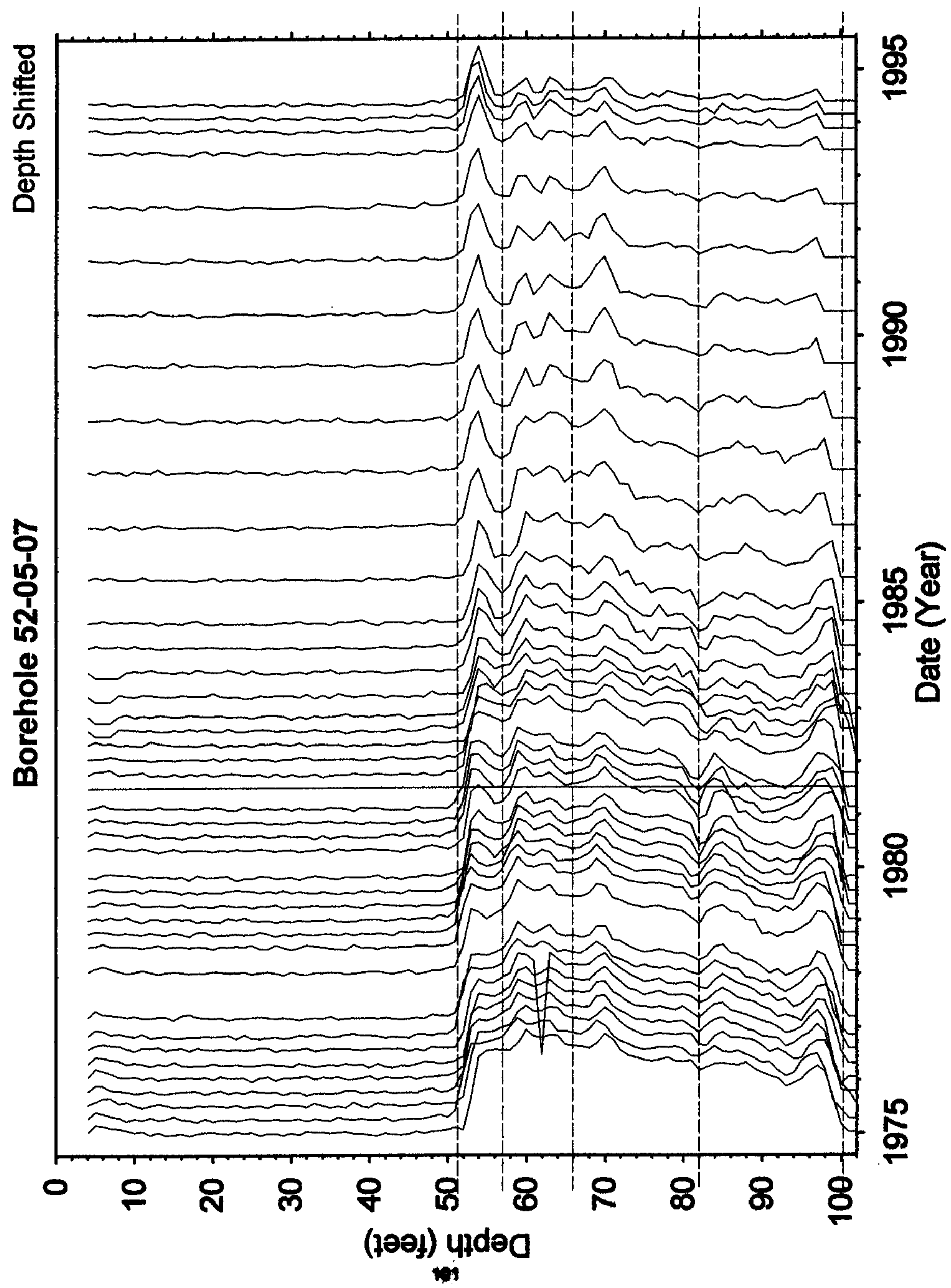




\section{HNF-3831-REVO}

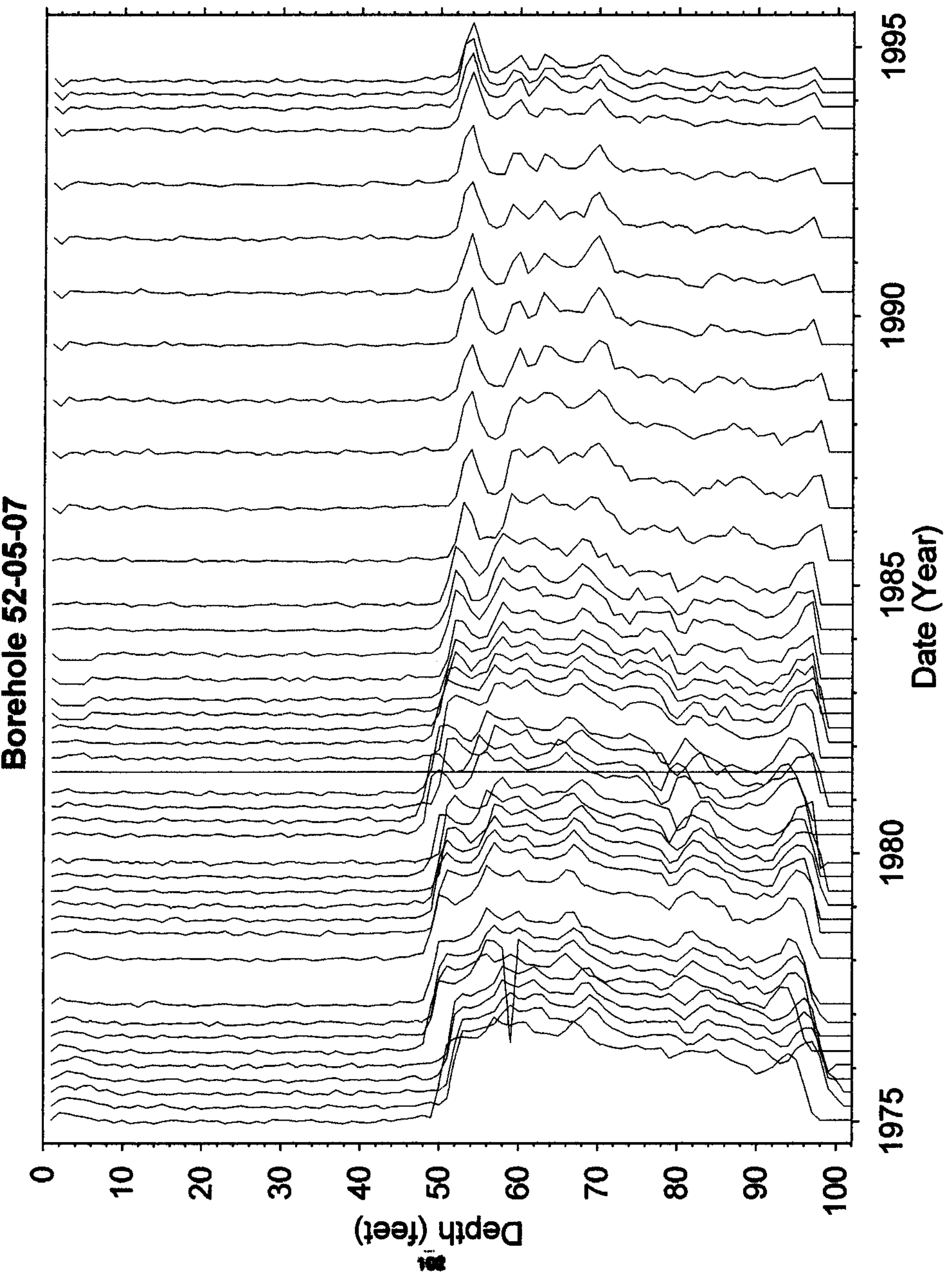




\section{Dry Well Survey Analysis - Notes}

Borehole TY(52-65-01) Total \# Surveys 268 Probe Type 04

Log Date: $75-01-041^{\text {st }} \quad$\begin{tabular}{lll} 
\# neutron surveys 3 & \# GR Surveys 265 \\
\hline & $94-05-25$ Last & Presentation Plot Dates
\end{tabular}

Isotope from Spectral Survey: $C S \& C_{0}$

Contamination Zone Depth(s): $47-57,57-65,65-83,82700$

(If different from $1^{2} \&$ Lust)

Max Survey Depth 100

GAPS.Txt

\begin{tabular}{|l|c|c|l|}
\hline Survey Date & num. Gaps & approx \#Sampl's & Comment \\
\hline $78-12-27$ & 15 & 98 & \\
\hline $81-67-08$ & 98 & 100 & \\
\hline & & & \\
\hline & & & \\
\hline
\end{tabular}

HI-ZONES.Txt

\begin{tabular}{|c|c|c|c|}
\hline Survey Date & Reason Selected & approx \#Samp's & Comment \\
\hline $75-61-30$ & $H 1-B K C$ & 100 & \\
\hline $75-02-08$ & $13 A D$ sureves & 130 & \\
\hline $26-11-25 A$ & Ban screves & 40 & \\
\hline $81-07-08$ & NORAS Zn & 100 & \\
\hline $81-12-16$ & Tool StII & 100 & \\
\hline $82-06-024$ & $T_{P_{01}} f_{f_{11}}$ & 100 & \\
\hline
\end{tabular}

BackGnd.Txt

\begin{tabular}{|c|c|c|c|c|c|}
\hline Survey Date & Reason Selected & num. Samples & Feg. Clean & Avg. Bkg & Comment \\
\hline $75-01-30$ & $A V G B K G$ & $9 q$ & $9 \%$ & 41.1 & \\
\hline $76-11-25$ & $\angle Q_{G}-T H$ & 36 & 07 & 0.0 & \\
\hline $80-07-29$ & A UG BKL & 97 & $48 \%$ & 19.4 & \\
\hline $81-07-08$ & $\%$ Clean & 98 & $0 \%$ & 0.0 & \\
\hline $82-06-02$ & $\%$ cuen & 97 & $0 \%$ & 0.0 & \\
\hline $83-12-14$ & $A \cup G$ BKG & 97 & $51 \%$ & 19,8 & \\
\hline $84-0.3-06$ & $A \vee G B K G$ & 97 & $52 \%$ & 14.0 & \\
\hline
\end{tabular}

Analysis Notes

num surveys rejected: $(0) \quad$ NONB Background $=(0 \leq 2550) \quad 25-45 \times 7$

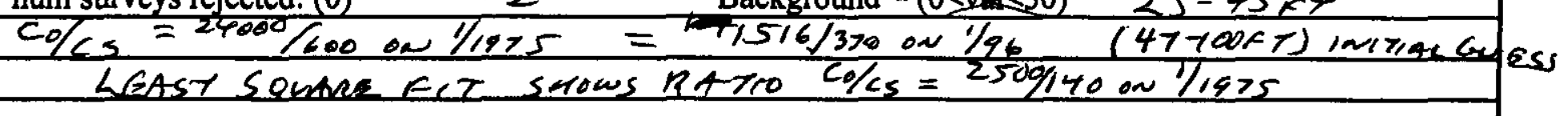

Category: (Stable, TF Activity, Undetermined, CHANGED

Analyst Name $/ 2$ andall Pues s/W ver(TFGROSS) V Z. 20. 


\section{HNF-3831 - REVO}

\section{filein := "GTP51-57.txt" Well 52-05-07}

$$
\begin{aligned}
& \text { A := READPRN(filein) } \\
& \text { yr }:=A^{<1>} \quad \text { net }:=A^{<7>} \\
& \operatorname{bkg}:=A^{<6>} \quad \max :=A^{<4>} \\
& \mathrm{N}:=\text { last }(\mathrm{yr}) \quad \mathrm{N}=91 \quad \mathrm{i}:=0 . . \mathrm{N} \quad \mathrm{k}:=0 . .300 \quad \mathrm{j}:=0 . .299
\end{aligned}
$$

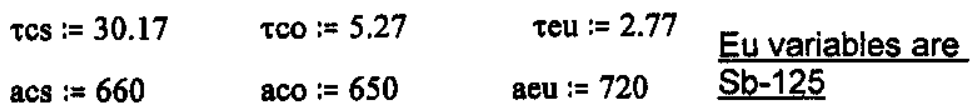

$$
\begin{aligned}
& C s_{i}:=a c s \cdot e^{-\left(y r_{i}-75\right) \cdot \frac{\ln (2)}{\tau c s}} \quad C o_{i}:=a c o \cdot e^{-\left(y r_{i}-75\right) \cdot \frac{\ln (2)}{\tau c o}} \quad E u_{i}:=a e u \cdot e^{-\left(y r_{i}-75\right) \cdot \frac{\ln (2)}{\tau e u}} \cdot 1 \quad \text { tot } i:=C s_{i}+E u_{i}+C o_{i}
\end{aligned}
$$

gross $_{\mathrm{i}}:=$ net $_{\mathrm{i}}$

This data edited for spurious points

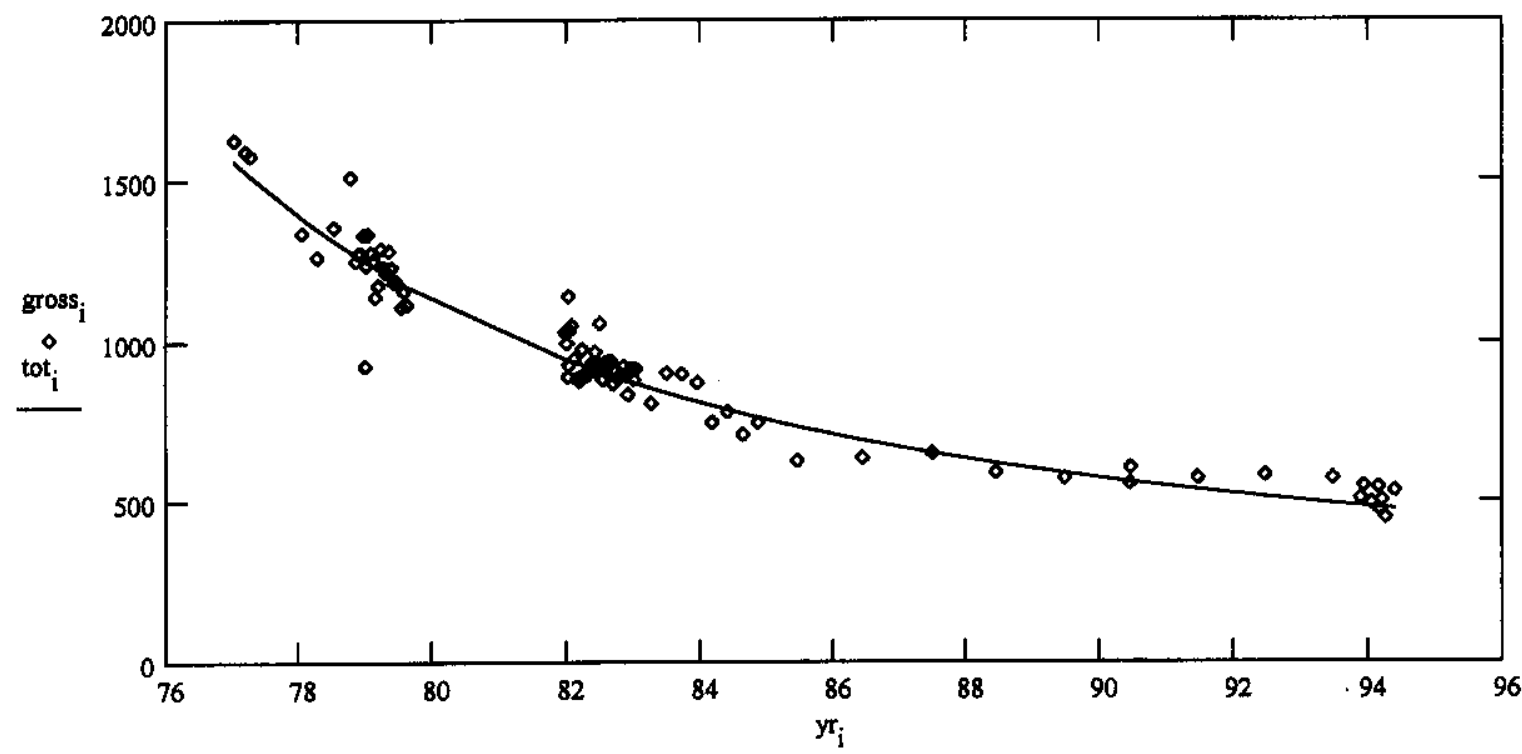

$\operatorname{ssq}(\mathrm{al} 1, \mathrm{a} 3, \mathrm{a} 2):=\sum_{i}\left[\text { gross }_{\mathrm{i}}-\left[\mathrm{a} 1 \cdot \mathrm{e}^{-\left(\mathrm{yr}_{\mathrm{i}}-75\right) \cdot \frac{\ln (2)}{\tau c s}}+\left[\mathrm{a} 3 \cdot \mathrm{e}^{-\left(\mathrm{yr}_{\mathrm{i}}-75\right) \cdot \frac{\ln (2)}{\tau e u}}+\mathrm{a} 2 \cdot \mathrm{e}^{-\left(\mathrm{yr}_{\mathrm{i}}-75\right) \cdot \frac{\ln (2)}{\tau c 0}}\right]\right]\right]^{2}$

Given

ssq(acs, aeu, aco $)=0 \quad 1=1 \quad 2=2$

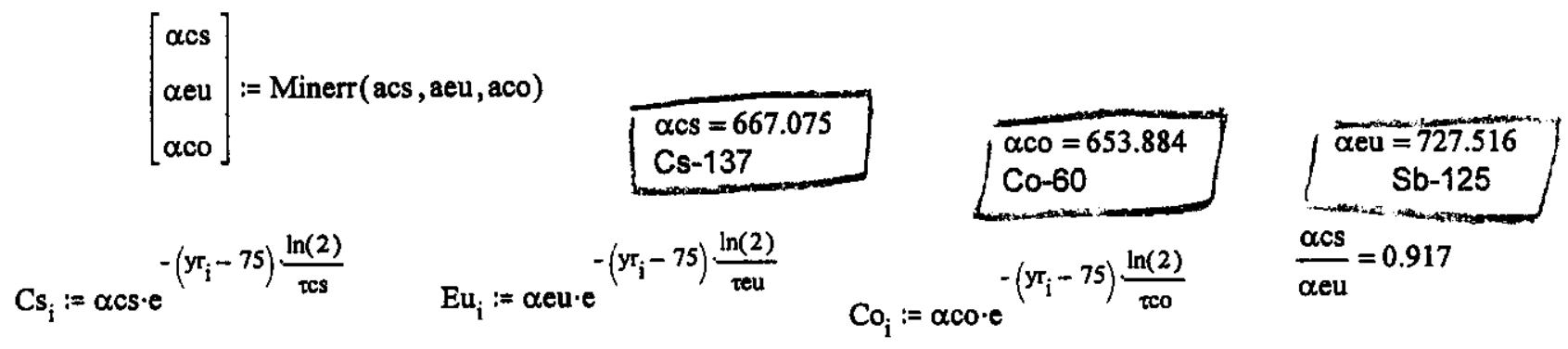

$$
\begin{aligned}
& \operatorname{tot}_{\mathrm{i}}:=\mathrm{Cs}_{\mathrm{i}}+\mathrm{Eu}_{\mathrm{i}}+\mathrm{Co}_{\mathrm{i}} \\
& \text { out } \left.^{<0\rangle_{i}}=\text { yr } \quad \text { out }^{<1>}:=\text { tot } \quad \text { WRITEPRN("twop44-52.txt" }\right):=\text { out } \\
& \frac{E u_{N}}{C s_{N}}=0.013
\end{aligned}
$$




\section{HNF- 3831 - REVO}

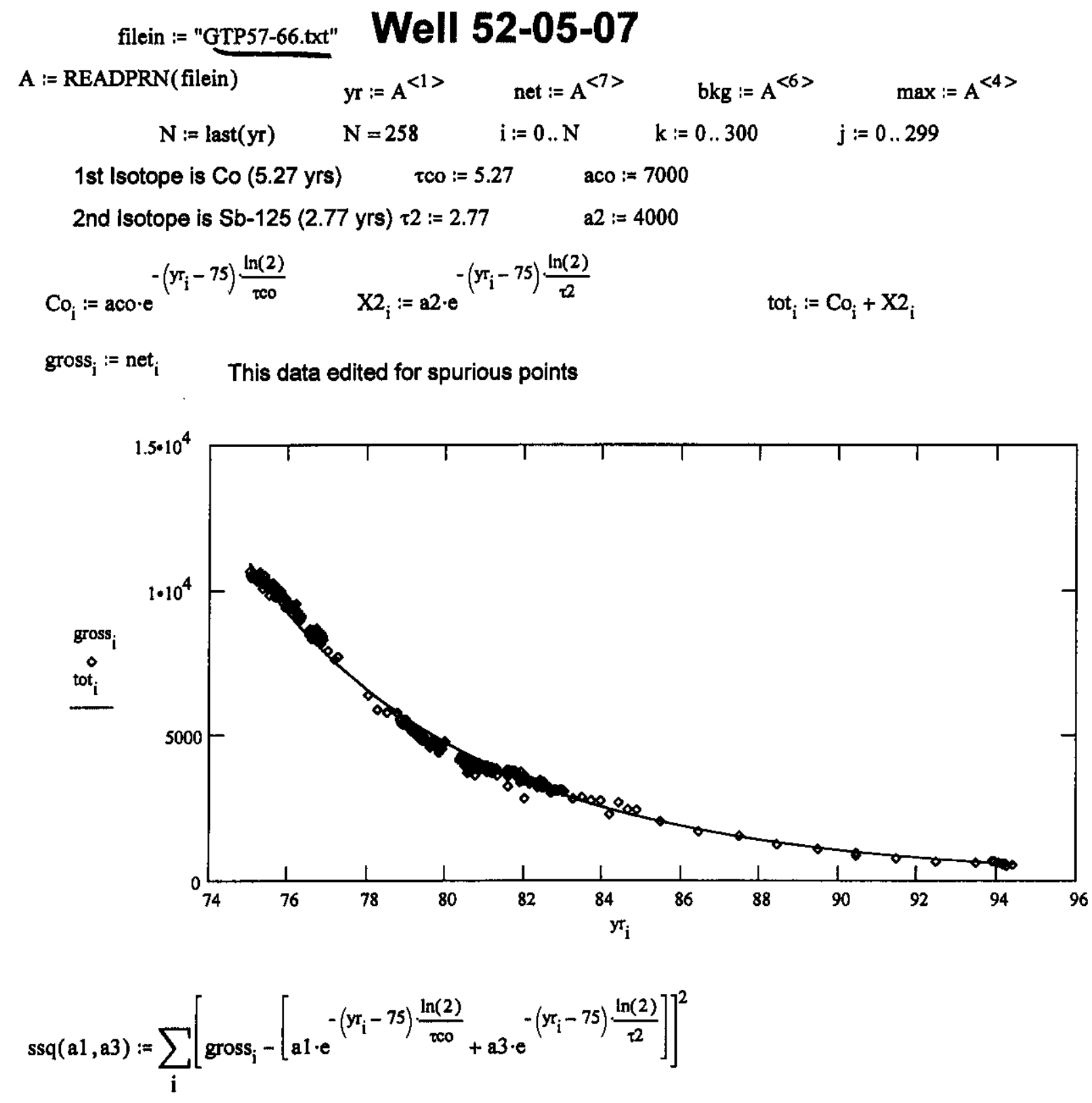

Given

$$
\begin{aligned}
& \operatorname{ssq}(\operatorname{aco}, a 2)=0 \quad 1=1 \\
& {\left[\begin{array}{l}
\alpha c o \\
\alpha 2
\end{array}\right]:=\operatorname{Minerr}(a c o, a 2)}
\end{aligned}
$$

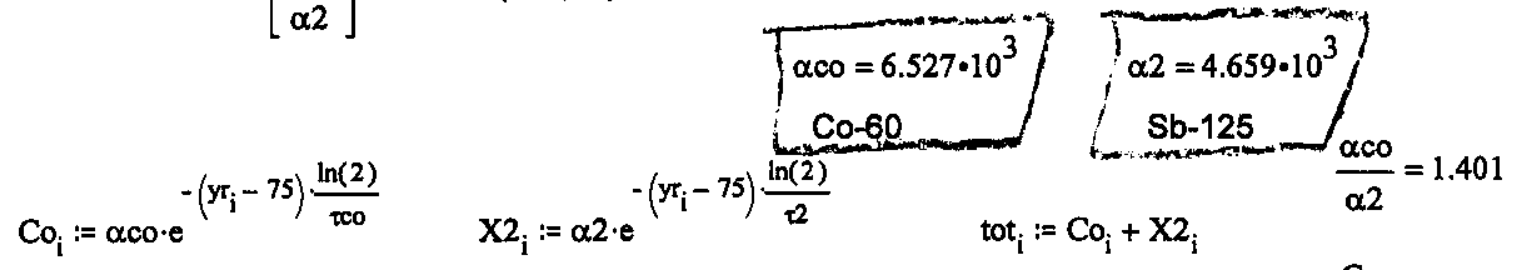

$$
\begin{aligned}
& \text { out }^{\langle 0\rangle}:=\text { yr } \quad \text { out }^{\langle 1\rangle}:=\text { tot } \quad \text { WRITEPRN("twop.txt") }:=\text { out } \quad \text { Ratio } \mathrm{Co} / \mathrm{Sb} \frac{\mathrm{C \textrm {C } _ { \mathrm { N } }}}{\mathrm{X} 2_{\mathrm{N}}}=14.011
\end{aligned}
$$




$$
\begin{aligned}
& \text { HNF-3831-REVO } \\
& \text { filein := "GTP66-82.txt" Well 52-05-07 }
\end{aligned}
$$

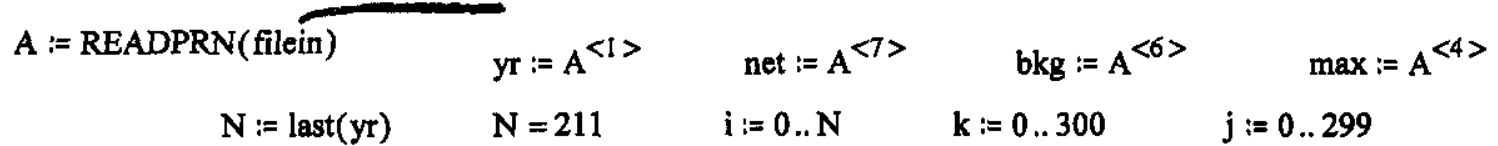

$$
\begin{aligned}
& \text { 1st Isotope is Co (5.27 yrs) } \quad \tau \text { co }:=5.27 \quad \text { aco }:=8600 \\
& \text { 2nd Isotope is Sb-125 (2.77 yrs) } \tau 2:=2.77 \quad \text { a2 }:=3100 \\
& \mathrm{Co}_{\mathrm{i}}:=\mathrm{aco} \cdot \mathrm{e}^{-\left(\mathrm{yr}_{\mathrm{i}}-75\right) \cdot \frac{\ln (2)}{\pi c 0}} \quad \mathrm{X} 2_{\mathrm{i}}:=\mathrm{a2} \cdot \mathrm{e}^{-\left(\mathrm{yr}_{\mathrm{i}}-75\right) \cdot \frac{\ln (2)}{22}} \quad \operatorname{tot}_{\mathrm{i}}:=\mathrm{Co}_{\mathrm{i}}+\mathrm{X} 2_{\mathrm{i}}
\end{aligned}
$$

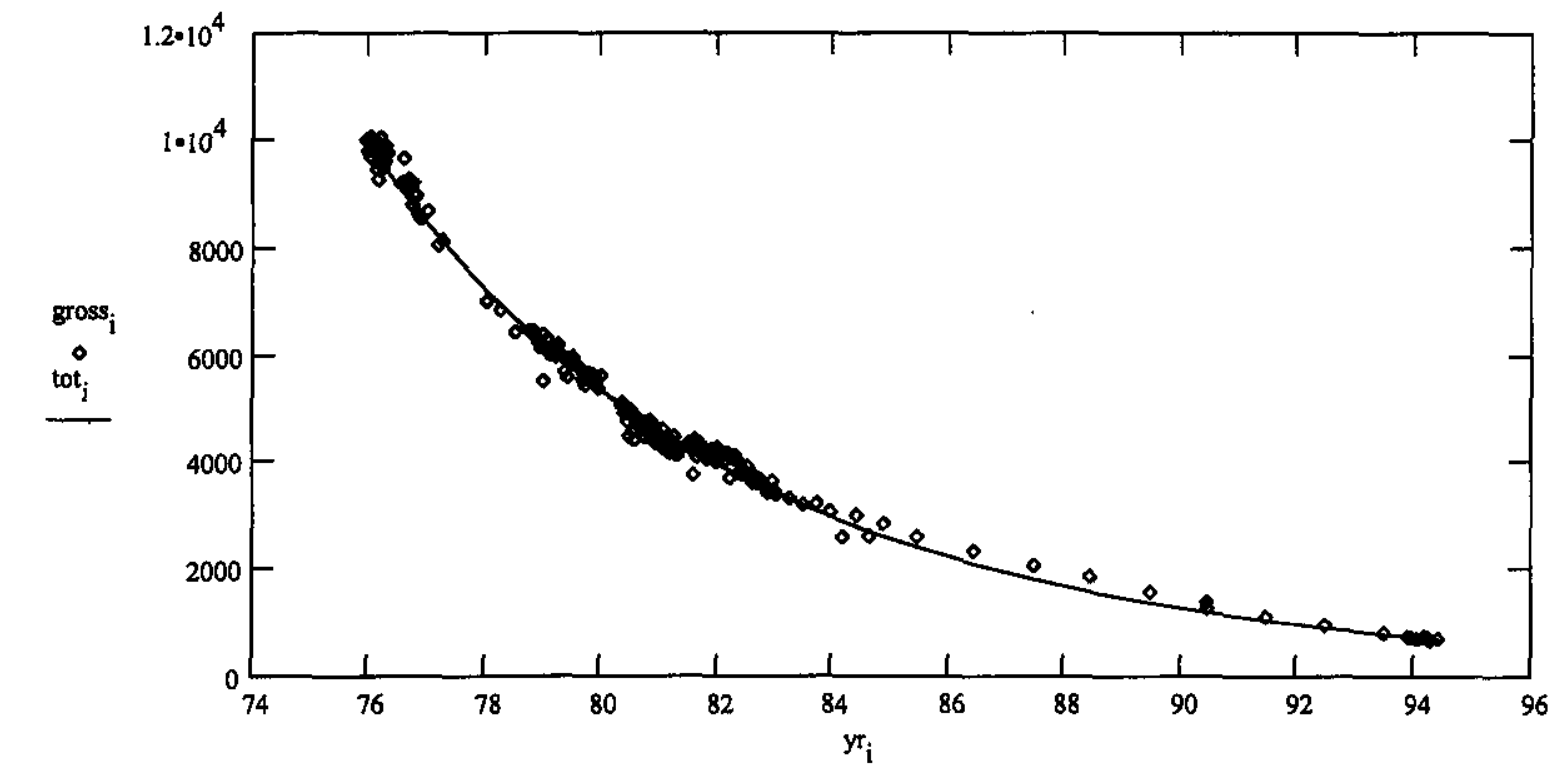

$\operatorname{ssq}(\mathrm{a} 1, \mathrm{a} 3):=\sum_{\mathrm{i}}\left[\mathrm{gross}_{\mathrm{i}}-\left[\mathrm{a} 1 \cdot \mathrm{e}^{-\left(y \mathrm{r}_{\mathrm{i}}-75\right) \frac{\ln (2)}{\tau c 0}}+\mathrm{a} 3 \cdot \mathrm{e}^{-\left(y \mathrm{x}_{\mathrm{i}}-75\right) \cdot \frac{\ln (2)}{\tau 2}}\right]\right]^{2}$

Given

$$
\begin{aligned}
& \operatorname{ssq}(\text { aco, a2 })=0 \quad 1=1 \\
& {\left[\begin{array}{l}
\alpha c 0 \\
\alpha 2
\end{array}\right]:=\operatorname{Minerr}(\mathrm{aco}, \mathrm{a} 2)} \\
& C 0_{i}:=\alpha c 0 \cdot e^{-\left(y r_{i}-75\right) \cdot \frac{\ln (2)}{x c o}} \quad X 2_{i}:=\alpha 2 \cdot e^{-\left(y_{i}-75\right) \frac{\ln (2)}{2}} \quad \text { tot }_{i}:=C_{i}+X 2_{i} \quad \frac{S b-125}{\alpha 2}=2.71 \\
& \text { out }^{<0>}:=\text { yr } \quad \text { out }^{<1>}:=\text { tot } \quad \text { WRITEPRN("twop.txt" ) }:=\text { out } \quad \text { Ratio } \mathrm{Co} / \mathrm{Sb} \frac{\mathrm{Co}{ }_{\mathrm{N}}}{\mathrm{X}_{\mathrm{N}}}=27.105
\end{aligned}
$$




\section{HNF-3831-REVO}

filein := "GTP51-100.txt" Well 52-05-07

$$
\begin{aligned}
& A:=\text { READPRN(filein) } \\
& \text { yr }:=A^{<1>} \quad \text { net }:=A^{<7>} \\
& \mathrm{N}:=\operatorname{last}(\mathrm{yr}) \\
& \mathrm{N}=176 \\
& \mathrm{i}:=0 \text {.. N } \\
& \text { bkg }:=A^{\langle 6\rangle} \quad \max :=A^{\langle 4\rangle} \\
& \tau c s:=30.17 \quad \tau c 0:=5.27 \\
& \tau \text { тeu }:=2.77 \\
& \text { acs }:=125 \\
& \text { aco }:=\mathbf{2 4 0 0 0} \\
& \text { aeu }:=\mathbf{2 2 0 0}
\end{aligned}
$$

gross $_{i}:=$ net $_{i}$

This data edited for spurious points

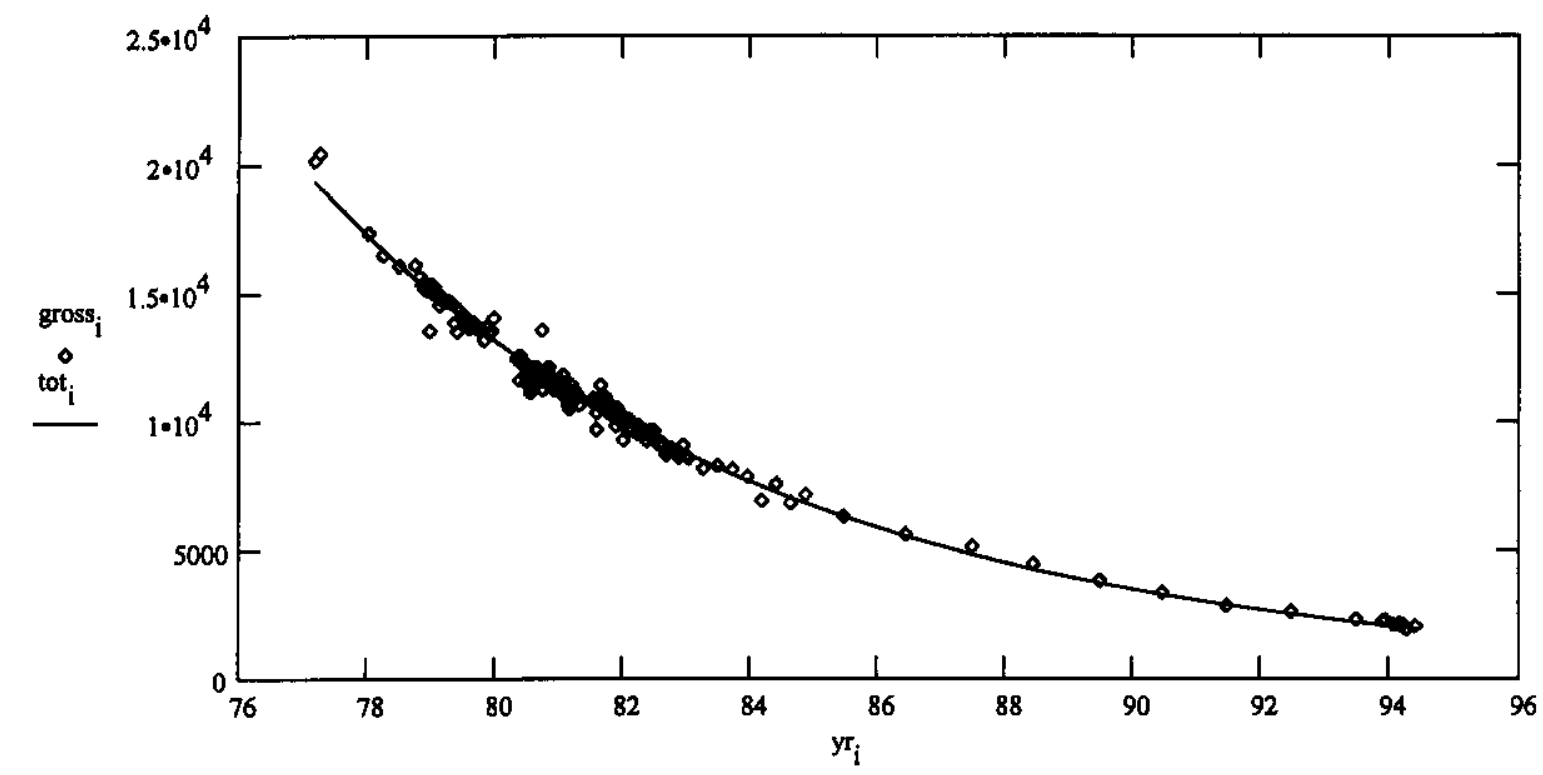

ssq(a1 , a3 , a2) $:=\sum_{i}\left[g_{\text {ross }}-\left[a 1 \cdot e^{-\left(y x_{i}-75\right) \cdot \frac{\ln (2)}{\tau c s}}+\left[23 \cdot e^{-\left(y r_{i}-75\right) \frac{\ln (2)}{\tau e u}}+a 2 \cdot e^{-\left(y x_{i}-75\right) \cdot \frac{\ln (2)}{\tau c o}}\right]\right]\right]^{2}$

Given

$$
\begin{aligned}
& \operatorname{ssq}(\text { acs }, a e u, a c o)=0 \quad 1=1 \quad 2=2 \\
& {\left[\begin{array}{l}
\alpha c s \\
\alpha e u \\
\alpha c o
\end{array}\right]:=\operatorname{Minerr}(\mathrm{acs}, \mathrm{aeu}, \mathrm{aco}) \quad\left[\begin{array}{l}
\alpha c s=121.722 \\
\mathrm{Cs}-137
\end{array}\right.} \\
& C s_{i}:=\alpha c s \cdot e^{-\left(y_{i}-75\right) \cdot \frac{\ln (2)}{\tau c s}} \quad E u_{i}:=\alpha e u \cdot e^{-\left(y_{i}-75\right) \cdot \frac{\ln (2)}{\tau e u}} \quad C o_{i}:=\alpha c 0 \cdot e^{-\left(y_{i}-75\right) \frac{\ln (2)}{\tau c 0}} \\
& \text { tot }_{\mathrm{i}}:=\mathrm{Cs}_{\mathrm{i}}+\mathrm{Eu}_{\mathrm{i}}+\mathrm{Co}_{\mathrm{i}}
\end{aligned}
$$

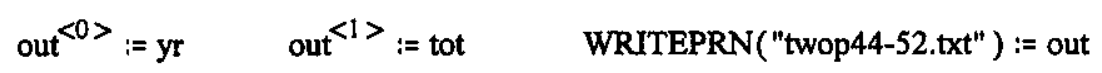
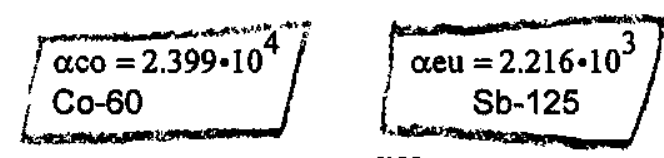

$$
\begin{aligned}
& \frac{\alpha c s}{\alpha e u}=0.055
\end{aligned}
$$




\section{Contamination (Cs-137) from 0-10 feet is Tank Farm Activity}

Grade thickness product for the low-level Cs-137 zone (HPGe identified) from 0-10 feet is erratic from 1975 through 1984, and is categorized as Tank Farm activity. A Cs-137 decay line is plotted with the grade thickness product computed from the monitoring surveys.

Gross Gamma Survey Information

\begin{tabular}{|r|l|}
\hline Probe Type : & 04: Sodium Iodide Scintillator \\
\hline Other Probe Types : & None \\
\hline Borehole Depth : & $64 \mathrm{ft}$ \\
\hline Survey Depth : & $64 \mathrm{ft}$ \\
\hline First Survey Date : & $4 / 14 / 1975$ \\
\hline Last Survey Date : & $6 / 14 / 1984$ \\
\hline Number Surveys : & 37 \\
\hline
\end{tabular}

Analysis Notes

\begin{tabular}{|r|l|}
\hline Number Surveys Rejected : & 0 \\
\hline Lower Threshold for Bad Survey Values : & $<=0$ \\
\hline Method Used to Compute Background : & $20-40 \mathrm{ft}$ \\
\hline & \\
\hline Depth(s) where Contamination Identified in & $0-10 \mathrm{ft}$ is TF Activity \\
Gross Gamma Surveys : & \\
\hline Analyst Name : & R.K. Price \\
\hline Company Name : & Three Rivers Scientific \\
\hline
\end{tabular}


HNF-3831-REVO

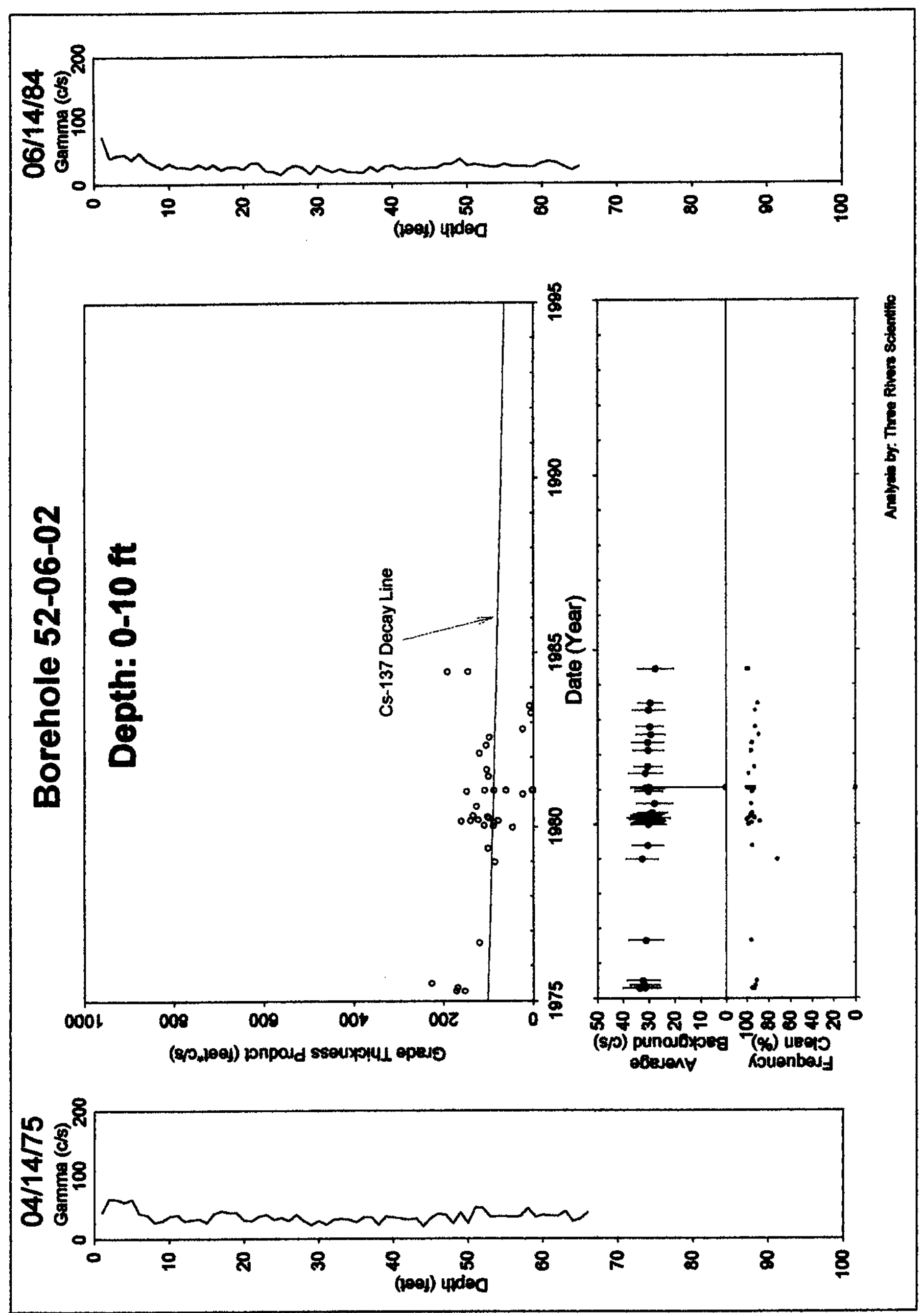


HNF-3831-REVO

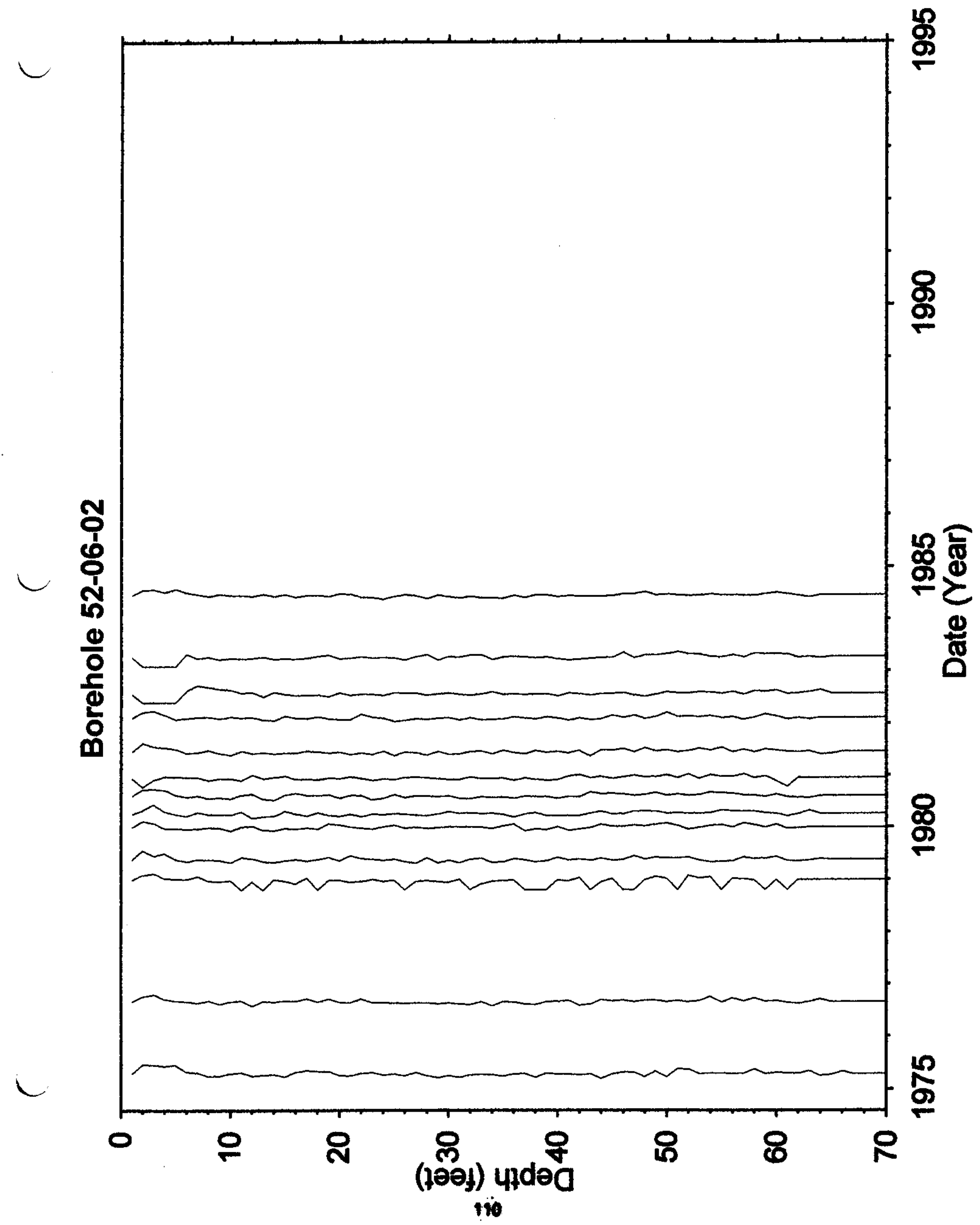




\section{Borehole 52-06-04}

\section{Contamination (Cs-137\&Sb-125) from 47-56 feet is Stable}

Grade thickness product of the radioactive zone (47-56 feet) is decreasing within the gross gamma sensitivity to each isotope and relative intensity at a rate consistent with a least squares fit of Cs-137 (HPGe identified) and Sb-125 (hypothesis) from 1975 to 1995. The least squares fit results in a gross gamma contribution ratio for Cs-137 to Sb-125 of 14 on May 1994. It should be noted that no Sb-125 was identified by the HPGe baseline surveys in any borehole within the TY Tank Farm and the level in this borehole is believed to be below the minimum detectable threshold at the time of the baseline survey.

Gross Gamma Survey Information

\begin{tabular}{|r|l|}
\hline Probe Type: & 04: Sodium Iodide Scintillator \\
\hline Other Probe Types: & 03: Neutron (1 surveys) \\
\hline Borehole Depth: & $100 \mathrm{ft}$ \\
\hline Survey Depth: & $100 \mathrm{ft}$ \\
\hline First Survey Date : & $1 / 09 / 1975$ \\
\hline Last Survey Date : & $5 / 25 / 1994$ \\
\hline Number Surveys : & 234 \\
\hline
\end{tabular}

Analysis Notes

\begin{tabular}{|r|l|}
\hline Number Surveys Rejected : & 0 \\
\hline Lower Threshold for Bad Survey Values : & $<=0$ \\
\hline Method Used to Compute Background : & $56-80 \mathrm{ft}$ \\
\hline & \\
\hline Depth(s) where Contamination Identified in \\
Gross Gamma Surveys : & $47-56 \mathrm{ft}$ is Unstable Early \\
\hline & \\
\hline Analyst Name: & R.K. Price \\
\hline Company Name : & Three Rivers Scientific \\
\hline
\end{tabular}




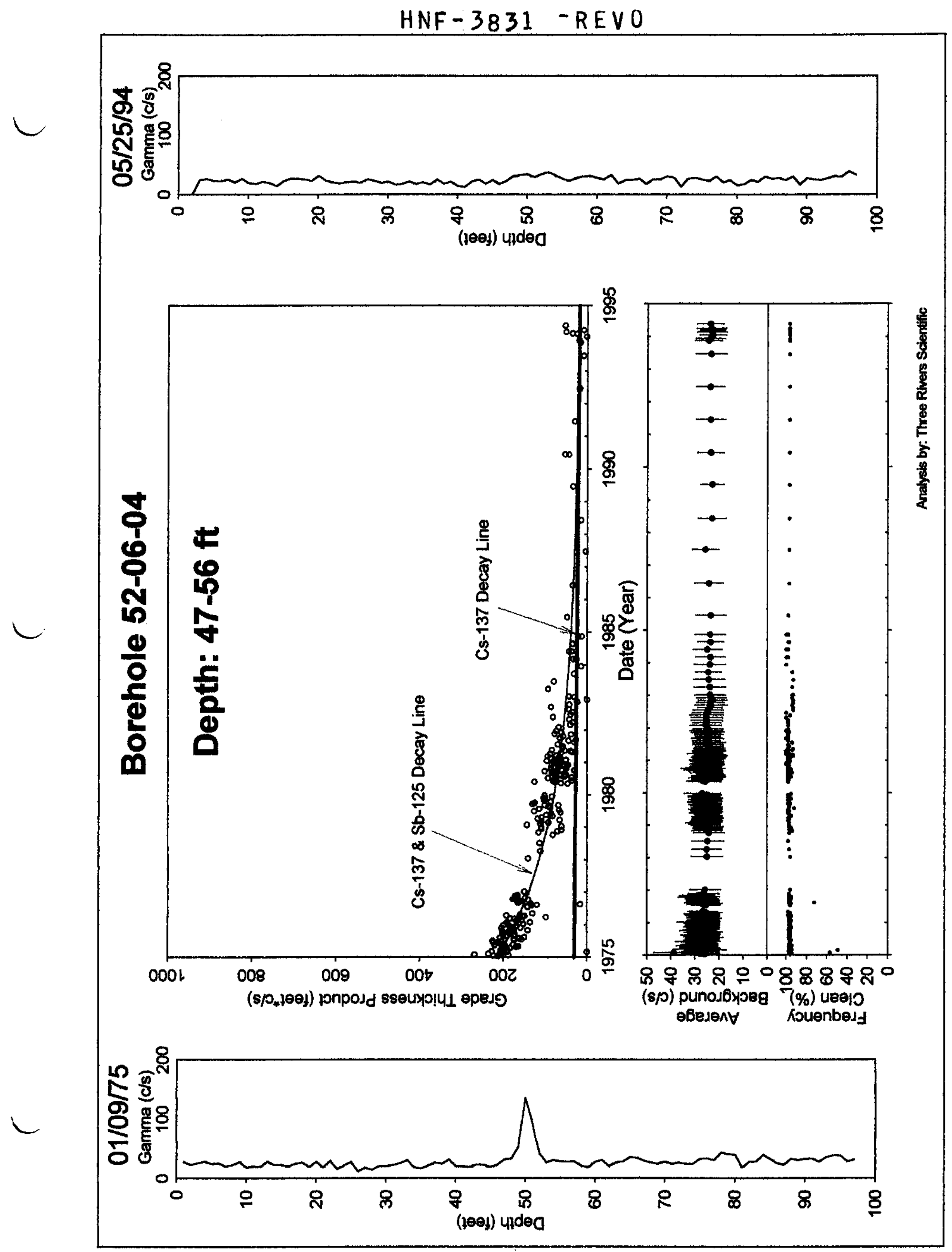


HNF- $3831-R E V O$

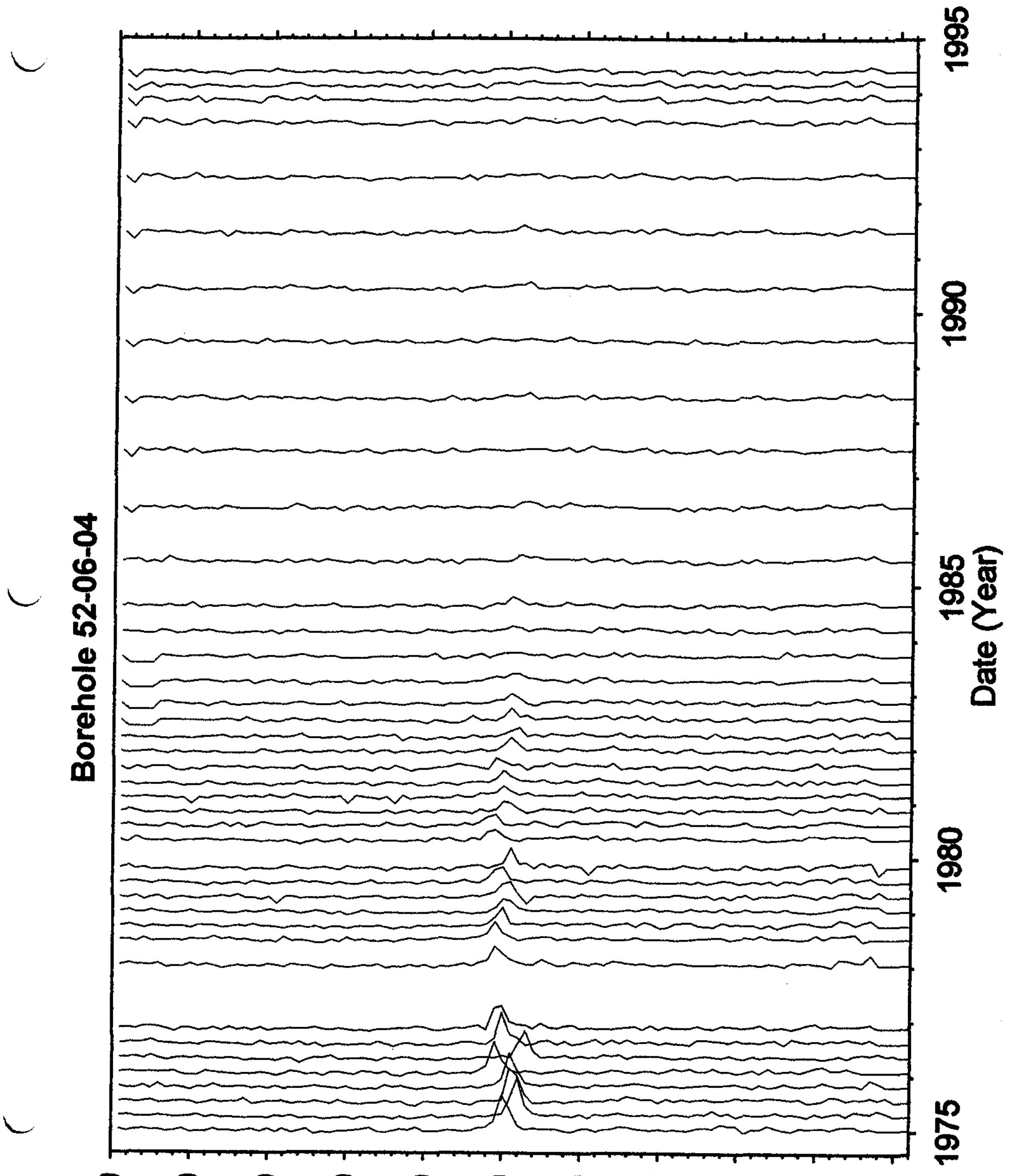

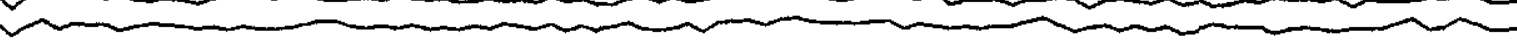
(2) 


\section{Borehole 52-06-05}

\section{Contamination (Cs-137\&Co-60) from 50-90 feet is Unstable Early}

Grade thickness product for the radioactive zone, 50-90 feet, has one time interval (19781980) in which the radioactivity was increasing, while the other time intervals (1975-1978 and 1980-1988) have decreasing rates that are not consistent with the decay rate of the HPGe identified isotopes (Cs-137 \& Co-60). Since 1988 the grade thickness product has been decreasing at a rate consistent with the computed decay rate. The gross gamma contribution ratio for Co-60 to Cs-137 was 2.3 in 1995. The category of this radioactive zone is Unstable Early. The stack plot shows the influx of radioactive contaminants in the depth interval of 50-56 feet from 1976 to 1981 . The depth shifted stack plot shows the influx clearer than the non-depth shifted stack plot. The grade thickness product for three sub zones $(50-56,56-67$, and 67-90 ft) are presented to show how the radiation levels were changing during the early years and the date at which stability was reached in each interval. A decay line for Co-60 is present on each of the sub zone plots as a reference.

Gross Gamma Survey Information

\begin{tabular}{|r|l|}
\hline Probe Type : & $04:$ Sodium Iodide Scintillator \\
\hline Other Probe Types : & $03:$ Neutron (1 survey) \\
\hline Borehole Depth : & $150 \mathrm{ft}$ \\
\hline Survey Depth : & $150 \mathrm{ft}$ \\
\hline First Survey Date : & $1 / 09 / 1975$ \\
\hline Last Survey Date: & $5 / 25 / 1994$ \\
\hline Number Surveys : & 176 \\
\hline
\end{tabular}

Analysis Notes

\begin{tabular}{|r|l|}
\hline Number Surveys Rejected : & 0 \\
\hline Lower Threshold for Bad Survey Values : & $<=0$ \\
\hline Method Used to Compute Background : & $25-45 \mathrm{ft}$ \\
\hline & \\
\hline Depth(s) where Contamination Identified in \\
Gross Gamma Surveys : & $50-90 \mathrm{ft}$ is Unstable Early \\
\hline & \\
\hline Analyst Name: & R.K. Price \\
\hline Company Name: & Three Rivers Scientific \\
\hline
\end{tabular}


HNF -3831 - REVO
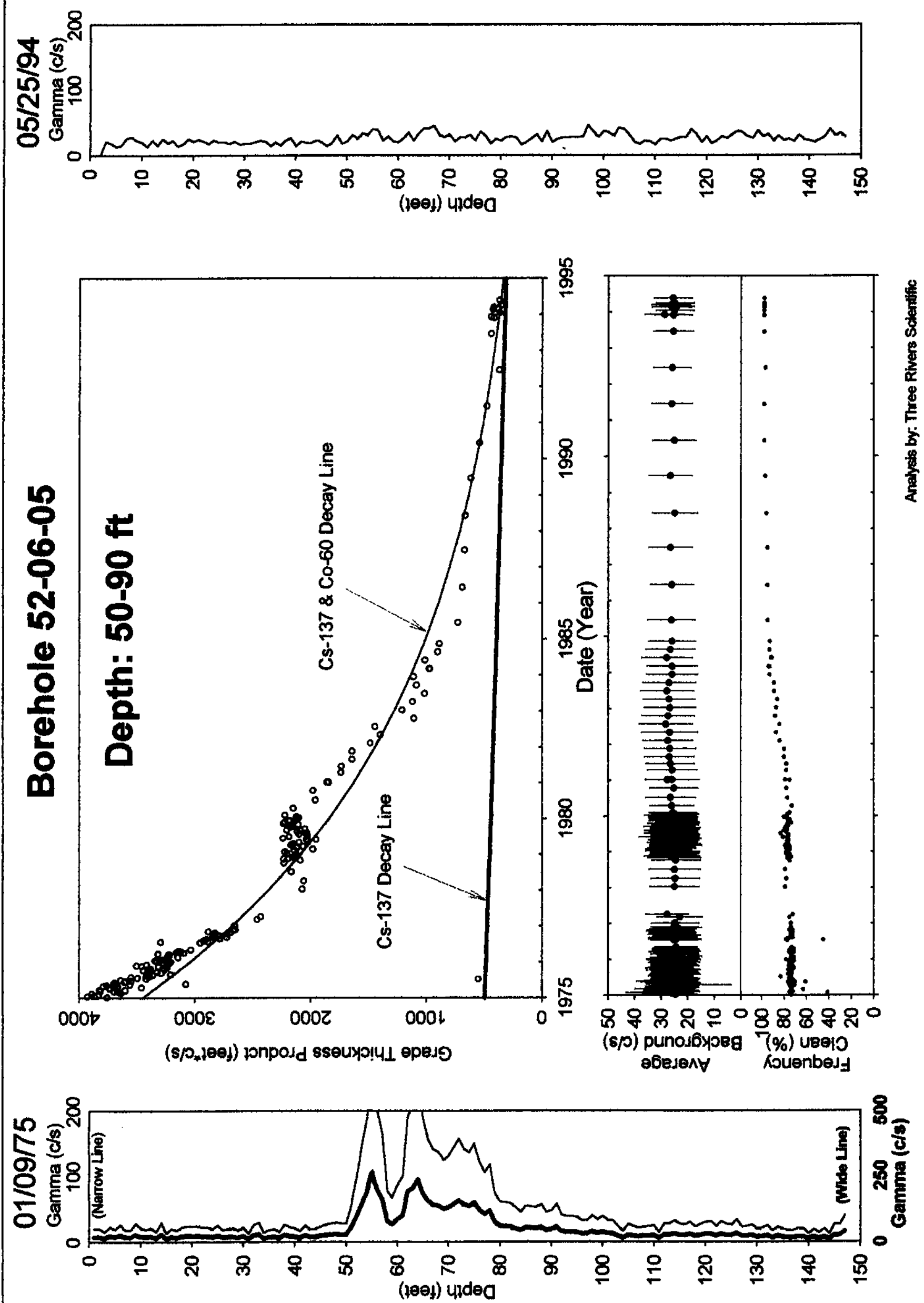
HNF-3831-REVO
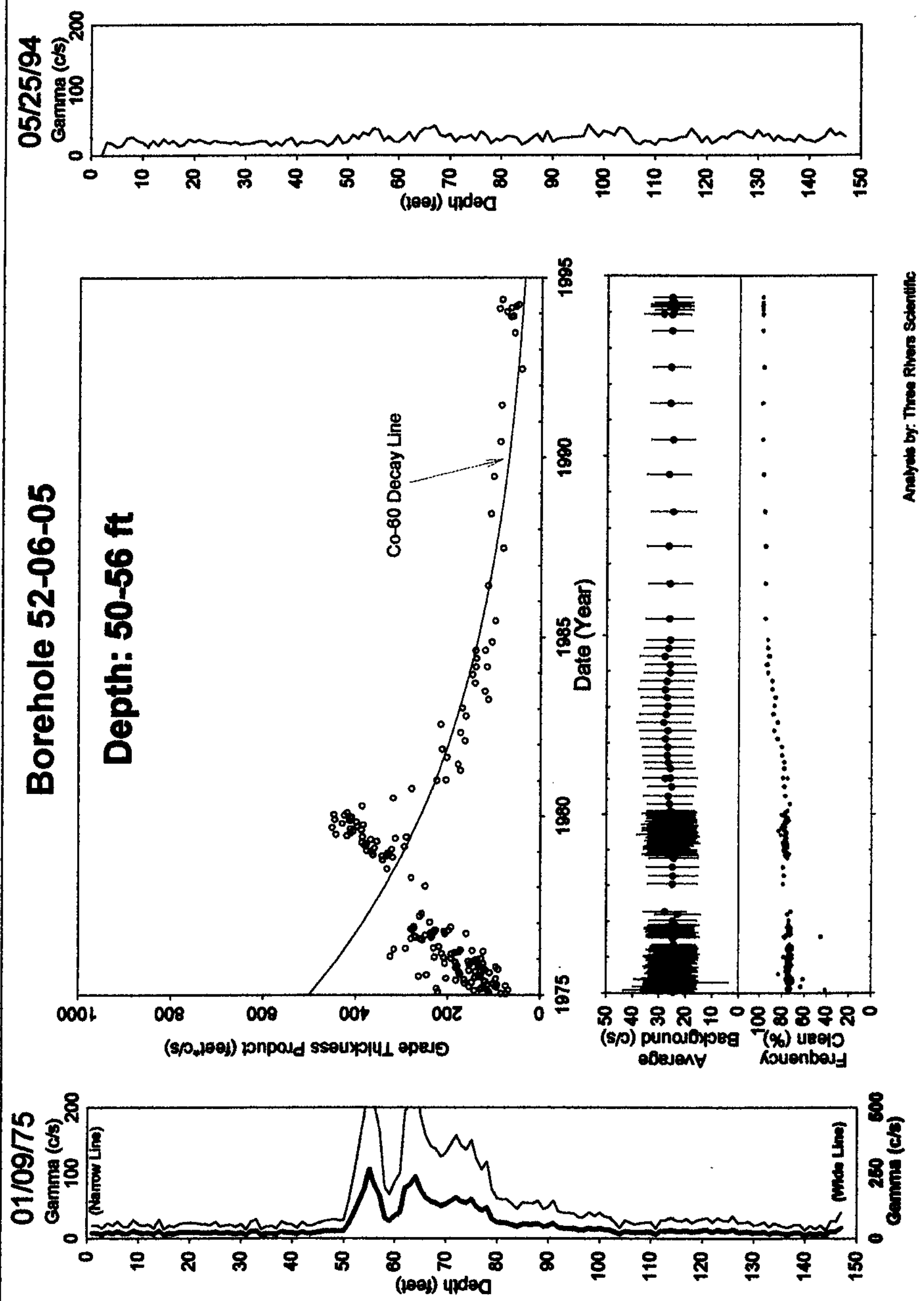
HNF-3831-REVO
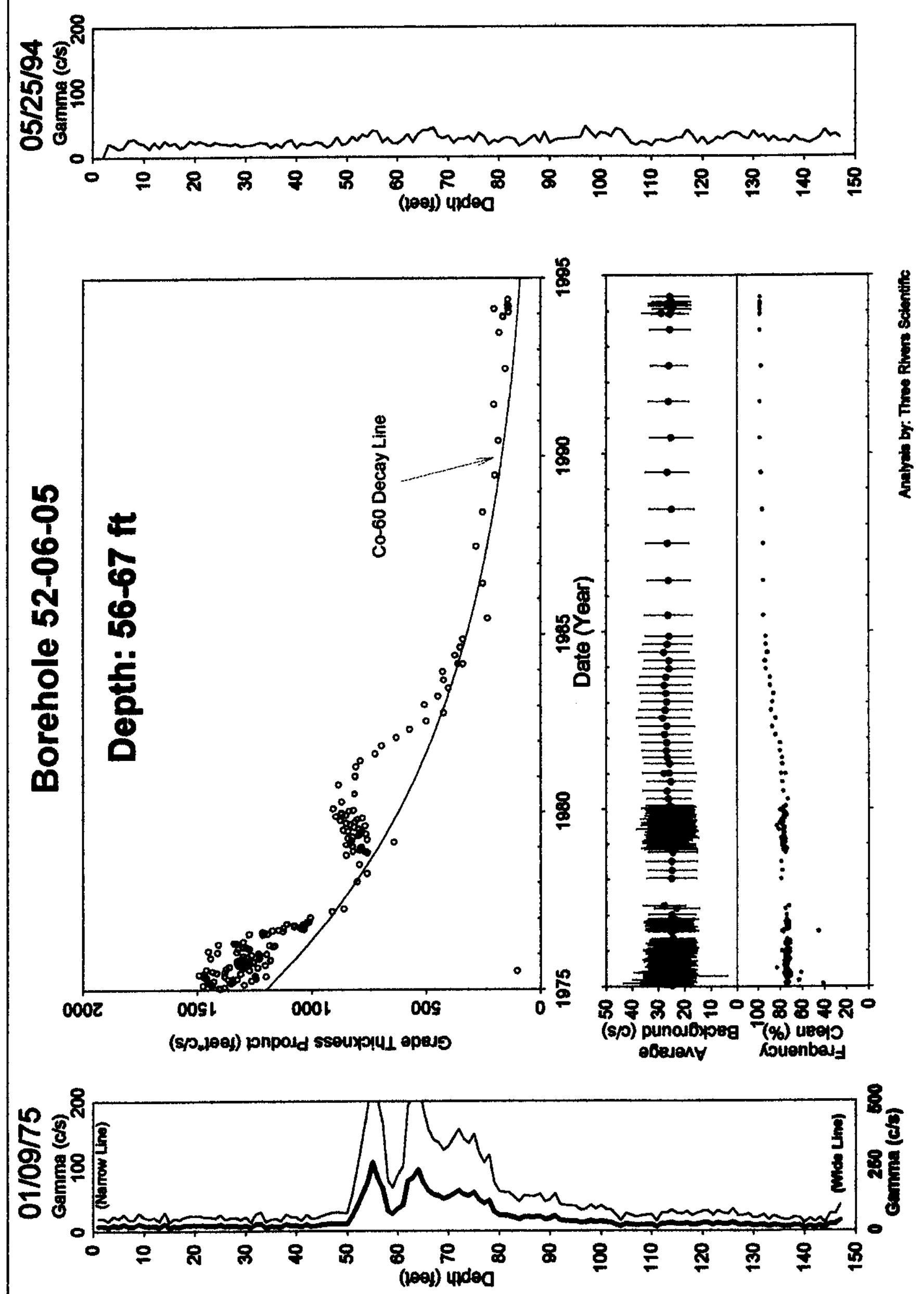
HNF-3831-REV0
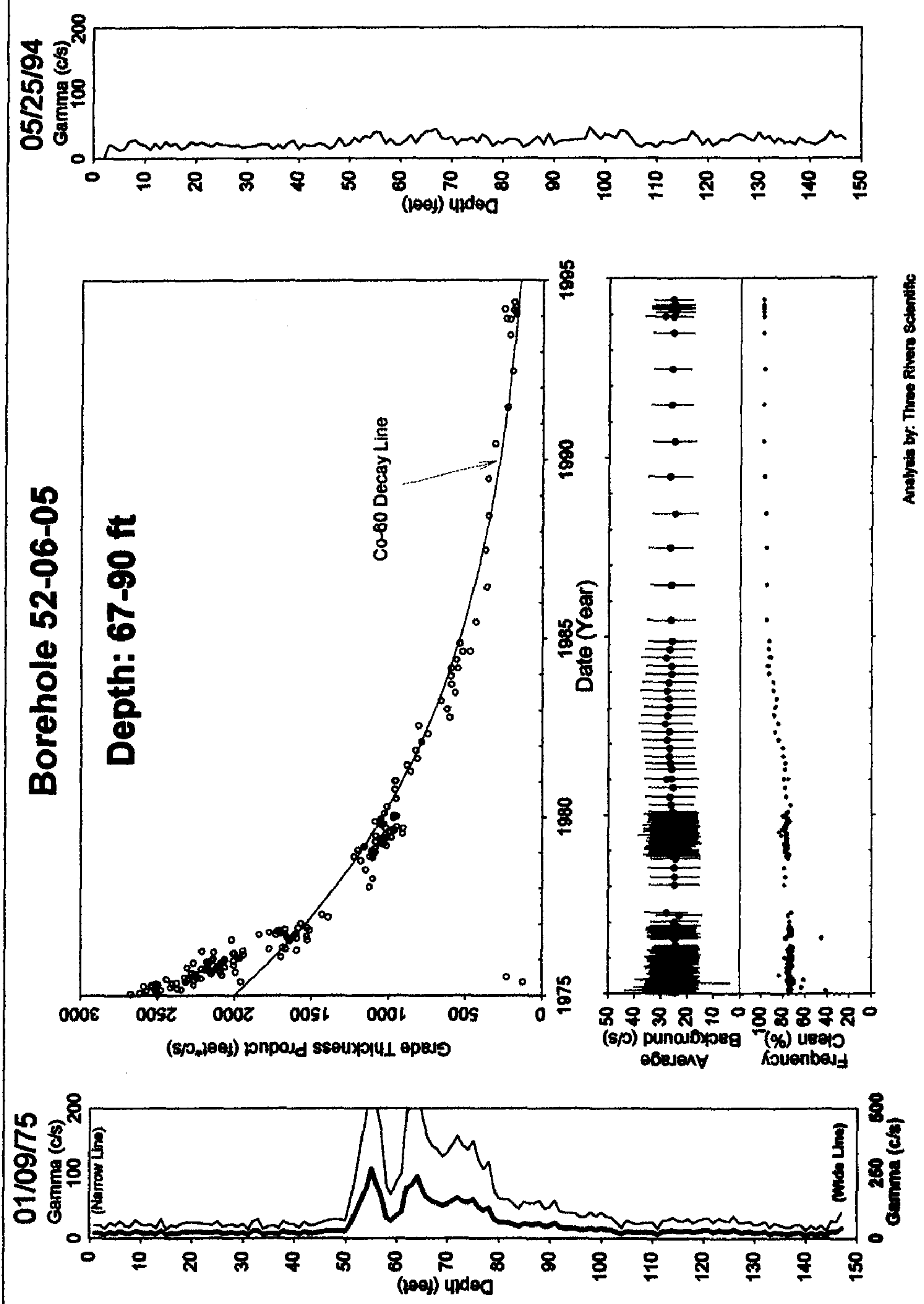
HNF-3831-REVO

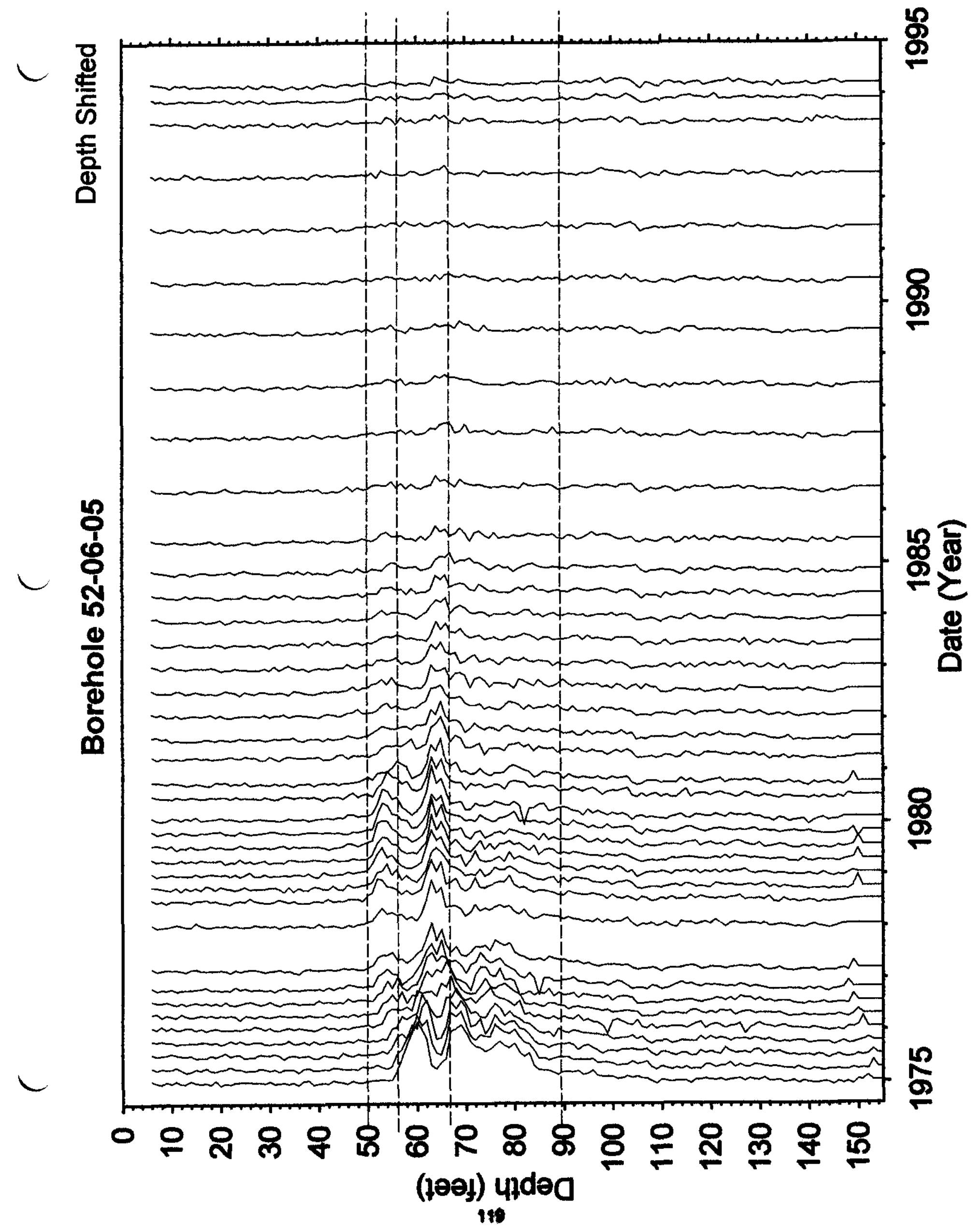


HNF-3831 - REVO

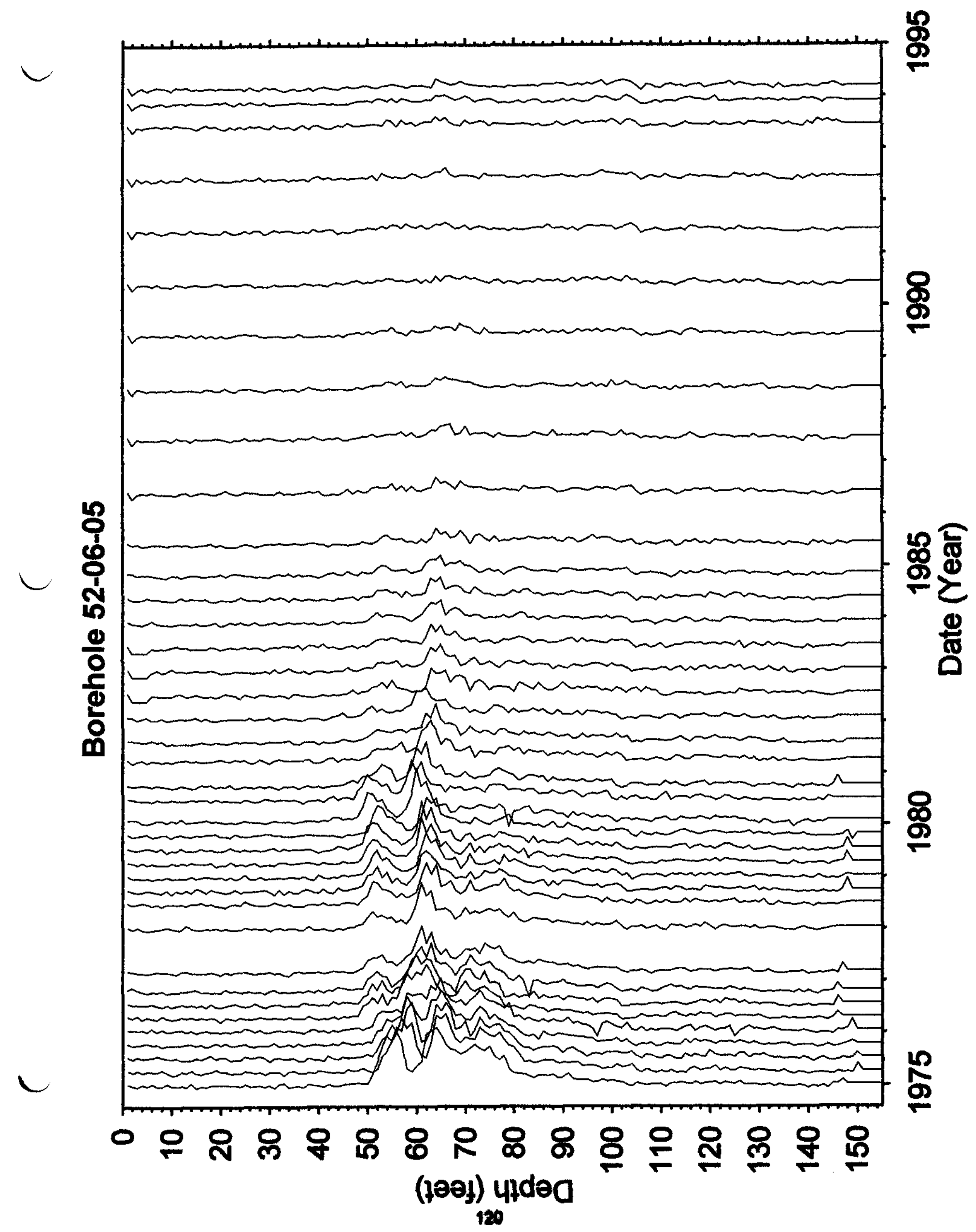


HNF-3831-REVO

\section{Borehole 52-06-06}

\section{Contamination (Cs-137) from 5-25 feet is Stable Contamination (Sb-125) from 72-82 feet is Stable}

Grade thickness product for the low level radioactive zone (5-25 feet) is decreasing within observed systematic limitations at a rate consistent with the decay of Cs-137 (HPGe identified) from 1975 to 1995.

The grade thickness product for the radioactive zone (72-82 feet) is decreasing from 1975 to 1984 at nearly a linear rate, then from 1984 to 1995 no gross gamma activity above background is identified. The HPGe survey identified only natural radionuclides in this interval. The grade thickness product decrease is within observed systematic limitations at a rate consistent with the decay of Sb-125 (hypothesis) between 1975 and 1984 and is categorized as stable. It is noted that the grade thickness product in the 1994 time frame is greater than zero and above the Sb-125 decay line. This is a low level radiation interval and there is not enough data to indicate a potentially unstable condition at this time.

Gross Gamma Survey Information

Probe Type: $04:$ Sodium Iodide Scintillator

Other Probe Types: $103:$ Neutron (1 survey)

Borehole Depth: $100 \mathrm{ft}$

Survey Depth: $100 \mathrm{ft}$

First Survey Date : $1 / 09 / 1975$

Last Survey Date : $5 / 31 / 1994$

Number Surveys : 179

Analysis Notes

\begin{tabular}{|r|l|}
\hline Number Surveys Rejected : & 0 \\
\hline Lower Threshold for Bad Survey Values : & $<=0$ \\
\hline Method Used to Compute Background : & $30-50 \mathrm{ft}$ \\
\hline & \\
\hline Depth(s) where Contamination Identified in & $5-25 \mathrm{ft}$ is Stable \\
Gross Gamma Surveys : & $72-82 \mathrm{ft}$ is Stable \\
\hline & \\
\hline Analyst Name : & R.K. Price \\
\hline Company Name : & Three Rivers Scientific \\
\hline
\end{tabular}


HNF-3831-REVO

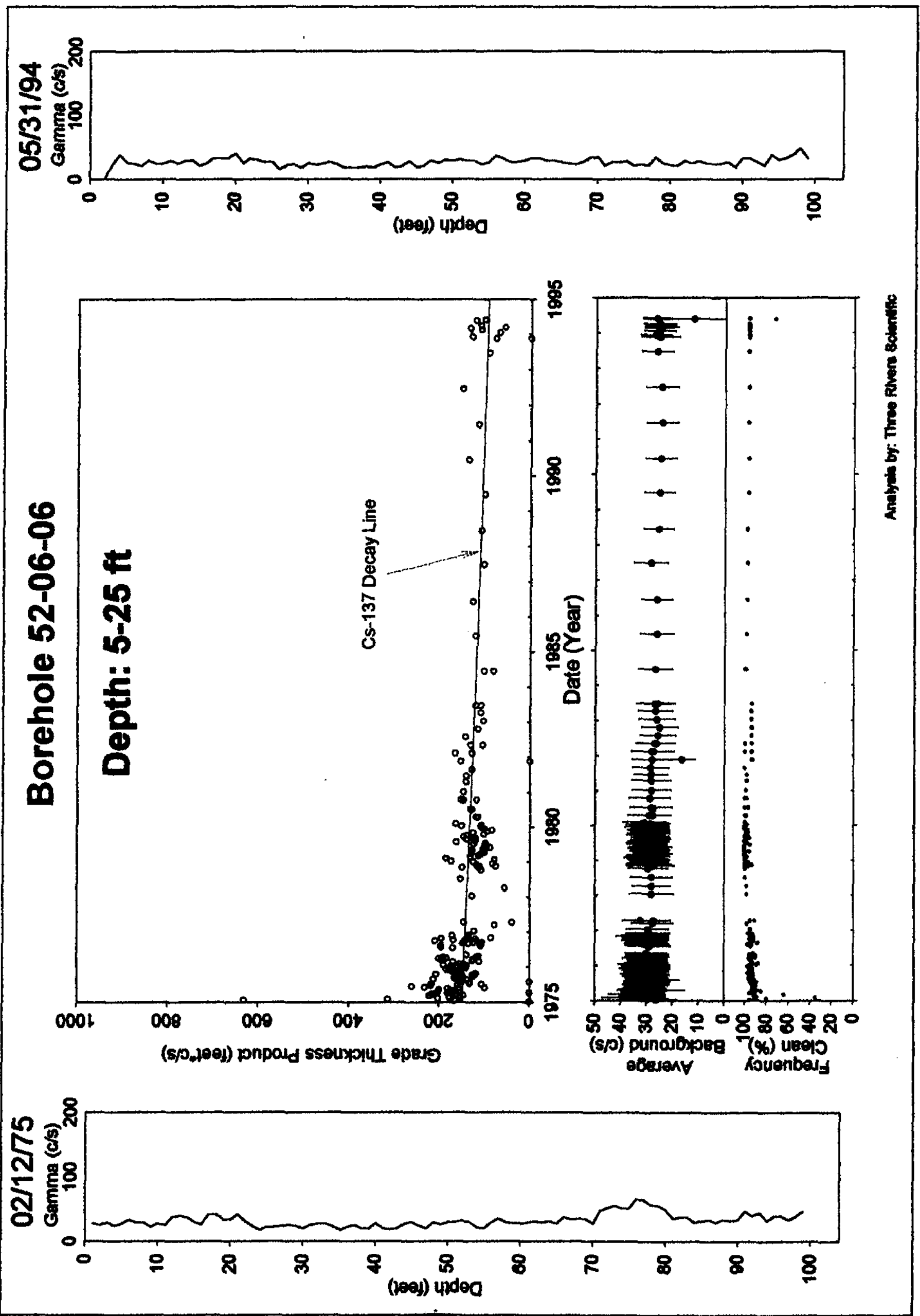


HNF-3831-REVO

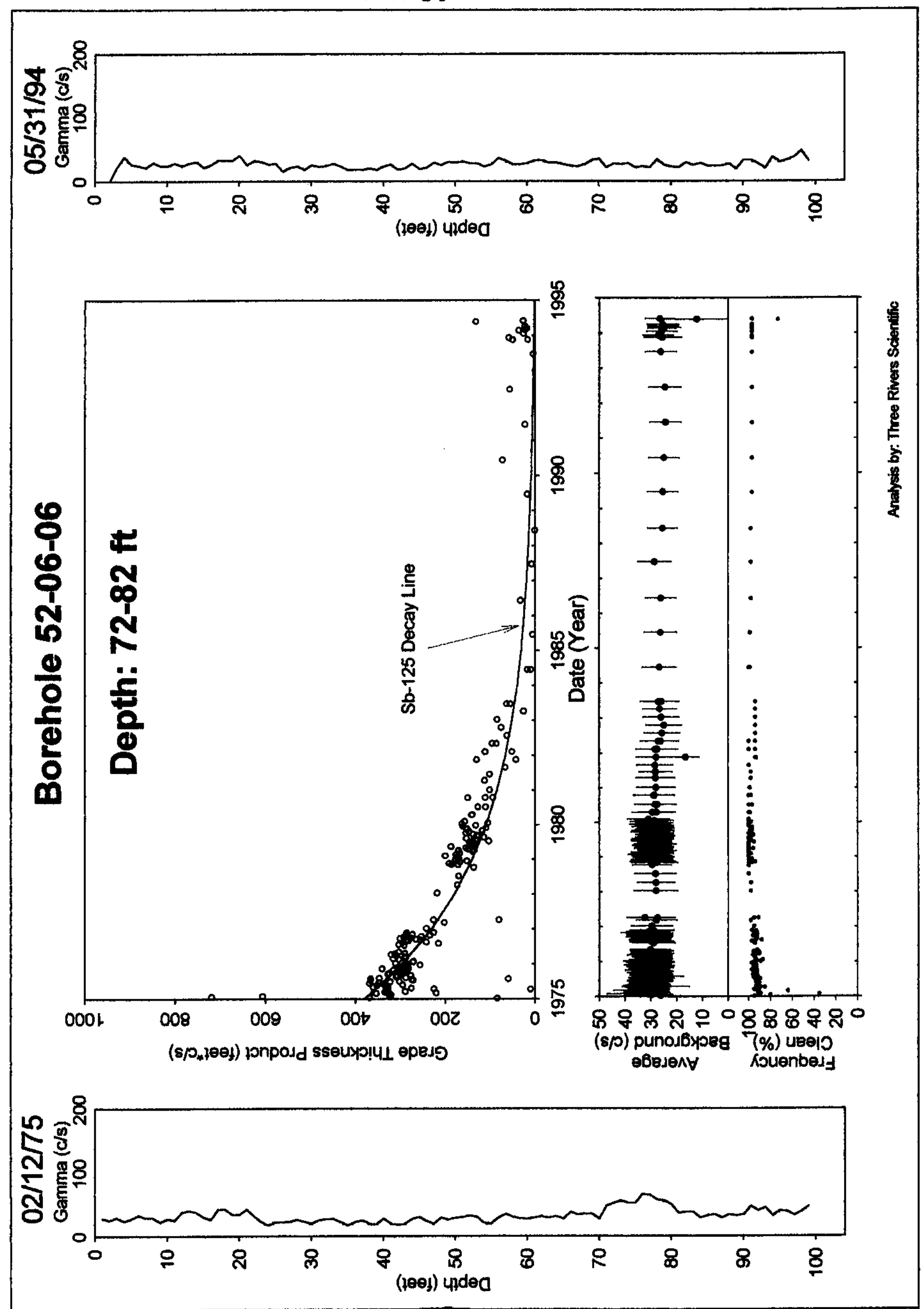




\section{HNF-3831-REVO}

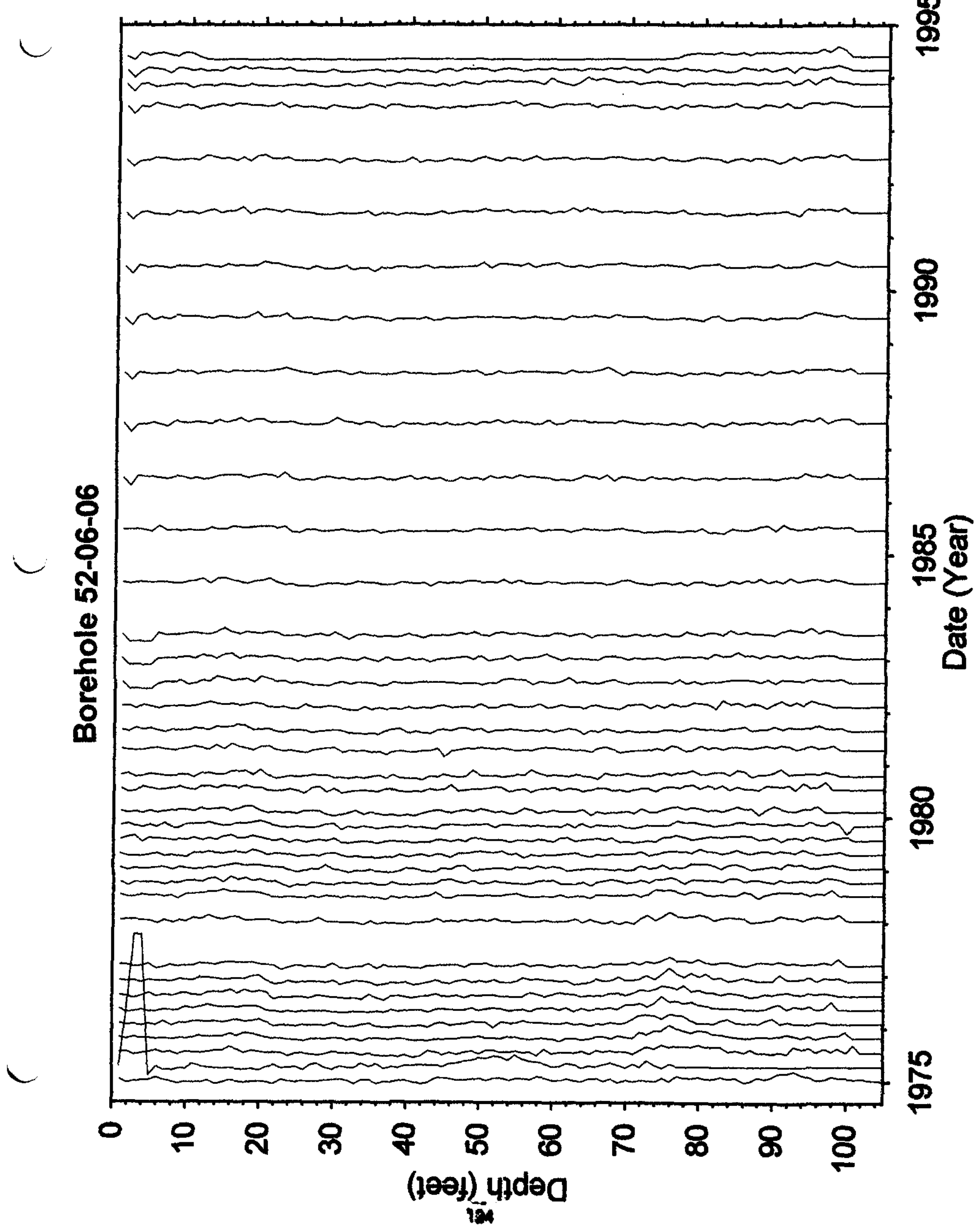




\section{Contamination (Co-60) from 86-100 feet is Stable}

The grade thickness product for the radioactive zone (86-100 feet) has a step decrease during mid year 1976 that corresponds with the decrease in Average Background. This coincides to well remediation activities (i.e. Webster completion) in March 1976 from 0 to $187 \mathrm{ft}$. The grade thickness product from 1976 to 1995 is decreasing within observed systematic limitations at a rate consistent with the decay of Cobalt-60 (hypothesis). The HPGe survey show slightly higher total gamma activity in this interval with only natural radionuclides and with increased concentrations of natural thorium. If Co- 60 were present in the zone it would be near the minimum detection level for the HPGe baseline survey.

The maximum depth of the gross gamma (dry well) logs was 150 feet while the maximum depth for the HPGe survey was 210 feet. The HPGe survey identified a radioactive zone (200-214 feet, Co-60 \& Cs-137) at a depth greater than the maximum monitor depth of the dry well logs.

Gross Gamma Survey Information

\begin{tabular}{|r|l|}
\hline Probe Type: & $04:$ Sodium Iodide Scintillator \\
\hline Other Probe Types : & $03:$ Neutron (3 surveys) \\
\hline Borehole Depth: & $210 \mathrm{ft}$ \\
\hline Survey Depth: & $150 \mathrm{ft}$ \\
\hline First Survey Date : & $1 / 15 / 1975$ \\
\hline Last Survey Date : & $5 / 25 / 1994$ \\
\hline Number Surveys : & 172 \\
\hline
\end{tabular}

Analysis Notes

\begin{tabular}{|r|l|}
\hline Number Surveys Rejected : & 0 \\
\hline Lower Threshold for Bad Survey Values: & $<=0$ \\
\hline Method Used to Compute Background : & $50-70 \mathrm{ft}$ \\
\hline & \\
\hline Depth(s) where Contamination Identified in \\
Gross Gamma Surveys : & $86-100 \mathrm{ft}$ is Stable \\
\hline & \\
\hline Analyst Name: & R.K. Price \\
\hline Company Name : & Three Rivers Scientific \\
\hline
\end{tabular}


HNF-3831-REVO

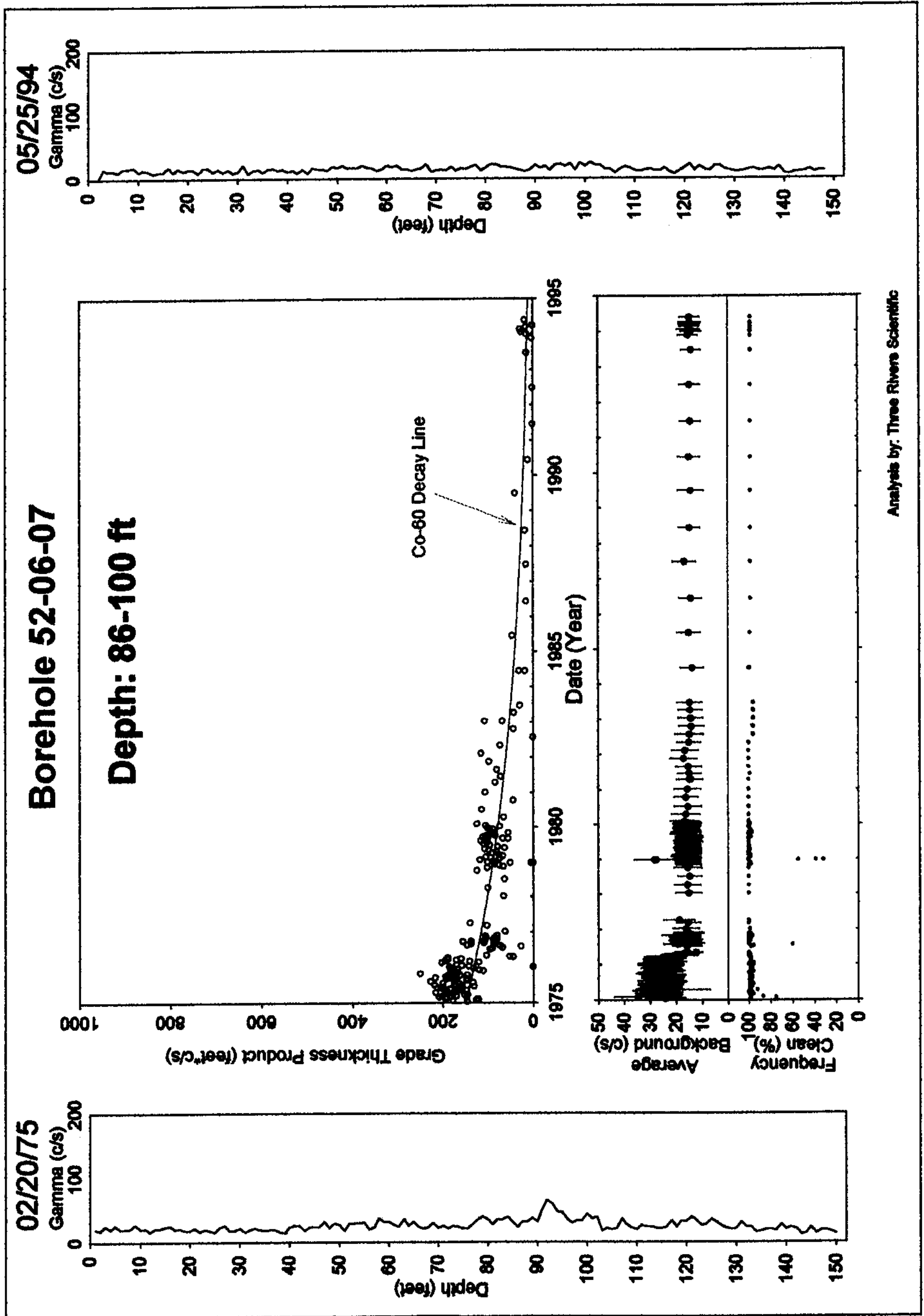


HNF-3831-REVO

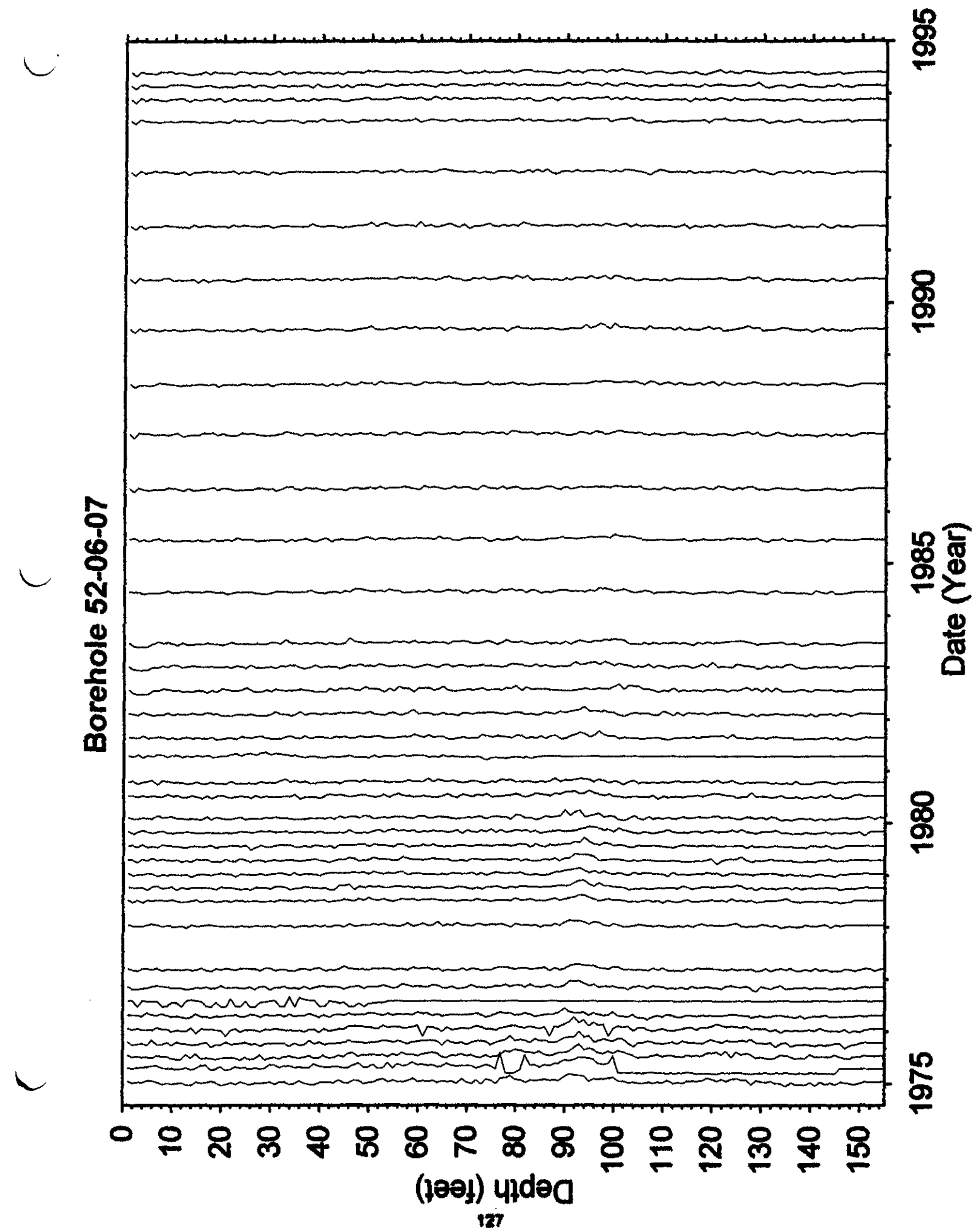


HNF-3831-REVO

\section{Dry Well Survey Analysis - Notes}

\begin{tabular}{|c|c|c|}
\hline Borehole $T Y(52-06-0 Z)$ & Total \# Surveys 37 & Probe Type 04 \\
\hline Log Date: $75-04-141^{\text {st }}$ & $\begin{array}{l}\text { \# neutron surveys } 0 \\
84-06-14 \text { Last }\end{array}$ & $\begin{array}{l}\text { \# GR Surveys } 37 \\
\text { Presentation Plot Dates }\end{array}$ \\
\hline
\end{tabular}

(If different from $1^{1 / 2}$ \& Last) Isotope from Spectral Survey: $C S-13\rangle \quad(0-8+7<10 \rho 6 / 4) / 8-64 \kappa 7$ Max Survey Depth 64 Contamination Zone Depth(s): $0-10<7<<0 \mathrm{ci} / \mathrm{s}$

GAPS.Txt

\begin{tabular}{|l|c|c|l|}
\hline Survey Date & num. Gaps & approx \#Sampl's & Comment \\
\hline $78-12-27$ & 16 & 60 & \\
\hline & & & \\
\hline & & & \\
\hline & & & \\
\hline
\end{tabular}

HI-ZONES.Txt

\begin{tabular}{|l|l|l|l|}
\hline Survey Date & Reason Selected & approx \#Samp's & Comment \\
\hline $80-02-06$ & Hi PS ATTOA & 66 & \\
\hline $81-01-22$ & To0 FAtC & 65 & \\
\hline & & & \\
\hline & & & \\
\hline & & & \\
\hline
\end{tabular}

BackGnd.Txt

\begin{tabular}{|c|c|c|c|c|c|}
\hline Survey Date & Reason Selectec & num. Samples & Feq. Clean & Avg. Bkg & Comment \\
\hline $75-04-14$ & A V G BKa & 66 & $93 \%$ & 33.4 & \\
\hline $81-01-22$ & $\theta<C_{6} A_{n}$ & 65 & $0 \%$ & 0.0 & \\
\hline $8<01-23$ & $\angle E N G T A$ & 52 & $\$ 00 \%$ & 29.8 & \\
\hline & & & & & \\
\hline & & & & & \\
\hline & & & & & \\
\hline 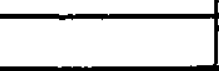 & 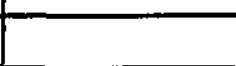 & & & & \\
\hline
\end{tabular}

Analysis Notes

\begin{tabular}{|c|c|c|c|}
\hline \multicolumn{2}{|l|}{ num surveys rejected: (0) } & Background $=(0<4<50)$ & $20-40$ \\
\hline
\end{tabular}
No BACK GROUne Zone of (CLEAN RAD) in Tres HOLS

Category: (Stable, TF Activity, Undetermined, CHANGED
Analyst Name
Panctall Pas S/W ver (TFGROSS) $\quad V 2.20$. 


\section{HNF-3831-REVO}

\section{Dry Well Survey Analysis - Notes}
Borehole TY (52-06-04)
Total \# Surveys 235
Probe Type o4
\# neutron surveys 1
\# GR Surveys 234
Log Date: $75-01-091^{\text {st }}$
$94-05-25$ Last
Presentation Plot Dates

(If different from $I^{n}$ \& Last) Isotope from Spectral Survey: $\frac{\left(5-137\left(0-20^{\circ}\right)<1,4 / 4,51-53^{\prime}\right.}{57^{\prime}(47-56<7)}<1.5 / \mathrm{Max}$ Survey Depth
Contamination Zone Depth(s):

\section{GAPS.Txt}

\begin{tabular}{|c|c|c|}
\hline Survey Date & num. Gaps & approx \#Sampl's \\
\hline $76-04-19$ & 26 & 98 \\
\hline & & \\
\hline & & \\
\hline & & \\
\hline
\end{tabular}

HI-ZONES.Txt

\begin{tabular}{|l|l|l|l|}
\hline Survey Date & Reason Selected & approx \#Samp's & Comment \\
\hline $75-01-30$ & HI BKC & 100 & \\
\hline $75-02-284$ & BAD SCRu34 & 100 & $700 \mathrm{C}$ A4tC \\
\hline & & & \\
\hline & & & \\
\hline & & & \\
\hline & & & \\
\hline
\end{tabular}

BackGnd.Txt

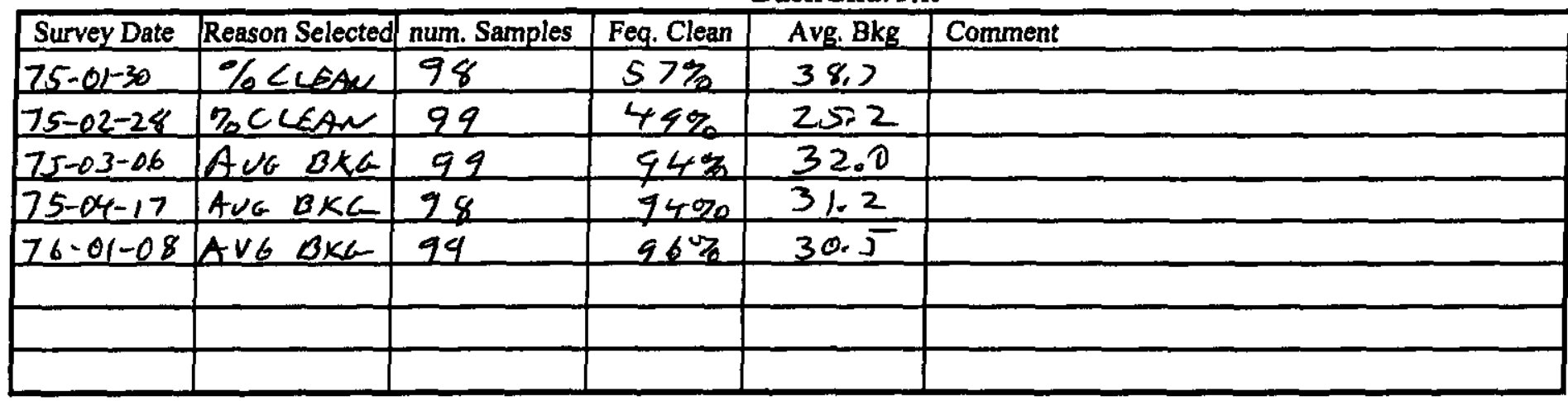

Analysis Notes

num surveys rejected: (0) Non $\quad$ Background $=(0<50) \quad 56-80 \mathrm{kz}$

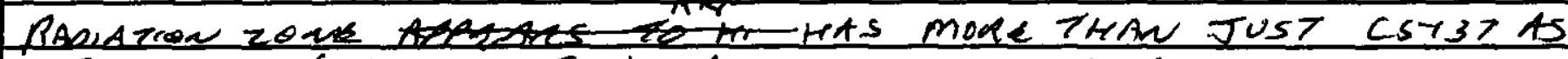

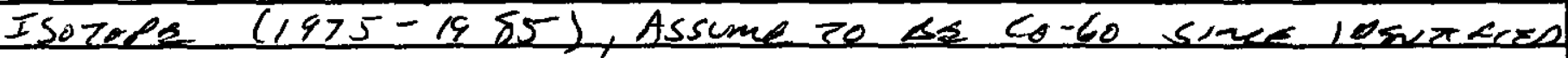
ino THER TY-BORkHoves

Yat

Category: (Stable, TF Activity, Undetermined, CHANGED

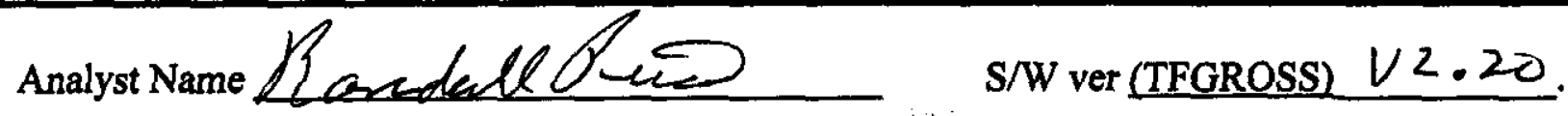


filein := "GTP47-56.txt" Well 52-06-04

$$
\begin{aligned}
& A:=\text { READPRN(filein) } \quad \text { yr }:=A^{<1>} \quad \text { net }:=A^{\langle 7\rangle} \quad \text { bkg }:=A^{\langle 6\rangle} \quad \max :=A^{<4>} \\
& N:=\text { last(yr) } \quad N=230 \quad i:=0 . . N \quad k:=0 . .300 \quad j:=0 . .299
\end{aligned}
$$

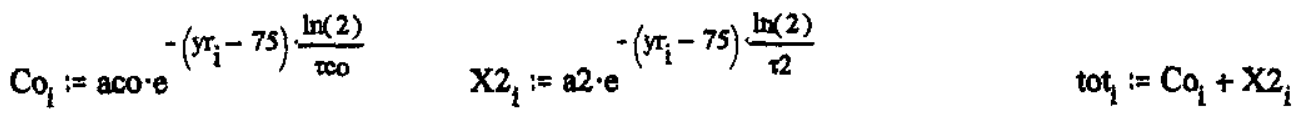

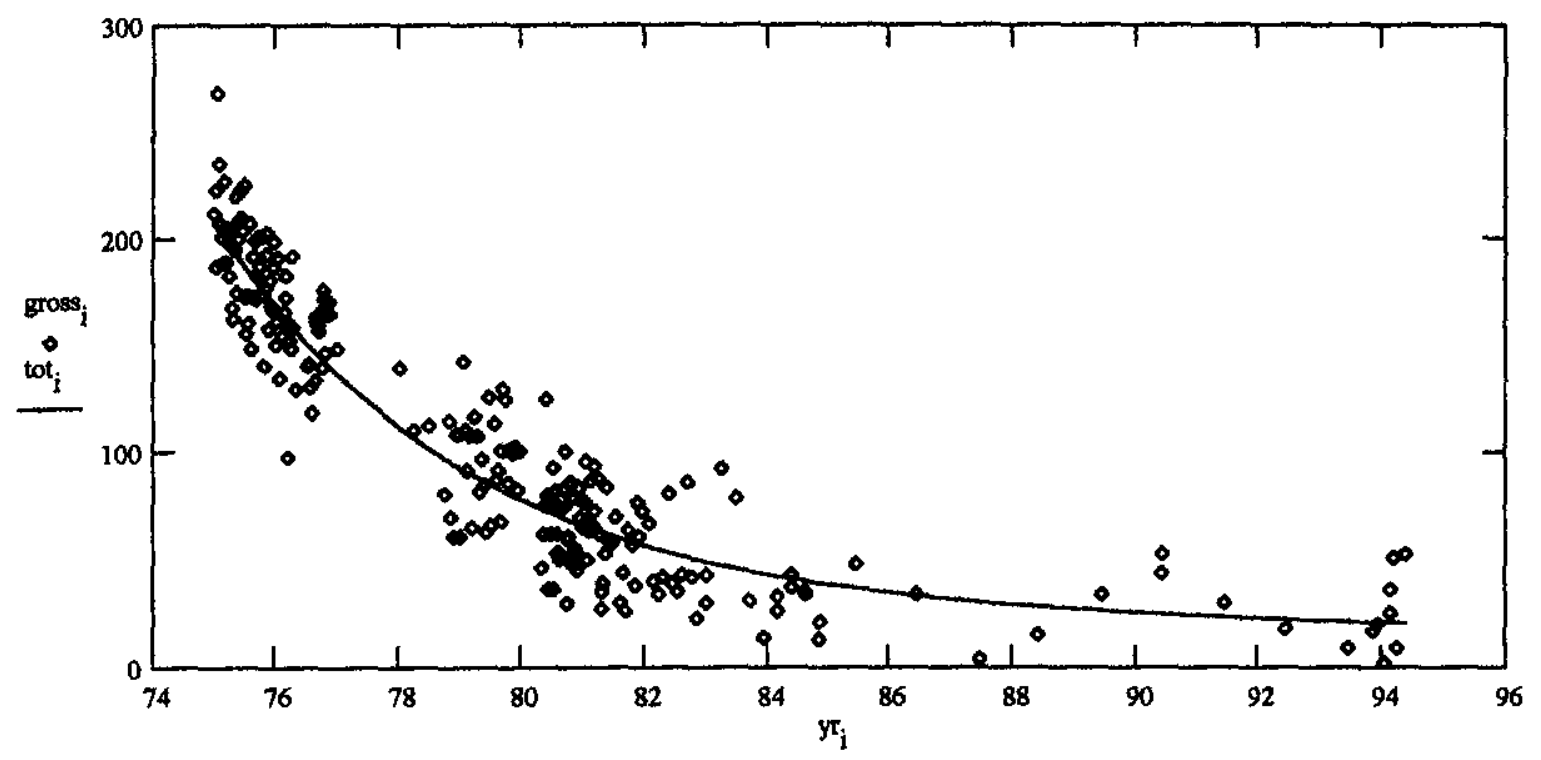

$\operatorname{ssq}(a 1, a 3):=\sum_{i}\left[\operatorname{gross}_{i}-\left[a 1 \cdot e^{-\left(y y_{i}-75\right) \cdot \frac{\ln (2)}{200}}+23 \cdot e^{-\left(y_{i}-75\right) \cdot \frac{\ln (2)}{2}}\right]\right]^{2}$

Given

$$
\begin{aligned}
& \operatorname{ssq}(a c o, a 2)=0 \\
& {\left[\begin{array}{l}
\alpha c o \\
\alpha 2
\end{array}\right]:=\operatorname{Minerr}(a c o, a 2)}
\end{aligned}
$$

$$
\alpha c 0=30.868 \quad \alpha 2=182.303
$$

Cs-137 Sb-125

$$
\begin{aligned}
& \mathrm{Co}_{\mathrm{i}} ;=\alpha \cos \cdot \theta^{-\left(\mathrm{y}_{\mathrm{i}}-75\right) \frac{\ln (2)}{200}} \quad \mathrm{X} 2_{\mathrm{i}} \mathrm{i}=\alpha 2 \cdot e^{-\left(\mathrm{yr}_{\mathrm{i}}-75\right) \frac{\ln (2)}{\tau^{2}}} \quad \operatorname{tot}_{\mathrm{i}} ;=\mathrm{Co}_{\mathrm{i}}+\mathrm{X2} 2_{\mathrm{i}} \\
& \text { out }^{\langle 0\rangle}:=\mathrm{yr} \quad \text { out }^{\langle 1\rangle}:=\text { tot WRTEPRN("twop.txt") }:=\text { out Ratio Cs/Sb } \frac{\mathrm{CO}_{\mathrm{N}}}{\mathrm{X} 2_{\mathrm{N}}}=13.908
\end{aligned}
$$




\section{HNF-3831-REVO}

\section{Dry Well Survey Analysis - Notes}
Borehole TY (52-06-05)
Total \# Surveys 177
Probe Type 4
Log Date: 75 -01-09 $1^{\text {st }}$
\# neutron surveys 1
\# GR Surveys 176
Presentation Plot Dates

Isotope from Spectral Survey: $C S\left\{C_{0}<2 \rho \mathrm{i} / \mathrm{C} 50-100 \times 7 / 30\right.$ Max Survey Depth $/ 50$

Contamination Zone Depth(s): $48-58,58-80,80,-106 \mathrm{er}, 130 y 50 \wedge$

\section{GAPS.Txt}

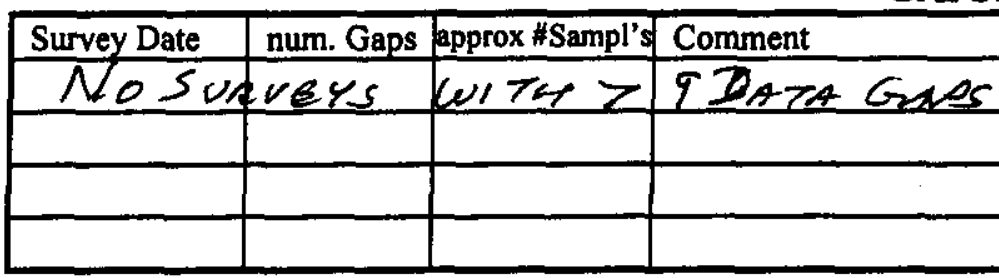

HI-ZONES.TXt

\begin{tabular}{|c|c|c|c|c|}
\hline Survey Date & Reason Selected & approx \#Samp's & Comment & \\
\hline $75-01-30$ & $\mathrm{H}, \mathrm{B} / \mathrm{Ca}$ & 150 & & \\
\hline $75 \times 05-15$ & BAD Surva & $170 t$ & & \\
\hline$(1978-11)$ & $1980-07$ & $\rightarrow$ Zount & $50 \in 7$ & Thereotode \\
\hline 1 & & & & \\
\hline $75-67-10$ & BaOsurengy & $170 t$ & & \\
\hline $76-07-23$ & BAOSCWVEEY & 150 & & \\
\hline
\end{tabular}

BackGnd.Txt

\begin{tabular}{|c|c|c|c|c|c|}
\hline Survey Date & Reason Selected & num. Samples & Feq. Clean & Avg. Bkg & Comment \\
\hline $75-01-30$ & $H I B K a$ & 149 & $4 / \%$ & 35.5 & \\
\hline $75-03-06$ & $\%$ cuear & 149 & $63 \%$ & 30.7 & \\
\hline $75-04+17$ & $A v a B K a$ & 146 & $70 \%$ & 17.0 & \\
\hline $75-05-15$ & Lsveter & 250 & $70 \%$ & 28.4 & \\
\hline $75-05-22$ & $T_{0}<\varphi \mathrm{m}$ & 149 & $6 / 07$ & 31.6 & \\
\hline $15-07-10$ & Levary & 248 & $83 \%$ & 25.0 & \\
\hline $76-07-23$ & $\%$ cuen & 148 & $45 \%$ & 24,2 & \\
\hline
\end{tabular}

Analysis Notes

num surveys rejected: (0) NoNe

Background $=(0<$ ral $2 x-45 p-1$

Category: (Stable, TF Activity, Undetermined, CHANGED

Analyst Name 


\section{HNF-3831-REVO}

\section{Dry Well Survey Analysis - Notes}
Borehole TY $(52-06-06)$
Total \# Surveys 180
Probe Type o4
\# neutron surveys 1
Log Date: $75-01-091^{\text {st }}$
$94-05-31$ Last
co-600any $95-10045$
Isotope from Spectral Survey:
Cs -13$\rangle$ once $0-35^{\prime}$
Contamination Zone Depth(s)
s): $72-82^{\prime}-\sigma \omega<3 v 2,5$
\# GR Surveys 179
Presentation Plot Dates 75 -02-12 (If different from $1^{\pi} \&$ Last)
Max Survey Depth $100^{\circ}$

\section{GAPS.Txt}

\begin{tabular}{|l|c|c|l|}
\hline Survey Date & num. Gaps & approx \#Sampl's & Comment \\
\hline $94-05-2 \sigma$ & 26 & 100 & \\
\hline & & & \\
\hline & & & \\
\hline & & & \\
\hline
\end{tabular}

\section{HI-ZONES.Txt}

\begin{tabular}{|c|c|c|}
\hline Survey Date & Reason Selected & approx \#Samp's \\
\hline $75-01-30$ & $H / 1, B / K C$ & 100 \\
\hline $75-03-06$ & H. BKG & 100 \\
\hline $76-01-15$ & Nocse AlO & 100 \\
\hline $77-04-08$ & $s_{\text {tope }} N_{0}$ uss & 140 \\
\hline & & \\
\hline
\end{tabular}

BackGnd.Txt

\begin{tabular}{|c|c|c|c|c|c|}
\hline Survey Date & Reason Selected & num. Samples & Feg. Clean & Avg. Bkg & Comment \\
\hline $75-01-30$ & $\%$ Cusa & 100 & $35 \%$ & $3 \xi 1$ & \\
\hline $76-01-08$ & AUGBKa & 100 & $89 \%$ & 33.7 & \\
\hline $76-10-28$ & $A \cup C B K C$ & 98 & $92 \%$ & 33.9 & \\
\hline $77-04-08$ & LeNZT/Z & 847 & 4590 & 274 & \\
\hline $81-11-19$ & $A \cup G \quad B K G$ & 99 & $94 \%$ & 16.6 & \\
\hline $94-05-25$ & $A \cup C B K C$ & 95 & $73 \%$ & 12.2 & \\
\hline & & & & & \\
\hline
\end{tabular}

Analysis Notes

\begin{tabular}{|c|c|c|c|}
\hline num surveys rejected: $(0)$ & Nons & Background $=(0<\nabla a<50)$ & $\rightarrow-0 \times \mathrm{PkP}$ \\
\hline
\end{tabular}

Category: (Stable, TF Activity, Undetermined, CHANGED

Analyst Name Panclall S/W ver(TFGROSS) V2.20. 


\section{Dry Well Survey Analysis - Notes}

\begin{tabular}{|c|c|c|c|}
\hline Borehole TY(52-06-07) & $\begin{array}{l}\text { Total \# Surveys } \frac{175}{3} \\
\text { \# neutron survevs }\end{array}$ & $\begin{array}{l}\text { Probe Type } \frac{04}{172} \\
\text { \# GR Survevs } 170\end{array}$ & \\
\hline Log Date: $75-01-151^{\text {st }}$ & $94-05-25$ Last & Presentation Plot Dates & $75-02-20$ \\
\hline
\end{tabular}

GAPS.Txt

\begin{tabular}{|l|c|c|c|}
\hline Survey Date & num. Gaps & approx \#Sampl's & Comment \\
\hline $76-07-29$ & $2 /$ & 50 & \\
\hline $78-12-27$ & 124 & 170 & \\
\hline & & & \\
\hline & & & \\
\hline
\end{tabular}

HI-ZONES.TXt

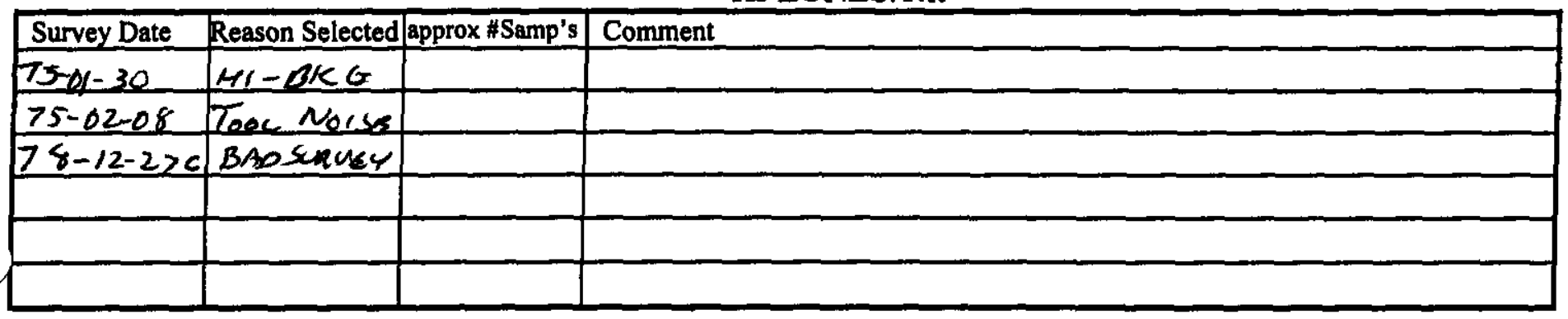

BackGnd.Txt

\begin{tabular}{|c|c|c|c|c|c|}
\hline Survey Date & Reason Selected & num. Samples & Feq. Clean & Avg. Bkg & Comment \\
\hline $75-01-30$ & $A \cup G B K a$ & 157 & $75 \%$ & 345 & \\
\hline $76-07-29$ & Socusar & 53 & $60 \%$ & $1 \varepsilon_{2}$ & \\
\hline $78-12-27$ & orcusen & 184 & $32 \%$ & 28.2 & \\
\hline $81-04-17$ & $\angle B N G T H$ & 84 & $100 \%$ & 14.8 & \\
\hline $84-06-14$ & $A \cup G B K G$ & 148 & $100 \%$ & 13.8 & \\
\hline & & & & & \\
\hline & & & & & \\
\hline & & & & & \\
\hline
\end{tabular}

Analysis Notes

\begin{tabular}{lll}
\hline num surveys rejected: $(0) \quad$ Ne $\sim e$ & Background $=(0<w a j 50)$ & $50-70 \times 7$
\end{tabular}

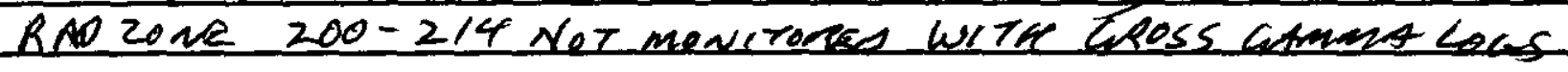

Category: (Stable, TF Activity, Undetermined, CHANGED

Analyst Name Rendall(Puie s/w ver(TFGROSS) V 2.20. 